ODINIR KLEIN JÚNIOR

PILARES DE CONCRETO ARMADO EM SITUAÇÃO DE INCÊNDIO SUBMETIDOS À FLEXÃO NORMAL COMPOSTA

SÃO PAULO 
ODINIR KLEIN JÚNIOR

\section{PILARES DE CONCRETO ARMADO EM SITUAÇÃO DE INCÊNDIO SUBMETIDOS À FLEXÃO NORMAL COMPOSTA}

Dissertação apresentada à Escola Politécnica da Universidade de São Paulo para obtenção do título de Mestre em Engenharia

SÃO PAULO 


\section{PILARES DE CONCRETO ARMADO EM SITUAÇÃO DE INCÊNDIO SUBMETIDOS À FLEXÃO NORMAL COMPOSTA}

Dissertação apresentada à Escola Politécnica da Universidade de São Paulo para obtenção do título de Mestre em Engenharia

Área de concentração:

Engenharia de Estruturas

Orientador:

Prof. Dr. Ricardo Leopoldo e Silva França

SÃO PAULO 
Este exemplar foi revisado e alterado em relação à versão original, sob responsabilidade única do autor e com a anuência de seu orientador.

São Paulo, 06 de julho de 2011.

Assinatura do autor

Assinatura do orientador

FICHA CATALOGRÁFICA

Klein Júnior, Odinir

Pilares de concreto armado em situação de incêndio submetidos à flexão normal composta / O. Klein Júnior. -- ed.rev. -- São Paulo, 2011.

$208 \mathrm{p}$.

Dissertação (Mestrado) - Escola Politécnica da Universidade de São Paulo. Departamento de Engenharia de Estruturas e Geotécnica.

1. Concreto armado 2.Pilares 3. Incêndio 4. Análise não linear de estruturas I. Universidade de São Paulo. Escola Politécnica. Departamento de Engenharia de Estruturas e Geotécnica II. t. 


\section{AGRADECIMENTOS}

Ao orientador, Prof. Dr. Ricardo Leopoldo e Silva França, pelas oportunidades de crescimento oferecidas e pela orientação atenciosa, transmitindo o seu conhecimento e experiência que superaram muitas vezes a orientação acadêmica.

Ao Prof. Dr. Valdir Pignatta e Silva, pela ajuda fundamental para o desenvolvimento deste trabalho e pela vontade incansável de esclarecer as dúvidas e propor novos desafios.

Aos colegas do escritório França \& Associados, pelo apoio e compreensão durante o desenvolvimento deste trabalho.

À minha família e amigos, pelo apoio e compreensão principalmente nos momentos de ausência quando foram necessários. 


\section{RESUMO}

KLEIN JÚNIOR, Odinir. Pilares de concreto armado em situação de incêndio submetidos à flexão normal composta. 2011. 210 f. Dissertação (Mestrado) - Escola Politécnica da Universidade de São Paulo, Departamento de Engenharia de Estruturas e Geotécnica, São Paulo, 2011.

Segundo a legislação brasileira, as estruturas de concreto armado devem ser verificadas em situação de incêndio, de modo a assegurar a capacidade portante para permitir a fuga dos usuários e o combate ao fogo com segurança e minimizar a propagação do incêndio para outros compartimentos. Para estruturas de concreto armado, especial atenção deve ser dada aos pilares. A redução da capacidade portante desses elementos é significativa em situação de incêndio e seu colapso pode resultar na instabilidade global da estrutura em certos casos. $\mathrm{O}$ cálculo do tempo de resistência ao fogo de pilares de concreto armado, em fase de projeto, é feito normalmente usando métodos simplificados dados pelas normas técnicas. Esses métodos possuem campos de validade limitados e podem apresentar resultados excessivamente seguros (antieconômicos) e em alguns casos contra a segurança. Neste trabalho foi desenvolvida uma ferramenta computacional para o cálculo do tempo de resistência ao fogo de pilares de concreto armado em situação de incêndio, dados os campos de temperaturas simétricos na seção transversal em função do tempo de exposição ao incêndio-padrão. O cálculo do pilar foi baseado no método da estimativa da curvatura dado pelo Eurocode 2 (EN 1992-1-2:2004). A seção transversal foi discretizada em elementos (concreto e aço), na qual as deformações térmicas e as propriedades termomecânicas de cada elemento foram calculadas de acordo com sua temperatura. O método da estimativa da curvatura permite ainda considerar os efeitos da não linearidade geométrica, que geralmente se tornam importantes devido à redução da rigidez do pilar sob temperaturas elevadas. Foram modelados pilares sob flexão normal composta considerando a seção transversal aquecida de forma simétrica. Os resultados do programa foram comparados a resultados de ensaios de laboratórios internacionais, com o objetivo de validar as hipóteses de cálculo adotadas.

Palavras- chave: concreto armado, pilares, incêndio, análise não linear de estruturas 


\begin{abstract}
KLEIN JÚNIOR, Odinir. Pilares de concreto armado em situação de incêndio submetidos à flexão normal composta. 2011. 210 f. Dissertação (Mestrado) - Escola Politécnica da Universidade de São Paulo, Departamento de Engenharia de Estruturas e Geotécnica, São Paulo, 2011.

According to Brazilian Codes, reinforced concrete structures must be verified under high temperatures, in order to assure the load bearing capacity to allow the safe evacuation of the users and the fire fighting and to reduce the fire spread to other compartments. For reinforced concrete structures, the columns must be analyzed carefully. The significant reduction in the load bearing capacity of reinforced concrete columns in fire can lead to collapse, which could result in global instability of the structure in some cases. The calculation of the fire resistance time of reinforced concrete columns, in the design phase, is usually done by means of simplified methods given by the standards. These methods are very limited and can result in excessively safe solutions (uneconomical) or unsafe solutions in some cases. A computational tool was developed for calculating the fire resistance time of reinforced concrete columns in fire, given symmetrical temperature fields in cross section as a function of exposure time to standard fire. The calculation method was developed using the method based on estimation of curvature given by Eurocode 2 (EN 1992-1-2:2004). The cross section was divided into elements (concrete and steel), in which the thermal strain and thermomechanical properties of each element were calculated according to its temperature. The mechanical behavior of the column under uniaxial bending considered the geometrically nonlinear effects of the structure, which generally become important due to reduced stiffness of the column at elevated temperatures. The results of the numerical analysis and experimental results of full-scale laboratory fire tests on concrete columns performed by international researchers were compared in order to validate the main hypothesis adopted.
\end{abstract}

Keywords: reinforced concrete, columns, fire, nonlinear structural analysis 


\section{LISTA DE FIGURAS}

Figura 1 - Curva temperatura-tempo de um incêndio real (LIE, 1992)..................................24

Figura 2 - Curva de incêndio-padrão ISO 834 (ISO, 1990) …..............................................28

Figura 3 - Curva de incêndio-padrão ASTM E119 (ASTM, 2000).........................................29

Figura 4 - Curva de incêndio-padrão de hidrocarbonetos (EN 1991-1-2:2004)........................ 30

Figura 5 - Comparativo entre as curvas de incêndio-padrão ............................................... 31

Figura 6 - Exemplos de curvas de incêndio-padrão para túneis ........................................... 32

Figura 7 - Curvas paramétricas de incêndio segundo o Eurocode 1 (EN 1991-1-2:2004) para diversas áreas de ventilação (Av), comparadas à curva de incêndio-padrão ISO 834 (ISO, 1990)

Figura 8 - Exemplo de simulação de incêndio utilizando modelo CFD (REIN et al., 2007) .. 34

Figura 9 - Conceito do Método do Tempo Equivalente (reproduzido de SILVA, 2004) ......... 36

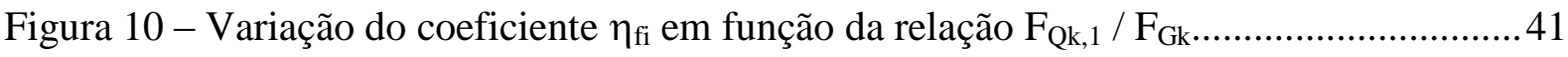

Figura 11 - Representação simplificada das reações físico-químicas em concretos feitos com cimento Portland, durante a fase de aquecimento (reproduzido de KHOURY, 2000b) 45

Figura 12 - Calor específico do concreto $c_{p}$ em função da temperatura, considerando três valores para o teor de umidade no concreto (EN 1992-1-2:2004)

Figura 13 - Massa específica do concreto $\rho$ em função da temperatura (EN 1992-1-2:2004). 48

Figura 14 - Condutividade térmica do concreto $\lambda_{c}$ em função da temperatura (EN 1992-12:2004)

Figura 15 - Parâmetros $\varepsilon_{\mathrm{c} 1, \theta}$ e $\varepsilon_{\mathrm{cu}, \theta}$ para concretos com agregados silicosos e calcários (EN 1992-1-2:2004)

Figura 16 - Parâmetros de redução da resistência do concreto sob compressão $\left(f_{c, \theta} / f_{c k}\right)$ em função da temperatura (EN 1992-1-2:2004)

Figura 17 - Curvas tensão-deformação do concreto sob compressão, para diversas temperaturas e concreto com agregados silicosos (EN 1992-1-2:2004)

Figura 18 - Curvas tensão-deformação do concreto sob compressão, para diversas temperaturas e concreto com agregados calcários (EN 1992-1-2:2004).....

Figura 19 - Parâmetros de redução da resistência à tração do concreto $\mathrm{k}_{\mathrm{c}, \mathrm{t}}$ em função da temperatura (EN 1992-1-2:2004) 56

Figura 20 - Comparação entre os parâmetros de redução da resistência à compressão e à tração do concreto em função da temperatura (EN 1992-1-2:2004) 
Figura 21 - Incompatibilidade térmica entre os agregados e a pasta de cimento sob temperaturas elevadas (reproduzido de FIB, 2007)

Figura 22 - Exemplo de LITS de um concreto com agregados de basalto, determinado como a diferença entre as deformações térmicas entre concreto com $0 \%$ e $10 \%$ de sua tensão resistente aplicada (reproduzido de KHOURY, 2006a)

Figura 23 - Desenvolvimento da LITS em ensaio de torção com aquecimento (reproduzido de FIB, 2007)

Figura 24 - Deformação térmica do concreto $\varepsilon_{\mathrm{th}, \mathrm{c}}$ em função da temperatura (EN 1992-1$2: 2004)$

Figura 25 - Variação da deformação por fluência $\varepsilon_{\mathrm{cr}, \mathrm{c}}\left(\right.$ ou $\left.\mathrm{D}_{\mathrm{cr}, \mathrm{c}}\right)$ do concreto com o tempo segundo o modelo analítico de Harmathy (1993, apud BRATINA et al., 2005) e resultados experimentais de Cruz (1968, apud BRATINA et al., 2005) - reproduzido de Bratina et al. (2005)

Figura 26 - Dados dos pilares analisados por Purkiss e Mustapha (1996 apud PURKISS, 2007) 68

Figura 27 - Resultados do pilar C1 analisado por Purkiss e Mustapha ${ }^{21}$ (1996 apud PURKISS, 2007)

Figura 28 - Resultados do pilar C2 analisado por Purkiss e Mustapha (1996 apud PURKISS, 2007)

Figura 29 - Resultados do pilar C3 analisado por Purkiss e Mustapha (1996 apud PURKISS, 2007)

Figura 30 - Variação com o tempo dos deslocamentos $\mathrm{u}^{*}$ no ponto B e w* no meio do vão do pilar ensaiado pelo NRCC (rótulo I7, ver Tabela 11) (reproduzido de BRATINA et al., 2005)

Figura 31 - Mecanismo do spalling devido às pressões nos poros do concreto (CONNOLLY,

R. J., 1995 apud KHOURY e ANDERBERG, 2000) 79

Figura 32 - Mecanismo do spalling explosivo (KHOURY e ANDERBERG, 2000a) 80

Figura 33 - Curva tensão-deformação de aços laminados a quente de alta ductilidade (CA 25/50) em função da temperatura (EN 1992-1-2:2004) 88

Figura 34 - Deformação térmica do aço $\varepsilon_{\mathrm{th}, \mathrm{s}}$ em função da temperatura (EN 1992-1-2:2004) 89 Figura 35 - Ruptura em pilar devido ao esforço cortante durante incêndio num depósito em Ghent, Bélgica, em 1974 (FIB, 2008) 
Figura 36 - Ruptura em pilar devido ao esforço cortante, devido somente à expansão térmica do piso superior, o pilar não foi exposto diretamente ao fogo (BEITEL e IWANKIW, 2002)93 Figura 37 - Exemplo dos efeitos do aquecimento em pórtico de concreto armado analisado numericamente (RIVA, 2005). (a) Deslocamentos, (b) momentos fletores, (c) esforços cortantes e (d) esforços axiais

Figura 38 - Representação esquemática do edifício ensaiado em Cardington (BAILEY, 2002)

Figura 39 - Compartimento de incêndio antes do ensaio (BAILEY, 2002) .98

Figura 40 - Compartimento de incêndio após o ensaio (BAILEY, 2002)

Figura 41 - Deslocamento lateral dos pilares externos devido à expansão térmica das lajes (BAILEY, 2002), que pode causar colapso prematuro das estruturas em situação de incêndio 100

Figura 42 - Recuperação da resistência do concreto após um ciclo de aquecimento a $250^{\circ} \mathrm{C}$, em função do tempo decorrido a partir do resfriamento 104

Figura 43 - Ensaio do martelo de Schmidt (POYESHYAR CO. LTD., 2011).... 107

Figura 44 - Ensaio de velocidade do pulso ultrassônico (DYWIDAG-SYSTEMS INTL., 2011) 107

Figura 45 - Sensor Windsor (TEST MARK INDUSTRIES, 2011) .................................... 108

Figura 46 - Ensaio de fratura interna BRE (IMPACT TEST EQUIPMENT LTD., 2010) ... 109 Figura 47 - (a) Ensaio CAPO; (b) cone de concreto extraído pelo anel expansível (GERMANN INSTRUMENTS A/S, 2009)

Figura 48 - Seção polida de uma amostra de concreto aquecido pela face esquerda, onde notase alteração da coloração em relação ao núcleo (SHORT, PURKISS e GUISE, 2001) .........110 Figura 49 - Equipamento de medição automática da termoluminescência do concreto (TLD, 2010)

Figura 50 - Ensaio de profundidade da carbonatação do concreto (AL TECHNOLOGIES LTD., 2011) 112

Figura 51 - Equipamento para ensaio termodilatométrico (ORTON, 2010) 113

Figura 52 - (a) Furadeira instrumentada para a medição da resistência à furação do concreto submetido a temperaturas elevadas; (b) efeito das temperaturas elevadas na resistência e tempo de furação (FELICETTI, 2006)

Figura 53 - Ensaio de disco de concreto (BENEDETTI; MANGONI ${ }^{47}, 2005$ apud FIB, 2008) 
Figura 54 - Procedimentos para análise de estruturas em situação de incêndio recomendados pelo Eurocode 1 (EN-1991-1-2:2004), destacando o procedimento utilizado neste trabalho 123 Figura 55 - Isotermas de $500^{\circ} \mathrm{C}$ em seção de concreto de $300 \mathrm{~mm}$ x $300 \mathrm{~mm}$ para $1 / 4$ da seção

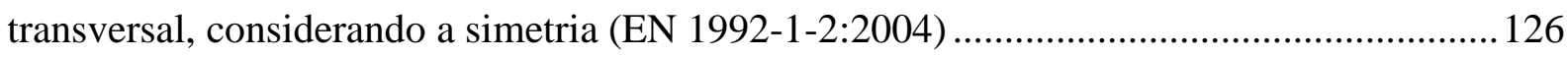

Figura 56 - Seção reduzida pela isoterma de $500^{\circ} \mathrm{C}$ (EN 1992-1-2:2004) ........................... 127 Figura 57 - Aplicação do Método da Isoterma de $500^{\circ} \mathrm{C}$ aplicado em seção retangular

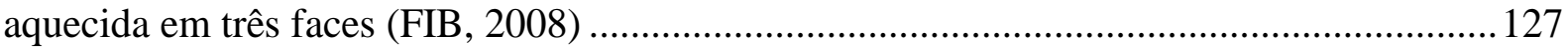
Figura 58 - Exemplos de aplicação do Método das Zonas (FIB, 2008). .............................. 128 Figura 59 - Seção transversal de um pilar com barras longitudinais em camadas (SILVA, 2008).

Figura 60 - Comprimentos efetivos de pilares em pórticos contraventados (a) seções ao longo do edifício, (b) modo de deformação à temperatura ambiente e (c) modo de deformação em

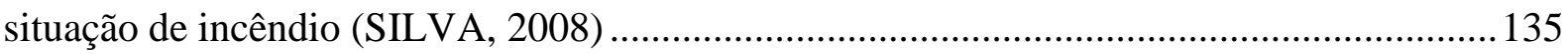
Figura 61 - Distribuição das isotermas numa seção transversal de concreto de 40 x $40 \mathrm{~cm}$, para diversos tempos de exposição ao incêndio-padrão (COSTA, 2008) .............................. 152 Figura 62 - Distribuição de temperaturas e pressões nos poros de uma seção de concreto calculados pelo software HITECOSP (ENEA; PADOVA UNIVERSITY, 1999) .................154 Figura 63 - Domínios de deformação no ELU (ABNT NBR 6118:2003) ………................. 155 Figura 64 - Curvas tensão-deformação do concreto sob temperaturas elevadas (FIB, 2008). Linha tracejada: modelo de Sargin; linha cheia: parábola-retângulo; linha traço-ponto: modelo constitutivo do Eurocode 2 (EN 1992-1-2:2004). 156 Figura 65 - Diagramas de interação esforço normal x momento fletor para uma seção transversal quadrada $\left(30 \mathrm{~cm}\right.$ x $30 \mathrm{~cm}, 4$ barras de $16 \mathrm{~mm}$ de diâmetro, $\mathrm{f}_{\mathrm{c}}=30 \mathrm{MPa}, \mathrm{f}_{\mathrm{y}}=500$ $\mathrm{MPa}$, cobrimento $3 \mathrm{~cm}$ ) obtidos por análise não linear, utilizando 3 diferentes curvas tensãodeformação (FIB, 2008) 156 Figura 66 - Processo iterativo-incremental para obtenção dos esforços resistentes últimos de pilares (a) à temperatura ambiente e (b) para diferentes tempos de exposição ao fogo . 157 Figura 67 - (a) Perfil de temperaturas ao longo do plano médio de seção transversal quadrada aquecida nas quatro faces e (b) domínios de deformação para o ELU (FIB, 2008)...............158 Figura 68 - Seções transversais estudadas (FIB, 2008) ..................................................... 159 Figura 69 - Curvas tensão-deformação do concreto em função da temperatura, para uso em análises com limitação das deformações (linhas contínuas) e curvas propostas pelo Eurocode 2 (EN 1992-1-2:2004) (linhas tracejadas) para uso em análises iterativo-incrementais (FIB, 2008) 
Figura 70 - Deformação de pico e deformação última das curvas tensão-deformação obtidas para os métodos com limitação das deformações (FIB, 2008)

Figura 71 - Diagrama de interação esforço normal x momento fletor resistentes $\left(\mathrm{N}_{\mathrm{u}}-\mathrm{M}_{\mathrm{u}}\right)$ para a Seção 1 aquecida nas quatro faces (FIB, 2008)

Figura 72 - Diagrama de interação esforço normal x momento fletor resistentes $\left(\mathrm{N}_{\mathrm{u}}-\mathrm{M}_{\mathrm{u}}\right)$ para a Seção 2 aquecida nas quatro faces (FIB, 2008) 162

Figura 73 - Forno do NRCC para ensaio de pilares em escala real em situação de incêndio com atuação do carregamento (NRCC, 2009)

Figura 74 - Exemplos de discretização em fibras da seção transversal do pilar de concreto armado em situação de incêndio, aquecido simetricamente em (a) 4 faces e (b) 2 faces........ 166 Figura 75 - Convenções para o cálculo dos esforços resistentes da seção transversal .......... 167 Figura 76 - Exemplo de gráfico esforço normal - momento resistente $\left(\mathrm{N}_{\mathrm{Rd}, \mathrm{fi}}-\mathrm{M}_{\mathrm{Rd}, \mathrm{fi}}\right) \ldots \ldots . . .169$ Figura 77 - Exemplo de diagrama momento-curvatura para um dado $\mathrm{N}_{\mathrm{Sd}, \mathrm{fi}}$ 170

Figura 78 - Exemplo de diagramas momento-curvatura para diversos tempos de exposição ao fogo

Figura 79 - Integração numérica de pilar em balanço..... 171

Figura 80 - Alguns casos básicos de esforços aplicados em um pilar em balanço e seus respectivos diagramas de momentos fletores de $1^{\mathrm{a}}$ ordem $\left(\mathrm{M}_{1}\right)$ 172

Figura 81 - Método da integração numérica para pilar biapoiado 174 Figura 82 - Divisão do pilar em balanço em $n$ segmentos iguais 175 Figura 83 - Passos para o cálculo dos deslocamentos transversais de um pilar biengastado. (a) Modelo inicial adotado na $1^{\mathrm{a}}$ iteração, (b) rotações calculadas nas extremidades, (c) aplicação de momentos nas extremidades para cálculo do diagrama momento-rotação (d) e modelo final do pilar 176

Figura 84 - Exemplo de diagrama momento-rotação na extremidade do pilar 177 Figura 85 - Método da bisseção. (a) $1^{a}$ iteração, com intervalo de pesquisa da solução arbitrado; (b) $2^{\mathrm{a}}$ iteração, com novo intervalo de pesquisa da solução. 178 Figura 86 - Comparação entre o TRF obtido experimentalmente e o TRF1 obtido analiticamente pelo método FNC-FOGO

Figura 87 - Avaliação da segurança do método FNC-FOGO considerando os valores de TRF1 da Tabela 11

Figura 88 - Comparação entre o TRF obtido experimentalmente e o TRF1 obtido analiticamente pelo método FNC-FOGO com modelo biapoiado, pilares ensaiados pela TUBr 
Figura 89 - Comparação entre o TRF obtido experimentalmente e o TRF3 obtido analiticamente pelo método FNC-FOGO com modelo apoiado-engastado, pilares ensaiados pela TUBr 186

Figura 90 - Comparação entre o TRF obtido experimentalmente e o TRF2 obtido analiticamente pelo método FNC-FOGO desconsiderando as deformações térmicas ............187 Figura 91 - Comparação entre o TRF obtido experimentalmente e o TRF5 obtido analiticamente pelo método FNC-FOGO, pilares ensaiados pelo Building Research Station BRS. 192 Figura 92 - Análise da influência da resistência do concreto no cálculo analítico do TRF dos pilares ensaiados pelo Building Research Station - BRS 193 


\section{LISTA DE TABELAS}

Tabela 1 - Temperatura dos gases em função do tempo conforme a curva ASTM E119 (ASTM, 2000)

Tabela 2 - Valores do coeficiente de combinação $\psi 2$ (ABNT NBR 8681:2003)

Tabela 3 - Condutividade térmica dos materiais à temperatura ambiente (KHOURY, 1983 apud EN 1992-1-2:2004)

Tabela 4 - Fatores que influenciam na ocorrência dos diversos tipos de spalling (KHOURY, 2006c)

Tabela 5 - Tipos de ensaios não destrutivos para avaliação do concreto após o incêndio (FIB, 2008)

Tabela 6 - Efeitos das altas temperaturas nos materiais normalmente encontrados em edificações (FIB, 2008)

Tabela 7 - Fatores de dano para estruturas de concreto (FIB, 2008) 118

Tabela 8 - Classes de danos causados pelo incêndio em estruturas de concreto (FIB, 2008) 120 Tabela 9 - Laboratórios cujos experimentos serviram de base ao Método A do Eurocode 2 (EN 1992-1-2:2004) (COSTA, 2006)

Tabela 10 - Características geométricas, dos materiais e dos carregamentos dos pilares de concreto armado utilizados no modelo de cálculo do Método A do Eurocode 2 (EN 1992-12:2004) (COSTA, 2006).

Tabela 11 - TRF medidos e calculados dos pilares utilizados na calibração do Método A do Eurocode 2 (EN 1992-1-2:2004) 180

Tabela 12 - TRF medidos e calculados dos pilares ensaiados pela TUBr 185

Tabela 13 - TRF medidos e calculados dos pilares ensaiados pelo BRS 189

Tabela 14 - Análise da influência da taxa de armaduras $\rho$ no TRF calculado pelo método FNC-FOGO para os pilares ensaiados pelo Building Research Station - BRS 193

Tabela 15 - Análise da influência do diâmetro das barras longitudinais no TRF calculado pelo método FNC-FOGO para os pilares ensaiados pelo Building Research Station - BRS 194

Tabela 16 - Análise da influência das dimensões da seção transversal no TRF calculado pelo método FNC-FOGO para os pilares ensaiados pelo Building Research Station - BRS 194 


\section{SUMÁRIO}

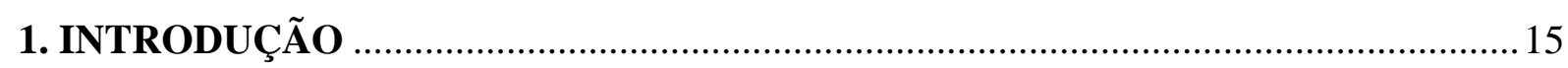

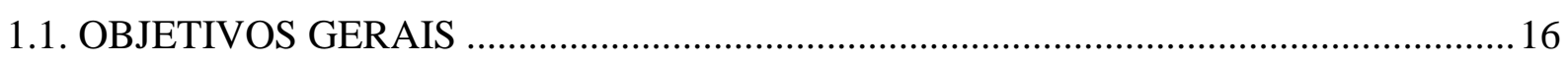

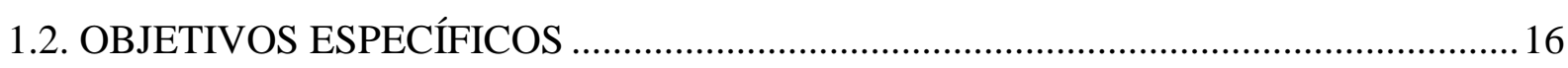

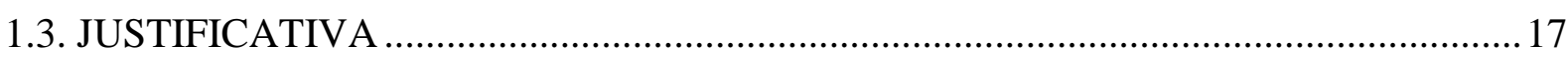

2. PROJETO DE ESTRUTURAS DE CONCRETO EM SITUAÇÃO DE INCÊNDIO. 19

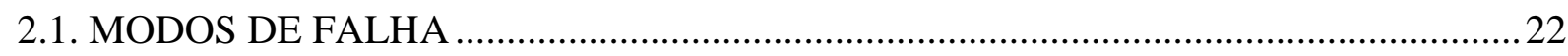

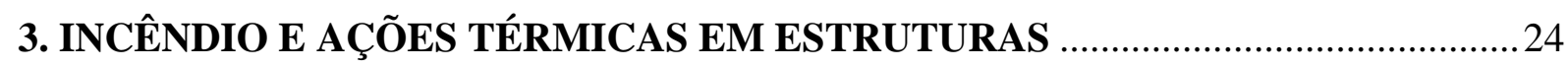

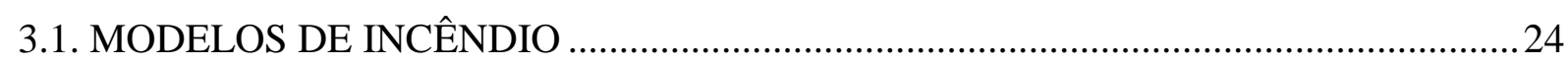

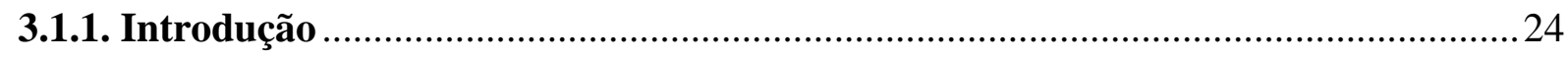

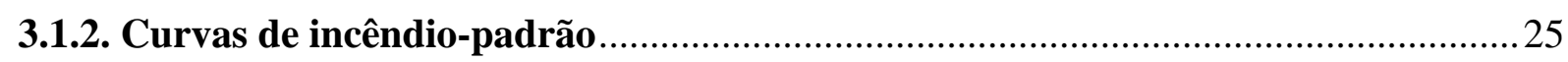

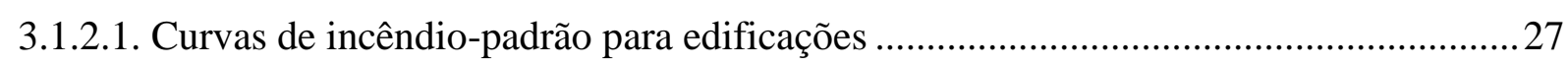

3.1.2.2. Curvas de incêndio-padrão para indústrias petroquímicas e offshore ……………........29

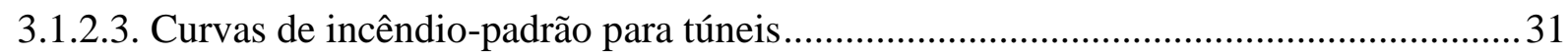

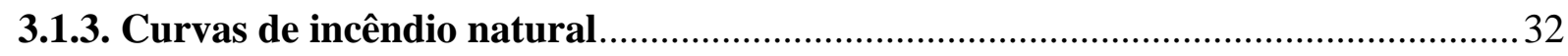

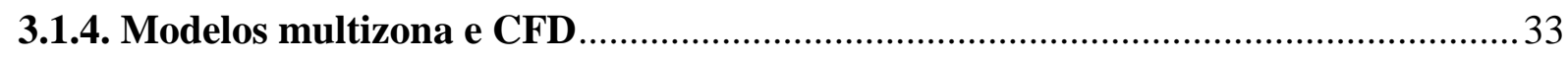

3.2. TEMPO REQUERIDO DE RESISTÊNCIA AO FOGO - TRRF ....................................... 34

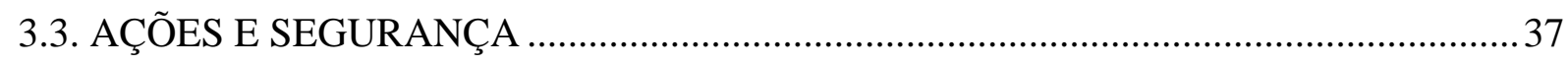

4. PROPRIEDADES DOS MATERIAIS SOB ALTAS TEMPERATURAS …………....43

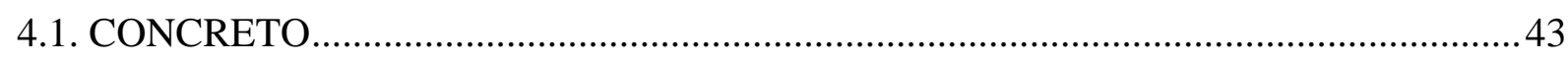

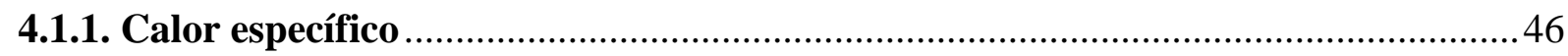

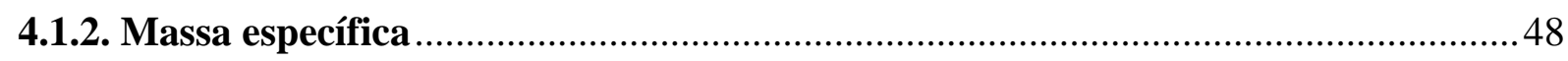

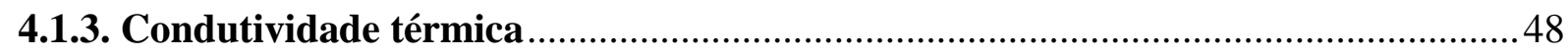

4.1.4. Curva tensão-deformação para concreto sob compressão …………………….......51

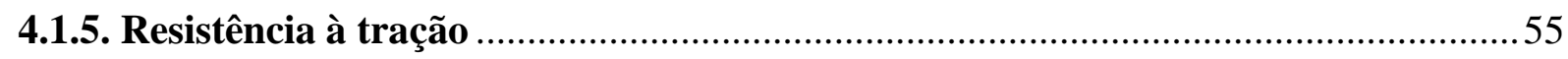

4.1.6. Deformação linear específica do concreto sob temperaturas elevadas.....................57

4.1.6.1. Deformação térmica linear específica .................................................................62

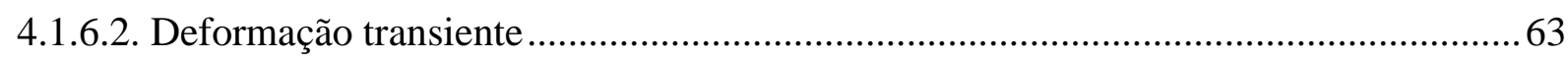

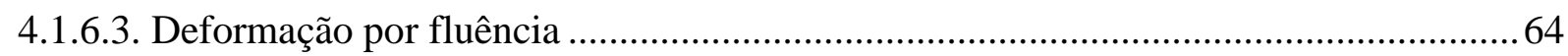

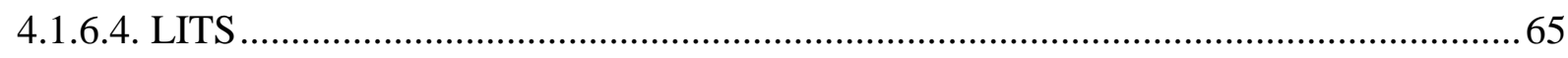

4.1.6.5. Influência das parcelas de deformações nos cálculos de pilares de concreto em

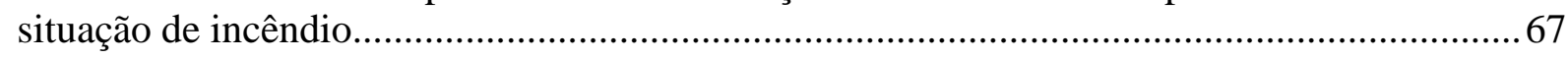

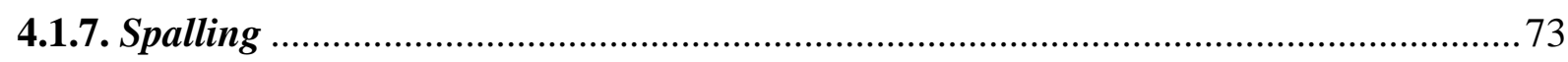

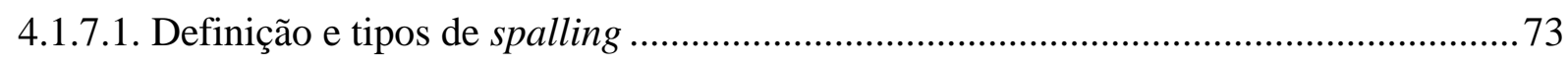

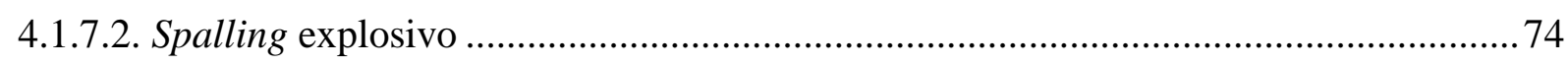

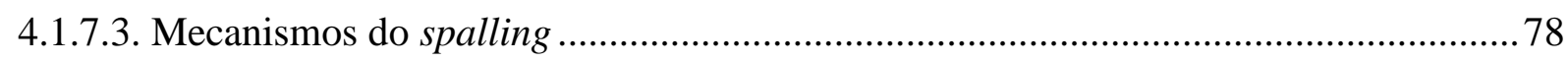


4.1.7.4. Consequências do spalling . .81

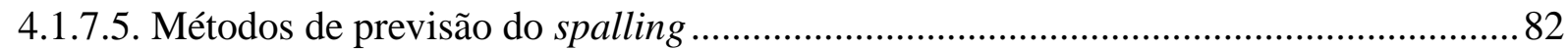

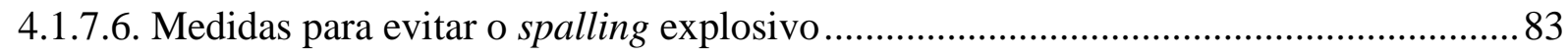

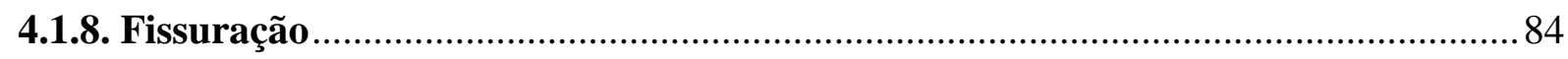

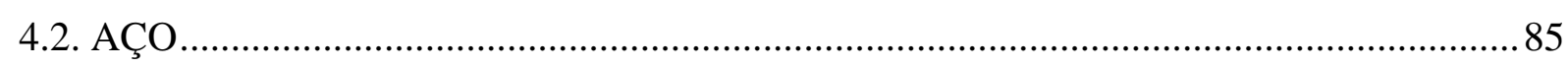

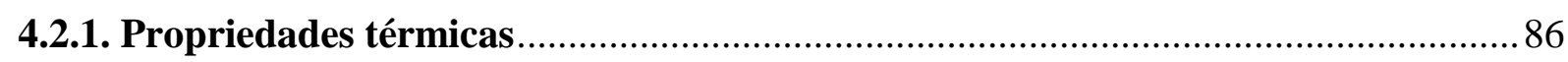

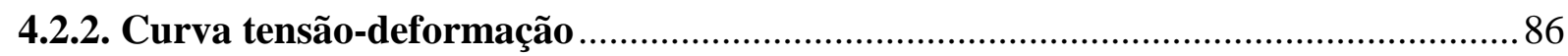

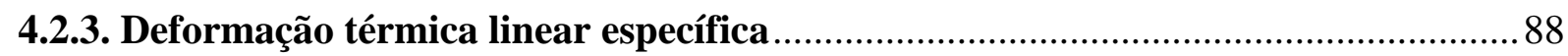

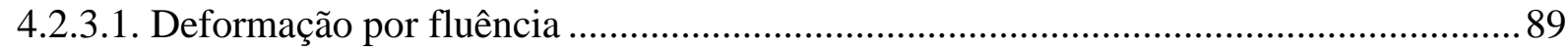

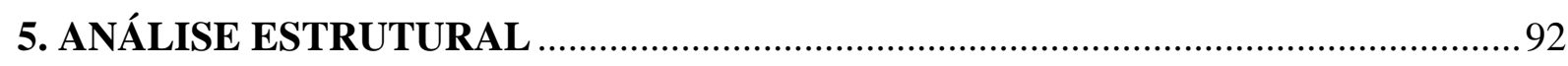

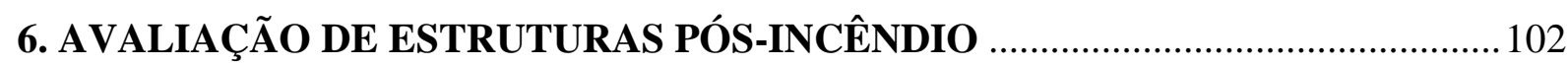

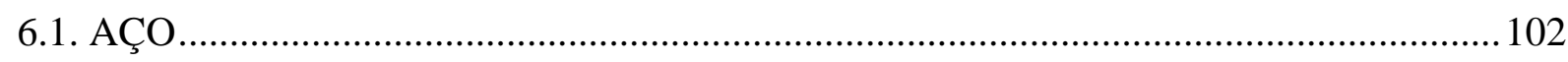

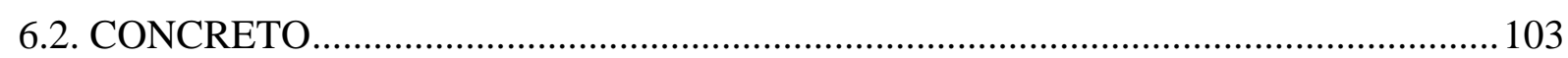

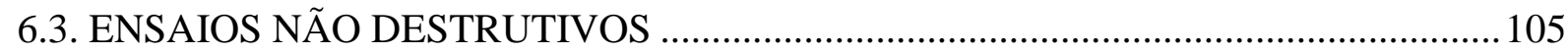

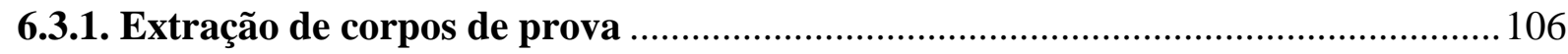

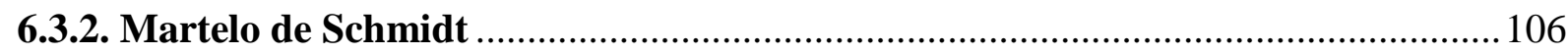

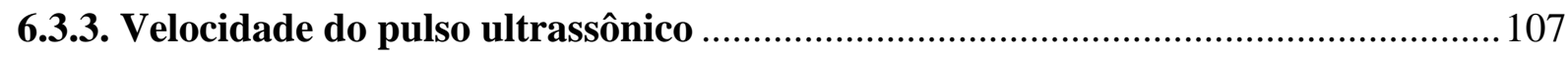

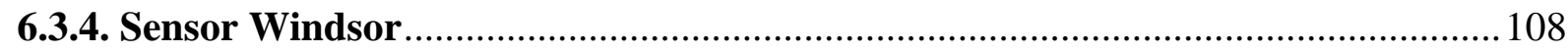

6.3.5. Ensaio de fratura interna BRE e ensaio CAPO ................................................. 108

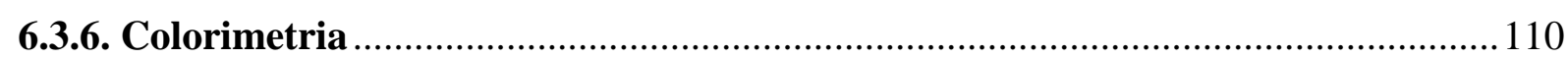

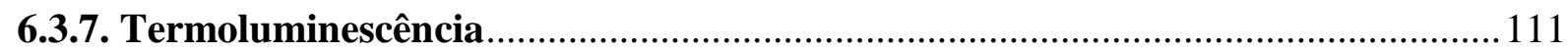

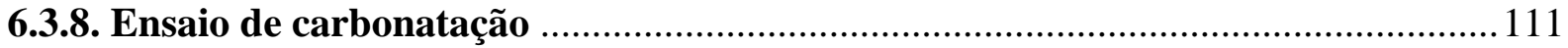

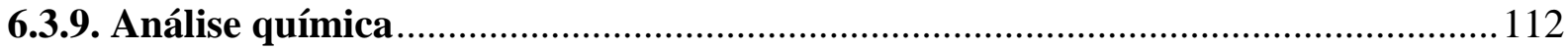

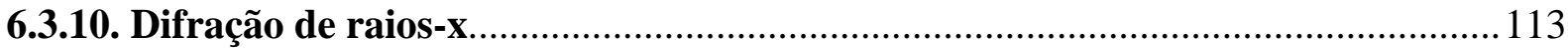

6.3.11. Ensaios físico-químicos e mecânicos ................................................................... 113

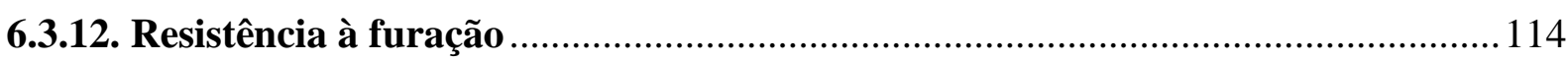

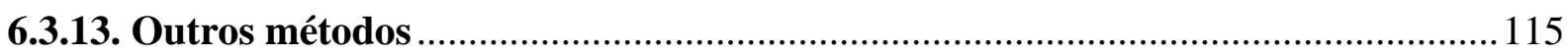

6.4. REPAROS DE ESTRUTURAS APÓS UM INCÊNDIO ........................................... 116

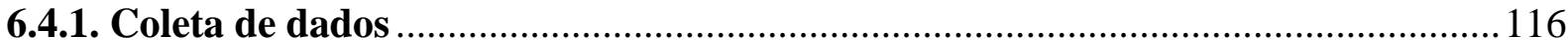

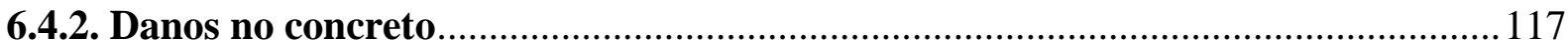

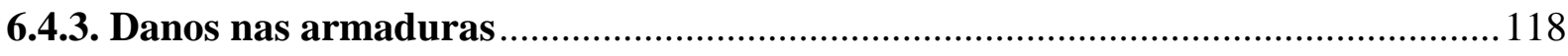

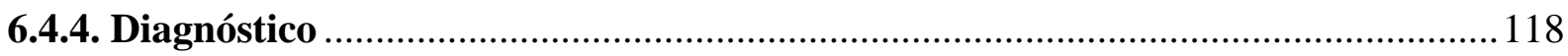

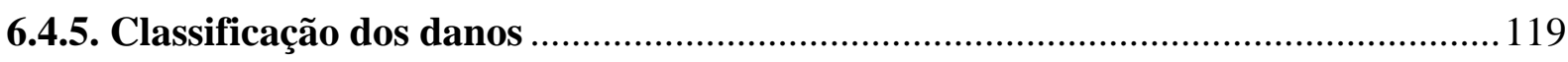

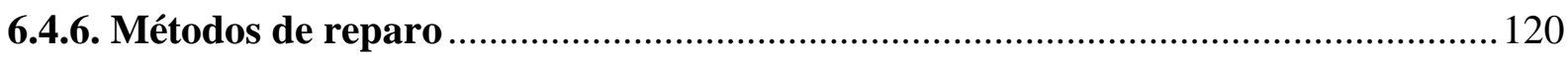

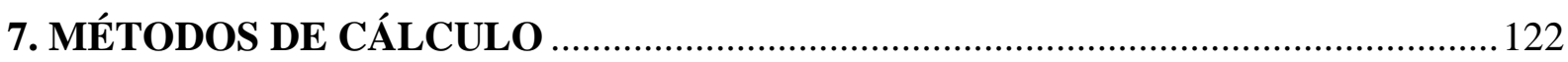

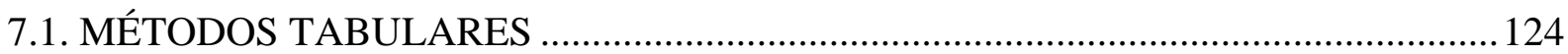

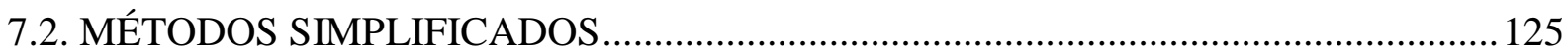


7.2.1. Análise da seção transversal 125

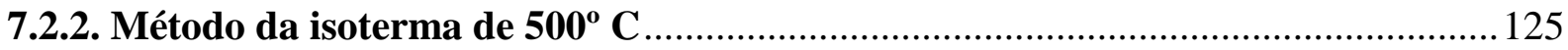

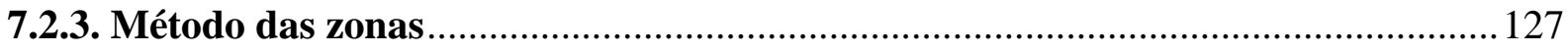

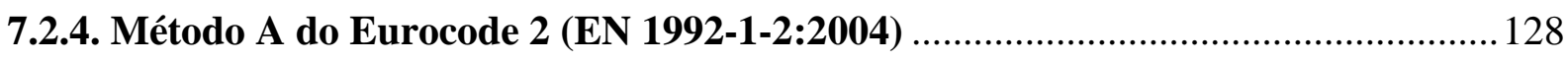

7.2.5. Método B do Eurocode 2 (EN 1992-1-2:2004) ....................................................... 137

7.2.6. Origem dos dados e análise do Método A............................................................. 137

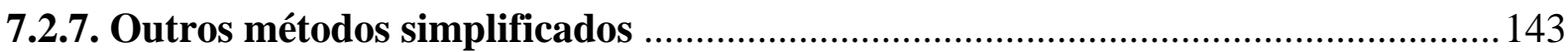

7.2.7.1. Método simplificado de Kodur e Raut (2009) ......................................................... 144

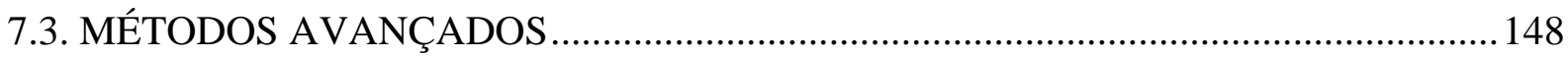

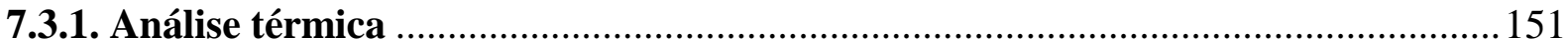

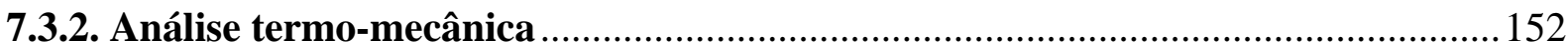

7.3.3. Análise termo-hidro-mecânica abrangente ............................................................ 153

7.3.4. Métodos baseados em limitação das deformações .............................................. 155

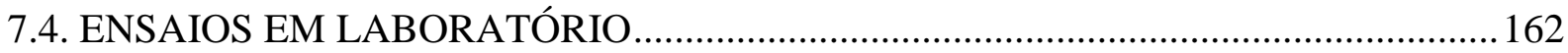

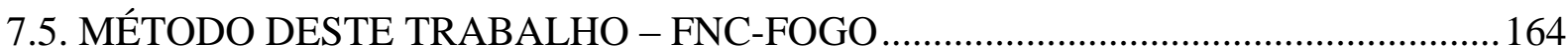

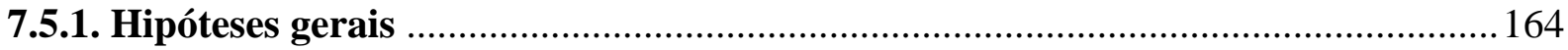

7.5.2. Cálculo dos esforços resistentes na seção transversal ......................................... 165

7.5.3. Cálculo do diagrama momento-curvatura ......................................................... 169

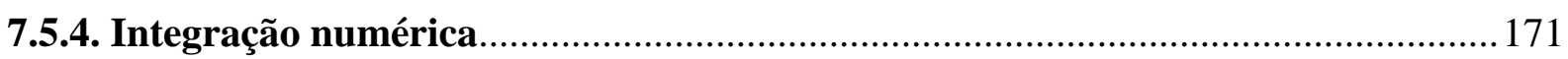

7.5.4.1. Processo para pilares apoiado-engastado e biengastado........................................ 176

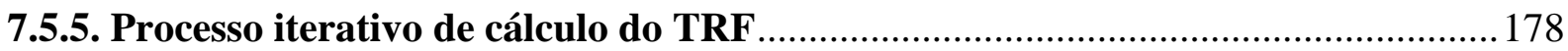

8. APLICAÇÃO DO MÉTODO FNC-FOGO E ANÁLISE DOS RESULTADOS ........ 179

8.1. PILARES USADOS NA CALIBRAÇÃO DO MÉTODO A (EN 1992-1-2:2004)........ 179

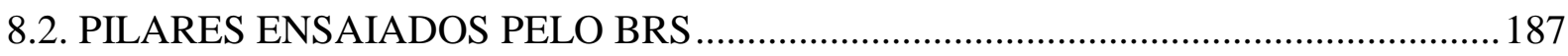

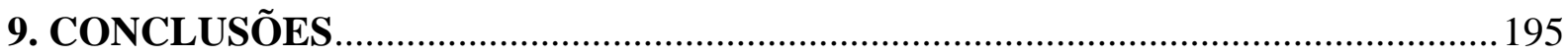

9.1. SUGESTÕES PARA TRABALHOS FUTUROS..................................................... 197

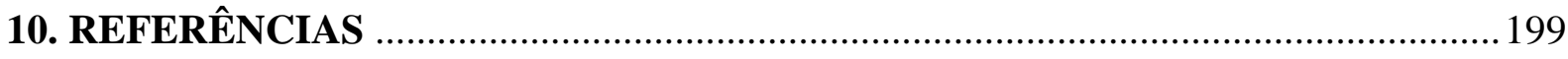




\section{INTRODUÇÃO}

O principal objetivo da segurança contra incêndio em edificações é proteger a vida humana. Mas a proteção visando proteger o patrimônio, que é um objetivo secundário, pode ser requerida para algumas edificações, principalmente de uso comercial, devido aos altos custos envolvidos caso ocorra um incêndio.

O fogo em edificações é um evento que deve ser evitado e combatido de todas as maneiras possíveis. Embora tenham baixa probabilidade de ocorrência, incêndios podem ocorrer em qualquer lugar e a qualquer período da vida da edificação, seja em fase de construção, serviço ou reformas. Suas origens podem ser das mais variadas, como simples curtos-circuitos em equipamentos elétricos ou mesmo atos criminosos.

O estudo sobre os efeitos do fogo em estruturas de concreto tem sido realizado desde pelo menos o século XIX, principalmente em relação a edifícios. Inicialmente esses estudos foram focados somente em concreto de resistência normal sob temperaturas elevadas, mas nos últimos 20 anos duas inovações se destacaram: o uso crescente de novos concretos (em especial o concreto de alta resistência) e a adoção de normas técnicas baseadas em desempenho para projeto de estruturas de concreto em situação de incêndio (FIB, 2007). O uso de tais técnicas exigiu que novas pesquisas, ensaios e investigações fossem realizados.

Tradicionalmente, o projeto de estruturas em situação de incêndio foi baseado numa série de prescrições e convenções, e não em métodos baseados em ferramentas de engenharia. A necessidade de desenvolver novos métodos veio a partir das limitações dos códigos prescritivos. Diversas nações já desenvolveram normas técnicas baseadas em desempenho (Reino Unido, Suécia, Noruega, Nova Zelândia, Austrália, etc.) e outros países estão fazendo o mesmo. Atualmente, esse assunto é foco de discussão, pesquisa e desenvolvimento ao redor do mundo (FIB, 2007). No Brasil, o projeto de estruturas em situação de incêndio é recente. As pesquisas ainda são escassas e as normas técnicas são bastante simplificadas se comparadas às normas vigentes em alguns países nos quais os conceitos de segurança contra incêndio são mais desenvolvidos e aplicados.

A análise do comportamento de estruturas de concreto armado em situação de incêndio é um problema complexo, para o qual métodos analíticos não são suficientes na maioria dos casos. Os ensaios em laboratório de elementos isolados ou mesmo de estruturas completas em situação de incêndio são caros e complexos de serem feitos. Por isso, a modelagem computacional se apresenta como a alternativa mais viável. Para isso, é preciso 
contar com modelos constitutivos confiáveis e capazes de representar os principais fenômenos observados em experimentos. Além disso, os engenheiros envolvidos devem possuir sólido conhecimento dos fenômenos presentes em estruturas de concreto armado em situação de incêndio, de modo a poder analisar criticamente os resultados durante as análises, projetos e verificações (FLETCHER et al., 2007).

Para o caso de estruturas de concreto armado, especial atenção deve ser dada aos pilares, que são o foco deste trabalho. Por serem elementos cujo colapso pode desencadear instabilidade global da estrutura em certas situações, além de serem sensíveis quanto à degradação da sua capacidade portante em temperaturas elevadas, uma análise mais rigorosa deve ser realizada. Para o dimensionamento de pilares de concreto armado em situação de incêndio, as normas nacionais e internacionais apresentam métodos simplificados que nem sempre conduzem a resultados econômicos, além de serem limitados aos casos contidos nas tabelas apresentadas nessas normas. Dessa forma, a utilização de métodos avançados de cálculo torna-se vantajosa por permitir a avaliação de um número maior de casos. Além disso, caso se disponha de dados a respeito dos materiais utilizados na região, podem-se estudar os problemas segundo a realidade e normatização local, evitando adaptações de normas e métodos estrangeiros.

\subsection{OBJETIVOS GERAIS}

Desenvolver um processo para a verificação da estabilidade de pilares de concreto armado em situação de incêndio.

\subsection{OBJETIVOS ESPECÍFICOS}

- Apresentação dos dados mais recentes sobre segurança de edificações de concreto armado em situação de incêndio, como: modelos de incêndio, comportamento dos materiais (aço e concreto) e de elementos de concreto armado em situação de incêndio;

- Apresentação e análise crítica dos métodos simplificados para o cálculo de pilares de concreto armado sugeridos pela literatura nacional e internacional; 
- Apresentação das prescrições normativas nacionais e internacionais para o projeto de estruturas de concreto armado em situação de incêndio;

- Desenvolvimento de um processo de verificação da estabilidade de pilares de concreto armado em situação de incêndio, com base nas características físicas e mecânicas do aço e concreto estrutural indicadas nas normas ABNT NBR 6118:2003, ABNT NBR 15200:2004 e Eurocode 2 (EN 1992-1-2:2004) , e nas diretrizes de projeto de estruturas das normas ABNT NBR 6120:1980, ABNT NBR 6118:2003, ABNT NBR 8681:2003, ABNT NBR 14432:2001 e ABNT NBR 15200:2004 para a situação normal e de incêndio;

- Aplicação do método desenvolvido a pilares ensaiados em laboratório e comparação entre os resultados analíticos e os obtidos experimentalmente.

\subsection{JUSTIFICATIVA}

Os métodos de cálculo simplificados sugeridos pelas normas técnicas vigentes nem sempre são aplicáveis a estruturas de geometria qualquer, diferentes daquelas propostas como padrão. Apenas adaptações por meio de interpolação dos valores tabelados são permitidos. Os dados apresentados pelas tabelas da norma ABNT NBR 15200:2004 são baseados em resultados experimentais de elementos com características geométricas e materiais ligeiramente diferentes daqueles usuais no Brasil. Além disso, o método tabular dessa norma não contempla os efeitos de imperfeições geométricas locais, de esbeltez, de excentricidade acidental e de não linearidade geométrica, os quais devem ser considerados em projeto, segundo a norma ABNT NBR 6118:2003 (COSTA e SILVA, 2005). Outra limitação é quanto ao TRF - tempo de resistência ao fogo, limitado pela norma em 120 minutos. Esses detalhes tornam o método tabular antieconômico dentro dos critérios aceitáveis de segurança estrutural para a realidade brasileira.

Os métodos simplificados sugeridos pela literatura técnica internacional nem sempre são práticos, racionais, econômicos e válidos para qualquer condição de carregamento. Outra limitação é que são necessários dados térmicos precisos para a sua aplicação, indisponíveis no meio técnico na maioria das vezes (COSTA, 2008). 
Os métodos gerais de cálculo, permitidos pela ABNT NBR 15200:2004, são de difícil aplicação, ficando restritos a centros de pesquisa que possuam infra-estrutura física, técnica e financeira adequadas.

Portanto, há necessidade de um método de cálculo prático para o dimensionamento de pilares em situação de incêndio, que respeite as normas brasileiras sem recorrer a análises termoestruturais avançadas que demandem grandes investimentos e pessoal especializado. Tal método deve ser genérico e prático o bastante para viabilizar sua incorporação aos softwares de cálculo estrutural disponíveis no mercado. Além disso, é importante manter o tempo de processamento dentro de padrões aceitáveis, utilizando os recursos de informática normalmente encontrados em escritórios de engenharia. 


\section{PROJETO DE ESTRUTURAS DE CONCRETO EM SITUAÇÃO DE INCÊNDIO}

O projeto de estruturas em situação de incêndio está inserido num conceito mais amplo: a engenharia de segurança contra incêndio. Purkiss (2007) sugere a seguinte definição para engenharia de segurança contra incêndio:

Engenharia de segurança contra incêndio pode ser definida como a aplicação de princípios científicos e de engenharia aos efeitos do fogo de modo a reduzir a perda de vidas e danos à propriedade mediante quantificação dos riscos e perigos envolvidos e fornecer uma solução ideal para a aplicação de medidas preventivas ou de proteção.

Os conceitos de segurança contra incêndio podem ser aplicados a quaisquer situações nas quais o fogo é um perigo em potencial. No âmbito da engenharia de estruturas, tais conceitos são aplicados ao projeto de edificações. As principais áreas que compõem a engenharia de segurança contra incêndio são (PURKISS, 2007):

1) Controle da ignição - controle da inflamabilidade dos materiais no interior da edificação ou adoção de medidas como proibição do ato de fumar ou do uso de chamas;

2) Controle dos meios de fuga - previsão de meios de fuga e treinamento dos ocupantes da edificação;

3) Detecção - uso de equipamentos para detecção do fogo, de preferência no estágio mais inicial possível;

4) Controle da propagação do fogo - uso de métodos para evitar a propagação do fogo dentro da edificação e para propriedades vizinhas. As medidas podem ser construtivas (compartimentação entre ambientes, controle da distância entre edificações vizinhas, entre outros) ou mecânicas (uso de chuveiros automáticos, por exemplo);

5) Prevenção do colapso estrutural - garantia da capacidade portante e integridade da estrutura, ou parte dela, durante um incêndio.

O colapso estrutural antes de certo período de tempo, normalmente chamado de tempo de resistência ao fogo, pode ser evitado projetando a estrutura de modo que, mesmo estando enfraquecida e sujeita a deformações significativas, a mesma ainda mantenha uma parte de 
sua capacidade portante (proteção passiva ${ }^{1}$ ) ou podem ser adotadas medidas de controle do fogo de modo que as temperaturas não atinjam níveis danosos à estrutura (proteção ativa ${ }^{2}$ ). Ambas as abordagens são interdependentes, ou seja, a atuação de um sistema pode ser usada para atender às necessidades de outro (PURKISS, 2007).

O dimensionamento de estruturas em situação de incêndio pode ser entendido como a verificação da estrutura, com ou sem proteção contra incêndio, de modo a garantir sua estabilidade e capacidade resistente, a fim de evitar o seu colapso em condições que prejudiquem a fuga dos ocupantes da edificação e, quando for o caso, prejudiquem a aproximação e o ingresso de pessoas e equipamentos de combate ao incêndio.

As normas ABNT NBR 15200:2004 e Eurocode 2 (EN 1992-1-2:2004) afirmam que os objetivos gerais da verificação de estruturas em situação de incêndio são:

- limitar o risco à vida humana;

- limitar o risco da vizinhança e da própria sociedade;

- limitar o risco da propriedade exposta ao fogo.

Para que os critérios acima sejam plenamente atendidos, a estrutura deve manter ainda as seguintes funções (ABNT NBR 15200:2004):

- função corta-fogo - a estrutura não permite que o fogo a ultrapasse ou que o calor a atravesse em quantidade suficiente para gerar combustão no lado oposto ao incêndio inicial. A função corta-fogo compreende o isolamento térmico e a estanqueidade à passagem de chamas;

- função de suporte - a estrutura mantém sua capacidade de suporte da construção como um todo ou de cada uma de suas partes, evitando o colapso global ou o colapso local progressivo.

A função corta-fogo (separação) é avaliada utilizando dois critérios: estanqueidade e isolamento. $\mathrm{O}$ critério de estanqueidade é a capacidade da estrutura de impedir a penetração de chamas e gases quentes por meio de rachaduras ou aberturas, o que poderia propagar o incêndio ao compartimento adjacente. O critério de isolamento limita, para incêndios nominais, que a temperatura no lado não exposto da estrutura atinja $140^{\circ} \mathrm{C}$ na média e $180^{\circ} \mathrm{C}$

${ }^{1}$ Segundo a norma ABNT NBR 14432:2000, proteção passiva é o "conjunto de medidas incorporado ao sistema construtivo do edifício, sendo funcional durante o uso normal da edificação e que reage passivamente ao desenvolvimento do incêndio, não estabelecendo condições propícias ao seu crescimento e propagação, garantindo a resistência ao fogo, facilitando a fuga dos usuários e a aproximação e o ingresso no edifício para o desenvolvimento das ações de combate".

${ }^{2}$ Segundo a norma ABNT NBR 14432:2000, proteção ativa é o "tipo de proteção contra incêndio que é ativada manual ou automaticamente em resposta aos estímulos provocados pelo fogo, composta basicamente das instalações prediais de proteção contra incêndio". 
em pontos localizados. Para incêndios reais, os limites correspondentes são $200^{\circ} \mathrm{C}$ e $240^{\circ} \mathrm{C}$, respectivamente (assumindo a mesma duração de incêndio para ambas as curvas), porque os incêndios reais possuem fase de resfriamento. Esses limites não são científicos, mas sim puramente práticos para aumentar a segurança (FIB, 2007).

O critério de estanqueidade pode geralmente ser atendido mediante detalhamento adequado, respeito a dimensões mínimas dos elementos, etc. Os critérios de isolamento térmico e capacidade portante podem ser atendidos pelos métodos descritos no Capítulo 5 deste trabalho.

O comportamento de estruturas em situação de incêndio é geralmente descrito sob o conceito de tempo de resistência ao fogo (TRF), que é o período de tempo para que uma estrutura atinja algum estado limite quando submetida ao incêndio-padrão. Nas normas técnicas baseadas em desempenho, esse estado limite é definido como um colapso estrutural propriamente dito ou uma falha de integridade (que permita ao fogo se espalhar, por exemplo), mas também pode ser baseado em deformações máximas admissíveis. As normas técnicas atuais caminham para se tornar normas baseadas totalmente em critérios de desempenho, permitindo aos engenheiros de estruturas tratarem o fogo como um dos estados limites básicos, levando em consideração (HUANG, BURGESS e PLANK, 2006):

- aquecimento não uniforme devido a proteção térmica parcial, que pode ser inerente ao esquema construtivo ou aplicado com esse propósito;

- nível de carregamento no estado limite em situação de incêndio, utilizando coeficientes de segurança parciais menores que aqueles utilizados em estados limites últimos, devido à baixa probabilidade de ocorrência do incêndio;

- curvas tensão-deformação realísticas dos materiais sob temperaturas elevadas.

As normas técnicas indicam ainda que nos casos que um elemento sirva de apoio para outro, o TRF do elemento de suporte deve ser no mínimo igual ao TRF do elemento suportado. Situações excepcionais que violem esse princípio também são dadas pelas mesmas normas.

A maior limitação das normas técnicas é que elas são baseadas no comportamento de elementos isolados, geralmente aquecidos segundo a curva de incêndio-padrão (item 3.1.2 deste trabalho). Em edificações reais os elementos estruturais fazem parte de um sistema estrutural, e o incêndio normalmente ocorre de forma localizada, mesmo que ele possa se propagar para outras partes da edificação. Sendo assim, os elementos aquecidos sofrem significativa restrição a deformações por parte das regiões mais frias da estrutura. $\mathrm{O}$ real comportamento desses elementos estruturais pode variar bastante em relação ao indicado por 
experimentos em laboratório (HUANG, BURGESS e PLANK, 2006). Maiores informações sobre o comportamento estrutural em situação de incêndio são dadas no Capítulo 5 deste trabalho.

\subsection{MODOS DE FALHA}

A função portante de um elemento estrutural está relacionada ao colapso sob cargas aplicadas. Todos os modos de falha relevantes devem ser avaliados durante o projeto: falha por momento fletor, esforço cortante, aderência aço-concreto e instabilidade. A capacidade portante mínima se manifesta na fase de resfriamento (FIB, 2007).

Em estruturas de concreto, todos os modos de falha devem ser considerados no projeto em situação de incêndio. Dependendo do tipo de carregamento, das características do incêndio e do tipo de estrutura, diversos modos de falha podem se manifestar (FIB, 2007):

a) falha por flexão: modo de falha mais comum em elementos horizontais (vigas e lajes armadas em uma direção, principalmente). Como normalmente a face inferior das vigas ou lajes sofre aquecimento, as barras de aço inferiores perdem resistência e o concreto aquecido expande-se, gerando tensões de compressão nessa região. Assim, a ruptura pode ocorrer por falha das barras de aço tracionadas nas regiões solicitadas por momentos fletores positivos ou falha por compressão do concreto onde atuam momentos fletores positivos, geralmente próximo aos apoios. Em lajes armadas em duas direções, o mecanismo resistente em situação de incêndio envolve ainda significativa contribuição por efeito de membrana;

b) falha de ancoragem das barras: é um tipo de falha de ocorrência rara, que pode praticamente resolvido mediante ancoragem mecânica (ganchos dobrados nos extremos das barras de aço). Pode ocorrer mais facilmente em elementos de concreto protendidos com cordoalhas aderentes. Nesse caso, a redução da resistência e do módulo de elasticidade do concreto e do aço, juntamente com as deformações térmicas, pode provocar deslizamento das cordoalhas;

c) falha por esforço cortante ou torção: geralmente não são modos de falha dominantes em estruturas de concreto em situação de incêndio. $O$ esforço cortante é transferido principalmente em regiões próximas ao centro da seção de concreto, que são relativamente frias se comparadas às regiões onde estão as 
armaduras que resistem aos esforços de flexão. Em vigas, um caso crítico seria vigas protendidas de seção I, já que a alma aquece mais rápido que as mesas;

d) falha por instabilidade ou compressão: são modos de falha típicos de elementos comprimidos, como pilares e paredes estruturais. A combinação da redução da capacidade resistente e da redução da rigidez conduz à instabilidade do elemento, que normalmente rompe por falha no concreto comprimido. Para elementos com altas taxas de armaduras, a perda de resistência do aço também contribui para a falha;

e) spalling: esse fenômeno não é um modo de falha propriamente dito, mas sua ocorrência pode levar à perda de seção resistente de concreto, conduzindo a um dos modos de falha apresentados anteriormente.

No caso de pilares de concreto armado em situação de incêndio, o estudo do spalling e da falha por instabilidade são os tópicos mais relevantes, por isso são discutidos em detalhes ao longo deste trabalho. 


\section{INCÊNDIO E AÇÕES TÉRMICAS EM ESTRUTURAS}

\subsection{MODELOS DE INCÊNDIO}

\subsubsection{Introdução}

A resposta dos materiais e da estrutura como um todo em situação de incêndio depende da evolução da temperatura ao longo do tempo, que pode variar substancialmente para diversos cenários de incêndio.

Para a avaliação da resistência ao fogo de estruturas (seja experimentalmente ou analiticamente), utiliza-se normalmente uma curva que relaciona o tempo à temperatura média dos gases no compartimento. Os principais parâmetros dessas curvas são (FIB, 2007):

a) a taxa de aquecimento, que influencia no desenvolvimento de gradientes de temperatura, de umidade e de pressão nos poros do concreto;

b) a temperatura máxima do incêndio, que influencia as reações físico-químicas nos materiais, que por sua vez afetam as suas propriedades termomecânicas;

c) a duração do incêndio, que influencia na evolução das temperaturas na estrutura ao longo do tempo;

d) a fase de resfriamento. Por exemplo, resfriamento natural ou resfriamento com uso de água geram diferentes impactos nos materiais e na distribuição de temperaturas.

Em incêndios reais, a evolução da temperatura dos gases no compartimento em função do tempo de incêndio pode ser representada conforme mostra a Figura 1.

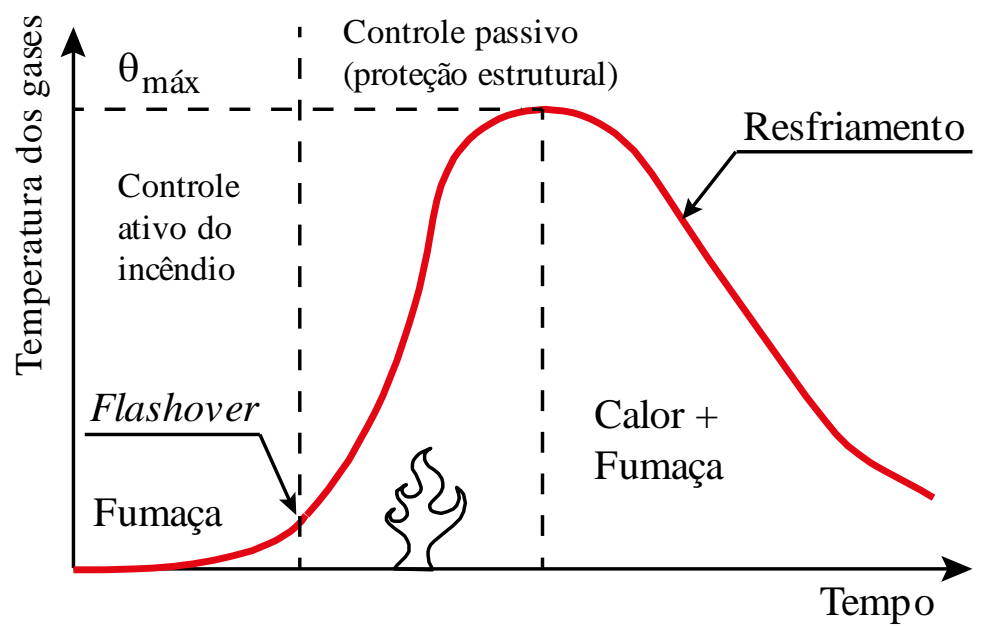

Figura 1 - Curva temperatura-tempo de um incêndio real (LIE, 1992) 
A curva de um incêndio real apresenta uma região inicial, denominada fase de ignição, na qual os materiais começam a queimar, mas as temperaturas são relativamente baixas, sem riscos às pessoas e às estruturas. Caso haja na edificação medidas de proteção contra incêndio (detectores de calor e fumaça, chuveiros automáticos, brigada de incêndio, etc.) e o fogo seja extinto nesse intervalo de tempo, nenhuma verificação posterior da estrutura será necessária (LIE, 1992; SILVA, 2004).

Caso o fogo não seja extinto na fase de ignição, o calor acumula-se no compartimento e todo o combustível presente no compartimento entra em ignição. A temperatura dos gases aumenta bruscamente para valores elevados. Esse instante é chamada de flashover ou inflamação generalizada. A partir desse instante, o incêndio torna-se de grandes proporções e o calor transmitido aos elementos estruturais pode reduzir suas resistências.

Quando todo o combustível presente no compartimento for queimado, a temperatura dos gases diminui com o passar do tempo (fase de resfriamento).

As curvas que representam a temperatura dos gases de um incêndio real são variáveis, dependendo de diversos parâmetros: carga de incêndio, condições de ventilação, características térmicas dos materiais de vedação, etc. Por isso, surgiu a necessidade de adotar curvas padronizadas para análise experimental de estruturas, materiais de revestimento contra o fogo, portas corta-fogo, etc., em laboratórios de pesquisa. As diferentes categorias de curvas de incêndio padronizadas são apresentadas a seguir.

\subsubsection{Curvas de incêndio-padrão}

As curvas de incêndio-padrão são representações de incêndios idealizados. Tais curvas não dependem de fatores como tipo e quantidade de combustível, grau de ventilação do compartimento, etc. Por outro lado, as curvas nominais são de fácil aplicação, sendo descritas por expressões dadas pelas normas técnicas.

As curvas de incêndio-padrão usadas em ensaios, análises e projetos foram criadas com base em incêndios reais e são divididas em categorias conforme sua aplicação: edificações, offshore/petroquímicas e túneis (FIB, 2007).

As principais características das curvas de incêndio-padrão são (FIB, 2008):

- são descritas como uma relação entre a temperatura média dos gases no compartimento em função do tempo. As curvas representam, portanto, a situação de incêndio plenamente desenvolvido. Para grandes compartimentos, essa situação 
só seria verificada após um longo tempo de incêndio (dependendo também da disponibilidade de material combustível, ventilação, etc.);

- todas essas relações são monotonicamente crescentes com o tempo. A fase de resfriamento não é modelada. Normalmente, quando certo tempo de resistência ao fogo é exigido, basta verificar a capacidade resistente para essa duração de incêndio, ou seja, nenhuma consideração é feita em relação aos instantes além desse período.

O uso de curvas de incêndio-padrão possui diversas limitações conhecidas pelo meio técnico especializado (FIB, 2007):

a) como a evolução da temperatura é padronizada e controlada nos ensaios, o impacto real do aquecimento da estrutura depende também de outras variáveis, incluindo as propriedades óticas dos gases do forno de ensaio e a resposta térmica da estrutura;

b) os resultados dos ensaios proporcionam pouca informação a respeito da resposta dos elementos estruturais in situ, por exemplo, levando em consideração a interação entre as diferentes partes da estrutura, os efeitos das restrições, etc.;

c) os gradientes térmicos no interior dos elementos de concreto são geralmente mais severos quando submetidos a incêndios reais, se comparados ao incêndio-padrão;

d) os efeitos decorrentes de incêndios não uniformes no compartimento são muito pouco conhecidos, e sabe-se que a ocorrência do spalling pode estar relacionada a esses efeitos;

e) as curvas de incêndio-padrão desconsideram os importantes efeitos do resfriamento (item 3.1.2.1 a seguir).

Os ensaios considerando o incêndio-padrão conseguem avaliar somente uma faixa limitada de regimes de aquecimento. Trabalhos recentes discutiram as diferentes respostas de estruturas de concreto submetidas a incêndios rápidos e com altas temperaturas e a incêndios longos e com temperaturas mais brandas. No primeiro caso, as deformações (e tensões) térmicas são mais severas, mas possuem curta duração. No segundo caso, a temperatura máxima atingida pelo fogo é menor, mas devido à longa duração do incêndio, os elementos de concreto são aquecidos em camadas mais profundas. Ainda está em discussão qual desses cenários seria mais danoso ao concreto (FIB, 2008).

Existem métodos que tentam correlacionar os resultados de ensaios considerando o incêndio-padrão e o comportamento dos elementos estruturais submetidos a incêndios reais. Mas esses métodos são na sua maioria aplicáveis a estruturas metálicas somente, e não ao 
concreto ou materiais de isolamento térmico. Alerta-se que esses métodos são pouco precisos, portanto seu uso não é recomendado (LAW³ 1971 apud FLETCHER et al., 2007).

\subsubsection{Curvas de incêndio-padrão para edificações}

A curva de incêndio-padrão ISO 834 (ISO, 1990) é a curva mais amplamente utilizada para análise da resistência ao fogo de estruturas de edificações. Diversos experimentos e métodos de cálculo são baseados nessa curva. Ela representa um incêndio típico em edifícios, tendo como combustíveis materiais celulósicos como madeira, papel, tecidos, etc. Nota-se que essa curva não apresenta fase de resfriamento, sendo que a temperatura aumenta indefinidamente. No entanto, em incêndios reais a temperatura diminui assim que todo o combustível for consumido pelo fogo (FIB, 2007). A expressão da curva de incêndio-padrão ISO 834 (ISO, 1990), que relaciona a temperatura média dos gases do compartimento em função do tempo é dada pela eq. (1).

$$
\theta_{g}=20+345 \cdot \log _{10}(8 t+1)
$$

Onde:

$\theta_{\mathrm{g}}$ : temperatura média dos gases no compartimento $\left[{ }^{\circ} \mathrm{C}\right]$;

t: tempo [min.].

A curva de incêndio-padrão ISO 834 (ISO, 1990) é apresentada graficamente pela Figura 2.

A norma brasileira ABNT NBR 14432:2000 adota a curva ISO 834 (ISO, 1990) como modelo de incêndio-padrão.

${ }^{3}$ LAW, M. A relationship between fire grading and building design and contents. Joint Fire Research Organization, Fire Research Note No. 877, Borehamwood, Reino Unido, 1971. 


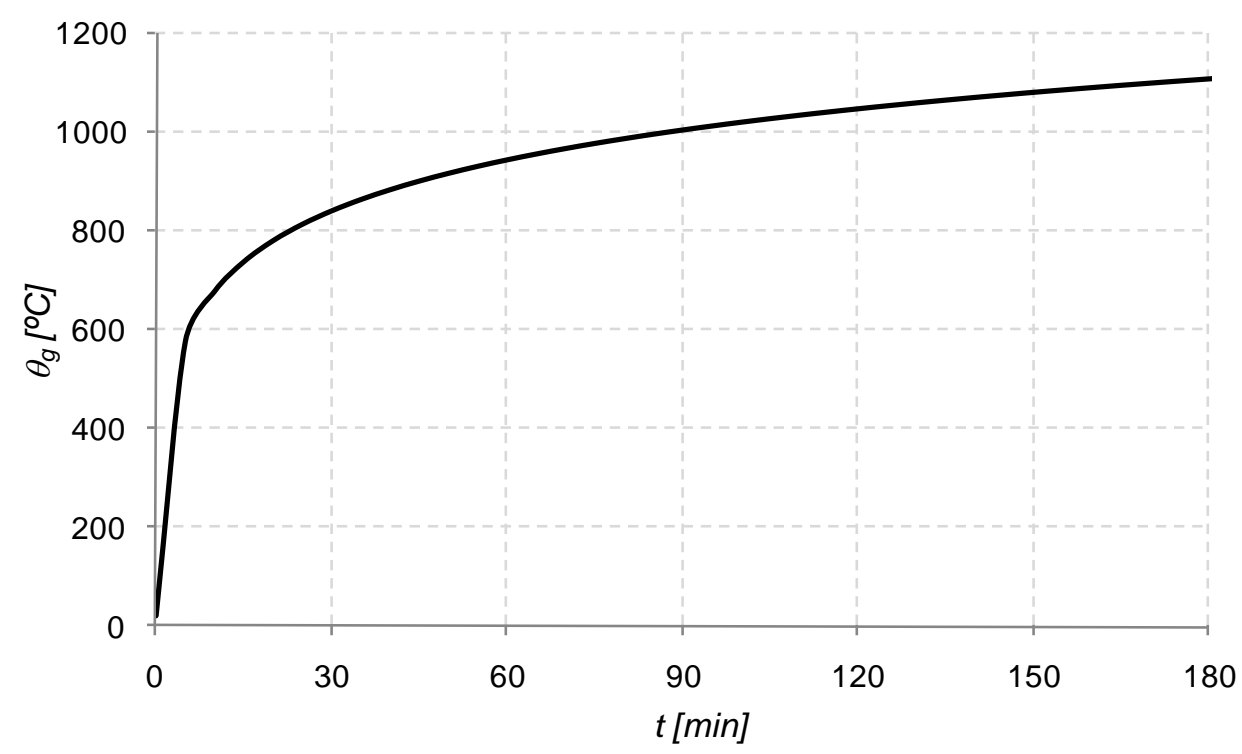

Figura 2 - Curva de incêndio-padrão ISO 834 (ISO, 1990)

Outra curva de incêndio-padrão para análises de edificações é a ASTM E119 (ASTM, 2000). Originalmente, a relação temperatura-tempo foi fornecida de forma tabelada (Tabela 1).

Tabela 1 - Temperatura dos gases em função do tempo conforme a curva ASTM E119 (ASTM, 2000)

\begin{tabular}{cc}
\hline Tempo $[\mathrm{min}]$ & $\theta_{\mathrm{g}}\left[{ }^{\mathrm{o}} \mathrm{C}\right]$ \\
\hline 0 & 20 \\
\hline 5 & 538 \\
\hline 10 & 704 \\
\hline 15 & 760 \\
\hline 20 & 795 \\
\hline 25 & 821 \\
\hline 30 & 843 \\
\hline 35 & 862 \\
\hline 40 & 878 \\
\hline 45 & 892 \\
\hline 50 & 905 \\
\hline
\end{tabular}

\begin{tabular}{cc}
\hline Tempo $[\mathrm{min}]$ & $\theta_{\mathrm{g}}\left[{ }^{\mathrm{o}} \mathrm{C}\right]$ \\
\hline 55 & 916 \\
\hline 60 & 927 \\
\hline 65 & 937 \\
\hline 70 & 946 \\
\hline 75 & 955 \\
\hline 80 & 963 \\
\hline 85 & 971 \\
\hline 90 & 978 \\
\hline 120 & 1010 \\
\hline 240 & 1093 \\
\hline 480 & 1260 \\
\hline
\end{tabular}

Diversas equações foram propostas para descrever a curva ASTM E119 (ASTM, 2000), sendo que a que apresenta a melhor acuracidade em relação aos valores tabelados é a expressão dada pela eq. (2) (SANTOS, 2009):

$$
\theta_{g}=750 \cdot\left[1-e^{-3,7955 \sqrt[3]{t_{h}}} \mid+170,41 \cdot \sqrt{t_{h}+\theta_{0}}\right.
$$


Onde:

$\theta_{\mathrm{g}}$ : temperatura média dos gases no compartimento $\left[{ }^{\circ} \mathrm{C}\right]$;

$\mathrm{t}_{\mathrm{h}}$ : tempo $[\mathrm{h}]$, devendo-se utilizar horas decimais, por exemplo: 2,75 horas $=165$ minutos;

$\theta_{0}$ : temperatura inicial $\left[{ }^{\circ} \mathrm{C}\right]$, normalmente igual a $20^{\circ} \mathrm{C}$.

A curva de incêndio-padrão ASTM E119 (ASTM, 2000) é apresentada graficamente pela Figura 3.

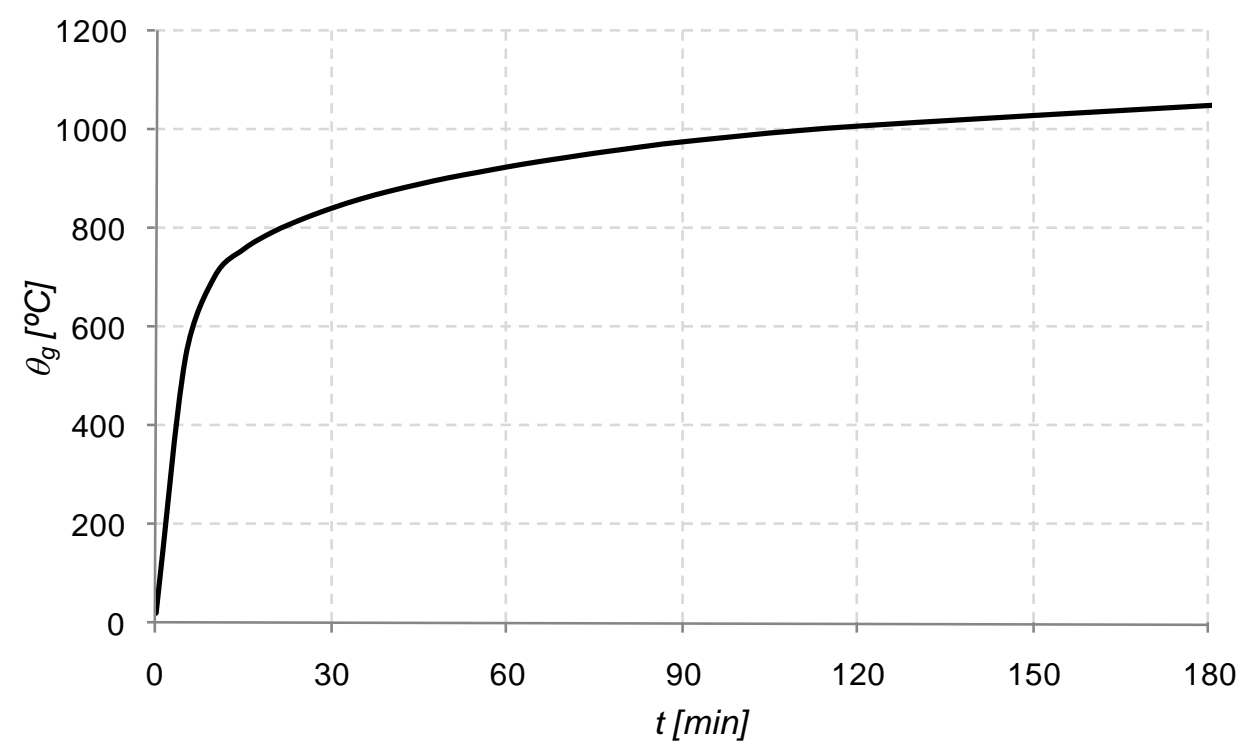

Figura 3 - Curva de incêndio-padrão ASTM E119 (ASTM, 2000)

3.1.2.2. Curvas de incêndio-padrão para indústrias petroquímicas e offshore

Na década de 1970, a companhia petrolífera Mobil investigou curvas de incêndio de hidrocarbonetos e desenvolveu relações temperatura-tempo com rápida elevação da temperatura nos primeiros 5 minutos. Essa pesquisa criou as bases para procedimentos experimentais quanto a materiais de proteção contra incêndio em indústrias offshore e petroquímicas. Na década de 1990, foram desenvolvidas outras curvas para hidrocarbonetos com taxas de aquecimento de 50 a $300 \mathrm{~kW} / \mathrm{m}^{2}$, de modo a representar maior variedade de cenários de incêndio envolvendo hidrocarbonetos como combustível (FIB, 2007).

A expressão da curva de incêndio-padrão de hidrocarbonetos proposta pelo Eurocode 1 (EN 1991-1-2:2004) é dada pela eq. (3). 


$$
\theta_{g}=1080 .\left(1-0,325 e^{-0,167 t}-0,675 e^{-2,5 t}\right)+20
$$

Onde:

$\theta_{\mathrm{g}}$ : temperatura média dos gases no compartimento $\left[{ }^{\circ} \mathrm{C}\right]$;

t: tempo [min.].

A curva de incêndio-padrão de hidrocarbonetos (EN 1991-1-2:2004) é apresentada graficamente pela Figura 4.

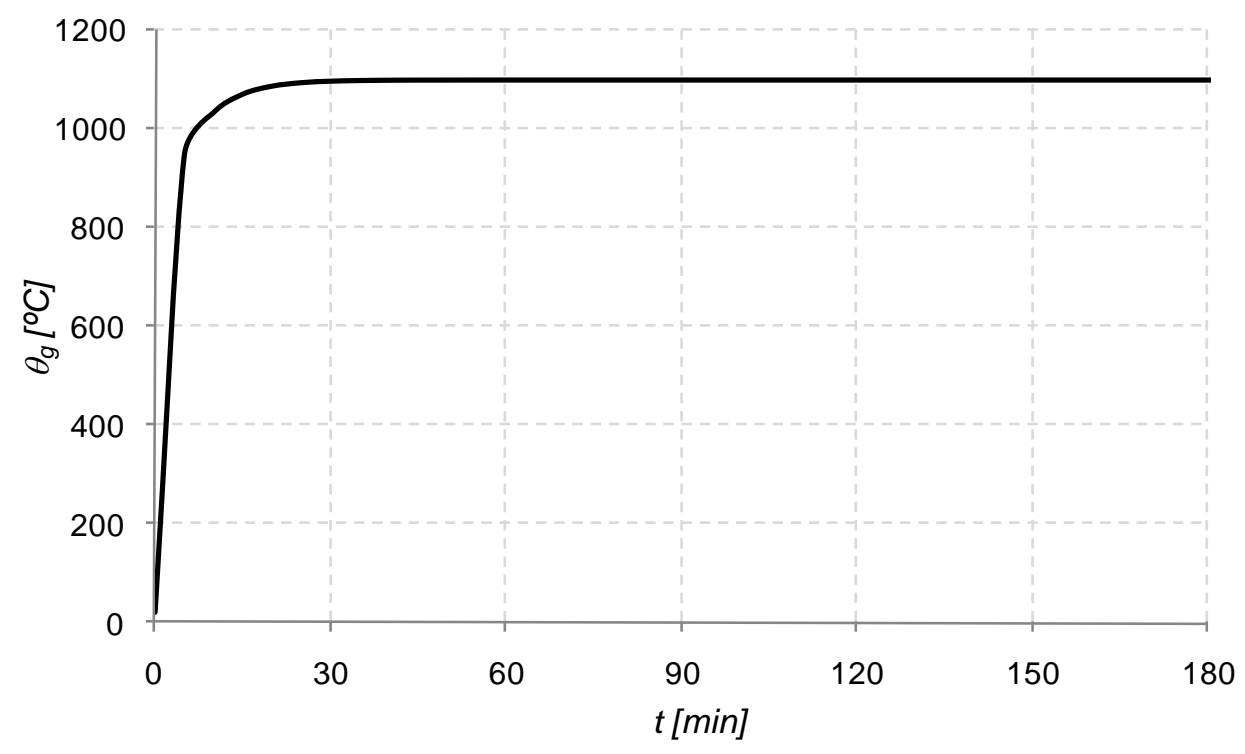

Figura 4 - Curva de incêndio-padrão de hidrocarbonetos (EN 1991-1-2:2004)

Para fins de comparação, a Figura 5 apresenta as quatro curvas de incêndio-padrão apresentadas anteriormente. 


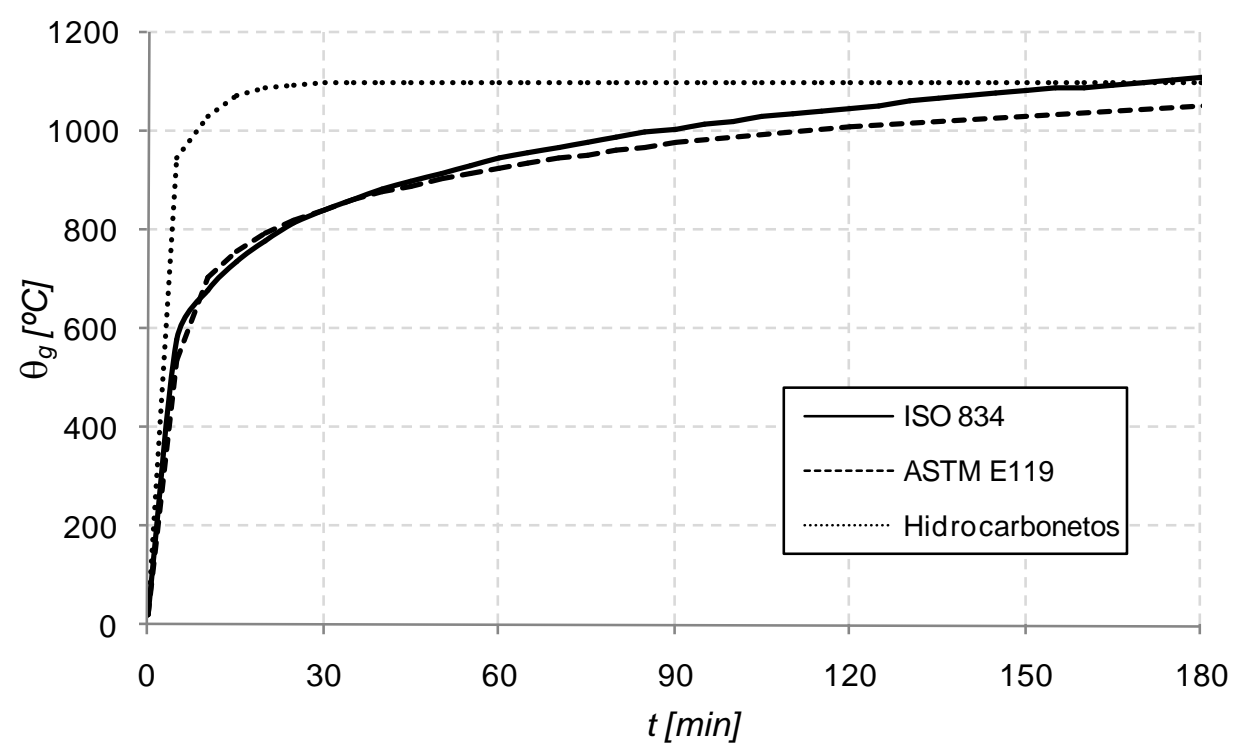

Figura 5 - Comparativo entre as curvas de incêndio-padrão

\subsubsection{Curvas de incêndio-padrão para túneis}

Avaliando-se casos de incêndios em túneis, verificou-se a necessidade de serem considerados casos de incêndio ainda mais severos.

Os Países Baixos estabeleceram a curva RWS para a avaliação de materiais de proteção contra incêndio em túneis. Essa curva representa uma rápida elevação da temperatura para $1200^{\circ} \mathrm{C}$ com temperatura máxima de $1350^{\circ} \mathrm{C}$ (ponto de fusão do concreto) após 60 minutos, seguido de redução para $1200^{\circ} \mathrm{C}$ aos 120 minutos de incêndio (o final da curva). A curva RWS visa simular um incêndio causado por um caminhão tanque carregado de petróleo com carga de incêndio de 300 MW, sendo baseada na experiência holandesa de modelagem de incêndio em túneis. A curva alemã RABT (também conhecida como fogo ZTV) possui um ramo descendente e representa um incêndio menos severo que a curva RWS. A temperatura máxima de incêndio nesta curva é de $1200^{\circ} \mathrm{C}$ (a temperatura de fusão de certos agregados) no período de 60 minutos, reduzindo então para a temperatura ambiente. Recentemente foi proposta outra curva, chamada de curva de incêndio de hidrocarbonetos modificada. Esta curva modificada representa uma taxa de aquecimento de $345 \mathrm{~kW} / \mathrm{m}^{2}$ para simular incêndios severos em túneis. A temperatura se eleva para $1200^{\circ} \mathrm{C}$ em menos de 10 minutos e alcança a temperatura máxima de $1300^{\circ} \mathrm{C}$ após aproximadamente 20 minutos, sendo que a duração total do incêndio é de no máximo 120 minutos (FIB, 2007). 


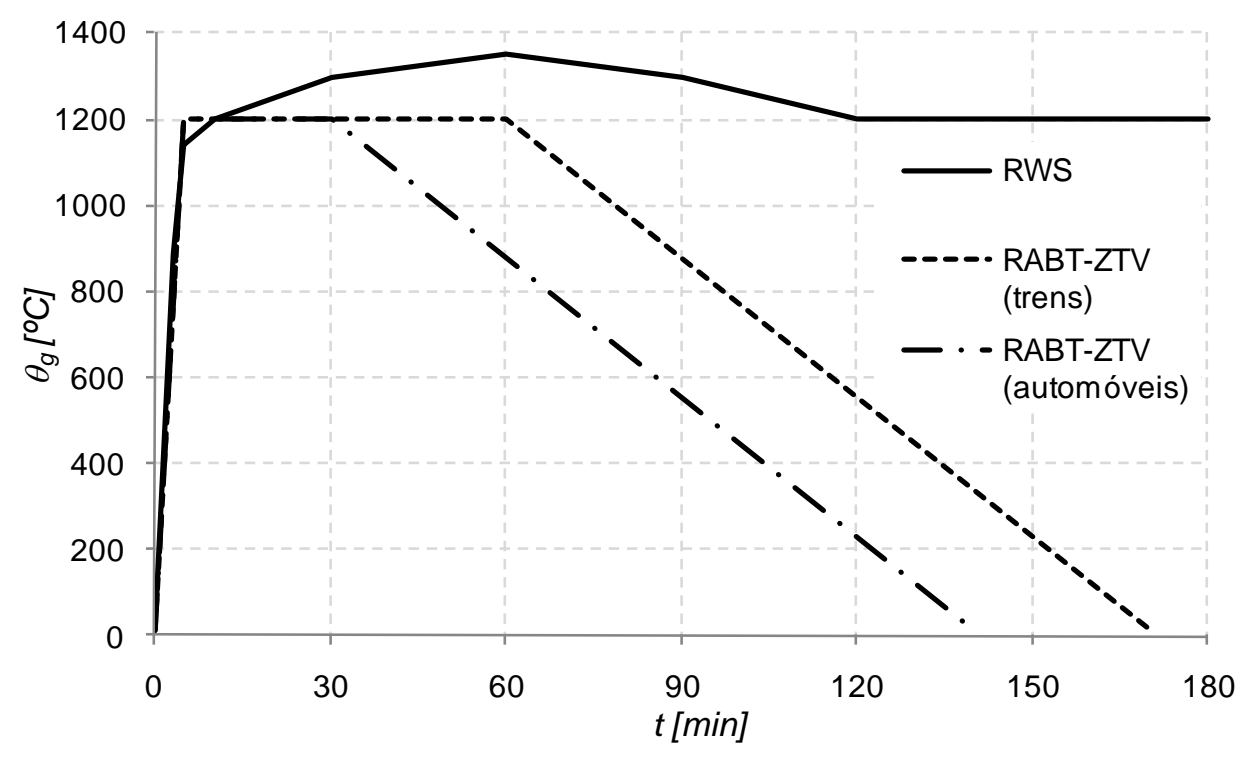

Figura 6 - Exemplos de curvas de incêndio-padrão para túneis

\subsubsection{Curvas de incêndio natural}

As curvas paramétricas de incêndio natural para compartimentos de incêndio em edifícios, ao contrário das demais curvas apresentadas, variam conforme a carga de incêndio (de 25 a $3750 \mathrm{MJ} / \mathrm{m}^{2}$ ) e os fatores de abertura (de 0.01 a $0.3 \mathrm{~m}^{0,5}$ ). Para compartimentos com área de piso inferior a $500 \mathrm{~m}^{2}$, as curvas de incêndio natural representam melhor um incêndio real do que as curvas nominais. Assim como as curvas nominais de incêndio, assume-se distribuição uniforme de temperatura ao longo do compartimento. As curvas de incêndio natural possuem ramo ascendente e ramo descendente (FIB, 2007).

Embora as curvas de incêndio natural não sejam muito práticas para testes experimentais (devido à dificuldade de simular o ramo descendente nos fornos de ensaios), elas são adequadas para cálculos analíticos. Elas possibilitam prever de forma mais precisa o comportamento de estruturas de concreto em situação de incêndio, se comparado ao uso de curvas nominais de incêndio. Isso pode resultar em projetos mais econômicos em certas situações. Por outro lado, é necessário dispor de modelos constitutivos adequados para a fase de resfriamento, o que é complexo especialmente para o concreto (FIB, 2007).

As curvas de incêndio natural são recomendadas para os métodos avançados de projeto, conduzidos por uma análise estrutural refinada, com o objetivo de analisar o desempenho da estrutura em situações especiais (SILVA, 2004). 
O Eurocode 1 (EN 1991-1-2:2004) apresenta no Anexo A curvas paramétricas de incêndio, para simular o incêndio natural em área compartimentada. As curvas sugeridas são válidas para compartimentos com área do piso de até $500 \mathrm{~m}^{2}$, sem aberturas no teto e com altura máxima do compartimento igual a $4 \mathrm{~m}$. Assume-se que a carga de incêndio do compartimento seja totalmente queimada. A Figura 7 apresenta uma comparação qualitativa das curvas paramétricas de incêndio segundo o Eurocode 1 (EN 1991-1-2:2004) com a curva de incêndio-padrão ISO 834 (ISO, 1990).

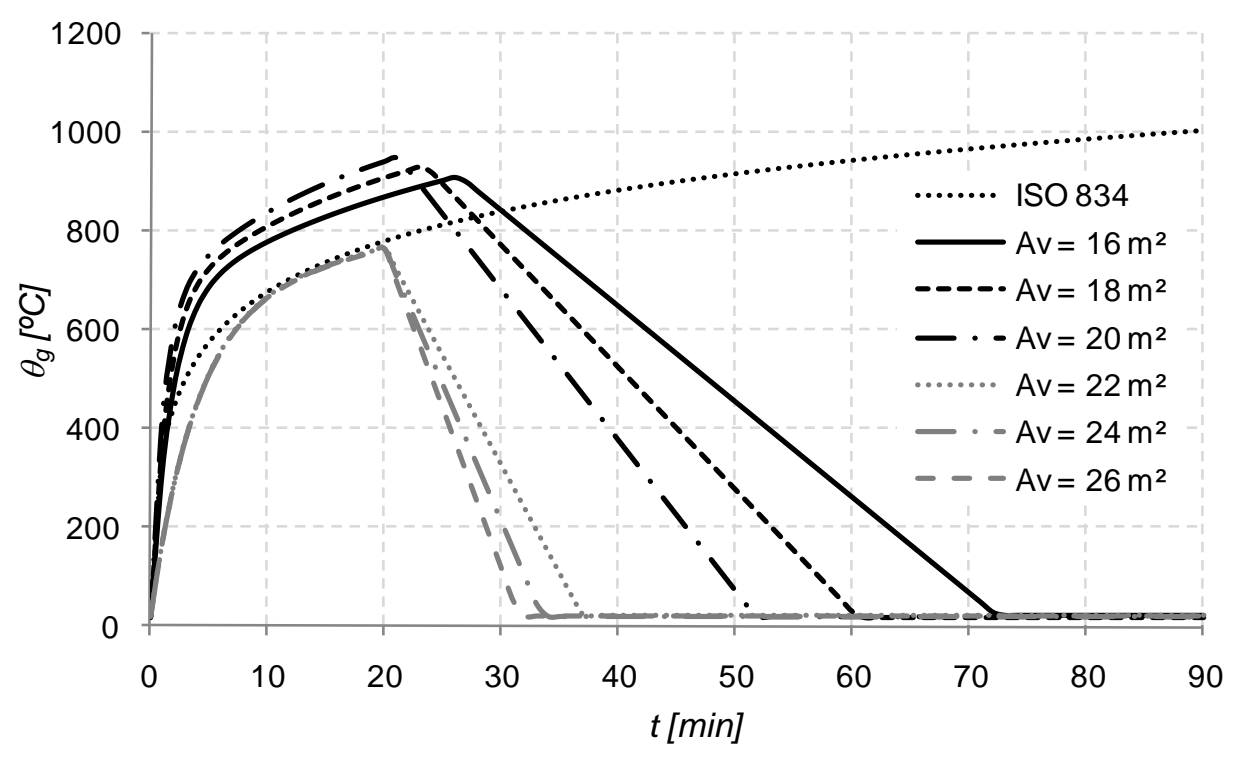

Figura 7 - Curvas paramétricas de incêndio segundo o Eurocode 1 (EN 1991-1-2:2004) para diversas áreas de ventilação (Av), comparadas à curva de incêndio-padrão ISO 834 (ISO, 1990)

Fernandes (2006) explica as etapas de cálculo das curvas paramétricas de incêndio do Eurocode 1 (EN 1991-1-2:2004) e compara a influência de diversas variáveis (área do compartimento, área de ventilação, carga de incêndio, inércia térmica dos materiais de vedação, etc.) no comportamento dessas curvas.

\subsubsection{Modelos multizona e CFD}

Os modelos mais avançados disponíveis atualmente para simulação de incêndios são os modelos multizona ou dinâmica de fluidos computacional (computational fluid dynamics, CFD). Esses modelos resolvem, para uma malha de elementos, as equações de equilíbrio de conservação de massa e de energia (Figura 8). Devido à sua dificuldade de implementação e 
necessidade de conhecimentos especializados para analisar os resultados, estes modelos são utilizados principalmente para fins de pesquisa, sendo raramente usados para projetos. Modelos de 2 zonas (por exemplo o Ozone®) são usados em diversos países, como Luxemburgo, França e Suécia, em fase de projeto e assumem temperatura constante na camada de fumaça, enquanto que modelos CFD simulam cenários mais realísticos quanto à variação da temperatura no tempo e no espaço. Atualmente os modelos CFD são utilizados principalmente para estudar a dispersão de fumaça e calor, e raramente para avaliar o impacto do fogo em elementos estruturais (FIB, 2007).

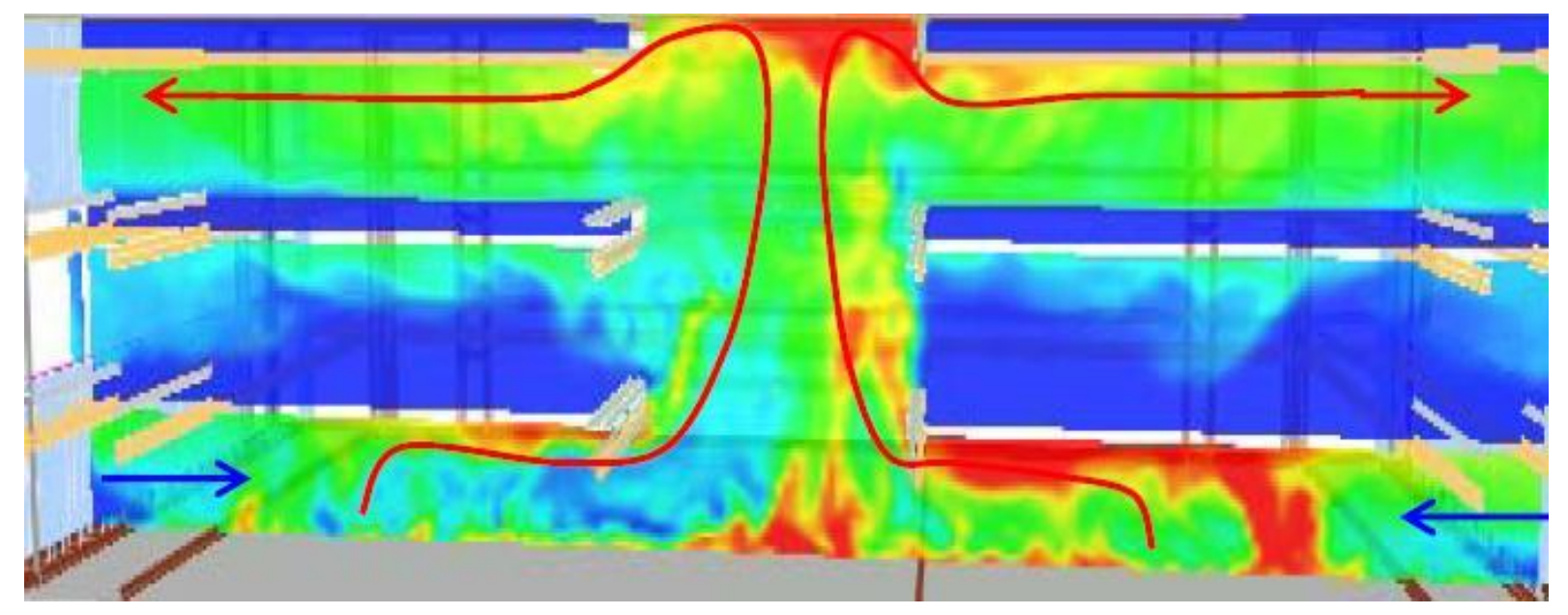

Figura 8 - Exemplo de simulação de incêndio utilizando modelo CFD (REIN et al., 2007)

\subsection{TEMPO REQUERIDO DE RESISTÊNCIA AO FOGO - TRRF}

O tempo requerido de resistência ao fogo (TRRF) é um tempo fictício, definido por consenso da sociedade e do meio técnico e estabelecido nas normas técnicas. A sua função é padronizar a ação térmica a ser utilizada no dimensionamento das estruturas em situação de incêndio, quando submetidas ao incêndio-padrão (SILVA, 2004).

É comum haver confusão no meio técnico quanto ao significado do TRRF. É importante esclarecer que o TRRF não significa a duração do incêndio ou o tempo de evacuação dos ocupantes da edificação ou o tempo de chegada do corpo de bombeiros. Por exemplo, resistir a um incêndio de 60 minutos segundo a curva de incêndio-padrão não significa que a estrutura resistirá 60 minutos durante um incêndio real. Na verdade, significa que a estrutura resistirá a um incêndio cuja severidade corresponde a 60 minutos segundo a curva de incêndio-padrão (FIB, 2007). 
A norma ABNT NBR 14432:2000 apresenta, no Anexo A, um método tabular para a determinação do TRRF de uma edificação. Os fatores que influenciam no valor do TRRF incluem o tipo de ocupação, altura da edificação e carga de incêndio.

A norma ABNT NBR 14432:2000 afirma ainda que quando severidade do incêndio para uma situação particular considerada apresentar-se comprovadamente mais branda do que se considerou para o estabelecimento dos requisitos dessa norma, em função especialmente de condições particulares assumidas pela carga de incêndio e pela ventilação, admite-se a utilização de curvas teóricas ou experimentais de elevação de temperatura durante o incêndio, das quais decorram tempos equivalentes de resistência ao fogo em substituição aos correspondentes estabelecidos nessa norma.

Considerando então que o uso de tempos equivalentes é permitido, uma opção é o Método do Tempo Equivalente (MTE) proposto no Anexo F do Eurocode 1 (EN 1991-12:2004). O MTE foi proposto originalmente como uma correlação entre a máxima temperatura alcançada pelo aço num incêndio natural e o tempo necessário para alcançar a mesma temperatura quando aquecido segundo a curva de incêndio-padrão (Figura 9). Algumas pesquisas (SCHLEICH; CAJOT ${ }^{4}, 1997$ apud SILVA, 2004) indicaram que o MTE seria adequado para estruturas de concreto e aço protegidas termicamente. Por isso, o Eurocode 1 (EN 1991-1-2:2004) permite utilizar o MTE para análise de elementos de concreto armado e aço, dimensionados segundo métodos tabulares ou simplificados. As variáveis do MTE incluem a carga de incêndio, os materiais que compõem a seção transversal do elemento e o grau de ventilação do compartimento de incêndio.

${ }^{4}$ SCHLEICH, J. B.; CAJOT, L. G. Global fire safety concept for buildings. La Revue de Métallurgie Cahier d'Informations Techniques, 94 (1), p. 129-149. Paris, jan. 1991. 


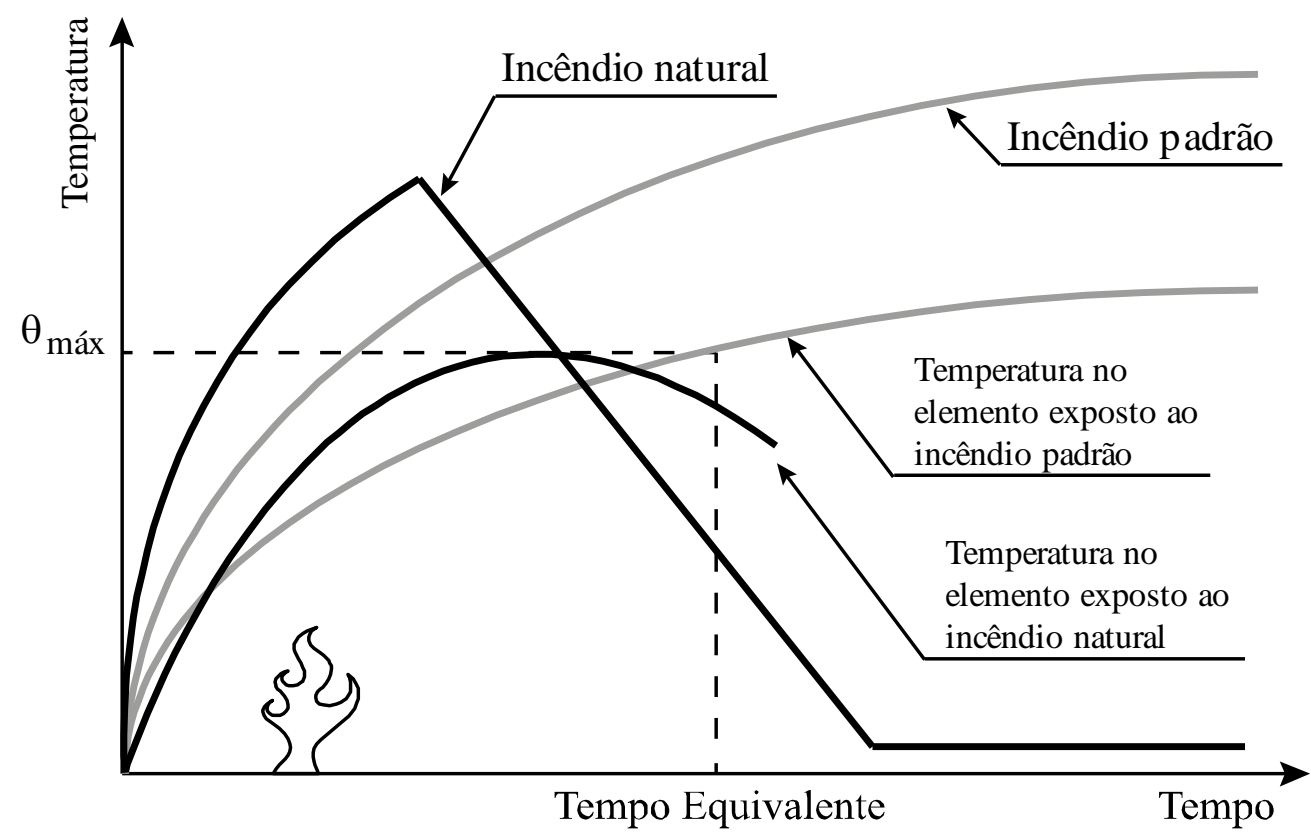

Figura 9 - Conceito do Método do Tempo Equivalente (reproduzido de SILVA, 2004)

Além do MTE, a norma ABNT NBR 14432:2000 permite ainda a utilização de métodos de análise de risco que considerem as medidas de proteção contra incêndio (ativas ou passivas) no cálculo do TRRF. A mesma norma sugere utilizar o Método de Gretener ou seus sucedâneos. O Método de Gretener é um método simplificado de análise de risco, proposto originalmente para atender às necessidades das companhias de seguros. Um resumo da aplicação do Método de Gretener e também do MTE são fornecidos por Silva (2004).

Por fim, o Corpo de Bombeiros do Estado de São Paulo publicou a Instrução Técnica No 08/2011 - Segurança estrutural nas edificações - resistência ao fogo dos elementos de construção (CB-PMESP, 2011), contendo um procedimento para a determinação do TRRF de elementos estruturais e de compartimentação. A mesma publicação apresenta ainda o MTE, que foi incorporado ao projeto de revisão da norma ABNT NBR 15200:2004. 


\subsection{AÇÕES E SEGURANÇA}

Segundo a norma ABNT NBR 8681:2003, as ações são causas que provocam esforços ou deformações nas estruturas, sendo classificadas em três categorias, segundo sua variabilidade no tempo:

- $\quad$ ações permanentes;

- $\quad$ ações variáveis;

- $\quad$ ações excepcionais.

O incêndio é considerado como uma ação excepcional, por possuir duração extremamente curta e muito baixa probabilidade de ocorrência durante a vida da construção, mas deve ser consideradas nos projetos de determinadas estruturas conforme orienta a norma ABNT NBR 8681:2003.

A verificação usual de estruturas de concreto em situação de incêndio segue o modelo semi probabilístico, ou seja, comparam-se os esforços resistentes da estrutura calculados considerando os valores de cálculo das propriedades dos materiais aos esforços solicitantes definidos segundo as combinações de ações apropriadas. Assim, a verificação usual da estrutura em situação de incêndio se reduz a mostrar a seguinte condição (eq. (4))

$$
S_{d, f i} \leq R_{d, f i}
$$

Onde:

$\mathrm{S}_{\mathrm{d}, \mathrm{fi}}$ : esforços atuantes na estrutura em situação de incêndio;

$\mathrm{R}_{\mathrm{d}, \mathrm{fi}}$ : esforços resistentes da estrutura em situação de incêndio.

Os esforços atuantes na estrutura em situação de incêndio são calculados à temperatura ambiente, no estado limite último (ELU) para a combinação excepcional de ações (item 4.3.2.3 da norma ABNT NBR 8681:2003). O ELU é caracterizado pelo colapso estrutural ou outras formas de falha, como perda do equilíbrio, deformações excessivas, instabilidades, etc. A combinação excepcional de ações para a situação de incêndio é dada pela eq. (5).

$$
F_{d}=\sum_{i=1}^{m} \gamma_{g i} F_{G k i}+F_{Q, e x c}+\gamma_{q} \sum_{j=1}^{n} \psi_{0 j, e f} F_{Q j, k}
$$


Onde:

$\mathrm{F}_{\mathrm{d}}$ : valor de cálculo das ações em situação de incêndio;

$\gamma_{\mathrm{g}}$ : coeficiente de ponderação das ações permanentes;

$\mathrm{F}_{\mathrm{Gk}}$ : valor característico das ações permanentes;

$\mathrm{F}_{\mathrm{Q} \text {,exc: }}$ valor característico das ações excepcionais;

$\gamma_{\mathrm{q}}$ : coeficiente de ponderação das ações variáveis;

$\psi_{0, \text { ef: }}$ fator de combinação das ações variáveis;

$\mathrm{F}_{\mathrm{Qj}, \mathrm{k}}$ : valor característico das ações variáveis.

A norma ABNT NBR 8681:2003 informa, no item 4.2.2.1.3, que nos casos particulares em que sejam consideradas ações que atuem simultaneamente com ações de período de atuação extremamente curto, que é o caso do incêndio, adotam-se para $\psi_{0}$ os mesmos valores especificados para os coeficientes $\psi_{2}$ definidos no item 4.2.2.2 da mesma norma. Assim, a eq. (5) assume a forma como é apresentada pela norma ABNT NBR 15200:2004, dada pela eq. (6).

$$
F_{d}=\gamma_{g} F_{g k}+F_{e x c}+\gamma_{q} \sum_{2}^{n} \psi_{2 j} F_{q j k}
$$

Caso as cargas permanentes sejam compostas de parcelas de pequena e grande variabilidade, seus efeitos podem ser considerados conforme as orientações da norma ABNT NBR 8681:2003. Outra observação importante é que o coeficiente $\psi_{2}$ possui valor nulo para a ação variável do vento (Tabela 6 da norma ABNT NBR 8681:2003), quando se adota a combinação de ações dada pela eq. (6).

A ação excepcional do incêndio consiste, usualmente, apenas na redução da resistência dos materiais e na capacidade dos elementos estruturais. Ou seja, usualmente, desprezam-se todos os esforços decorrentes de deformações impostas, por serem muito reduzidos e pelas grandes deformações plásticas que ocorrem em situação de incêndio, conforme orienta a norma ABNT NBR 15200:2004.

A mesma orientação é fornecida no item 4.1 do Eurocode 1 (EN 1991-1-2:2004), que afirma que as ações indiretas causadas pelas deformações térmicas dos elementos adjacentes não precisam ser consideradas quando os requisitos de segurança contra incêndio referem-se à análise de elementos submetidos ao incêndio-padrão. Essa orientação não é válida quando são utilizadas outras curvas de incêndio. 
Assim, ao desconsiderar os esforços decorrentes de deformações impostas, a eq. (6) assume a forma dada pela eq. (7).

$$
F_{d}=\gamma_{g} F_{g k}+\gamma_{q} \sum_{2}^{n} \psi_{2 j} F_{q j k}
$$

Em casos de incêndios reais, as evidências mostram que ignorar os esforços aplicados pelos elementos adjacentes pode causar a ruptura dos elementos. Isso é especialmente crítico em pilares de fachada, que devem resistir aos esforços transversais devido à expansão térmicas das vigas e lajes que se apoiam nesses elementos. Esses efeitos são explicados em detalhes no Capítulo 5 deste trabalho.

A partir da eq. (7), pode-se assumir a relação simplificada entre os esforços solicitantes de cálculo à temperatura ambiente e em situação de incêndio conforme mostra a eq (8).

$$
F_{d, f i}=\eta_{f i} \cdot F_{d, 0}
$$

Onde:

$\mathrm{F}_{\mathrm{d}, \mathrm{fi}}$ : esforços solicitantes de cálculo em situação de incêndio;

$\eta_{\mathrm{fi}}$ : coeficiente redutor dos esforços solicitantes para a combinação de ações em situação de incêndio;

$\mathrm{F}_{\mathrm{d}, 0}$ : esforços solicitantes de cálculo à temperatura ambiente.

O coeficiente redutor $\eta_{\mathrm{fi}}$ fica definido conforme mostra a eq. (9).

$$
\eta_{f i}=\frac{\gamma_{g, f i} \cdot F_{G k}+\gamma_{q, f i} \cdot \psi_{2} \cdot F_{Q k, 1}}{\gamma_{g, 0} \cdot F_{G k}+\gamma_{q 0,1} \cdot F_{Q k, 1}}
$$

Onde:

$\gamma_{\mathrm{g}, \mathrm{fi}}$ : coeficiente de ponderação das ações permanentes em situação de incêndio;

$\mathrm{F}_{\mathrm{Gk}}$ : valor característico das ações permanentes;

$\gamma_{\mathrm{q}, \mathrm{fi}}:$ coeficiente de ponderação das ações variáveis em situação de incêndio;

$\psi_{2}$ : fator de combinação da ação variável principal em situação de incêndio;

$\mathrm{F}_{\mathrm{Qk}, 1}$ : valor característico da ação variável principal; 
$\gamma_{\mathrm{g}, 0}$ : coeficiente de ponderação das ações permanentes à temperatura ambiente;

$\gamma_{\mathrm{q} 0,1}$ : coeficiente de ponderação da ação variável principal à temperatura ambiente.

Analisa-se a seguir a variação do coeficiente $\eta_{\mathrm{fi}}$ para estruturas de concreto armado, em função da relação entre a ação variável principal e a ação permanente $\left(\mathrm{F}_{\mathrm{Qk}, 1} / \mathrm{F}_{\mathrm{Gk}}\right)$.

À temperatura ambiente, os valores típicos dos coeficientes de ponderação das ações permanentes e variáveis para estruturas de concreto moldadas in loco podem ser tomados igual a 1,4 (conforme o item 11.7 da norma ABNT NBR 6118:2003).

Em situação de incêndio, o coeficiente de ponderação das ações permanentes para estruturas de concreto moldadas in loco é igual a 1,20 (conforme a Tabela 1 da norma ABNT NBR 8681:2003). Para as ações variáveis, o coeficiente de ponderação é dado pelas Tabelas 4 e 5 da norma ABNT NBR 8681:2003. Ambas as tabelas indicam valor desse coeficiente igual a 1,0. Por último, o fator de combinação da ação variável principal em situação de incêndio é dado pela Tabela 6 da norma ABNT NBR 8681:2003, conforme mostra a Tabela 2 a seguir.

Tabela 2 - Valores do coeficiente de combinação $\psi 2$ (ABNT NBR 8681:2003)

\begin{tabular}{|c|c|c|}
\hline Ação & $\psi_{2}$ & $0,7 \cdot \psi_{2}$ \\
\hline $\begin{array}{l}\text { Locais em que não há predominância de pesos e de equipamentos que } \\
\text { permanecem fixos por longos períodos de tempo, nem de elevadas } \\
\text { concentrações de pessoas (edificações residenciais, de acesso restrito) }\end{array}$ & 0,3 & 0,21 \\
\hline $\begin{array}{l}\text { Locais em que há predominância de pesos de equipamentos que } \\
\text { permanecem fixos por longos períodos de tempo, ou de elevadas } \\
\text { concentrações de pessoas (edificações comerciais, de escritórios e de } \\
\text { acesso público) }\end{array}$ & 0,4 & 0,28 \\
\hline Bibliotecas, arquivos, depósitos, oficinas e garagens & 0,6 & 0,42 \\
\hline
\end{tabular}

Os valores da última coluna da Tabela 2 refletem a recomendação presente na Tabela 6 da norma ABNT NBR 8681:2003, a qual afirma que, para combinações excepcionais onde a ação principal for o fogo, o fator de redução $\psi_{2}$ pode ser reduzido, multiplicando-o por 0,7 .

Considerando os valores dos coeficientes de ponderação e combinação apresentados, a eq. (9) assume a forma mostrada pela eq. (10).

$$
\eta_{f i}=\frac{1,2 \cdot F_{G k}+0,7 \cdot \psi_{2} \cdot F_{Q k, 1}}{1,4 \cdot\left(F_{G k}+F_{Q k, 1}\right)}=\frac{1,2+0,7 \cdot \psi_{2} \cdot\left(F_{Q k, 1} / F_{G k}\right)}{1,4 \cdot\left(1+F_{Q k, 1} / F_{G k}\right)}
$$


As curvas que relacionam o coeficiente $\eta_{\text {fi }}$ para estruturas de concreto armado, em função da relação entre a ação variável principal e a ação permanente $\left(\mathrm{F}_{\mathrm{Qk}, 1} / \mathrm{F}_{\mathrm{Gk}}\right)$, são apresentadas pela Figura 10.

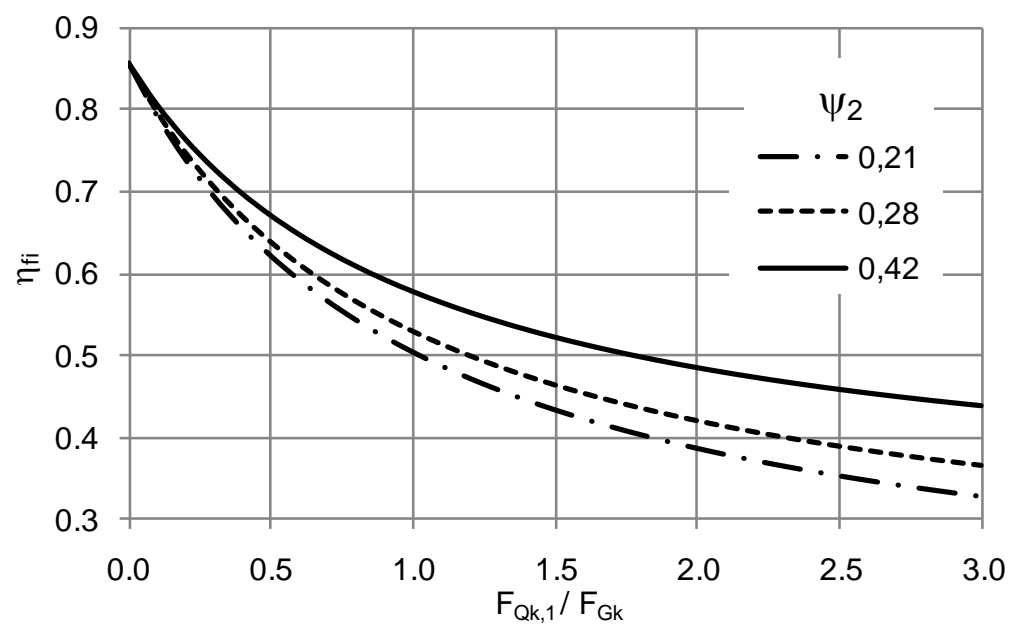

Figura 10 - Variação do coeficiente $\eta_{f i}$ em função da relação $F_{Q k, 1} / F_{G k}$

Como simplificação, o Eurocode 2 (EN 1992-1-2:2004) e a norma ABNT NBR 15200:2004 permitem adotar o coeficiente $\eta_{\mathrm{fi}}$ com valor igual a 0,7. Essa simplificação é permitida apenas para a análise de elementos isolados, na ausência de qualquer solicitação gerada pelas deformações impostas pelos elementos adjacentes em situação de incêndio.

O valor de cálculo das propriedades mecânicas dos materiais (geralmente resistências e módulo de elasticidade) é expresso genericamente segundo a eq. (11).

$$
X_{d, f i}=k_{\theta} \cdot \frac{X_{k}}{\gamma_{M, f i}}
$$

Onde:

$\mathrm{X}_{\mathrm{d}, \mathrm{fi}}$ : valor de cálculo da propriedade mecânica do material sob temperaturas elevadas;

$\mathrm{k}_{\theta}$ : fator de redução da propriedade mecânica em função da temperatura;

$\mathrm{X}_{\mathrm{k}}$ : valor característico da propriedade mecânica do material à temperatura ambiente;

$\gamma_{\mathrm{M}, \mathrm{fi}}:$ coeficiente de segurança do material sob temperaturas elevadas.

O valor de cálculo das propriedades térmicas dos materiais é definido segundo a eq. (12), caso o aumento do valor da propriedade seja favorável à segurança. 


$$
X_{d, f i}=\frac{X_{k}}{\gamma_{M, f i}}
$$

Caso o aumento do valor das propriedades térmicas do material seja desfavorável à segurança, o seu valor de cálculo assume a forma dada pela eq. (13).

$$
X_{d, f i}=\gamma_{M, f i} \cdot X_{k}
$$

O Eurocode 2 (EN 1992-1-2:2004) recomenda adotar o valor 1,0 para os coeficientes de segurança das propriedades térmicas e mecânicas do concreto e aço das armaduras passivas e ativas. A norma ABNT NBR 15200:2004 recomenda adotar o valor 1,2 para o coeficiente de segurança do concreto e 1,0 para o aço, para a combinação excepcional de ações, conforme a Tabela 12.1 da norma ABNT NBR 6118:2003. O projeto de revisão da norma ABNT NBR 15200:2004 propõe que esses valores sejam revistos, para que haja concordância com a norma europeia.

Para o projeto de estruturas de concreto à temperatura ambiente, é usual multiplicar o valor de cálculo da resistência à compressão do concreto por um coeficiente de modificação $\alpha$ (normalmente igual a 0,85 ), para levar em consideração os efeitos do carregamento de longa duração ${ }^{5}$. Como a duração de um incêndio é pequena, da ordem de minutos ou algumas horas, se comparado ao tempo de vida útil da edificação, o coeficiente de modificação $\alpha$ não é utilizado nos cálculos de estruturas em situação de incêndio (FIB, 2008).

5 Para maiores informações sobre os efeitos do carregamento de longa duração na resistência à compressão do concreto, recomenda-se consultar o trabalho: FUSCO, P.B. Resistência do concreto comprimido. $35^{\text {a }}$ Reunião do Instituto Brasileiro do Concreto, Brasília, 1993. 


\section{PROPRIEDADES DOS MATERIAIS SOB ALTAS TEMPERATURAS}

O concreto, apesar de ser claramente um material heterogêneo, composto de agregados, pasta de cimento e água, é tratado como se fosse homogêneo à temperatura ambiente. Além disso, as barras de aço são normalmente nervuradas, o que melhora a aderência com o concreto e permite considerar, nos cálculos, a perfeita aderência entre os materiais.

Sob temperaturas elevadas, principalmente acima dos $100^{\circ} \mathrm{C}$, ocorrem diversas transformações físico-químicas no concreto e no aço. Além disso, essas transformações são influenciadas pelas características da mistura (tipo de cimento, tipo de agregados, fator água/cimento, fator cimento/agregados, teor de umidade), resultando em ampla variabilidade das propriedades dos materiais à temperatura ambiente e, sobretudo, sob temperaturas elevadas (COSTA, 2008).

São apresentados neste capítulo aspectos gerais das propriedades do concreto e do aço sob temperaturas elevadas, obtidas na literatura e nas normas técnicas vigentes. Informações mais detalhadas podem ser consultadas na extensa literatura específica (COSTA, 2008; FIB, 2007; GEORGALI e TSAKIRIDIS, 2005; JANSSON, 2008; KHOURY, 2000b; KHOURY e ANDERBERG, 2000a; LI e PURKISS, 2005; PURKISS, 2007; HARMATHY, 1993).

\subsection{CONCRETO}

Tradicionalmente, o concreto foi considerado como "à prova de fogo", devido às suas características de incombustibilidade e isolamento térmico. Os três principais efeitos observados no concreto sob temperaturas elevadas são: (a) deterioração das propriedades mecânicas, (b) danos causados por deformações térmicas e (c) spalling. Alguns desses problemas podem ser controlados mediante dosagem do concreto (por exemplo, escolha criteriosa dos agregados, relação água-cimento, etc.) e projeto estrutural adequado (por exemplo, adoção de chanfros nos cantos de pilares para evitar o spalling nessa região) (FIB, 2007). Para maiores informações, ver item 4.1.7 neste trabalho.

De modo geral, o concreto apresenta comportamento bastante complexo e instável nos primeiros instantes do aquecimento, devido a mudanças na microestrutura do material. As propriedades termo-hidro-mecânicas também mudam em função da temperatura, taxa de 
aquecimento, teor de umidade inicial, geometria e dimensões do elemento estrutural, carregamento, materiais constituintes, interações físico-químicas, etc. Informações detalhadas sobre o comportamento de cada componente da microestrutura do concreto em situação de incêndio são apresentadas pelo Boletim 38 do fib (FIB, 2007).

Dentre as alterações físico-químicas ocorrem no concreto sob temperaturas elevadas, algumas são reversíveis após o resfriamento, outras são irreversíveis e podem reduzir a capacidade resistente da estrutura após o incêndio.

As alterações físico-químicas experimentadas pelo concreto sob temperaturas elevadas são (KHOURY ${ }^{6}, 1992$ apud FIB, 2007)

- $20^{\circ} \mathrm{C}$ a $80^{\circ} \mathrm{C}$ : aumento da hidratação do cimento, perda lenta de água nos capilares e redução das forças de coesão;

- $100^{\circ} \mathrm{C}$ : aumento significativo da permeabilidade;

- $80^{\circ} \mathrm{C}$ a $200^{\circ} \mathrm{C}$ : aumento da taxa de perda da água capilar e água livre;

- $80^{\circ} \mathrm{C}$ a $850^{\circ} \mathrm{C}$ : perda da água unida quimicamente;

- $150^{\circ} \mathrm{C}$ : pico do primeiro estágio de decomposição dos hidratos de silicato de cálcio $(\mathrm{CSH})$;

- $300^{\circ} \mathrm{C}$ e acima: aumento significativo da porosidade e microfissuração;

- $350^{\circ} \mathrm{C}$ : ruptura de alguns agregados do tipo seixos de rio;

- $374^{\circ} \mathrm{C}$ : temperatura crítica para a qual não é possível haver água livre;

- $400^{\circ} \mathrm{C}$ a $600^{\circ} \mathrm{C}$ : dissociação do $\mathrm{Ca}(\mathrm{OH})_{2}$ em $\mathrm{CaO}$ e água;

- $573^{\circ} \mathrm{C}$ : os agregados silicosos (à base de quartzo) expandem;

- $700^{\circ} \mathrm{C}$ e acima: dissociação do $\mathrm{CaCO}_{3}$ em $\mathrm{CaO}$ e $\mathrm{CO}_{2}$;

- $720^{\circ} \mathrm{C}$ : segundo pico da decomposição do CSH;

- $800^{\circ} \mathrm{C}$ : os agregados calcários se decompõem;

- $1060^{\circ} \mathrm{C}$ : início da fusão de alguns constituintes do concreto.

As alterações físico-químicas que ocorrem para cada faixa de temperaturas são apresentadas esquematicamente pela Figura 11.

${ }^{6}$ KHOURY, G. A. Compressive strength of concrete at high temperatures: a reassessment. Magazine of Concrete Research, 44, No. 161, pp. 291-309, Dez. 1992. 


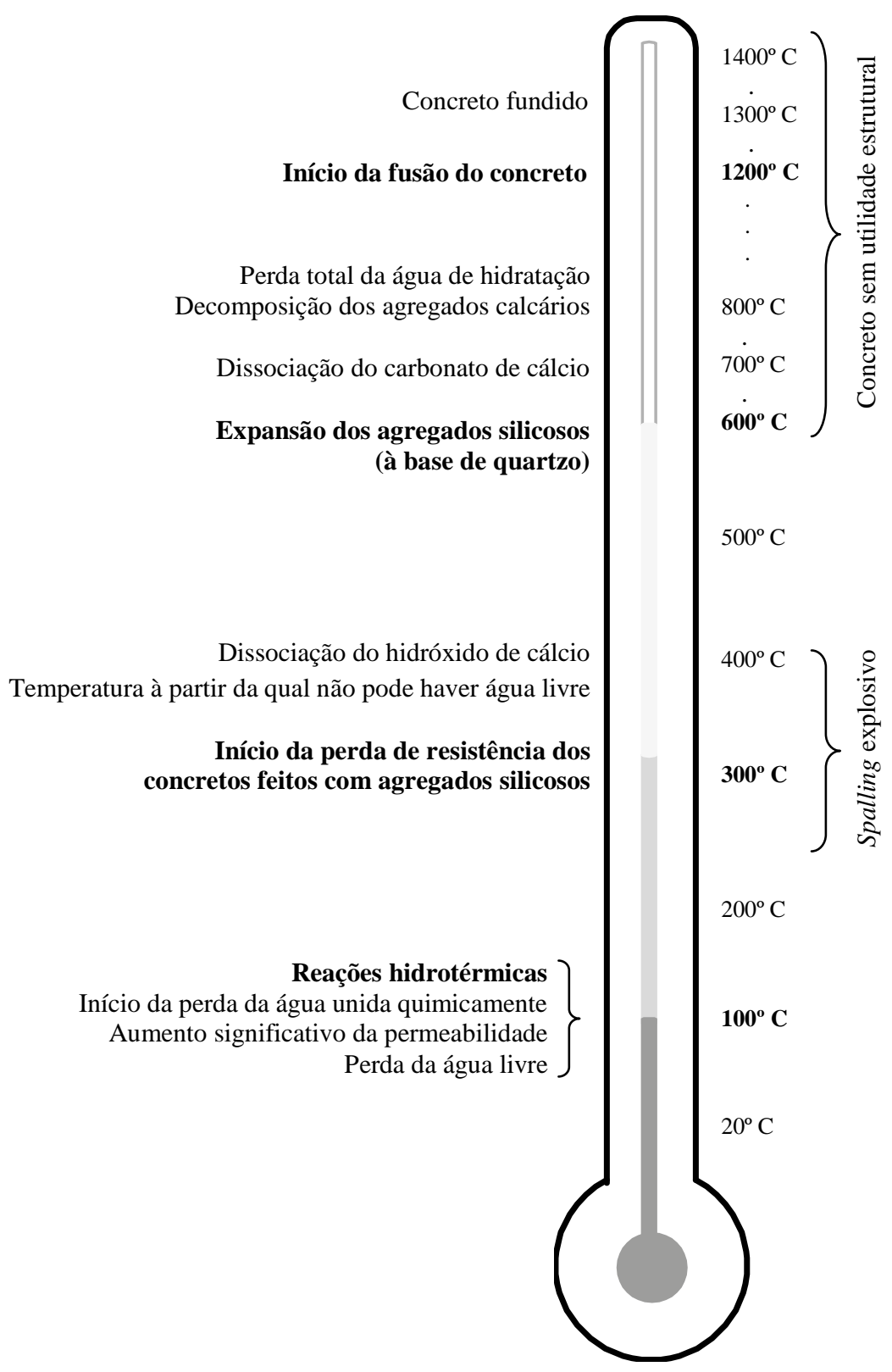

Figura 11 - Representação simplificada das reações físico-químicas em concretos feitos com cimento Portland, durante a fase de aquecimento (reproduzido de KHOURY, 2000b)

A combinação das alterações físicas e químicas do concreto resulta na diminuição da resistência do concreto. A temperatura crítica a partir da qual o concreto perde resistência mais significativamente varia conforme o agregado: $650^{\circ} \mathrm{C}$ para concreto com agregados leves, $660^{\circ} \mathrm{C}$ para concreto com agregados calcários e $430^{\circ}$ para concreto com agregados silicosos (FLETCHER et al., 2007). É importante ressaltar que as temperaturas mencionadas servem apenas de indicativos indiretos do desempenho da estrutura em situação de incêndio, principalmente devido aos significativos gradientes térmicos presentes na seção transversal dos elementos estruturais. 
Embora diversos estudos tenham sido realizados com o objetivo de compreender em detalhes as transformações físico-químicas do concreto sob temperaturas elevadas, muitos desses estudos foram baseados em cenários de incêndios predeterminados, que podem não representar com precisão os incêndios reais. Por exemplo: (a) uso de curvas de incêndiopadrão, (b) resfriamento lento, que resultam em gradientes térmicos mais brandos na seção transversal e (c) uso de outras curvas de incêndio adequadas somente para aplicações específicas. Como consequência, pouco se estudou a respeito do comportamento do concreto em cenários de incêndios reais. Fletcher et al. (2007) sugerem que um campo de pesquisas a ser explorado é a avaliação dos gradientes térmicos para vários tempos de exposição ao fogo segundo curvas de incêndio natural para, por exemplo, determinar os piores cenários de incêndio reais aos quais uma estrutura pode estar sujeita.

Todas as características apresentadas a seguir dependem naturalmente dos resultados de pesquisas e que podem variar significativamente, mesmo quando se analisa uma única propriedade do concreto. Isso se deve a alguns fatores, tais como considerar diversos tipos de concreto como um único material "concreto", diferentes condições de ensaios (tipo de cura, modo de aplicação do carregamento, modo de aquecimento, vinculações, etc.), características dos equipamentos de ensaios, uso de métodos de ensaio inadequados, entre outros. Esses fatores se devem, em parte, à falta de compreensão sobre o comportamento do concreto em situação de incêndio e suas diversas particularidades. Assim, os resultados de ensaios atualmente disponíveis apresentam muita variabilidade, podendo ser até mesmo conflitantes (FIB, 2007).

\subsubsection{Calor específico}

A variação do calor específico do concreto em função da temperatura é dada pelo item 3.3.2 do Eurocode 2 (EN 1992-1-2:2004), sendo as relações válidas para concretos feitos com agregados silicosos ou calcários. Para concretos secos $(u=0 \%)$, o calor específico em função da temperatura é dado pela eq. (14).

$$
\begin{array}{ll}
c_{p}(\theta)=900 & 20^{\circ} \mathrm{C} \leq \theta \leq 100^{\circ} \mathrm{C} \\
c_{p}(\theta)=900+(\theta-100) & 100^{\circ} \mathrm{C}<\theta \leq 200^{\circ} \mathrm{C} \\
c_{p}(\theta)=1000+(\theta-200) / 2 & 200^{\circ} \mathrm{C}<\theta \leq 400^{\circ} \mathrm{C} \\
c_{p}(\theta)=1100 & 400^{\circ} \mathrm{C}<\theta \leq 1200^{\circ} \mathrm{C}
\end{array}
$$


Onde:

$\mathrm{c}_{\mathrm{p}}$ : calor específico do concreto $[\mathrm{J} /(\mathrm{kg} . \mathrm{K})]$;

$\theta$ : temperatura do concreto $\left[{ }^{\circ} \mathrm{C}\right]$.

Quando a umidade não for considerada explicitamente no modelo de cálculo, a função do calor específico pode ser modificada acrescentando um valor constante de pico ( $\mathrm{c}_{\mathrm{p}, \text { pico }}$ ), situado entre $100^{\circ} \mathrm{C}$ e $115^{\circ} \mathrm{C}$ com decaimento linear entre $115^{\circ} \mathrm{C}$ e $200^{\circ} \mathrm{C}$ (EN 1992-12:2004). Esse pico ocorre devido à evaporação da água livre no concreto. Os valores de $\mathrm{c}_{\mathrm{p} \text {,pico }}$ são:

- $\mathrm{c}_{\mathrm{p}, \text { pico }}=900 \mathrm{~J} /(\mathrm{kg} \cdot \mathrm{K})$ para teor de umidade $\mathrm{u}=0,0 \%$ da massa do concreto

- $\mathrm{c}_{\mathrm{p} \text {,pico }}=1470 \mathrm{~J} /(\mathrm{kg} . \mathrm{K})$ para teor de umidade $\mathrm{u}=1,5 \%$ da massa do concreto

- $\mathrm{c}_{\mathrm{p} \text {,pico }}=2020 \mathrm{~J} /(\mathrm{kg} . \mathrm{K})$ para teor de umidade $\mathrm{u}=3,0 \%$ da massa do concreto

Para outros teores de umidade é permita interpolação linear entre os valores acima.

A Figura 12 apresenta o gráfico da variação do calor específico do concreto com a temperatura, para três teores de umidade $(0 \%, 1,5 \%$ e $3,0 \%)$.

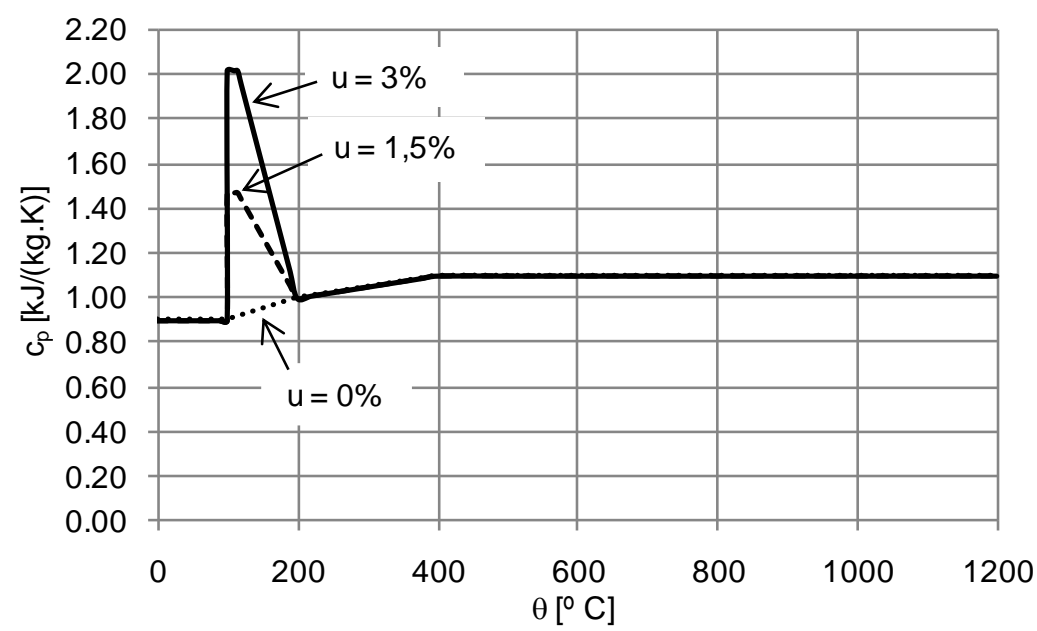

Figura 12 - Calor específico do concreto $c_{p}$ em função da temperatura, considerando três valores para o teor de umidade no concreto (EN 1992-1-2:2004)

Normalmente, os elementos de concreto dentro de ambientes secos internos às edificações possuem teor de umidade $\mathrm{U} \leq 1,5 \%$ (em peso), enquanto que os elementos externos possuem, normalmente, teor de umidade $U \leq 3,0 \%$. Não se recomenda que os concretos possuam teor de umidades superior a 3\%, pois a durabilidade pode ser comprometida (COSTA, 2008). 


\subsubsection{Massa específica}

A variação da massa específica do concreto em função da temperatura é dada pelo item 3.3.2 do Eurocode 2 (EN 1992-1-2:2004), sendo as relações válidas para concretos feitos com agregados silicosos ou calcários, conforme mostra a eq. (15).

$$
\begin{aligned}
& \rho(\theta)=\rho\left(20^{\circ} \mathrm{C}\right) \quad 20^{\circ} \mathrm{C} \leq \theta \leq 115^{\circ} \mathrm{C} \\
& \rho(\theta)=\rho\left(20^{\circ} \mathrm{C}\right) \cdot[1-0,02 .(\theta-115) / 85] \quad 115^{\circ} \mathrm{C}<\theta \leq 200^{\circ} \mathrm{C} \\
& \rho(\theta)=\rho\left(20^{\circ} \mathrm{C}\right)[0,98-0,03 \cdot(\theta-200) / 200] \quad 200^{\circ} \mathrm{C}<\theta \leq 400^{\circ} \mathrm{C} \\
& \rho(\theta)=\rho\left(20^{\circ} \mathrm{C}\right) .[0,95-0,07 .(\theta-400) / 800] \quad 400^{\circ} \mathrm{C}<\theta \leq 1200^{\circ} \mathrm{C}
\end{aligned}
$$

Onde:

$\rho:$ massa específica do concreto $\left[\mathrm{kg} / \mathrm{m}^{3}\right]$;

$\theta$ : temperatura do concreto $\left[{ }^{\circ} \mathrm{C}\right]$.

As relações da eq. (15) são apresentadas graficamente na Figura 13.

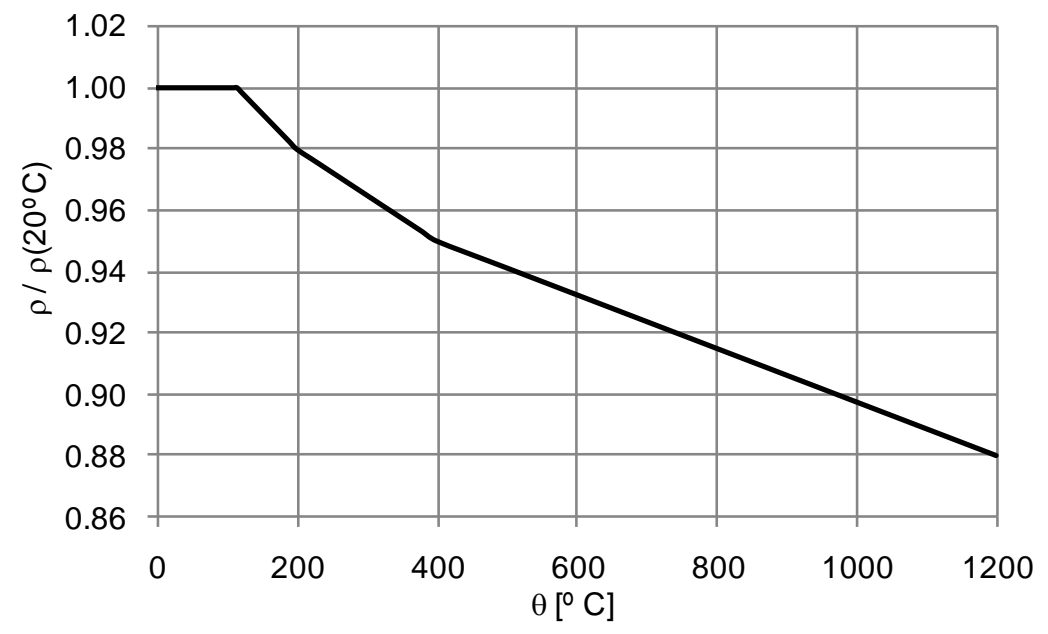

Figura 13 - Massa específica do concreto $\rho$ em função da temperatura (EN 1992-1-2:2004)

\subsubsection{Condutividade térmica}

A variação da condutividade térmica do concreto em função da temperatura é apresentada por meio de duas curvas (limite superior e limite inferior) no item 3.3.3 do 
Eurocode 2 (EN 1992-1-2:2004). A curva do limite superior da condutividade térmica do concreto em função da temperatura é dada pela eq. (16).

$$
\lambda_{c}=2-0,2451 .(\theta / 100)+0,0107 .(\theta / 100)^{2}
$$

Onde:

$\lambda_{\mathrm{c}}$ : condutividade térmica do concreto $[\mathrm{W} /(\mathrm{m} \mathrm{K})]$;

$\theta$ : temperatura do concreto $\left[{ }^{\circ} \mathrm{C}\right]$.

A curva do limite inferior da condutividade térmica do concreto em função da temperatura é dada pela eq. (17).

$$
\lambda_{c}=1,36-0,136 \cdot(\theta / 100)+0,0057 \cdot(\theta / 100)^{2}
$$

Ambas as relações anteriores são válidas para $20^{\circ} \mathrm{C} \leq \theta \leq 1200^{\circ} \mathrm{C}$.

As relações das eqs. (16) e (17) são apresentadas graficamente na Figura 14.

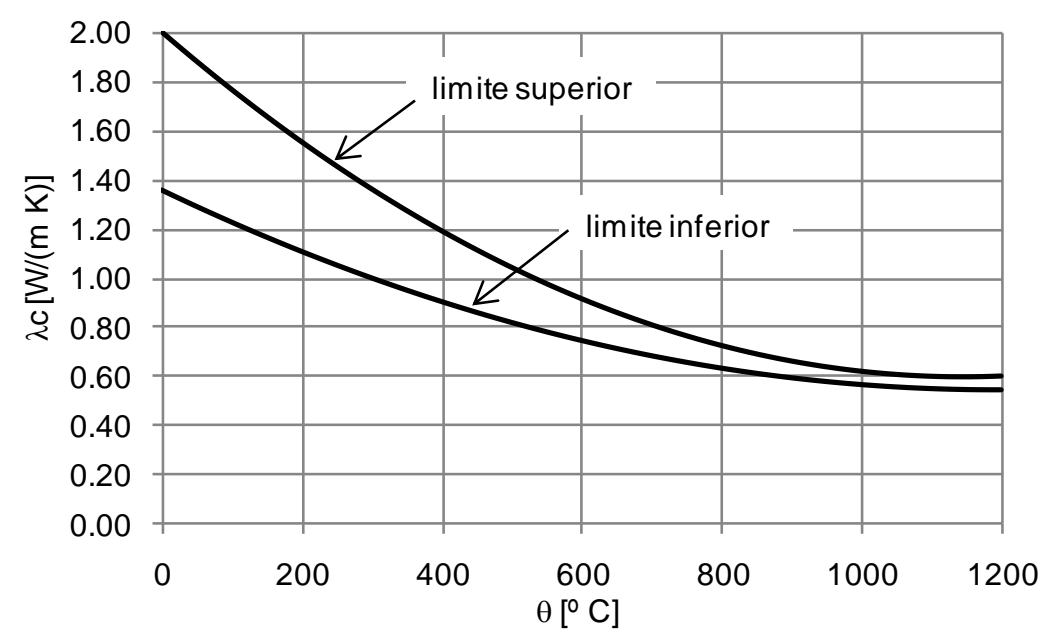

Figura 14 - Condutividade térmica do concreto $\lambda_{\mathrm{c}}$ em função da temperatura (EN 1992-1-2:2004)

Segundo o Anexo A do Eurocode 2 (EN 1992-1-2:2004), a curva do limite superior foi deduzida a partir de ensaios com estruturas mistas, enquanto a curva do limite inferior foi definida com base em ensaios de diferentes tipos de estruturas de concreto em situação de incêndio. A mesma norma afirma ainda que a utilização da curva do limite inferior em análises térmicas de estruturas de concreto resulta em temperaturas mais confiáveis do que 
utilizando o limite superior. O projeto de revisão da norma ABNT NBR 15200:2004 apresenta apenas a expressão da curva do limite inferior, sem citar a existência do limite superior, permitindo adotar, de forma simplificada, o valor constante de $\lambda_{\mathrm{c}}=1,3 \mathrm{~W} /\left(\mathrm{m}{ }^{\circ} \mathrm{C}\right)$ para a condutividade térmica do concreto em situação de incêndio.

Nota-se que o Eurocode 2 (EN 1992-1-2:2004) apresenta a unidade [W/(m K)] para a condutividade térmica do concreto, enquanto que o projeto de revisão da norma ABNT NBR 15200:2004 utiliza a unidade $\left[\mathrm{W} /\left(\mathrm{m}^{\circ} \mathrm{C}\right)\right]$. Como ambos os sistemas de medida da temperatura são centígrados, os valores de $\lambda_{c}$ são os mesmos para os dois sistemas.

O Boletim 38 do fib (FIB, 2007) explica que, embora a condutividade térmica do concreto dependa de todos os seus constituintes, ela é determinada principalmente pelo tipo de agregado utilizado, uma vez que os agregados constituem de $60 \%$ a $80 \%$ do volume do concreto. Outro fator importante é o teor de umidade do concreto, devido à condutividade térmica da água ser muito maior que a do ar (Tabela 3).

Tabela 3 - Condutividade térmica dos materiais à temperatura ambiente (KHOURY ${ }^{7}, 1983$ apud EN 1992-1-2:2004)

\begin{tabular}{lc}
\hline \multicolumn{1}{c}{ Material } & $\begin{array}{c}\text { Condutividade } \\
\text { térmica }\left[\mathbf{W} /\left(\mathbf{m}^{\mathbf{}}{ }^{\mathbf{C}} \mathbf{C}\right)\right]\end{array}$ \\
\hline Agregados & $0,7-4,2$ \\
\hline Concretos saturados & $1,0-3,6$ \\
\hline Pasta de cimento endurecida saturada & $1,1-1,6$ \\
\hline Água & 0,515 \\
\hline Ar & 0,0034 \\
\hline
\end{tabular}

Analisando os valores da Tabela 3, pode-se concluir que as proporções da mistura do concreto e a quantidade de cimento influenciam a condutividade térmica do concreto por causa da diferença entre os valores da condutividade térmica da pasta de cimento e dos agregados. Uma mistura mais rica em cimento, para concretos de peso normal, apresenta condutividade térmica mais baixa que uma mistura mais pobre. Aumentando a relação água/cimento, aumenta a porosidade do concreto e consequentemente reduz sua condutividade térmica, especialmente para baixos teores de umidade (FIB, 2007). Apesar de todos os fatores que influenciam os valores da condutividade térmica do concreto, o Eurocode 2 (EN 1992-1-2:2004) não faz nenhuma menção aos mesmos.

Costa (2008) explica as dúvidas envolvendo a determinação das curvas do limite superior e inferior da condutividade térmica do concreto propostas pelo Eurocode 2 (EN

${ }^{7}$ KHOURY, G. A. Transient thermal creep of nuclear reactor concrete pressure vessel type concretes. PhD Thesis, University of London, 1983. 
1992-1-2:2004). Como esse é um parâmetro importante em análises térmicas, seria prudente que as curvas fossem reavaliadas, com base em novos ensaios aferidos com maior precisão.

Para análises térmicas destinadas a modelos simples de cálculo, pode-se utilizar um valor constante para a condutividade térmica do concreto de $\lambda_{\mathrm{c}}=1,30 \mathrm{~W} /(\mathrm{m} . \mathrm{K}$ ) (SCHLEICH, 2005). Essa recomendação consta também no projeto de revisão da norma ABNT NBR 15200:2004.

\subsubsection{Curva tensão-deformação para concreto sob compressão}

O modelo constitutivo do concreto sob compressão uniaxial em situação de incêndio disponível no Eurocode 2 (EN 1992-1-2:2004) foi baseado numa expressão genérica proposta por Popovics $^{8}$ (1973 apud PURKISS, 2007), conforme mostra a eq. (18).

$$
\frac{\sigma_{c}}{\sigma_{0, c}}=\frac{\varepsilon_{c}}{\varepsilon_{0, c}} \cdot \frac{n}{n-1+\left(\frac{\varepsilon_{c}}{\varepsilon_{0, c}}\right)^{n}}
$$

Onde:

$\sigma_{\mathrm{c}}:$ tensão no concreto;

$\sigma_{0, c}:$ tensão no concreto correspondente à deformação $\varepsilon_{0, c}$;

$\varepsilon_{\mathrm{c}}$ : deformação no concreto;

$\varepsilon_{0, \mathrm{c}}:$ deformação no concreto correspondente à tensão $\sigma_{0, c}$;

n: parâmetro que mede o grau de não linearidade da curva tensão-deformação.

Para ajustar a eq. (18) a quaisquer resultados de ensaios, é necessário determinar apenas o parâmetro $n$, conforme a eq. (19).

$$
\frac{1}{n}=1-\frac{\sigma_{0, c}}{\varepsilon_{0, c} E_{c}}
$$

Onde:

$\mathrm{E}_{\mathrm{c}}$ : módulo de elasticidade do concreto;

${ }^{8}$ POPOVICS, S. A numerical approach to the complete stress-strain curve of concrete. Cement and Concrete Research, 3, pp. 583-599, 1973. 
Purkiss (2007) verificou, com base em curvas tensão-deformação obtidas por meio de ensaios de elementos de concreto sob temperaturas elevadas, que o parâmetro $n$ depende da resistência do concreto, do tamanho dos agregados e da relação agregados-cimento.

A curva tensão-deformação (uniaxial) do concreto comprimido em situação de incêndio apresentada pelo Eurocode 2 (EN 1992-1-2:2004) segue o modelo da eq. (18), com parâmetro $n=3$, conforme mostra a eq. (20).

$$
\sigma_{c, \theta}=\frac{3 \cdot \varepsilon \cdot f_{c, \theta}}{\varepsilon_{c 1, \theta} \cdot\left[2+\left(\frac{\varepsilon}{\varepsilon_{c 1, \theta}}\right)^{3}\right]}
$$

Onde:

$\sigma_{\mathrm{c}, \theta}:$ tensão no concreto;

$\varepsilon$ : deformação no concreto;

$\varepsilon_{\mathrm{c} 1, \theta}$ : deformação no concreto correspondente à tensão $\mathrm{f}_{\mathrm{c}, \theta}$;

$\mathrm{f}_{\mathrm{c}, \theta}:$ tensão no concreto correspondente à deformação $\varepsilon_{\mathrm{c} 1, \theta}$;

A eq. (20) é válida para $\varepsilon \leq \varepsilon_{\mathrm{c} 1, \theta}$. Para $\varepsilon_{\mathrm{c} 1, \theta}<\varepsilon \leq \varepsilon_{\mathrm{cu}, \theta}$, deve-se adotar um ramo descendente na curva tensão-deformação por questões numéricas da análise não linear. Podese considerar um modelo linear ou não linear (seguindo a mesma eq. (20)) (EN 1992-12:2004), mas deve-se tem em mente a falta de precisão dessa parte do diagrama (FIB, 2008). A curva tensão-deformação apresentada é válida somente para análises segundo a curva de incêndio-padrão ISO 834 (1975) e possíveis ganhos de resistência do concreto durante a fase de resfriamento devem ser desconsiderados. Os efeitos da fluência transiente foram incorporados implicitamente à curva tensão-deformação, sendo discutidos em detalhes no item 0 deste trabalho.

Os parâmetros $\mathrm{f}_{\mathrm{c}, \theta} / \mathrm{f}_{\mathrm{ck}}, \varepsilon_{\mathrm{c} 1, \theta}$ e $\varepsilon_{\mathrm{cu}, \theta}$ são dados pela tabela 3.1 do Eurocode 2 (EN 19921-2:2004). A Figura 15 mostra a variação dos parâmetros $\varepsilon_{\mathrm{c} 1, \theta}$ e $\varepsilon_{\mathrm{cu}, \theta}$ em função da temperatura. 


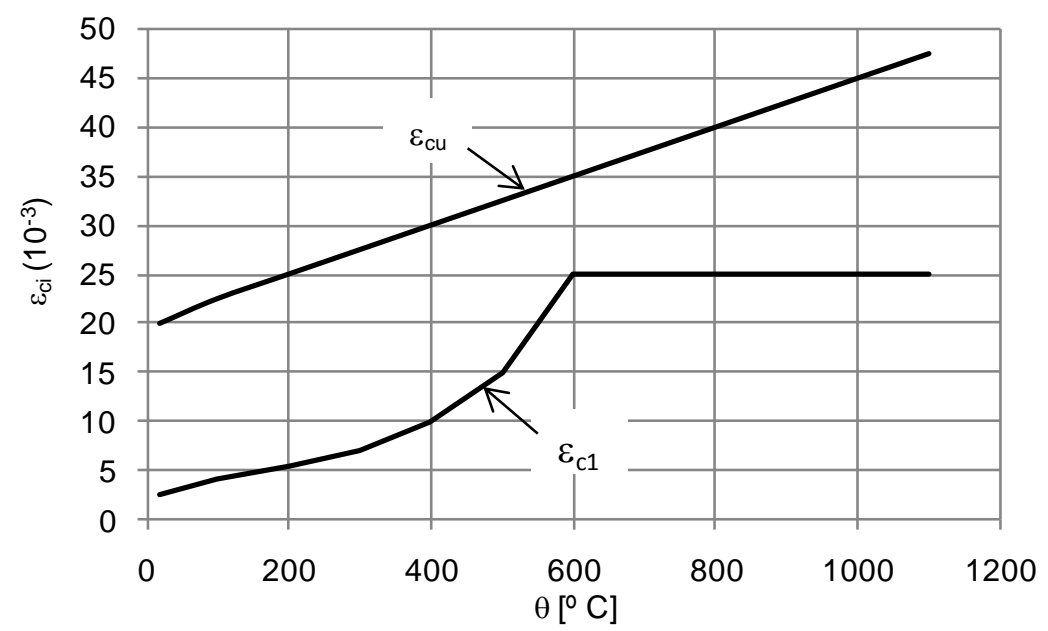

Figura 15 - Parâmetros $\varepsilon_{\mathrm{c} 1, \theta}$ e $\varepsilon_{\mathrm{cu}, \theta}$ para concretos com agregados silicosos e calcários (EN 1992-1-2:2004)

Percebe-se na Figura 15 o aumento da deformação última $\varepsilon_{\mathrm{cu}, \theta}$ com o aumento da temperatura, evidenciando que o concreto torna-se mais tolerante a maiores deformações sob temperaturas elevadas e também após o resfriamento (FIB, 2008).

A Figura 16 mostra a redução da resistência do concreto $\left(f_{c, \theta} / f_{c k}\right)$ em função da temperatura.

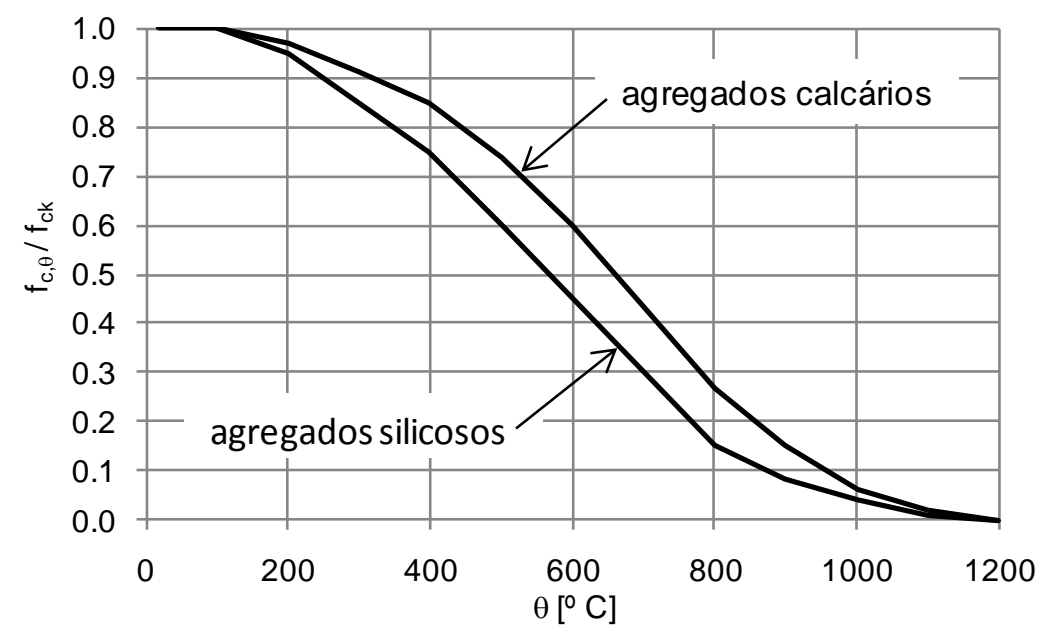

Figura 16 - Parâmetros de redução da resistência do concreto sob compressão $\left(f_{c, \theta} / f_{c k}\right)$ em função da temperatura (EN 1992-1-2:2004)

Utilizando a eq. (20) e os parâmetros da Figura 15 e Figura 16, foram traçadas as curvas tensão-deformação para concretos com agregados silicosos (Figura 17) e calcários (Figura 18). 


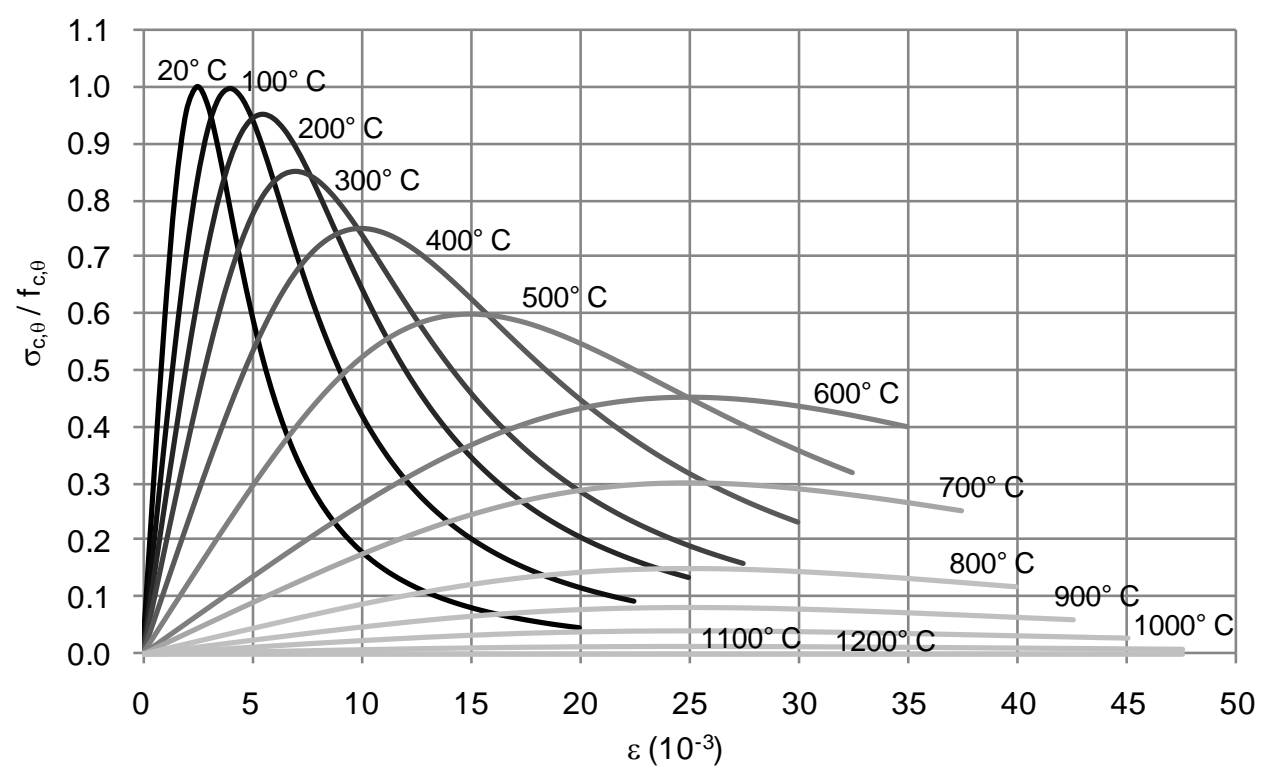

Figura 17 - Curvas tensão-deformação do concreto sob compressão, para diversas temperaturas e concreto com agregados silicosos (EN 1992-1-2:2004)

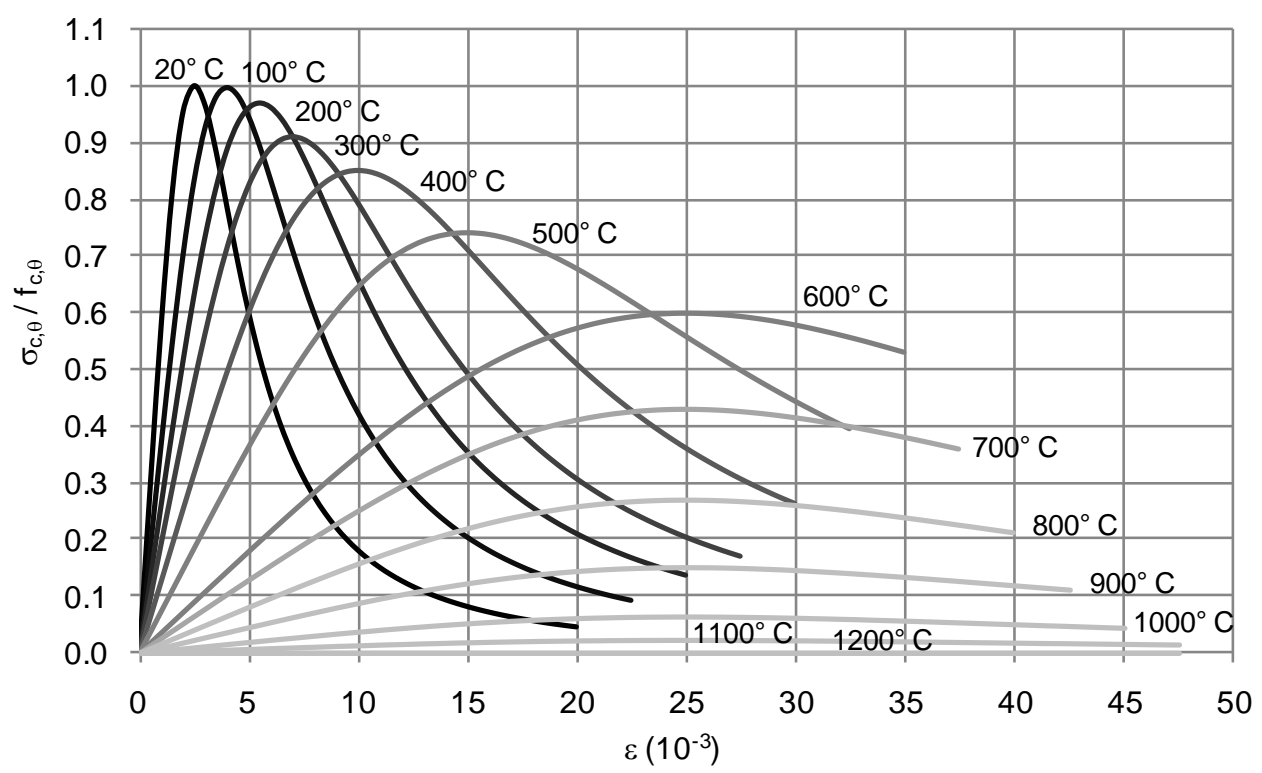

Figura 18 - Curvas tensão-deformação do concreto sob compressão, para diversas temperaturas e concreto com agregados calcários (EN 1992-1-2:2004)

Comparando-se a Figura 17 com a Figura 18, percebe-se que o concreto com agregados calcários apresenta resistências maiores, se comparado ao concreto com agregados silicosos, para uma mesma temperatura. Essa conclusão está diretamente ligada ao parâmetro de resistência do concreto $\left(f_{c, \theta} / f_{c k}\right)$, apresentado graficamente na Figura 16. 


\subsubsection{Resistência à tração}

O comportamento do concreto à tração sob temperaturas elevadas é um assunto em aberto. Os resultados de ensaios disponíveis na literatura são escassos. Resultados mais detalhados são necessários para a correta avaliação de fenômenos relacionados à fratura, como energia específica, resistência e comprimento característico, bem como a curva tensãoabertura de fissura. Esses parâmetros foram exaustivamente investigados após o resfriamento, com relação à máxima temperatura alcançada no material, mas há evidências não totalmente esclarecidas em termos de perda da capacidade resistente. Sabe-se com certeza que os materiais admitem grandes deformações sob temperaturas elevadas (FIB, 2008).

Como hipótese conservadora, recomenda-se ignorar a resistência à tração do concreto em situação de incêndio, em fase de projeto. Caso seja necessário levar em conta a resistência à tração do concreto, podem-se adotar os valores do coeficiente redutor da resistência à tração do concreto em situação de incêndio, conforme a eq. (21) (EN 1992-1-2:2004).

$$
\begin{array}{ll}
k_{c, t}(\theta)=1,0 & 20^{\circ} \mathrm{C} \leq \theta \leq 100^{\circ} \mathrm{C} \\
k_{c, t}(\theta)=1,0-1,0 .(\theta-100) / 500 & 100^{\circ} \mathrm{C}<\theta \leq 600^{\circ} \mathrm{C}
\end{array}
$$

O coeficiente redutor da eq. (21) é utilizado para multiplicar a resistência característica do concreto sob tração, conforme mostra a eq. (22).

$$
f_{c, t}(\theta)=k_{c, t}(\theta) \cdot f_{c k, t}
$$

A Figura 19 mostra a variação do redutor da resistência do concreto à tração $\mathrm{k}_{\mathrm{c}, \mathrm{t}} \mathrm{em}$ função da temperatura. 


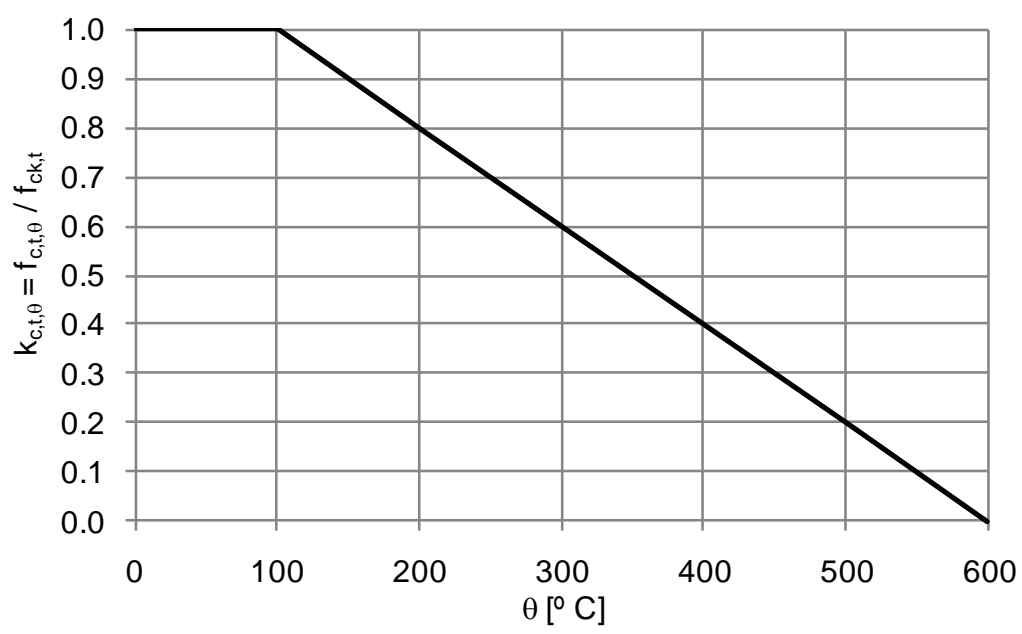

Figura 19 - Parâmetros de redução da resistência à tração do concreto $\mathbf{k}_{\mathrm{c}, \mathrm{t}}$ em função da temperatura (EN 1992-1-2:2004)

A resistência do concreto à tração decresce mais rapidamente com a elevação da temperatura do que a resistência à compressão, como mostra a Figura 20. Segundo o Boletim 46 do fib (FIB, 2008), alguns estudos indicam que a energia de fratura do concreto não é reduzida sob temperaturas elevadas, podendo inclusive ser ligeiramente maior que à temperatura ambiente.

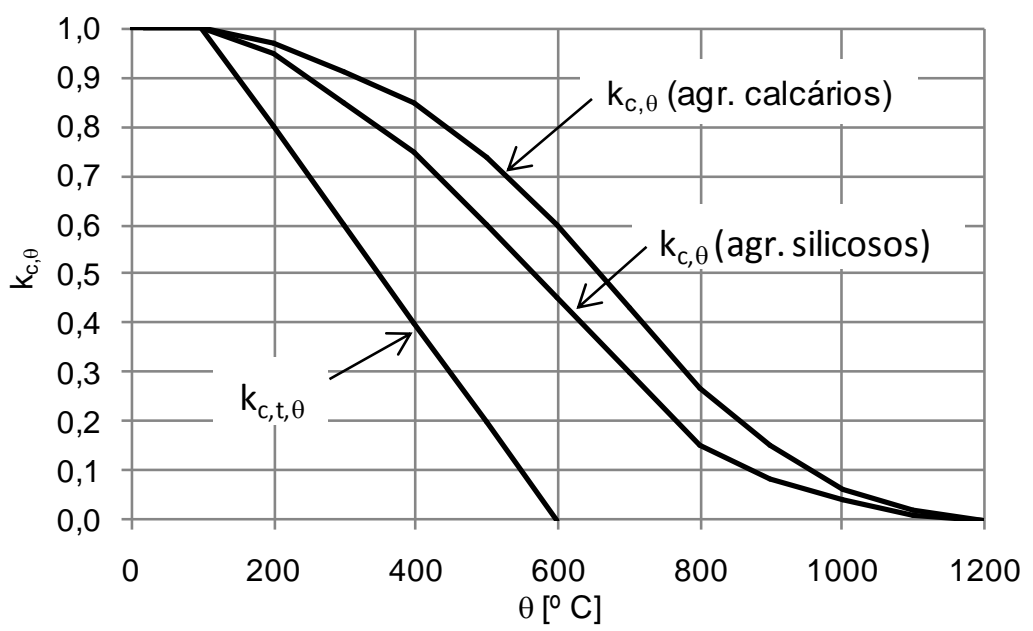

Figura 20 - Comparação entre os parâmetros de redução da resistência à compressão e à tração do concreto em função da temperatura (EN 1992-1-2:2004) 


\subsubsection{Deformação linear específica do concreto sob temperaturas elevadas}

A deformação linear específica total do concreto sob temperaturas elevadas pode ser decomposta nas seguintes componentes, conforme mostra a eq. (23) (KHOURY, 2006c).

$$
\varepsilon_{t o t}=\varepsilon_{e}+\varepsilon_{p}+\varepsilon_{t h}+\varepsilon_{s h}+\varepsilon_{c r a c k}+\varepsilon_{t t c}+\varepsilon_{c r-d}+\varepsilon_{c r-t-d e p}+\varepsilon_{\Delta e l}
$$

Onde:

$\varepsilon_{\text {tot }}:$ deformação total;

$\varepsilon_{\mathrm{e}}$ : deformação elástica inicial;

$\varepsilon_{\mathrm{p}}$ : deformação plástica inicial;

$\varepsilon_{\text {th }}:$ deformação térmica (thermal);

$\varepsilon_{\mathrm{sh}}$ : deformação devido à retração (shrinkage);

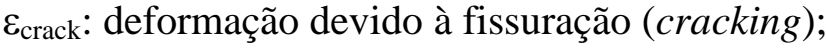

$\varepsilon_{\mathrm{ttc}}$ : deformação térmica transicional (transitional thermal creep);

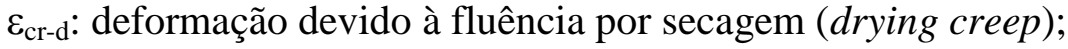

$\varepsilon_{\text {cr-t-dep }}$ : deformação devido à fluência dependente do tempo (time-dependent creep);

$\varepsilon_{\Delta \mathrm{el}}$ : deformação devido a alterações na deformação elástica que se manifestam durante o aquecimento com atuação do carregamento.

Das parcelas de deformação da eq. (23), apenas a deformação térmica $\left(\varepsilon_{\text {th }}\right)$ e a deformação devido à retração $\left(\varepsilon_{\mathrm{sh}}\right)$ são independentes do carregamento aplicado (load-free), sendo todas as demais parcelas dependentes do carregamento aplicado (load-induced).

As parcelas de deformação elástica $\left(\varepsilon_{\mathrm{e}}\right)$ e plástica $\left(\varepsilon_{\mathrm{p}}\right)$ iniciais são normalmente determinadas juntas, de forma experimental, durante aplicação de carregamento sob temperatura constante. Agrupadas, as duas parcelas são chamadas de deformação elastoplástica, conforme mostra a eq. (24). A deformação elasto-plástica não se manifesta quando o concreto é aquecido sem carregamento aplicado (KHOURY, 2006c).

$$
\varepsilon_{e l-p l}=\varepsilon_{e}+\varepsilon_{p}
$$

De forma análoga, as parcelas de deformação térmica $\left(\varepsilon_{\mathrm{th}}\right)$ e devido à retração $\left(\varepsilon_{\mathrm{sh}}\right)$ são medidas juntas, de forma experimental, sendo consideradas inseparáveis. Por esse motivo, as 
duas deformações, juntas, são chamadas na literatura simplesmente de "deformação térmica", conforme mostra a eq. (25).

$$
\varepsilon_{t h-s h}=\varepsilon_{t h}+\varepsilon_{s h}
$$

A deformação devido à retração, durante o aquecimento inicial, deve-se principalmente à perda de umidade. Sob temperaturas elevadas, a retração também é causada por dissociações químicas (por exemplo, C-S-H, $\mathrm{CH}, \mathrm{CaCO}_{3}$ ). Um método para isolar a componente da deformação devido à retração foi apresentado por Khoury (2006c).

A parcela de deformação devido à fissuração $\left(\varepsilon_{\text {crack }}\right)$ é geralmente ignorada na literatura, sendo considerada como parte da deformação térmica (eq. (25)). Khoury (2006c) apresenta com maiores detalhes essa parcela de deformação.

Finalmente, as quatro últimas parcelas de deformação, agrupadas, compõem a chamada LITS (Load Induced Thermal Strain, ou deformação térmica induzida pelo carregamento). A compreensão sobre a existência da LITS remonta a década de 1970. Até então, não se compreendia como o concreto suportava temperaturas acima de $100^{\circ} \mathrm{C}$ sem se romper, considerando as deformações diferenciais entre a expansão dos agregados e a retração da pasta de cimento (Figura 21). A LITS é muito maior que as deformações elásticas, contribuindo para significativa relaxação e redistribuição das tensões térmicas no concreto aquecido. A LITS se manifesta apenas no concreto submetido à compressão (FIB, 2007).

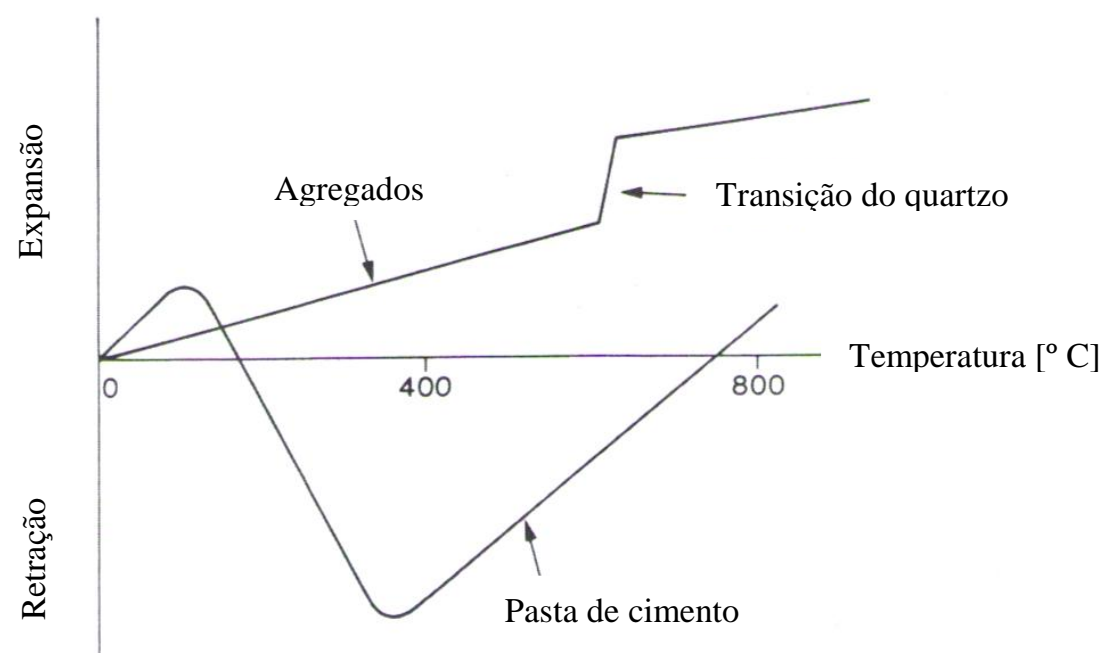

Figura 21 - Incompatibilidade térmica entre os agregados e a pasta de cimento sob temperaturas elevadas (reproduzido de FIB, 2007)

Com base na eq. (23), a LITS é definida conforme mostra a eq. (26). 


$$
\varepsilon_{l i t s}=\varepsilon_{t t c}+\varepsilon_{c r-d}+\varepsilon_{c r-t-d e p}+\varepsilon_{\Delta e l}
$$

A LITS é obtida de forma indireta, calculando-se a diferença entre a deformação térmica de um corpo de prova aquecido sem carregamento e a deformação medida em outro corpo de prova (idêntico ao primeiro) sob carregamento constante antes do aquecimento e mantido constante durante o aquecimento, descontando a deformação elasto-plástica inicial. A Figura 22 ilustra a definição da LITS apresentada acima.

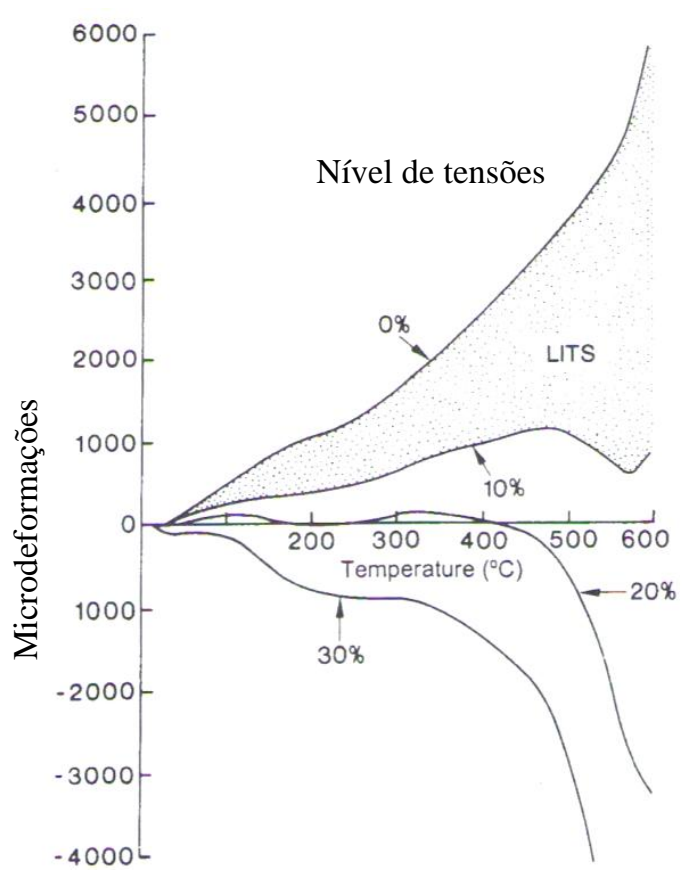

Figura 22 - Exemplo de LITS de um concreto com agregados de basalto, determinado como a diferença entre as deformações térmicas entre concreto com $0 \%$ e $10 \%$ de sua tensão resistente aplicada (reproduzido de KHOURY, 2006a)

A eq. (27) apresenta o cálculo da LITS segundo a definição apresentada anteriormente.

$$
\varepsilon_{l i t s}=\varepsilon_{t o t}^{\sigma \neq 0}-\varepsilon_{\text {tot }}^{\sigma=0}+\varepsilon_{e l-p l}^{\sigma \neq 0}
$$

A LITS varia razoavelmente pouco em função do agregado utilizado, mas por outro lado é fortemente influenciada pela quantidade (em volume) dos agregados no concreto. Fatores que pouco ou nada influenciam na LITS são: idade do concreto, teor de umidade inicial e tipo de concreto (relacionado ao tipo de agregado). Esses fatores, associados à quase linearidade da LITS conforme a tensão aplicada e à pequena influência da taxa de 
aquecimento, permitem considerável simplificação na análise de estruturas de concreto sob temperaturas elevadas (FIB, 2007).

Como a LITS varia pouco para diferentes tipos de concreto, verificou-se a existência de uma curva mestra (master curve) para a LITS, para temperaturas até $450^{\circ} \mathrm{C}$ aproximadamente (FIB, 2007).

Considerando a definição da LITS dada pela eq. (26), descreve-se a seguir as suas parcelas componentes.

A deformação térmica transicional $\left(\varepsilon_{\mathrm{ttc}}\right)$ consiste estritamente na deformação que ocorre em concretos não drenados, induzida pelo primeiro aquecimento sofrido pelo concreto sob atuação do carregamento. A deformação transiente, definida pela eq. (28), ocorre em concretos drenados e inclui a deformação térmica transicional $\left(\varepsilon_{\mathrm{ttc}}\right)$ e a deformação devido à fluência por secagem $\left(\varepsilon_{\mathrm{cr-d}}\right)$. Ambas as parcelas da deformação transiente são irreversíveis após o descarregamento.

$$
\varepsilon_{t r}=\varepsilon_{t t c}+\varepsilon_{c r-d}
$$

A rigor, ambas as deformações transiente $\left(\varepsilon_{\mathrm{tr}}\right)$ e térmica transicional $\left(\varepsilon_{\mathrm{ttc}}\right)$ não contém nenhuma mudança nas deformações plásticas que ocorrem durante o aquecimento sob atuação do carregamento. Ambas também não devem conter a deformação por fluência que depende unicamente do tempo sob carregamento mantido $\left(\varepsilon_{\text {cr-t-dep }}\right)$. Na prática, essas componentes não são separadas, e a LITS de concretos não drenados é chamada simplesmente de "deformação térmica transicional ou TTC" e a LITS de concretos drenados é chamada de "deformação transiente" (FIB, 2007).

A deformação transiente (eq. (28)) é a maior componente da LITS, conforme pode ser visto na Figura 23. Essa deformação é irreversível com o resfriamento e/ou descarregamento e ocorre unicamente durante o aquecimento inicial sob atuação do carregamento. A deformação transiente ocorre de forma pronunciada acima de $100^{\circ} \mathrm{C}$ e é considerada, por pesquisadores, como sendo dependente unicamente da temperatura, e não do tempo. Tal consideração pode ser feita para situações envolvendo aquecimento que dure apenas algumas horas. (FIB, 2007). 


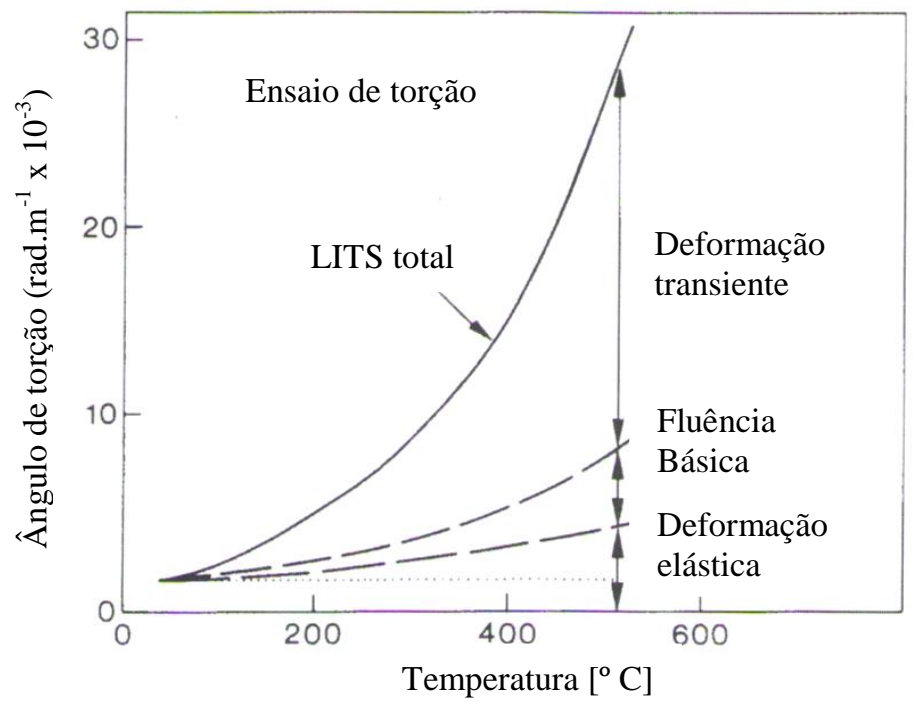

Figura 23 - Desenvolvimento da LITS em ensaio de torção com aquecimento (reproduzido de FIB, 2007)

Considerando ainda a Figura 23, verifica-se que a variação das deformações elásticas que se manifestam durante o aquecimento do concreto sob atuação do carregamento $\left(\varepsilon_{\Delta \mathrm{el}}\right)$ e a deformação devido à fluência dependente do tempo $\left(\varepsilon_{\text {cr-t-dep }}\right)$ são relativamente pequenas em relação ao valor total da LITS. Ambas as deformações são irreversíveis após o descarregamento (FIB, 2007).

Informações detalhadas sobre a LITS podem ser encontradas no Boletim 38 do fib (FIB, 2007) e na sequência de trabalhos publicados por Khoury (2006a, 2006b e 2006c).

Inserindo as eqs. (24), (25) e (26) na eq. (23), obtém-se a expressão dada pela eq. (29).

$$
\varepsilon_{t o t}=\varepsilon_{e l-p l}+\varepsilon_{t h-s h}+\varepsilon_{l i t s}
$$

A parcela de deformação elasto-plástica é também conhecida por deformação instantânea relacionada às tensões $\left(\varepsilon_{\sigma}\right)$, visto que essa deformação é a utilizada para se obter as tensões dos materiais segundo os seus diagramas tensão-deformação. Para uniformizar a notação, a deformação térmica será identificada simplesmente por $\varepsilon_{\text {th }}$, conforme a eq. (30).

$$
\varepsilon_{\text {tot }}=\varepsilon_{\sigma}+\varepsilon_{\text {th }}+\varepsilon_{\text {lits }}
$$

O diagrama tensão-deformação do concreto sob temperaturas elevadas dado pelo Eurocode 2 (EN 1992-1-2:2004) considerada a LITS de forma implícita (GERNAY e FRANSSEN, 2010). Portanto, as parcelas de deformação instantânea relacionada às tensões 
$\left(\varepsilon_{\sigma}\right)$ e LITS $\left(\varepsilon_{\text {lits }}\right)$ podem ser agrupadas numa parcela chamada deformação mecânica $\left(\varepsilon_{\mathrm{m}}\right)$, conforme mostra a eq. (31).

$$
\varepsilon_{\text {tot }}=\varepsilon_{m}+\varepsilon_{\text {th }}
$$

A eq. (31) deve ser adotada quanto se utiliza modelos nos quais a LITS é considerada de forma implícita, que é o caso deste trabalho. Para cálculos nos quais a LITS é considerada de forma explícita, deve-se utilizar a eq. (30).

\subsubsection{Deformação térmica linear específica}

A deformação térmica linear específica do concreto varia de forma não linear conforme a temperatura. Esse comportamento não linear deve-se em parte às transformações físico-químicas dos agregados e em parte à incompatibilidade térmica entre os agregados e a pasta de cimento. A presença de umidade também afeta a deformação térmica linear específica (ZHA, 2003).

A deformação térmica linear específica do concreto em função da temperatura $\varepsilon_{t h, c}$ é apresentada no item 3.3.1 do Eurocode 2 (EN 1992-1-2:2004). Para concretos com agregado silicoso, a deformação térmica é dada pela eq. (32).

$$
\begin{array}{ll}
\varepsilon_{t h, c}(\theta)=-1,8 \times 10^{-4}+9 \times 10^{-6} . \theta+2,3 \times 10^{-11} \cdot \theta^{3} & 20^{\circ} \mathrm{C} \leq \theta \leq 700^{\circ} \mathrm{C} \\
\varepsilon_{t h, c}(\theta)=14 \times 10^{-3} & 700^{\circ} \mathrm{C}<\theta \leq 1200^{\circ} \mathrm{C}
\end{array}
$$

Onde:

$\varepsilon_{\text {th,c }}:$ deformação térmica linear específica do concreto, em relação ao comprimento a $20^{\circ} \mathrm{C}$

$\theta$ : temperatura do concreto $\left[{ }^{\circ} \mathrm{C}\right]$.

Para concretos com agregado calcário, a deformação térmica é dada pela eq. (33).

$$
\begin{array}{ll}
\varepsilon_{t h, c}(\theta)=-1,2 \times 10^{-4}+6 \times 10^{-6} \cdot \theta+1,4 \times 10^{-11} \cdot \theta^{3} & 20^{\circ} \mathrm{C} \leq \theta \leq 805^{\circ} \mathrm{C} \\
\varepsilon_{t h, c}(\theta)=12 \times 10^{-3} & 805^{\circ} \mathrm{C}<\theta \leq 1200^{\circ} \mathrm{C}
\end{array}
$$


As relações das eqs. (32) e (33) são apresentadas graficamente na Figura 24.

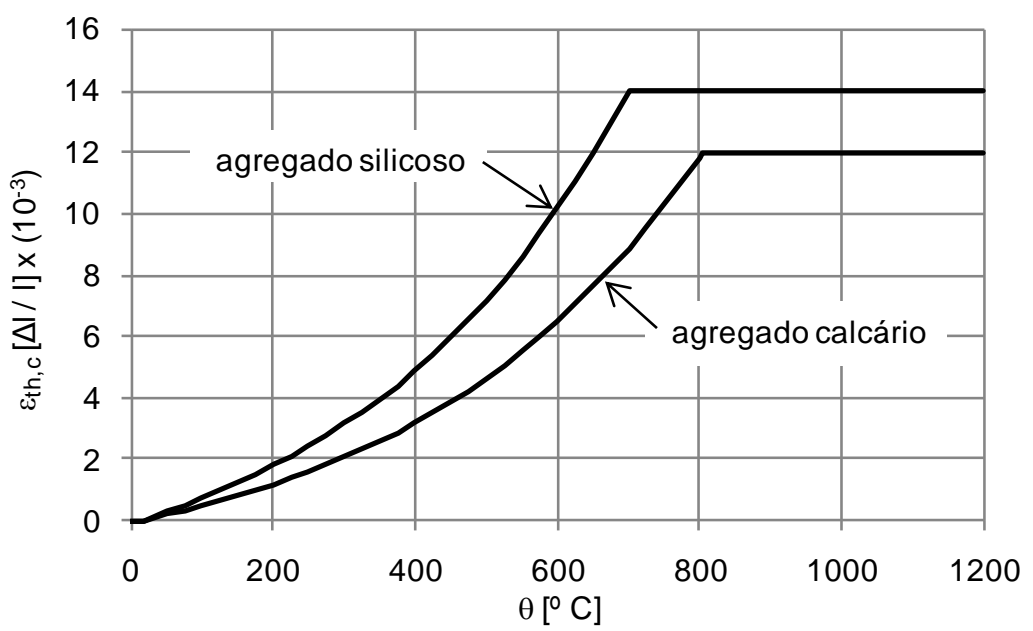

Figura 24 - Deformação térmica do concreto $\varepsilon_{\mathrm{th}, \mathrm{c}}$ em função da temperatura (EN 1992-1-2:2004)

Embora o Eurocode 2 (EN 1992-1-2:2004) não deixe claro, é provável que as expressões aqui apresentadas para o cálculo da deformação térmica do concreto incluem, implicitamente, as parcelas de deformação devido à retração e fissuração, conforme foi discutido anteriormente no item 0 (eq. (25)) deste trabalho.

\subsubsection{Deformação transiente}

A deformação transiente do concreto é irreversível e resulta de transformações físicoquímicas que ocorrem durante os primeiros instantes do aquecimento (BRATINA, S. et al., 2005). Anderberg e Thelandersson ${ }^{9}$ (1976, apud BRATINA, S. et al., 2005) propuseram a seguinte expressão para o cálculo da deformação transiente do concreto (eq. (34)).

$$
\varepsilon_{t r, c}=k_{2} \cdot \frac{\sigma_{c}}{f_{c 0}} \cdot \varepsilon_{t h, c}
$$

Onde:

$\varepsilon_{\text {tr,c }}:$ deformação transiente do concreto;

$\mathrm{k}_{2}$ : constante adimensional cujo valor varia de 1,8 a 2,35;

${ }^{9}$ ANDERBERG, Y.; THELANDERSSON, S. Stress and deformation characteristics of concrete, 2 - Experimental investigation and material behavior model, Bulletin 54. University of Lund, Suécia, 1976. 
$\sigma_{c}:$ tensão no concreto $\left[\mathrm{N} / \mathrm{m}^{2}\right]$;

$f_{\mathrm{c} 0}$ : tensão resistente do concreto à temperatura ambiente $\left[\mathrm{N} / \mathrm{m}^{2}\right]$;

$\varepsilon_{\text {th,c }}:$ deformação térmica linear específica do concreto.

Bratina et al. (2005) utilizaram nos seus estudos o valor 1,8 para a constante $\mathrm{k}_{2}$. Bamonte e Lo Monte (2010) indicam o valor de 2,35 para a constante $\mathrm{k}_{2}$ no caso de agregados silicosos.

\subsubsection{Deformação por fluência}

A deformação por fluência do concreto sob temperaturas elevadas é uma função das tensões e da temperatura, num dado instante de tempo. Harmathy ${ }^{10}$ (1993, apud BRATINA et al., 2005) propôs o seguinte modelo para o cálculo da deformação por fluência do concreto $\varepsilon_{\mathrm{cr}, \mathrm{c}}($ eq. (35)).

$$
\varepsilon_{c r, c}=\beta_{1} \cdot \frac{\sigma_{c}}{f_{c, \theta}} \cdot \sqrt{t} \cdot e^{d .(\theta-293)}
$$

Onde:

$\varepsilon_{\mathrm{cr}, \mathrm{c}}$ : deformação por fluência do concreto;

$\beta_{1}$ : constante empírica do material $\left[\mathrm{s}^{-1 / 2}\right]$;

$\sigma_{\mathrm{c}}$ : tensão no concreto $\left[\mathrm{N} / \mathrm{m}^{2}\right]$;

$f_{\mathrm{c}, \theta}$ : tensão resistente do concreto em função da temperatura $\left[\mathrm{N} / \mathrm{m}^{2}\right]$;

$\mathrm{t}$ : tempo $[\mathrm{s}]$;

$\mathrm{d}$ : constante empírica do material $\left[\mathrm{K}^{-1}\right]$;

$\theta$ : temperatura do concreto $[\mathrm{K}]$.

Bratina et al. (2005) obtiveram os valores de $\beta_{1}=6,28 \times 10^{-6}\left[\mathrm{~s}^{-1 / 2}\right] \mathrm{e}$ $\mathrm{d}=2,658 \times 10^{-3}\left[\mathrm{~K}^{-1}\right]$, ajustando a eq. (35) aos resultados de experimentos de $\mathrm{Cruz}^{11}$ (1968,

\footnotetext{
${ }^{10}$ HARMATHY, T. Z. Fire safety design and concrete. Longman Scientific and Technical: Harlow, Inglaterra, 1993.

${ }^{11}$ CRUZ, C. R. Apparatus for measuring creep of concrete at high temperatures. Journal of PCA Research and Development Laboratories, 10 (3), p. 36-42, 1968.
} 
apud BRATINA, S. et al., 2005). A Figura 25 mostra a comparação entre os resultados analíticos (eq. (35)) e experimentais para a deformação por fluência do concreto para temperaturas variando entre $24^{\circ} \mathrm{C}$ e $649^{\circ} \mathrm{C}$.

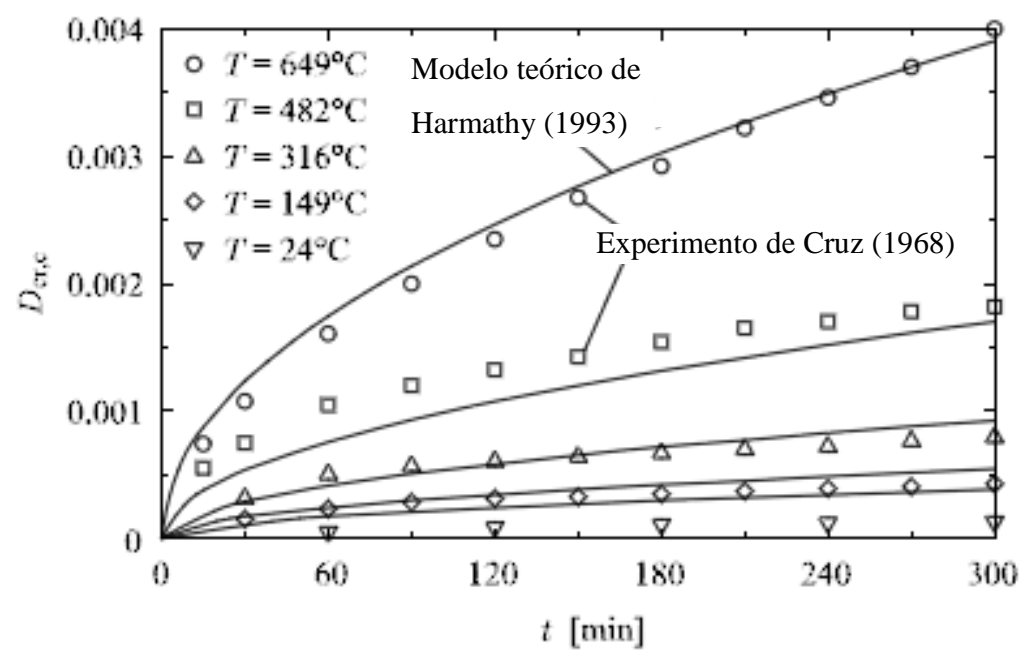

Figura 25 - Variação da deformação por fluência $\varepsilon_{\text {cr,c }}\left(\right.$ ou $\left.D_{\text {cr,c }}\right)$ do concreto com o tempo segundo o modelo analítico de Harmathy ${ }^{12}$ (1993, apud BRATINA et al., 2005) e resultados experimentais de Cruz ${ }^{13}$ (1968, apud BRATINA et al., 2005) - reproduzido de Bratina et al. (2005)

A fluência $\varepsilon_{\mathrm{cr}, \mathrm{c}}$ aqui apresentada é específica para concreto sob temperaturas elevadas, não devendo ser confundida com a fluência do concreto à temperatura ambiente, pois cada qual possui efeitos e tempo de atuação distintos.

\subsubsection{LITS}

A expressão para o cálculo da LITS proposto por Khoury, Grainger e Sullivan ${ }^{14}$ (1985 apud PURKISS, 2007) é dada pela eq. (36).

$$
\operatorname{LITS}\left(\theta_{c}, \sigma\right)=\varepsilon_{t o t, c}-\varepsilon_{t h, c}-\frac{\sigma_{c}}{E_{0,20}}
$$

${ }^{12}$ HARMATHY, T. Z. Fire safety design and concrete. Longman Scientific and Technical: Harlow, Inglaterra, 1993.

${ }^{13}$ CRUZ, C. R. Apparatus for measuring creep of concrete at high temperatures. Journal of PCA Research and Development Laboratories, 10 (3), p. 36-42, 1968.

${ }^{14}$ KHOURY, G. A.; GRAINGER, B. N.; SULLIVAN, P. J. E. Strain of concrete during first heating to 600 ${ }^{\circ} \mathrm{C}$ under load. Magazine of Concrete Research, 37, p. 195-215, 1985. 
Onde:

$\varepsilon_{\text {tot,c }}:$ deformação total do concreto;

$\varepsilon_{\mathrm{th}, \mathrm{c}}:$ deformação térmica do concreto;

$\sigma_{c}:$ tensão no concreto;

$\mathrm{E}_{0,20}$ : módulo de elasticidade do concreto à temperatura ambiente.

A relação $\sigma_{\mathrm{c}} / \mathrm{E}_{0,20}$ corresponde à deformação elástica do concreto.

Terro (1998) ajustou a curva mestra da LITS para o nível de tensão igual a 0,3. $\sigma_{0,20}$, resultando na eq. (37).

$$
\begin{aligned}
\operatorname{LITS}\left(\theta_{c}, 0,3 . \sigma_{0,20}\right)= & 43,87 \times 10^{-6}-2,73 \times 10^{-6} \theta_{c}-6,35 \times 10^{-8} \theta_{c}^{2} \\
& +2,19 \times 10^{-10} \theta_{c}^{3}-2,77 \times 10^{-13} \theta_{c}^{4}
\end{aligned}
$$

Onde:

$\sigma_{0,20}$ : tensão de pico do concreto à temperatura ambiente;

$\theta_{\mathrm{c}}$ : temperatura do concreto $\left[{ }^{\circ} \mathrm{C}\right]$.

Para outros níveis de carregamento, a LITS é dada pela eq. (38).

$$
\operatorname{LITS}\left(\theta_{c}, \sigma_{c}\right)=\operatorname{LITS}\left(\theta_{c}, 0,3 . \sigma_{0,20}\right) \cdot\left(0,032+3,226 \cdot \frac{\sigma_{c}}{\sigma_{0,20}}\right)
$$

Para concreto utilizando agregados silicosos, a eq. (37) é modificada, resultando na eq. (39).

$$
\begin{aligned}
\operatorname{LITS}\left(\theta_{c}, 0,3 . \sigma_{0,20}\right)= & -1,48 \times 10^{-6} \cdot\left(1098,5-39,12 \theta_{c}+0,43 \theta_{c}^{2}\right) \\
& -1,48 \times 10^{-9} \cdot\left(2,44 \theta_{c}^{3}-6,27 \times 10^{-3} \theta_{c}^{4}+5,95 \times 10^{-6} \theta_{c}^{5}\right)
\end{aligned}
$$

Por último, os valores da LITS podem ser corrigidos para um volume de agregado $V_{a}$ diferentes dos $65 \%$ considerados na expressão original. Essa correção é dada pela eq. (40).

$$
\left.\operatorname{LITS}\left(\theta_{c}, \sigma_{c}\right)\right|_{V_{a}}=\left.\operatorname{LITS}\left(\theta_{c}, \sigma_{c}\right)\right|_{65 \%} \cdot \frac{V_{a}}{0,65}
$$


O modelo para cálculo da LITS aqui apresentado é válido somente para temperaturas de até $590^{\circ} \mathrm{C}$ (PURKISS, 2007).

Gernay e Franssen (2010) propuseram uma formulação alternativa à curva tensãodeformação genérica do concreto dada pelo Eurocode 2 (EN 1992-1-2:2004), incluindo um termo explícito para a LITS. Essa proposta foi motivada principalmente pelo fato da LITS, no modelo dessa norma, ser tratado como reversível porque, para uma dada temperatura, o módulo de elasticidade usado para o descarregamento é tomado como a tangente inicial à curva tensão-deformação em termos de $\left(\varepsilon_{\mathrm{m}} ; \sigma\right)$ ao invés de $\left(\varepsilon_{\sigma} ; \sigma\right)$ (ver eqs. (30) e $\left.(31)\right)$. $\mathrm{O}$ novo modelo proposto é particularmente útil para analisar com maior precisão o comportamento da estrutura durante a fase de resfriamento, pois considera a irreversibilidade da LITS.

4.1.6.5. Influência das parcelas de deformações nos cálculos de pilares de concreto em situação de incêndio

Apesar dos diversos estudos realizados para avaliar os efeitos da consideração das diversas parcelas de deformação dos materiais sob temperaturas elevadas nos cálculos analíticos, ainda há controvérsias a respeito da necessidade de considerá-las, principalmente em fase de projeto. Para simulações avançadas, nas quais se deseja estudar o comportamento da estrutura em todas as fases do aquecimento (e, às vezes, do resfriamento), a consideração de todas as parcelas de deformação dos materiais é imprescindível para a coerência e precisão dos resultados analíticos, quando comparados aos resultados de ensaios experimentais.

Purkiss (2007) afirma que a componente de deformação transiente do concreto deve ser sempre considerada nas análises. Tal recomendação deve-se aos resultados de estudos feitos por Mustapha ${ }^{15}$ (1994 apud PURKISS, 2007) e Purkiss e Mustapha ${ }^{16}$ (1996 apud PURKISS 2007). Foram analisados pilares de seção quadrada aquecidos em 3 faces com carregamento axial centrado e com excentricidades (Figura 26). Os dados experimentais foram obtidos de ensaios conduzidos por Haksever e Anderberg ${ }^{17}$ (1981 apud PURKISS,

\footnotetext{
${ }^{15}$ MUSTAPHA, K. N. Modelling the effects of spalling on the failure modes of concrete columns in fire. $\mathrm{PhD}$ Thesis, University of Aston, 1994.

${ }^{16}$ PURKISS, J. A.; MUSTAPHA, K. N. An investigation into the influence of concrete constitutive models on the behavior of reinforced concrete columns exposed to fire. Journal of the Institution of Engineers, Malaysia, 57, p. 23-32, 1996.

17 HAKSEVER, A.; ANDERBERG, Y. Comparison between measured and computed structural response of some reinforced concrete columns in fire. Fire Safety Journal, 4, p. 293-297, 1981.
} 
2007). Os modelos constitutivos utilizados nos cálculos analíticos foram: M1 (modelo de Anderberg e Thelandersson ${ }^{18}$ (1976 apud PURKISS, 2007) ligeiramente modificado, com inclinação variável para o ramo decrescente da curva tensão-deformação), M2 (modelo de Schneider ${ }^{19}$ (1988 apud PURKISS, 2007)) e M3 (modelo sem deformação transiente).

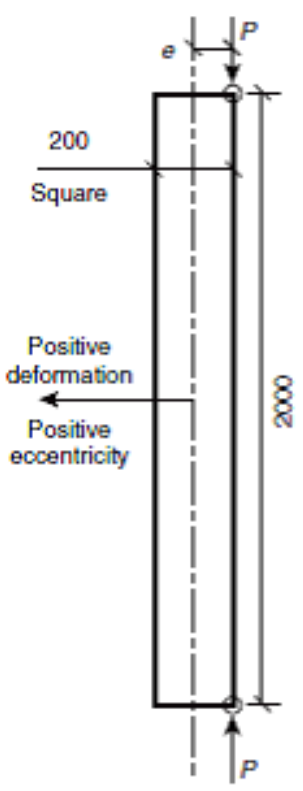

Elevation

\begin{tabular}{ccc}
\multicolumn{3}{c}{ Loading details } \\
\hline Column & Load $(P)$ & Ecoentricity $(e)$ \\
\hline C1 & 0,900 & 0 \\
C2 & 0,600 & -60 \\
C3 & 0,300 & +60 \\
& $($ MN $)$ & $(\mathrm{mm})$ \\
\hline
\end{tabular}

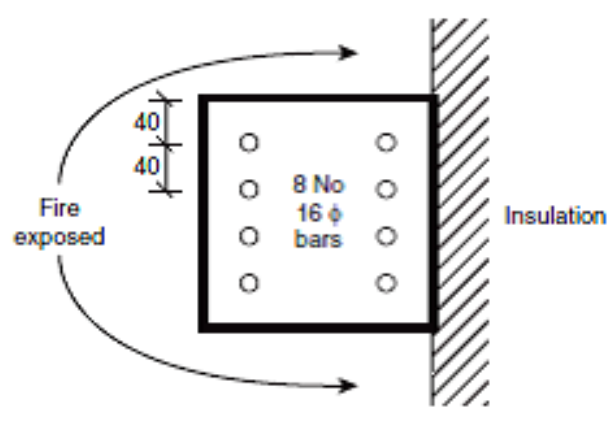

Cross-section

Figura 26 - Dados dos pilares analisados por Purkiss e Mustapha ${ }^{20}$ (1996 apud PURKISS, 2007)

Os resultados das análises são apresentados na Figura 27, Figura 28 e Figura 29.

${ }^{18}$ ANDERBERG, Y.; THELANDERSSON, S. Stress and deformation characteristics of concrete, 2 - Experimental investigation and material behavior model, Bulletin 54. University of Lund, Suécia, 1976.

${ }^{19}$ SCHNEIDER, U. Concrete at high temperatures - a general review. Fire Safety Journal, 13, p. 5568, 1988.

${ }^{20}$ PURKISS, J. A.; MUSTAPHA, K. N. An investigation into the influence of concrete constitutive models on the behavior of reinforced concrete columns exposed to fire. Journal of the Institution of Engineers, Malaysia, 57, p. 23-32, 1996. 


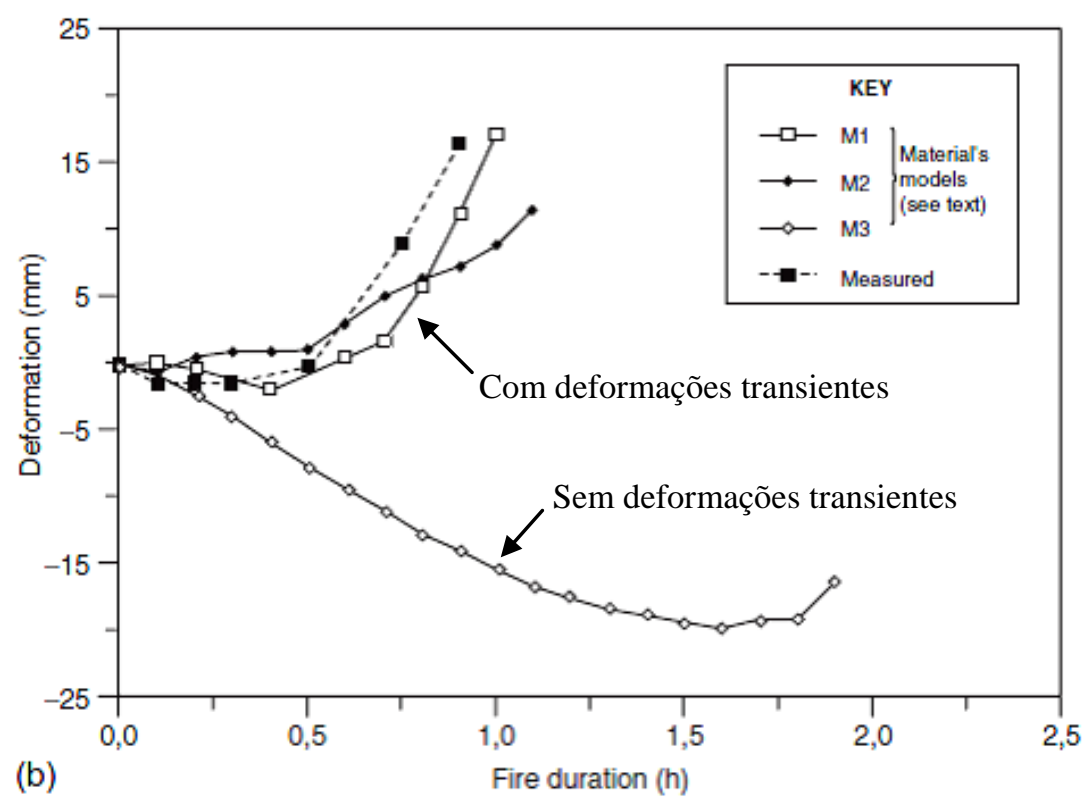

Figura 27 - Resultados do pilar C1 analisado por Purkiss e Mustapha ${ }^{21}$ (1996 apud PURKISS, 2007)

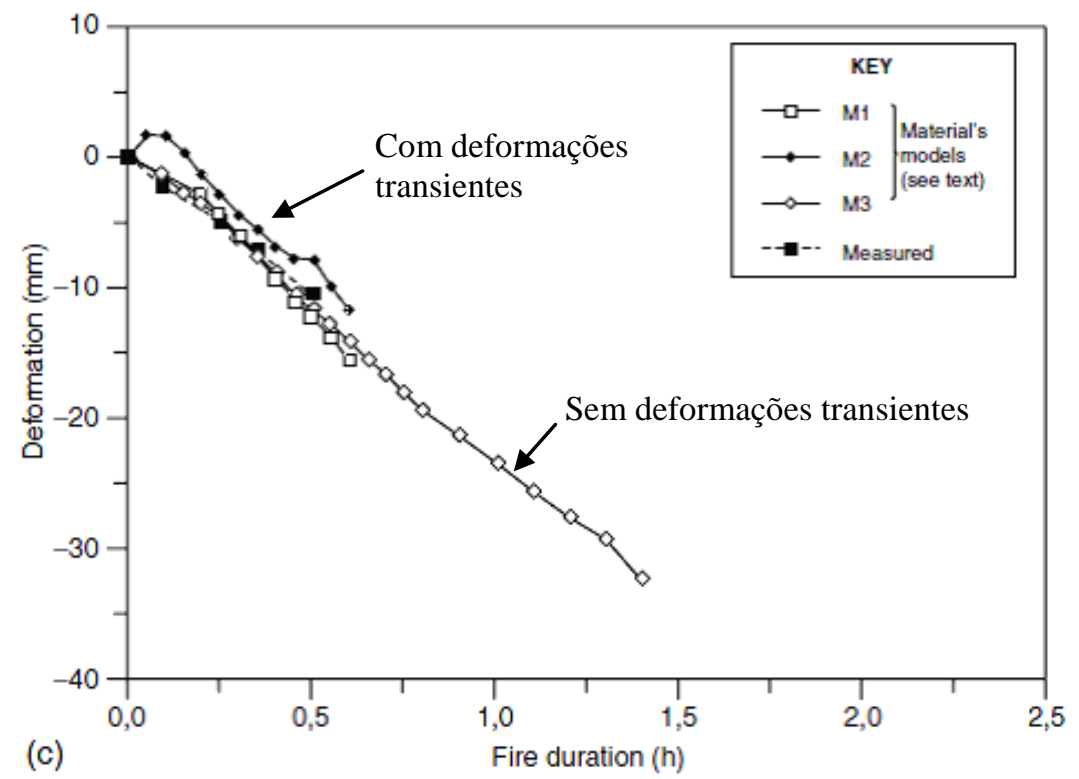

Figura 28 - Resultados do pilar C2 analisado por Purkiss e Mustapha ${ }^{21}$ (1996 apud PURKISS, 2007)

${ }^{21}$ PURKISS, J. A.; MUSTAPHA, K. N. An investigation into the influence of concrete constitutive models on the behavior of reinforced concrete columns exposed to fire. Journal of the Institution of Engineers, Malaysia, 57, p. 23-32, 1996. 


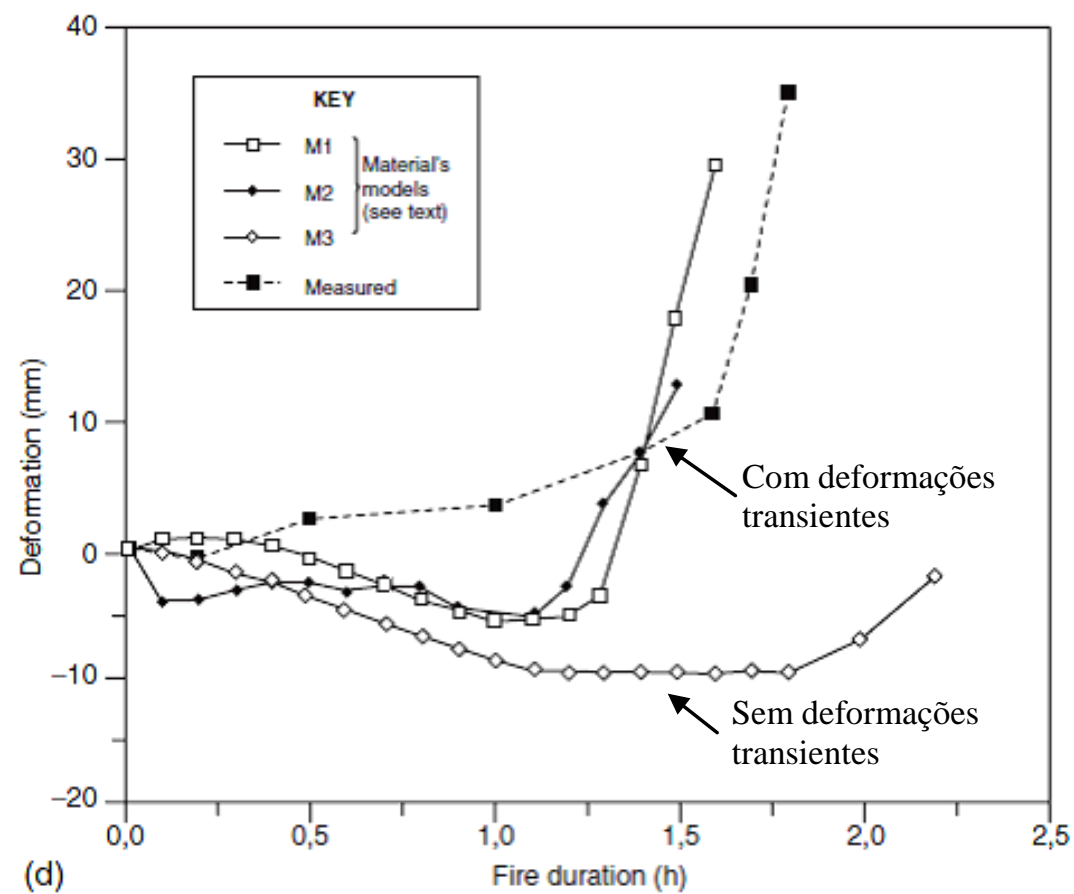

Figura 29 - Resultados do pilar C3 analisado por Purkiss e Mustapha ${ }^{22}$ (1996 apud PURKISS, 2007)

Para o pilar C2 (Figura 28), no qual a zona comprimida compreende a face não aquecida, os três modelos analíticos apresentam tendências bastante semelhantes, mas o tempo de resistência ao fogo calculado utilizando o material M3 (sem deformações transientes) é superestimado de 2 a 2,5 vezes. Para os pilares C1 e C3 (Figura 27 e Figura 29, respectivamente), nos quais a região comprimida compreende as faces aquecidas da seção transversal, é inaceitável ignorar os efeitos da deformação transiente. Para o pilar $\mathrm{C} 1$, a deformação lateral do pilar foi calculada para o lado oposto aos demais resultados, além do tempo de resistência ao fogo ser aproximadamente o dobro do verificado no ensaio experimental. Para o pilar C3, os três modelos analíticos apresentam tendências semelhantes até aproximadamente 75 minutos, quando os modelos que consideram as deformações transientes (M1 e M2) seguem os resultados experimentais, enquanto que o modelo M3 (sem deformação transiente) continuam prevendo deformações com o mesmo sinal até próximo da ruptura. No início das simulações, o momento devido à excentricidade do carregamento controla o comportamento do pilar, sendo superado mais tarde pelas deformações devido ao gradiente térmico.

${ }^{22}$ PURKISS, J. A.; MUSTAPHA, K. N. An investigation into the influence of concrete constitutive models on the behavior of reinforced concrete columns exposed to fire. Journal of the Institution of Engineers, Malaysia, 57, p. 23-32, 1996. 
Por fim, avaliando os resultados do estudo acima descrito, nota-se que, uma vez consideradas as deformações transientes do concreto aquecido, o TRF calculado pouco muda entre os diversos modelos constitutivos utilizados. Conforme mencionado anteriormente, o modelo constitutivo do concreto apresentado pelo Eurocode 2 (EN 1992-1-2:2004) inclui, de forma implícita, a LITS, que contém a deformação transiente do concreto sob temperaturas elevadas (GERNAY e FRANSSEN, 2010).

Bratina et al. (2005) desenvolveram um modelo numérico avançado para o cálculo de pilares de concreto armado em situação de incêndio utilizando elementos finitos, com capacidade de considerar individualmente cada parcela de deformação do aço e do concreto. Assim, cada parcela pôde ser avaliada no cálculo de pilares isolados de concreto armado submetidos a aquecimento em todas as faces (simétrico). Informações detalhadas sobre o modelo numérico e parâmetros de cálculo utilizados são dados no artigo publicado (BRATINA et al., 2005).

A Figura 30 exemplifica uma das avaliações feitas por Bratina et al. (2005), tomando como exemplo o pilar de rótulo I7 ensaiado pelo NRCC (ver Tabela 11).

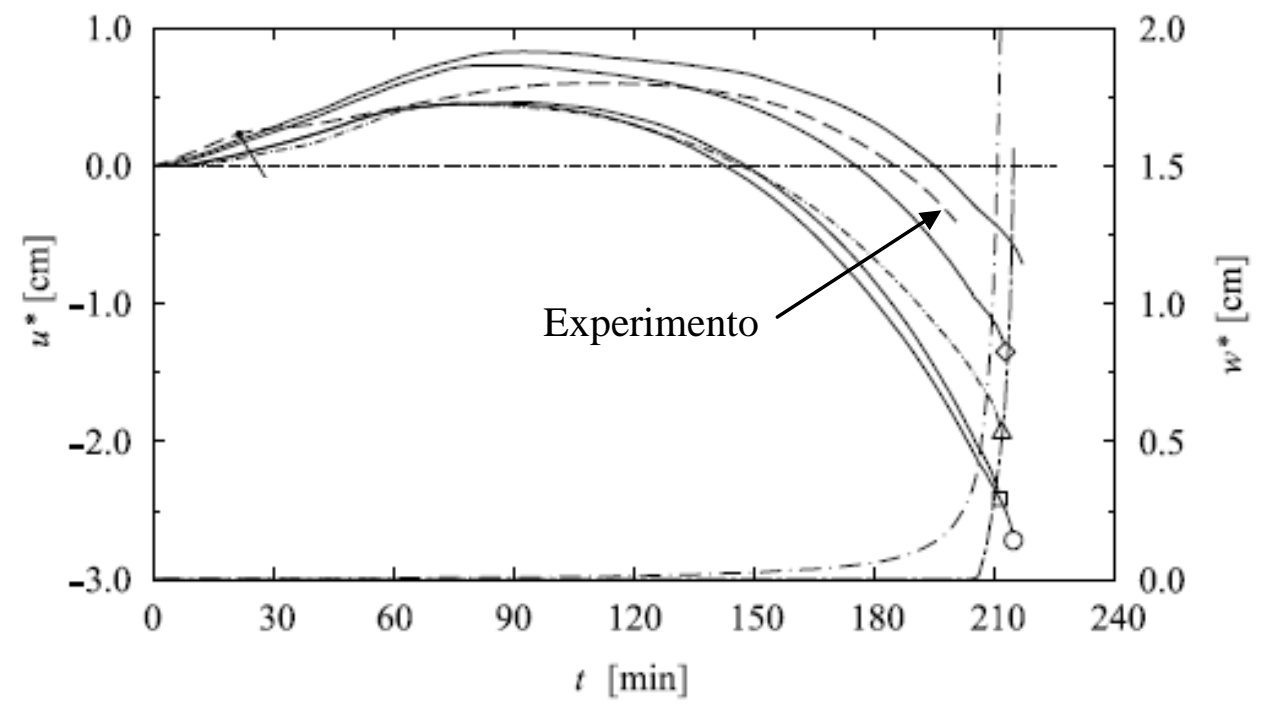

$\operatorname{FEM}\left(u^{*}\right)$ :

$\operatorname{FEM}\left(w^{*}\right)$ : considered

- $D_{\text {th }}$ --- considered $D_{\mathrm{th}}, D_{\mathrm{cr}}, D_{\mathrm{tr}, \mathrm{c}}$

$\multimap D_{\text {th }}, D_{\mathrm{cr}, \mathrm{c}}$

$\longrightarrow D_{\mathrm{th}}, D_{\mathrm{cr}, \mathrm{c}}, D_{\mathrm{tr}, \mathrm{c}}$

$\multimap D_{\mathrm{th}}, D_{\mathrm{cr}, \mathrm{c}}, D_{\mathrm{tr}, \mathrm{c}}, D_{\mathrm{cr}, \mathrm{s}}$

FEM $\left(u^{*}\right)$, fire curve EC 1: $\quad$ FEM $\left(w^{*}\right)$, fire curve EC 1:

$-\triangle-$ considered $D_{\mathrm{th}}, D_{\mathrm{cr}}, D_{\mathrm{tr}, \mathrm{c}}--$ considered $D_{\mathrm{th}}, D_{\mathrm{cr}}, D_{\mathrm{tr}, \mathrm{c}}$ 
Nota-se na Figura 30 que o deslocamento axial $\mathrm{u}^{*}$ medido no ensaio experimental aumentam durante os primeiros 120 minutos de ensaio. Isso corresponde ao alongamento do pilar devido à deformação térmica crescente nesse intervalo de tempo. Em seguida, o deslocamento axial decresce devido ao rápido aumento das deformações transientes e por fluência. Esse tipo de comportamento é típico de pilares de concreto armado em situação de incêndio (BRATINA et al., 2005). Se somente as deformações térmicas do concreto e do aço são consideradas nos cálculos analíticos, o deslocamento axial $u^{*}$ calculado é máximo aos 90 minutos, aproximadamente, sendo maior que o valor medido no ensaio experimental. À medida que mais parcelas de deformação são consideradas, percebe-se aumento significativo no deslocamento axial $\mathrm{u}^{*}$ no momento do colapso do pilar. Bratina et al. (2005) utilizaram o menor valor possível para a constante $\mathrm{k}_{2}$ da expressão da deformação transiente do concreto (item 4.1.6.2 deste trabalho). O valor elevado do deslocamento axial $\mathrm{u}^{*}$ calculado, nesse caso, sugere que o pilar estivesse com teor de umidade muito baixo no momento do ensaio experimental, consequentemente a deformação transiente não precisa ser considerada. A deformação por fluência do aço não afetou consideravelmente o deslocamento axial u* calculado (ver Figura 30), porque a máxima temperatura calculada nas armaduras longitudinais não superou os $400^{\circ} \mathrm{C}$ e porque foi utilizado aço do tipo Au 50, que é o menos susceptível à fluência (BRATINA et al., 2005).

Apesar das grandes diferenças entre os valores calculados do deslocamento axial $\mathrm{u}^{*}$, os tempos de resistência ao fogo calculados mostraram não depender muito de quais parcelas de deformação dos materiais sob temperaturas elevadas foram consideradas no exemplo da Figura 30. É importante perceber que a parcela de deformação linear específica térmica sempre foi considerada em todas as análises.

Bamonte e Lo Monte (2010) calcularam o TRF de 60 pilares utilizados na calibração do Método A do Eurocode 2 (EN 1992-1-2:2004) utilizando quatro modelos constitutivos para o concreto. Três modelos consideram as parcelas de deformação do concreto de forma explícita e o outro modelo, que é a curva tensão-deformação do concreto dada pelo Eurocode 2 (EN 1992-1-2:2004), considera as parcelas de deformação do concreto de forma implícita. Os autores concluíram que os resultados do TRF calculados pelos diferentes modelos ficaram muito próximos. No entanto, o modelo constitutivo do concreto dado pelo Eurocode 2 (EN 1992-1-2:2004) apresentou os melhores resultados, ou seja, gerou valores de TRF calculados mais próximos dos valores obtidos experimentalmente. Esse mesmo modelo, segundo Bamonte e Lo Monte (2010), é o mais rígido dentre os modelos analisados. Por fim, com base nos bons resultados apresentados pelo modelo constitutivo do concreto do Eurocode 2 (EN 
1992-1-2:2004), os autores questionam a probabilidade dos resultados experimentais usados no estudo terem sido utilizados para a calibração da curva tensão-deformação proposta por essa norma.

Um desempenho satisfatório do modelo constitutivo do concreto do Eurocode 2 (EN 1992-1-2:2004) também foi constatado por Martins e Rodrigues (2010).

Com base nas conclusões obtidas pelos estudos anteriormente apresentados, foi adotado neste trabalho o modelo constitutivo do concreto do Eurocode 2 (EN 1992-1-2:2004).

\subsubsection{Spalling}

\subsubsection{Definição e tipos de spalling}

Um dos mais complexos e pouco compreendidos fenômenos experimentado pelo concreto sob temperaturas elevadas é o spalling. Esse fenômeno consiste na expulsão, de forma explosiva ou não explosiva, de porções de concreto da superfície de elementos estruturais submetidos a altas temperaturas e rápidas taxas de aquecimento (FIB, 2007).

O spalling pode ser classificado em diversos tipos (FIB, 2007):

- Spalling dos agregados;

- Spalling explosivo;

- Spalling superficial;

- Spalling por delaminação;

- Spalling de canto;

- Spalling após o resfriamento.

Não há uma divisão clara entre os tipos de spalling apresentados, pois em um único incêndio podem ser observados diversos tipos de spalling, até mesmo todos os tipos citados. Normalmente, os três primeiros se manifestam nos instantes iniciais do incêndio, enquanto os três últimos ocorrem momentos mais tarde. Além disso, a extensão e a severidade do spalling podem variar bastante, desde expulsão de pequenos pontos localizados até destacamento de grandes porções do cobrimento (FIB, 2007). 


\subsubsection{Spalling explosivo}

O spalling explosivo é considerado o mais severo tipo de spalling que pode ocorrer em estruturas de concreto em situação de incêndio. Sua ocorrência pode resultar na expulsão, de forma explosiva, de camadas de concreto com espessuras de $25 \mathrm{~mm}$ a $100 \mathrm{~mm}$, geralmente na primeira meia hora de um incêndio. Os fatores que influenciam a ocorrência do spalling explosivo incluem: resistência, idade e permeabilidade do concreto, taxa de aquecimento e intensidade dos gradientes térmicos na seção transversal, dimensões e forma da seção transversal, tipo e tamanho dos agregados, teor de umidade do concreto, presença de fissuras, tipo e quantidade de armaduras, presença de fibras de polipropileno e carregamento aplicado. O spalling explosivo pode ocorrer de duas formas: devido à pressão nos poros do concreto ou devido às tensões térmicas, ambas influenciadas pelos carregamentos aplicados. Elas podem ocorrer isoladamente ou simultaneamente, dependendo das dimensões da seção transversal, características dos materiais e teor de umidade do concreto (FIB, 2007).

Os fatores que influenciam na ocorrência dos diversos tipos de spalling são apresentados na Tabela 4.

Tabela 4 - Fatores que influenciam na ocorrência dos diversos tipos de spalling (KHOURY, 2006c)

\begin{tabular}{|c|c|c|c|c|c|}
\hline Spalling & $\begin{array}{l}\text { Tempo provável } \\
\text { de ocorrência }\end{array}$ & Natureza & Som & Severidade & $\begin{array}{l}\text { Fatores de } \\
\text { influência }\end{array}$ \\
\hline Agregados & 7 a $30 \mathrm{~min}$. & Separação & "Pipocamento" & Superficial & $\mathrm{T}, \mathrm{E}, \mathrm{S}, \mathrm{D}, \mathrm{U}$ \\
\hline Canto & 30 a $90 \mathrm{~min}$. & Não violento & Nenhum & Pode ser severo & $\mathrm{M}, \mathrm{E}, \mathrm{Fc}, \mathrm{As}$ \\
\hline Superficial & 7 a 30 min. & Violento & Fissuração & Pode ser severo & $\begin{array}{l}\text { T, U, P, Fc } \\
\text { T, E, A, Fs, I, }\end{array}$ \\
\hline Explosivo & 7 a $30 \mathrm{~min}$. & Violento & Explosão & Severo & $\begin{array}{l}\mathrm{C}, \mathrm{G}, \mathrm{P}, \mathrm{Q}, \mathrm{As}, \\
\mathrm{A}, \mathrm{U}, \mathrm{S}\end{array}$ \\
\hline Delaminação & $\begin{array}{l}\text { Quando o } \\
\text { concreto perde } \\
\text { resistência }\end{array}$ & Não violento & Nenhum & Pode ser severo & $\mathrm{M}, \mathrm{Fs}, \mathrm{C}, \mathrm{Q}, \mathrm{As}$ \\
\hline $\begin{array}{l}\text { Após o } \\
\text { resfriamento }\end{array}$ & $\begin{array}{l}\text { Durante e após } \\
\text { o resfriamento, } \\
\text { com absorção } \\
\text { de umidade }\end{array}$ & Não violento & Nenhum & Pode ser severo & $\begin{array}{l}\text { M, Fs, C, Q, As, } \\
\text { UA, AT }\end{array}$ \\
\hline \multicolumn{3}{|c|}{ E: Expansão térmica dos agregados } & \multicolumn{3}{|l|}{ P: Permeabilidade } \\
\hline \multicolumn{3}{|c|}{ D: Difusividade térmica dos agregados } & \multicolumn{3}{|c|}{ Q: Forma da seção transversal } \\
\hline \multicolumn{3}{|c|}{ Fs: Resistência do concreto ao cisalhamento } & \multicolumn{3}{|c|}{ As: Área de aço } \\
\hline \multicolumn{3}{|c|}{ Fc: Resistência do concreto à compressão } & \multicolumn{3}{|c|}{ A: Tamanho dos agregados } \\
\hline \multicolumn{3}{|c|}{ I: Idade do concreto } & \multicolumn{3}{|c|}{ M: Temperatura máxima } \\
\hline \multicolumn{3}{|c|}{ T: Taxa de aquecimento } & \multicolumn{3}{|l|}{ U: Teor de umidade } \\
\hline \multicolumn{3}{|c|}{ C: Carregamento/restrições } & \multicolumn{3}{|c|}{ S: Dimensões da seção transversal } \\
\hline \multicolumn{3}{|c|}{ G: Gradientes térmicos } & \multirow{2}{*}{\multicolumn{3}{|c|}{ UA: Absorção de umidade }} \\
\hline AT: Tipo de a & & & & & \\
\hline
\end{tabular}


O Boletim 38 do fib (FIB, 2007) apresenta a descrição, com base em diversos estudos, dos fatores que influenciam a ocorrência do spalling explosivo:

- Permeabilidade do concreto: a permeabilidade do concreto afeta o transporte de vapor no concreto aquecido, influenciando na evolução das pressões nos poros do material. Geralmente, concretos de alta qualidade possuem maior massa específica e menor porosidade, oferecendo maior resistência ao transporte de vapor. Pesquisas sugeriram que o spalling seria improvável de ocorrer em concretos com porosidade superior a $5 \times 10^{-11} \mathrm{~cm}^{2}$, mas essa afirmação deve ser comprovada com estudos mais aprofundados.

- Idade do concreto: a influência da idade do concreto na susceptibilidade à ocorrência do spalling é um assunto controverso entre diversas pesquisas. Muitos estudos afirmam que a probabilidade de ocorrência do spalling diminui com o aumento da idade do concreto, mas isso pode ser devido a menores teores de umidade nesses concretos.

- Resistência do concreto: geralmente, concretos de baixa resistência apresentam menos spalling que concretos de alta resistência. Nos últimos anos tem sido crescente o uso de concretos de alta resistência, obtidos mediante redução da relação água-cimento e uso de aditivos. Em geral, a redução da relação águacimento favorece o spalling devido à pressão nos poros do concreto (devido à baixa permeabilidade), mas reduz o spalling devido às tensões térmicas (devido à alta resistência). Considerando a baixa permeabilidade do concreto de alta resistência, acreditava-se que esse seria mais susceptível ao spalling do que concretos de resistência normal. Entretanto, pesquisas recentes mostraram que isso não é sempre verdade, considerando que a melhor resistência à tração desse concreto pode anular as tensões que originam o spalling. Por fim, concretos com adição de microssílica são muito susceptíveis ao spalling, mesmo para baixas taxas de aquecimento.

- Tensões de compressão e restrições às deformações: o carregamento aplicado, aliado às restrições às deformações em situação de incêndio, aumenta a probabilidade de ocorrência do spalling. $\mathrm{O}$ aumento das tensões de compressão, seja pela redução da seção transversal ou aumento do carregamento, favorece a ocorrência do spalling explosivo. Tensões de compressão elevadas (devido a restrições às deformações térmicas) surgem 
quando a taxa de aquecimento possui valor tal que as tensões não podem ser aliviadas suficientemente rápido pela fluência transiente. Combinações de tensões de compressão acima de $2 \mathrm{~N} / \mathrm{mm}^{2}$ e teores de umidade superiores a $3,3 \%$ em massa tornam praticamente certa a ocorrência do spalling. Outro estudo (SCHNEIDER e LEBEDA ${ }^{23}$ apud FLETCHER et al., 2007) sugeriu que a ocorrência do spalling é facilitada quando há teores de umidade do concreto de no mínimo $2 \%$ e gradientes de temperaturas abruptos na seção transversal (no mínimo 5K/mm, aproximadamente, sendo que gradientes de 7 a $8 \mathrm{~K} / \mathrm{mm}$ resultam em spalling na maioria dos casos).

- $\quad$ Tipo de agregado: os resultados de diversas pesquisas são inconsistentes, mas pode-se afirmar que o spalling é menos intenso para concretos feitos com agregados de baixa expansão térmica. O risco de ocorrência do spalling é crescente para a seguinte ordem de agregados: granito, basalto, silicoso e calcário. Essa indicação é válida quando os agregados estão relativamente secos, uma vez que pesquisas indicaram que um concreto feito com agregado leve saturado possui alta probabilidade de ocorrência do spalling.

- Tamanho dos agregados: as pesquisas evidenciam que agregados maiores aumentam o risco de ocorrência do spalling explosivo.

- Fissuração: a ocorrência de fissuração interna possui duplo efeito. Por um lado, as microfissuras facilitam o escape das pressões de vapor durante $\mathrm{o}$ aquecimento, por outro, lado elas favorecem o spalling devido à propagação dessas fissuras.

- Armaduras: pesquisas indicaram que a presença ou ausência de armaduras é um fator mais importante para a ocorrência do spalling do que a sua quantidade. No entanto, regiões onde as barras encontram-se congestionadas, com espaçamento reduzido, induzem à formação de fissuras que podem favorecer o spalling.

- Cobrimento: se o cobrimento exceder $40 \mathrm{~mm}$ para concretos feitos com agregados densos ou $50 \mathrm{~mm}$ para concretos feitos com agregados leves, há risco de ocorrência do spalling. Por outro lado, cobrimentos de $15 \mathrm{~mm}$ ou menos parecem menos susceptíveis ao spalling, provavelmente porque a massa de concreto desprovido de armação é menor.

${ }^{23}$ SCHNEIDER, U.; LEBEDA, C. Baulicher Brandschutz (Structural Fire Protection). Bauwerk Verlag: Berlim, Alemanha, $400 \mathrm{p}$. 
- Armação adicional: o uso de uma malha metálica leve não evita o spalling, mas limita a extensão do fenômeno e melhora a resistência ao fogo de pilares de concreto armado, além de facilitar possíveis reparos após o incêndio. Utilizam-se malhas metálicas, às vezes, em elementos cujo cobrimento exceda $40 \mathrm{~mm}$. No entanto, pode ser difícil posicionar essas telas, especialmente em seções transversais esbeltas, como em lajes nervuradas. Recomenda-se o uso de telas metálicas complementares apenas em situações onde os padrões de resistência ao fogo sejam bastante exigentes. Outros estudos (HAN et al., 2005; BISBY, GREEN e KODUR, 2005) concluíram que o uso de malhas de fibras de carbono e fibras de vidro não contribuiu significativamente para a redução do spalling, devido à redução da aderência desses materiais com o concreto sob temperaturas elevadas, reduzindo, portanto, sua capacidade de confinamento.

- Fibras de polipropileno: estudos recentes indicaram que a adição de 0,05\% a $0,1 \%$ (em massa) de fibras de polipropileno na mistura de concreto elimina (ou ao menos reduz muito) o spalling explosivo, mesmo em concretos de alta resistência (60 a $110 \mathrm{MPa}$ ), mas não necessariamente em concretos de ultra alta resistência (acima de $150 \mathrm{MPa}$ ). A tecnologia do uso de fibras de polipropileno no concreto, embora já adotada em algumas obras, ainda está em fase de desenvolvimento, sendo que estão sendo feitos estudos experimentais de elementos em escala real (incluindo a microestrutura) e estudos de modelagem numérica, dentro do projeto NewCon (KHOURY ${ }^{24}, 2006$ apud FIB, 2007). O efeito da adição das fibras de polipropileno se manifesta pela fusão das mesmas durante o incêndio, criando canais de escape que aliviam a pressão interna dos poros do concreto. Por outro lado, as fibras de polipropileno podem induzir à fissuração nas regiões mais internas de uma peça de concreto, o que poderia mitigar o spalling na superfície, mas gerando problemas estruturais adversos, a serem estudados mais detalhadamente (ALI et al., 2004). Ainda discute-se sobre quais tipos de fibras - monofilamento ou multifilamento - seriam mais eficiente para mitigar o spalling. Já foram feitos também estudos (SHUTTLEWORTH ${ }^{25}, 2001$ apud FLETCHER et al., 2007)

\footnotetext{
${ }^{24}$ KHOURY, G. A. NewCon project. Concrete Engineering International, p. 6-11, Spring 2006.

${ }^{25}$ SHUTTLEWORTH, P. Fire protection of concrete tunnel linings, Proceedings, $3{ }^{\text {rd }}$ Intl. Conference on Tunnel Fires \& Escape From Tunnels. p. 157-165. Washington, Estados Unidos, Outubro, 2001.
} 
para avaliar os efeitos da adição de fibras de aço ao concreto, com o objetivo de aumentar a sua ductilidade e a sua capacidade de absorver as grandes pressões internas. Entretanto, os resultados foram inconclusivos.

- Aditivos incorporadores de ar: o uso de aditivos incorporadores de ar pode reduzir o risco de ocorrência do spalling explosivo. O efeito do uso desse aditivo é reduzir a saturação dos poros do concreto, aliviando as suas pressões.

\subsubsection{Mecanismos do spalling}

O estudo do mecanismo do spalling é bastante extenso, portanto apenas uma breve descrição é apresentada neste trabalho. Cada tipo de spalling (Tabela 4) tem seu próprio mecanismo de ocorrência, sendo que às vezes alguns mecanismos atuam em conjunto.

Os principais mecanismos do spalling explosivo são (FIB, 2007):

- Spalling devido às pressões nos poros: esse mecanismo é afetado principalmente pela permeabilidade do concreto, o teor de umidade inicial do concreto (saturação dos poros) e taxa de aquecimento. O spalling devido às pressões nos poros só age sozinho em pequenos corpos de prova sem atuação de carregamento. Para elementos maiores, a pressão nos poros do concreto deve ser considerada em conjunto com as tensões térmicas e as tensões devido ao carregamento, para então se avaliar a probabilidade de ocorrência do spalling explosivo. Um dos modos de descrever o mecanismo do spalling devido às pressões nos poros do concreto é pelo modelo de "entupimento" (moisture clog), ilustrado na Figura 31. Na fase de aquecimento inicial, o aumento da temperatura induz ao aumento da pressão do vapor nos poros do concreto, forçando sua migração para as zonas mais frias. Inicialmente os poros não estão totalmente saturados, mas após a migração do vapor os poros são preenchidos e forma-se um mecanismo de "entupimento" (moisture clog). A pressão nos poros aumenta, uma vez que o vapor não possui mais caminhos por onde penetrar. Associado a isso, tem-se a degradação das propriedades mecânicas do concreto nas camadas mais aquecidas. 


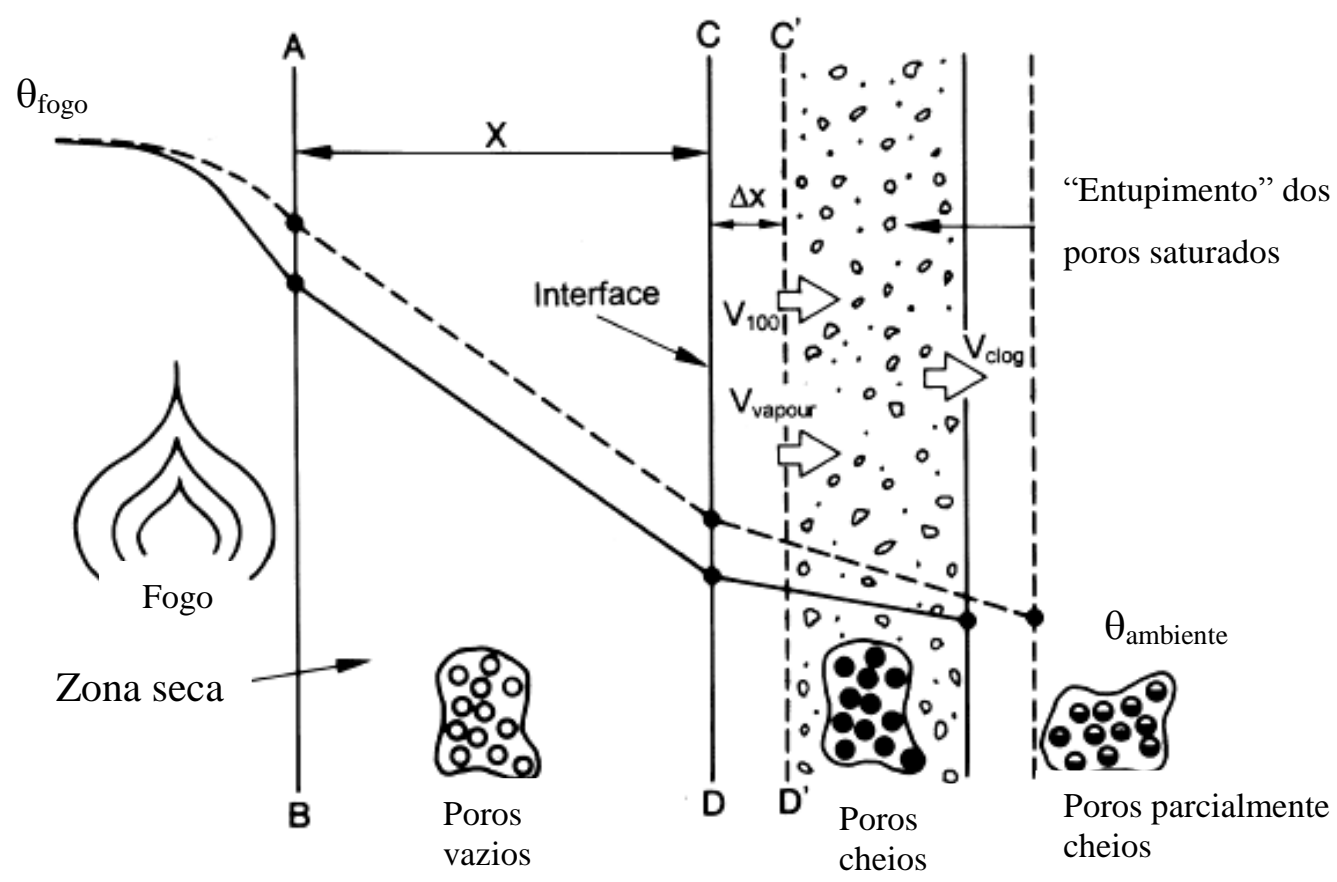

Figura 31 - Mecanismo do spalling devido às pressões nos poros do concreto (CONNOLLY, R. J. ${ }^{26}, 1995$ apud KHOURY e ANDERBERG, 2000)

- Spalling devido às tensões térmicas: sob taxas de aquecimento suficientemente elevadas, cerâmicas e concreto seco podem apresentar spalling explosivo. O fenômeno é atribuído às tensões que se desenvolvem sob altas taxas de aquecimento, evidenciando que outros fatores podem contribuir para a ocorrência do spalling, além das pressões nos poros do concreto. $\mathrm{O}$ aquecimento do concreto gera gradientes de pressão que induzem tensões de compressão próximas à superfície aquecida (devido à expansão térmica restringida) e tensões de tração nas regiões mais frias. As tensões de compressão na superfície do elemento podem ser aumentadas pelo carregamento ou protensão existentes, que se somam às tensões térmicas. No entanto, são raras as situações nas quais os elementos de concreto possuem níveis de carregamento suficientes para atingir as tensões limites. Sendo assim, a ocorrência do spalling devido às tensões térmicas, por si só, é um fenômeno raro, mas não impossível de ocorrer.

- Spalling combinado, devido às pressões nos poros e às tensões térmicas: o spalling explosivo ocorre geralmente pela combinação dos dois mecanismos descritos anteriormente, ou seja, havendo pressão elevada nos poros do

${ }^{26}$ CONNOLLY, R. J. The spalling of concrete in fires. PhD Thesis, University of Aston, 1995. 
concreto, tensões de compressão próximas a superfície do elemento e fissuração interna, conforme mostrado na Figura 32. As fissuras se desenvolvem paralelas à superfície quando a soma das tensões supera a resistência à tração do concreto. Isso é acompanhado por uma rápida liberação e energia e falha violenta da região aquecida.

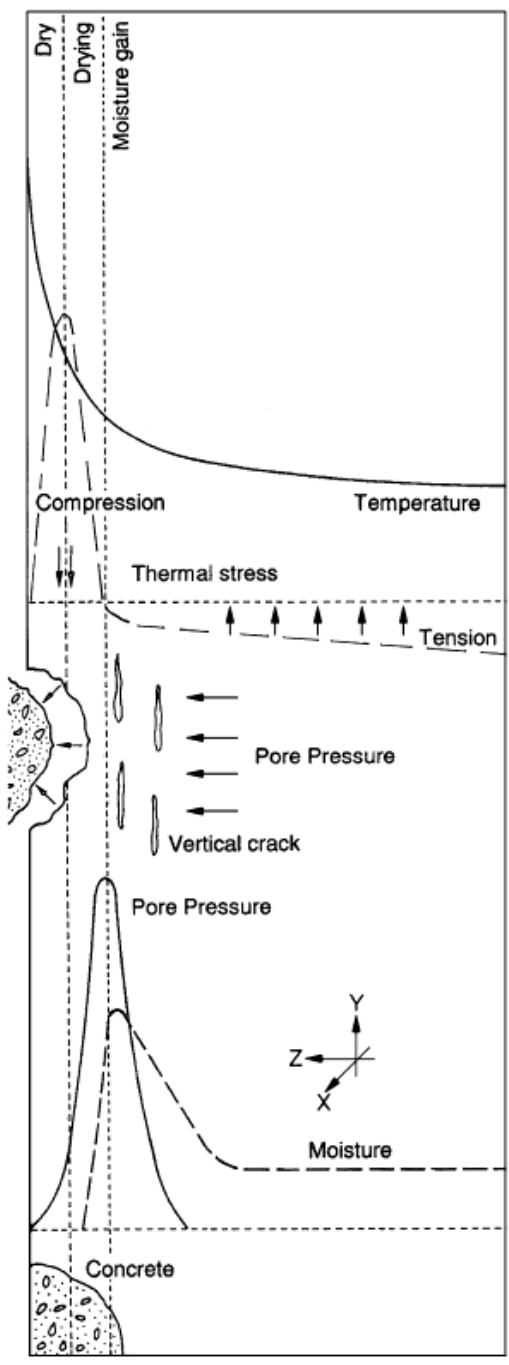

Figura 32 - Mecanismo do spalling explosivo (KHOURY e ANDERBERG, 2000a)

O spalling combinado, ou seja, que sofre influência do carregamento atuante, foi constatado também numericamente nas simulações de Khoury et al. (2002).

Embora se divulgue que o spalling ocorra somente sob altas temperaturas, o fenômeno já foi constatado nos primeiros instantes de incêndio, sob temperaturas relativamente baixas, 
da ordem de $200^{\circ} \mathrm{C}$ (CANISIUS, WALEED e MATTHEWS ${ }^{27}, 2005$ apud FLETCHER et al., 2007). A taxa de aquecimento, como já mencionado, também possui papel importante na manifestação do spalling, pois, geralmente, maiores taxas de aquecimento resultam em maior ocorrência de spalling, mas há exceções. Por exemplo, um pilar submetido a uma taxa de aquecimento elevada pode gerar fissuras que ajudam a dissipar as pressões de vapor nos poros do concreto. O mesmo pilar submetido a uma taxa de aquecimento mais branda poderia não fissurar, dificultando a dissipação da pressão de vapor nos poros e favorecendo o spalling explosivo.

Há evidências de que a fase de resfriamento em um incêndio pode ter papel significativo na manifestação do spalling. Essas evidências foram verificadas em ensaios de elementos de concreto armado na Hagerbach Test Gallery, na Suíça (WETZIG ${ }^{28}, 2001$ apud FLETCHER et al., 2007). Durante um dos testes, um exemplar resistiu a temperaturas de até $1600^{\circ} \mathrm{C}$ por duas horas sem qualquer falha, mas após meia hora de resfriamento a amostra apresentou spalling explosivo. Para incêndios reais, pouco se sabe o quanto de spalling acontece na fase de aquecimento ou de resfriamento.

\subsubsection{Consequências do spalling}

A ocorrência do spalling deve ser evitada ao máximo, pois pode invalidar hipóteses de cálculo e diminuir significativamente os níveis de segurança da estrutura em situação de incêndio. A incapacidade atual de se prever a ocorrência do spalling é um fator que limita o desenvolvimento de modelos de cálculo robustos para prever o comportamento de estruturas de concreto em situação de incêndio (FIB, 2007).

As principais consequências do spalling são a exposição direta das armaduras ao fogo, resultando em rápida perda de resistência das mesmas devido ao aquecimento, e a redução da área da seção transversal, o que diminui a capacidade resistente da peça, pois aumenta a tensão aplicada ao concreto e aço remanescentes. Isso pode ser importante principalmente quando ocorre spalling a temperaturas relativamente baixas, antes mesmo que outros efeitos devido ao aquecimento possam se manifestar (FLETCHER et al., 2007).

\footnotetext{
${ }^{27}$ CANISIUS, T. D. G.; WALEED, N.; MATTHEWS, S. L. Evaluation of effects of the fire test on Cardington concrete building. Proceedings, CIB Publication No. 290, Conference on Tall Buildings, p. 353360. Kuala Lumpur, Malásia, Outubro 2003.

${ }^{28}$ WETZIG, V. Destruction mechanisms in concrete material in case of fire, and protection systems. Proceedings, $4^{\text {th }}$ Intl. Conference on Safety in Road \& Rail Tunnels (SIRRT), p. 281.290. Madri, Espanha, Abril 2001.
} 


\subsubsection{Métodos de previsão do spalling}

Embora o spalling seja um assunto bastante estudado nas últimas décadas, os métodos de análise e previsão do fenômeno ainda estão em desenvolvimento. Importantes progressos foram feitos nos últimos anos, especialmente em relação à compreensão dos mecanismos que levam ao spalling. Até o presente momento, a previsão do spalling se baseou principalmente em critérios empíricos pouco precisos (FIB, 2007).

Ensaios experimentais de elementos de concreto em escala real também podem usados como parâmetro para avaliar a probabilidade de ocorrência do spalling. Esse processo é normalmente usado para elementos de túneis. Embora seus resultados sejam confiáveis, os custos dos ensaios são elevados e é recomendável ensaiar uma quantidade satisfatória de elementos para se obter resultados estatisticamente confiáveis.

Modelos simplificados baseados em diagramas (que relacionam o teor de umidade do concreto e as tensões à probabilidade de ocorrência do spalling) foram sugeridos em algumas pesquisas. As principais limitações são considerar apenas dois fatores envolvidos no spalling (quando na realidade há muitos outros) e não são indicados parâmetros chave, como características dos agregados, aditivos, relação resistência/permeabilidade, etc. Os modelos também não consideram a natureza estocástica do concreto. Os diagramas são úteis para indicar influências na ocorrência do spalling, mas não preveem adequadamente o fenômeno, por isso devem ser usados com muito cuidado (FIB, 2007).

Modelos teóricos analíticos também foram sugeridos no passado. A complexidade dos diversos fatores de influência do spalling faz com que seja difícil deduzir um modelo analítico confiável. Esses modelos não conseguiram prever adequadamente a ocorrência do spalling e, portanto, seu uso não é recomendado (FIB, 2007).

Diversos modelos numéricos para avaliar o comportamento de estruturas em situação de incêndio foram desenvolvidos nos últimos anos (BRATINA et al., 2005; ELLINGWOOD e LIN, 1991; HUANG e PLATTEN, 1997; TERRO, 1998; CAPUA e MARI, 2007) mas nenhum deles levou em consideração o fenômeno do spalling.

Mesmo as normas técnicas como o Eurocode 2 (EN 1992-1-2:2004) apresentam apenas orientações simples a respeito da influencia do spalling na resistência ao fogo de estruturas de concreto.

Modelos numéricos avançados estão sendo desenvolvidos, mas ainda não estão disponíveis para uso corrente. Como exemplos, citam-se os trabalhos de (KHOURY, 2000b; KHOURY, MAJORANA, et al., 2002; TENCHEV e PURNELL, 2005; HUANG, BURGESS 
e PLANK, 2009; KHOURY, MAJORANA, et al., 2002; SCHREFLER, KHOURY, et al., 2002).

Por meio de estudos utilizando o software Vulcan, Huang, Burgess e Plank (2006) verificaram que o colapso da estrutura como um todo ocorreu sempre por instabilidade dos pilares. Por esse motivo, os pesquisadores ressaltaram a necessidade de medidas de proteção para os pilares, principalmente contra o spalling.

\subsubsection{Medidas para evitar o spalling explosivo}

Os meios mais eficazes para reduzir a probabilidade de ocorrência do spalling explosivo são (FIB, 2007):

a) uso de proteção térmica nas estruturas;

b) adição de fibras de polipropileno à mistura de concreto $(0,05 \%$ a $0,1 \%$ em massa);

c) uso de aditivo incorporador de ar;

d) uso de agregados de baixa expansão térmica e estáveis sob temperaturas elevadas;

e) adoção de seções transversais com maiores dimensões.

O risco de ocorrência do spalling explosivo, que pode ocorrer na primeira meia hora de incêndio, diminui se o teor de umidade for baixo (inferior a 5\% em volume ou 2-3\% em massa) e a permeabilidade do concreto for alta.

Além disso, o posicionamento das armaduras pode limitar a extensão do spalling, mas não impede a ocorrência do fenômeno em si.

O Boletim 38 do fib (FIB, 2007) indica que o risco de spalling, e a deterioração das propriedades térmicas do concreto com o aumento da temperatura, podem ser diminuídos mediante dosagem cuidadosa da mistura de concreto. Essa dosagem deve levar em conta o comportamento dos agregados, da pasta de cimento e da interação entre eles. A escolha dos agregados talvez seja a etapa mais importante, pois alguns agregados (como sílex ou alguns tipos de rochas sedimentares) podem romper abaixo de $350^{\circ} \mathrm{C}$, enquanto outros (como os granitos) são estáveis termicamente até por volta de $600^{\circ} \mathrm{C}$. A estabilidade térmica dos agregados é crescente na seguinte ordem: agregado calcário, agregado silicoso, basalto, granito, gabro (KHOURY ${ }^{29}, 1997$ apud FIB, 2007). Outras características desejáveis para os agregados são: baixa expansão térmica para melhorar a compatibilidade com a pasta de

${ }^{29}$ KHOURY, G. A. Aggregate characteristics at high temperature in compression. HITECO Report, Imperial College, Dezembro, 1997. pp. 27. 
cimento, superfície rugosa para melhorar a aderência com a pasta e presença de sílica ativa, para melhorar a ligação química com a pasta. Sobre o cimento, é desejável que possua baixos teores de hidróxido de cálcio $\left(\mathrm{Ca}(\mathrm{OH})_{2}\right)$. Esse componente não é desejável, pois o mesmo sofre dissociação a $400^{\circ} \mathrm{C}$, resultando em $\mathrm{CaO}$ e $\mathrm{H}_{2} \mathrm{O}$. O CaO reidrata expansivamente após o resfriamento e na presença de umidade. Na prática, o teor de hidróxido de cálcio pode ser reduzido pela adição de escória, cinzas volantes (do tipo PFA - pulverised fuel ash) ou microssílica. Ensaios mostraram que a escória apresentou melhores resultados sob temperaturas elevadas, seguido pelas cinzas volantes e pela microssílica. O desempenho inferior da microssílica sob temperaturas elevadas (contrastando com seu ótimo desempenho quanto à durabilidade do concreto à temperatura ambiente) pode ser atribuído à baixa permeabilidade da pasta de cimento, o que dificulta o escape das pressões de vapor, aumentando a pressão nos poros e favorecendo o aparecimento de microfissuras (FIB, 2007).

Para informações detalhadas sobre o fenômeno do spalling, seus mecanismos e formas de prevenção, recomenda-se consultar os trabalhos de Khoury e Anderberg (2000) e Jansson (2008).

\subsubsection{Fissuração}

Os mecanismos que levam à fissuração do concreto em situação de incêndio são geralmente similares àqueles que originam o spalling. A expansão térmica e desidratação do concreto devido ao aquecimento podem levar à formação de fissuras, podendo ou não haver spalling explosivo simultâneo. Essas fissuras podem favorecer o aquecimento das barras de aço, podendo gerar mais expansão térmica e fissuração mais intensa. Além disso, a fissuração intensa pode criar caminhos para a propagação do fogo a compartimentos adjacentes (falta de estanqueidade) (FLETCHER et al., 2007).

Geogali e Tsakiridis (2005) fizeram um estudo de caso de um edifício de concreto armado após um incêndio, avaliando principalmente a profundidade das fissuras nos elementos estruturais. Foi constatado que a profundidade das fissuras depende da temperatura atingida pelo incêndio e que essas fissuras possuem penetração considerável nos elementos de concreto armado. Os maiores danos situam-se próximos à superfície, mas análises de coloração do concreto e características das fissuras indicaram que próximo às armaduras a temperatura havia atingido $700^{\circ} \mathrm{C}$. Fissuras com profundidade superior a $30 \mathrm{~mm}$ foram 
atribuídas a um curto período entre aquecimento e resfriamento, por causa da extinção do fogo.

As tensões presentes nos elementos estruturais também podem influenciar a formação de fissuras em situação de incêndio. As tensões de compressão decorrentes da expansão térmica de elementos restringidos podem ser benéficas ao compactar o material e impedir (ou diminuir) a formação de fissuras. Esse efeito não é totalmente considerado pelo meio técnico e não é adequadamente explicado pelas normas vigentes. A resistência à compressão e o módulo de elasticidade de corpos de prova ensaiados com atuação do carregamento em situação de incêndio sofreram menor redução do que as mesmas propriedades medidas em corpos de prova ensaiados sem carregamento (FIB, 2007).

\subsection{AÇO}

O comportamento do aço em situação de incêndio é compreendido com mais profundidade que o concreto, sendo que a resistência do aço para uma dada temperatura pode ser previsto com razoável precisão. As barras de aço necessitam ser protegidas contra a exposição a temperaturas superiores a $250-300^{\circ} \mathrm{C}$. Isso se deve ao comportamento conhecido como blue brittleness (fragilidade azul, em tradução livre) dos aços com baixo teor de carbono na sua composição, manifestando-se por redução da ductilidade do material (FLETCHER et al., 2007).

A presença das barras de aço influencia no transporte de água no interior do concreto aquecido, forçando a água a contornar as barras, aumentando a pressão nos poros do concreto nas regiões próximas e aumentando o risco de spalling. Por outro lado, a retenção da água em torno das barras altera a transmissão de calor, tendendo a reduzir a temperatura no interior do concreto (CHUNG e CONSOLAZIO ${ }^{30}, 2005$ apud FLETCHER et al., 2007).

Pesquisas recentes estudam os efeitos de utilizar fibras de carbono substituindo as barras de aço em elementos de concreto (KODUR e BISBY ${ }^{31}$, 2005 apud FLETCHER et al., 2007; ABBASI e $\mathrm{HOGG}^{32}$, 2005 apud FLETCHER et al., 2007). Boa parte das pesquisas são feitas devido à falta de informações sobre plásticos reforçados com fibras (fibre reinforced

\footnotetext{
${ }^{30}$ CHUNG, J. H.; CONSOLAZIO, G. R. Numerical modeling of transport phenomena in reinforced concrete exposed to elevated temperatures. Cement \& Concrete Research, 42, p. 597-608, 2005.

${ }^{31}$ KODUR, V. K. R.; BISBY, L. A. Evaluation of fire endurance of concrete slabs reinforced with FRP bars. Journal of Structural Engineering, ASCE, 131, p. 34-43, 2005.

${ }^{32}$ ABBASI, A.; HOGG, P. J. Temperature and environmental effects on glasss fiber rebar: modulus, strength and interfacial bond strength with concrete. Composites Part B: Engineering, 36, p. 394-404, 2005.
} 
plastic, FRP) sob temperaturas elevadas. A maioria dos ensaios indicou que cobrimento suficiente pode garantir resistência ao fogo adequada para elementos de concreto com FRP (KODUR e BISBY ${ }^{33}$, 2005 apud FLETCHER et al., 2007; ABBASI e HOGG ${ }^{34}, 2006$ apud FLETCHER et al., 2007). O uso de FRP colado externamente também pode ser utilizado para reforçar estruturas existentes, sendo que neste caso deve ser previsto algum material de proteção contra incêndio.

\subsubsection{Propriedades térmicas}

Com o aumento da temperatura, a condutividade térmica diminui e o calor específico sofre ligeiro aumento. Em estruturas de concreto armado, essas variações não são significativas na maioria das vezes, uma vez que a taxa de armadura numa seção transversal é baixa a ponto de não influenciar a distribuição de temperaturas. Uma exceção ocorre no pico da curva de calor específico do aço, observada em torno de $735^{\circ} \mathrm{C}$ e que pode atrasar ligeiramente o aumento de temperatura das barras de aço. Isso só é válido se ainda há estabilidade para uma temperatura tão elevada quanto esta (FIB, 2008).

\subsubsection{Curva tensão-deformação}

A curva tensão-deformação para o aço da armadura passiva é apresentada no item 3.2.3 do Eurocode 2 (EN 1992-1-2:2004), conforme mostra a eq. (41).

$$
\begin{aligned}
& \sigma_{s}(\theta)=\varepsilon \cdot E_{s, \theta} \quad \varepsilon \leq \varepsilon_{\mathrm{sp}, \theta} \\
& \sigma_{s}(\theta)=f_{s p, \theta}-c+(b / a) \cdot\left[a^{2}-\left(\varepsilon_{s y, \theta}-\varepsilon\right)^{2}\right]^{0,5} \quad \varepsilon_{\mathrm{sp}, \theta} \leq \varepsilon \leq \varepsilon_{\mathrm{sy}, \theta} \\
& \sigma_{s}(\theta)=f_{s y, \theta} \quad \varepsilon_{\mathrm{sy}, \theta} \leq \varepsilon \leq \varepsilon_{\mathrm{st}, \theta} \\
& \sigma_{s}(\theta)=f_{s y, \theta} \cdot\left[1-\left(\varepsilon-\varepsilon_{s t, \theta}\right) /\left(\varepsilon_{s u, \theta}-\varepsilon_{s t, \theta}\right)\right] \quad \varepsilon_{\mathrm{st}, \theta} \leq \varepsilon \leq \varepsilon_{\mathrm{su}, \theta}
\end{aligned}
$$

Os parâmetros $a, b$ e $c$ presentes na eq. (41) são explicitados na eq. (42).

\footnotetext{
${ }^{33}$ KODUR, V. K. R.; BISBY, L. A. Evaluation of fire endurance of concrete slabs reinforced with FRP bars. Journal of Structural Engineering, ASCE, 131, p. 34-43, 2005. Fire testing of concrete beams with fibre reinforced plastic rebar. Composites Part A: Applied Science \& Manufscturing, 37, p. 1142-1150, 2006.
} 


$$
\begin{aligned}
& a^{2}=\left(\varepsilon_{s y, \theta}-\varepsilon_{s p, \theta}\right) \cdot\left(\varepsilon_{s y, \theta}-\varepsilon_{s p, \theta}+c / E_{s, \theta}\right) \\
& b^{2}=c \cdot\left(\varepsilon_{s y, \theta}-\varepsilon_{s p, \theta}\right) \cdot E_{s, \theta}+c^{2} \\
& c=\frac{\left(f_{s y, \theta}-f_{s p, \theta}\right)^{2}}{\left(\varepsilon_{s y, \theta}-\varepsilon_{s p, \theta}\right) \cdot E_{s, \theta}-2 \cdot\left(f_{s y, \theta}-f_{s p, \theta}\right)}
\end{aligned}
$$

Onde:

$\sigma_{s}:$ tensão no aço;

$\varepsilon$ : deformação no aço;

$\varepsilon_{\mathrm{sp}, \theta}$ : deformação correspondente ao limite de proporcionalidade do aço, com $\varepsilon_{\mathrm{sp}, \theta}=\mathrm{f}_{\mathrm{sp}, \theta} / \mathrm{E}_{\mathrm{s}, \theta}$;

$\varepsilon_{\mathrm{sy}, \theta}$ : deformação correspondente à tensão de escoamento do aço, com $\varepsilon_{\mathrm{sy}, \theta}=0,02$;

$\varepsilon_{\mathrm{st}, \theta}$ : deformação correspondente ao fim do patamar de escoamento do aço, com $\varepsilon_{\mathrm{st}, \theta}=0,15$

$\varepsilon_{\mathrm{su}, \theta}:$ deformação última do aço, $\operatorname{com} \varepsilon_{\mathrm{su}, \theta}=0,20$;

$\mathrm{f}_{\mathrm{sp}, \theta}$ : tensão correspondente ao limite de proporcionalidade do aço, em função da temperatura;

$\mathrm{f}_{\mathrm{sy}, \theta}$ : tensão de escoamento do aço, em função da temperatura;

$\mathrm{E}_{\mathrm{s}, \theta}$ : módulo de elasticidade do aço, em função da temperatura.

Os valores dos parâmetros $\varepsilon_{\mathrm{sp}, \theta}, \varepsilon_{\mathrm{sy}, \theta}, \varepsilon_{\mathrm{st}, \theta}$ e $\varepsilon_{\mathrm{su}, \theta}$ apresentados anteriormente são dados pelo Eurocode 2 (EN 1992-1-2:2004), dependendo da classe de ductilidade do aço. Os valores dos parâmetros $\mathrm{f}_{\mathrm{sp}, \theta} / \mathrm{f}_{\mathrm{yk}}$ e $\mathrm{E}_{\mathrm{s}, \theta} / \mathrm{E}_{\mathrm{s}}$ são dados na tabela 3.2a da mesma norma.

A Figura 33 apresenta os diagramas tensão-deformação do aço sob temperaturas elevadas. Foram adotados os parâmetros $\varepsilon_{\mathrm{st}, \theta}=0,15$ e $\varepsilon_{\mathrm{su}, \theta}=0,20$, correspondentes aos aços de alta ductilidade CA 25/50. 


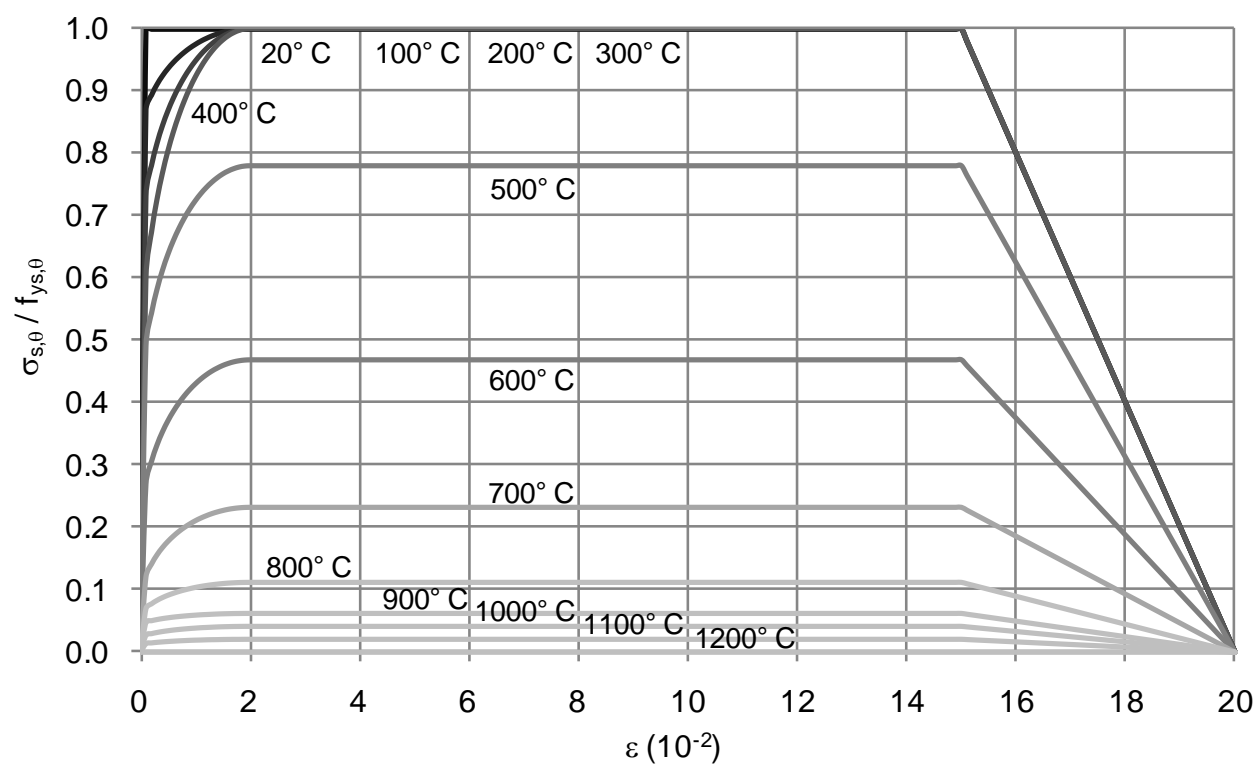

Figura 33 - Curva tensão-deformação de aços laminados a quente de alta ductilidade (CA 25/50) em função da temperatura (EN 1992-1-2:2004)

Os parâmetros da tabela 3.2 do Eurocode 2 (EN 1992-1-2:2004) podem ser adotados como uma aproximação suficiente em análises que utilizem curvas de incêndio natural. A mesma norma permite ainda a interpolação linear entre os parâmetros da tabela 3.2, para valores intermediários de temperatura. O Eurocode 2 (EN 1992-1-2:2004) disponibiliza também os parâmetros para aços trabalhados a frio (cold worked) e para aços de armaduras ativas.

\subsubsection{Deformação térmica linear específica}

A deformação térmica linear específica do aço $\varepsilon_{\mathrm{th}, \mathrm{s}}$ em função da temperatura é apresentada no item 3.4 do Eurocode 2 (EN 1992-1-2:2004), conforme mostra a eq. (43).

$$
\begin{array}{ll}
\varepsilon_{t h, s}(\theta)=-2,416 \times 10^{-4}+1,2 \times 10^{-5} \cdot \theta+0,4 \times 10^{-8} \cdot \theta^{2} & 20^{\circ} \mathrm{C} \leq \theta \leq 750^{\circ} \mathrm{C} \\
\varepsilon_{t h, s}(\theta)=11 \times 10^{-3} & 750^{\circ} \mathrm{C}<\theta \leq 860^{\circ} \mathrm{C} \\
\varepsilon_{t h, s}(\theta)=-6,2 \times 10^{-3}+2 \times 10^{-5} . \theta & 860^{\circ} \mathrm{C}<\theta \leq 1200^{\circ} \mathrm{C}
\end{array}
$$


Onde:

$\varepsilon_{\mathrm{th}, \mathrm{s}}:$ deformação térmica linear específica do concreto, em relação ao comprimento a $20^{\circ} \mathrm{C}$;

$\theta$ : temperatura do aço $\left[{ }^{\circ} \mathrm{C}\right]$.

As relações da eq. (43) são apresentadas graficamente na Figura 34.

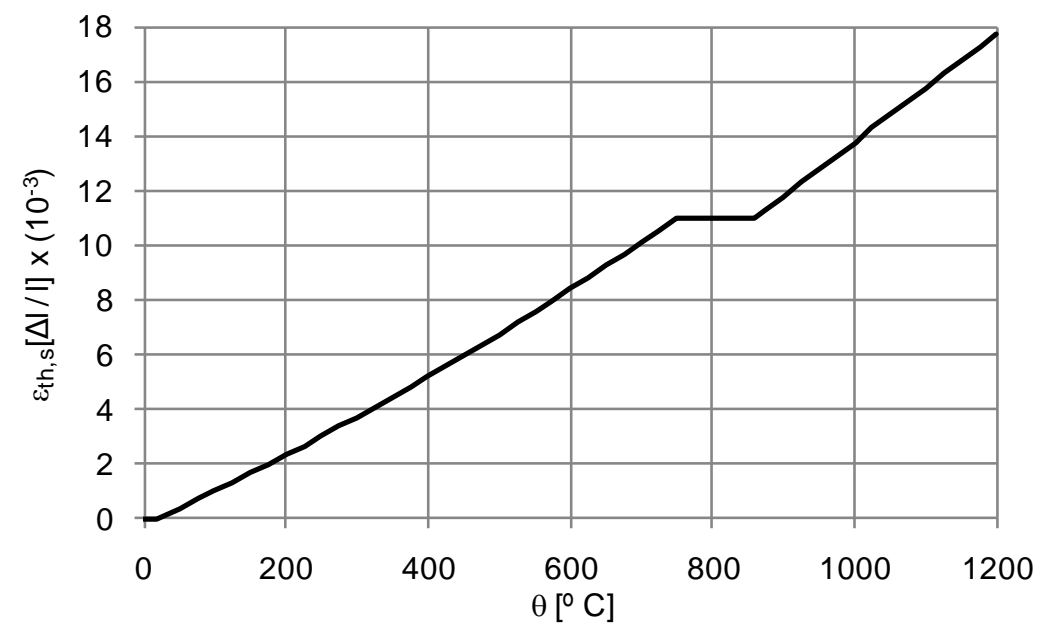

Figura 34 - Deformação térmica do aço $\varepsilon_{\mathrm{th}, s}$ em função da temperatura (EN 1992-1-2:2004)

\subsubsection{Deformação por fluência}

Williams-Leir $^{35}$ (1983 apud BRATINA et al., 2005) propôs o seguinte modelo para o cálculo da deformação por fluência do aço $\varepsilon_{\mathrm{cr}, \mathrm{s}}$ (eq.(44)).

$$
\dot{\varepsilon}_{c r, s}=\operatorname{sgn}\left(\sigma_{s}\right) \cdot b_{1} \cdot \operatorname{coth}^{2}\left(b_{2} \cdot\left|\varepsilon_{c r, s}\right|\right)
$$

Onde:

$\varepsilon_{\text {cr,s: }}:$ deformação por fluência do aço;

$\sigma_{\mathrm{s}}:$ tensão no aço $\left[\mathrm{N} / \mathrm{m}^{2}\right]$;

$b_{1}$ e $b_{2}$ : parâmetros do material, função da temperatura e da tensão no aço.

${ }^{35}$ WILLIAMS-LEIR, G. Creep of structural steel in fire: analytical expressions. Fire and materials 7 (2), p.73-78, 1983. 
A eq. (44) é uma equação diferencial que, devido à sua complexidade, deve ser resolvida numericamente. Os parâmetros $b_{1}$ e $b_{2}$ são dados no artigo original de WilliamsLeir $^{14}$ (1983 apud BRATINA et al., 2005).

Witteveen et al. ${ }^{36}$ (1977 apud ZHA, 2003) sugeriu uma curva tensão-deformação que inclui os efeitos da fluência sob temperaturas elevadas, obtidas à partir de experimentos com taxas de aquecimento semelhantes a um incêndio real. Essa curva tensão-deformação é expressa pela eq. (45).

$$
\begin{array}{ll}
\sigma_{s}=E_{s}(\theta) \cdot \varepsilon_{s} & \text { para } \varepsilon_{\mathrm{s}} \leq \varepsilon_{\mathrm{sp}} \\
\sigma_{s}=E_{s}(\theta) \cdot \varepsilon_{s p}+\alpha E_{s}(\theta) \cdot\left(\varepsilon_{s}-\varepsilon_{s p}\right) & \text { para } \varepsilon_{\mathrm{s}}>\varepsilon_{\mathrm{sp}}
\end{array}
$$

Onde:

$\sigma_{\mathrm{s}}:$ tensão no aço $\left[\mathrm{N} / \mathrm{m}^{2}\right]$;

$\mathrm{E}_{\mathrm{s}}(\theta)$ : módulo de elasticidade do aço em função da temperatura $\left[\mathrm{N} / \mathrm{m}^{2}\right]$;

$\varepsilon_{\mathrm{s}}$ : deformação do aço;

$\varepsilon_{\mathrm{sp}}$ : deformação do aço correspondente ao limite de proporcionalidade;

$\alpha$ : coeficiente redutor igual a 0,005 .

A deformação $\varepsilon_{\mathrm{sp}}$ é definida pela eq. (46).

$$
\varepsilon_{s p}=0,84 \cdot \frac{\sigma_{s y 0}}{E_{s 0}}
$$

Onde:

$\sigma_{\mathrm{sy} 0}$ : tensão no aço à temperatura ambiente $\left[\mathrm{N} / \mathrm{m}^{2}\right]$;

$\mathrm{E}_{\mathrm{s} 0}$ : módulo de elasticidade do aço à temperatura ambiente $\left[\mathrm{N} / \mathrm{m}^{2}\right]$.

O módulo de elasticidade do aço em função da temperatura é definido pela eq. (47).

$$
E_{s}(\theta)=\left(1,64-\frac{\theta}{761}\right) \cdot\left[1-\exp \left(\frac{\theta}{1054}-0,95\right)\right] \cdot E_{s 0}
$$

${ }^{36}$ WITTEVEEN, J. et al. The stability of braced and unbraced frames at elevated temperatures. Second International Colloquium Strength, Liège, Bélgica, 1977. 
O coeficiente de Poisson para o aço pode ser assumido constante, com valor igual a 0,28, assim como o coeficiente de expansão térmica, que pode ser assumido com valor constante de $1,4 \times 10^{-5}\left[{ }^{\circ} \mathrm{C}^{-1}\right]$ (WITTEVEEN et al. ${ }^{37}, 1977$ apud ZHA, 2003).

${ }^{37}$ WITTEVEEN, J. et al. The stability of braced and unbraced frames at elevated temperatures. Second International Colloquium Strength, Liège, Bélgica, 1977. 


\section{ANÁLISE ESTRUTURAL}

O Eurocode 2 (EN 1992-1-2:2004), no item 2.4.1, afirma que a análise de elementos isolados é suficiente para a verificação de estruturas em situação de incêndio. A verificação consiste em comparar os esforços solicitantes com os esforços resistentes em situação de incêndio, sendo os últimos calculados com métodos avançados, simplificados ou tabulares.

Os esforços solicitantes em situação de incêndio são calculados a partir dos esforços à temperatura ambiente, aplicando-se uma combinação de carregamentos e fatores de redução dados pelas normas técnicas. Ou seja, as ações indiretas na estrutura que surgem devido às expansões térmicas podem ser desconsideradas. Para a análise de elementos isolados, o Eurocode 2 (EN 1992-1-2:2004) permite desconsiderar os efeitos da expansão térmica axial dos elementos, exigindo apenas considerar as deformações térmicas devido aos gradientes térmicos na seção transversal. A mesma norma orienta ainda que as condições de contorno dos elementos nos seus apoios podem ser assumidas iguais às condições à temperatura ambiente $(\mathrm{t}=0)$.

Diversos estudos, incluindo esta dissertação, preocupam-se com a modelagem de pilares em situação de incêndio, mas tratando-os como elementos individuais. Embora a análise de elementos individuais seja importante para a compreensão de diversos fenômenos, o comportamento dos mesmos elementos como parte de uma estrutura completa pode divergir completamente da sua resposta independente. Por isso, alguns aspectos do comportamento de estruturas em situação de incêndio, observados em modelos numéricos ou em casos de incêndios reais, são discutidos a seguir.

Em vigas de concreto com extremidades engastadas, os gradientes térmicos induzem momentos fletores que geram tração na face oposta à face aquecida. Esses momentos, em certos casos, poderiam antecipar a ruptura da viga nas extremidades. Além disso, vigas com restrição à deformação axial são submetidas ao esforço axial induzido pelo aquecimento que, combinado às deflexões em situação de incêndio, pode antecipar o colapso do elemento devido aos esforços adicionais (não linearidade geométrica) (FIB, 2008).

Em pórticos em situação de incêndio, a interação entre vigas e pilares pode induzir esforços axiais nas vigas devido à expansão térmica. Esses esforços nas vigas podem gerar esforços cortantes significativos nos pilares e provocar sua ruptura por cisalhamento, como já foi observado em diversos incêndios reais, conforme ilustrado pela Figura 35 e Figura 36. 


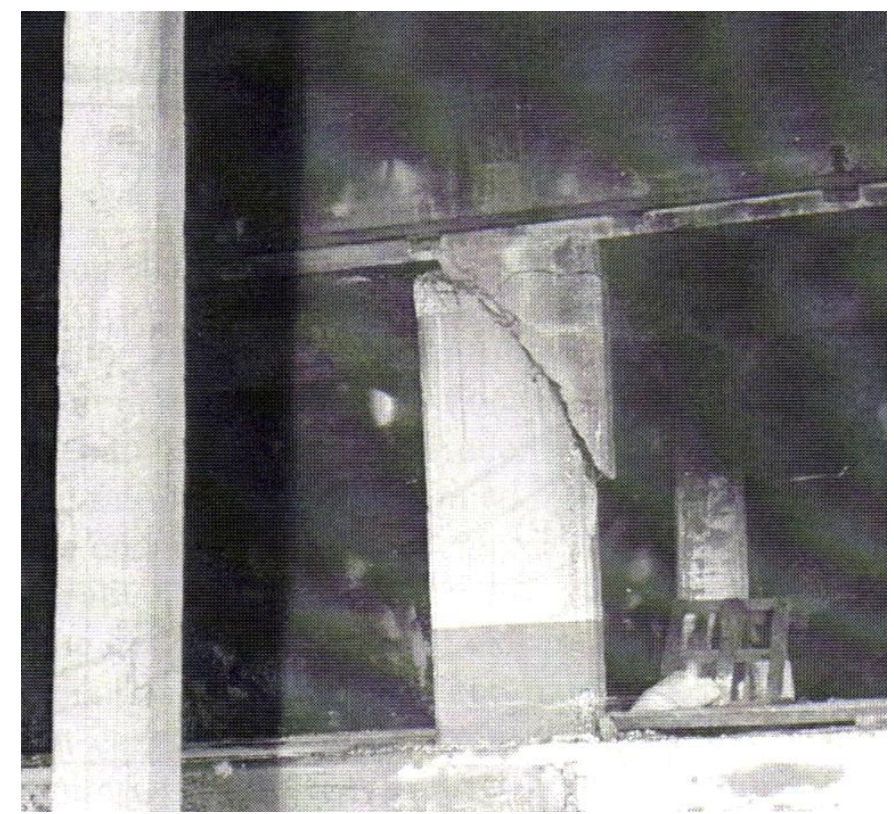

Figura 35 - Ruptura em pilar devido ao esforço cortante durante incêndio num depósito em Ghent, Bélgica, em 1974 (FIB, 2008)

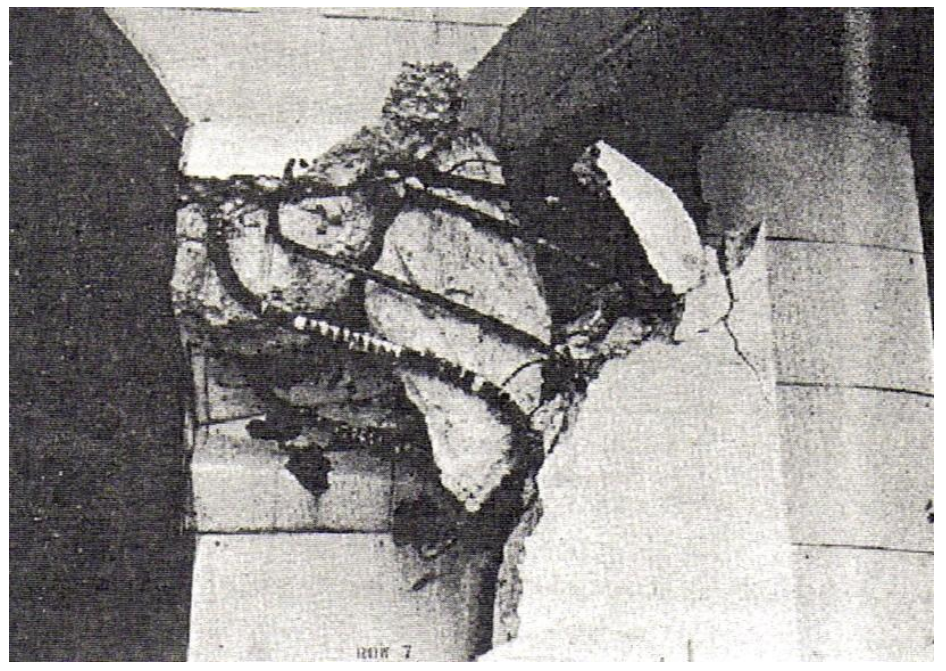

Figura 36 - Ruptura em pilar devido ao esforço cortante, devido somente à expansão térmica do piso superior, o pilar não foi exposto diretamente ao fogo (BEITEL e IWANKIW, 2002)

Para permitir melhores avaliações do problema, o Eurocode 2 (EN 1992-1-2:2004) sugere análise de partes da estrutura ou mesmo da estrutura completa em situação de incêndio.

O Boletim 46 do fib (FIB, 2008) apresenta os resultados de um estudo numérico do comportamento de vigas e pórticos de concreto em situação de incêndio, feito pelo pesquisador Paolo Riva (2005). A Figura 37 mostra um pórtico bidimensional estudado por Riva (2005), considerando a viga aquecida em três faces e os pilares aquecidos em somente uma face. 

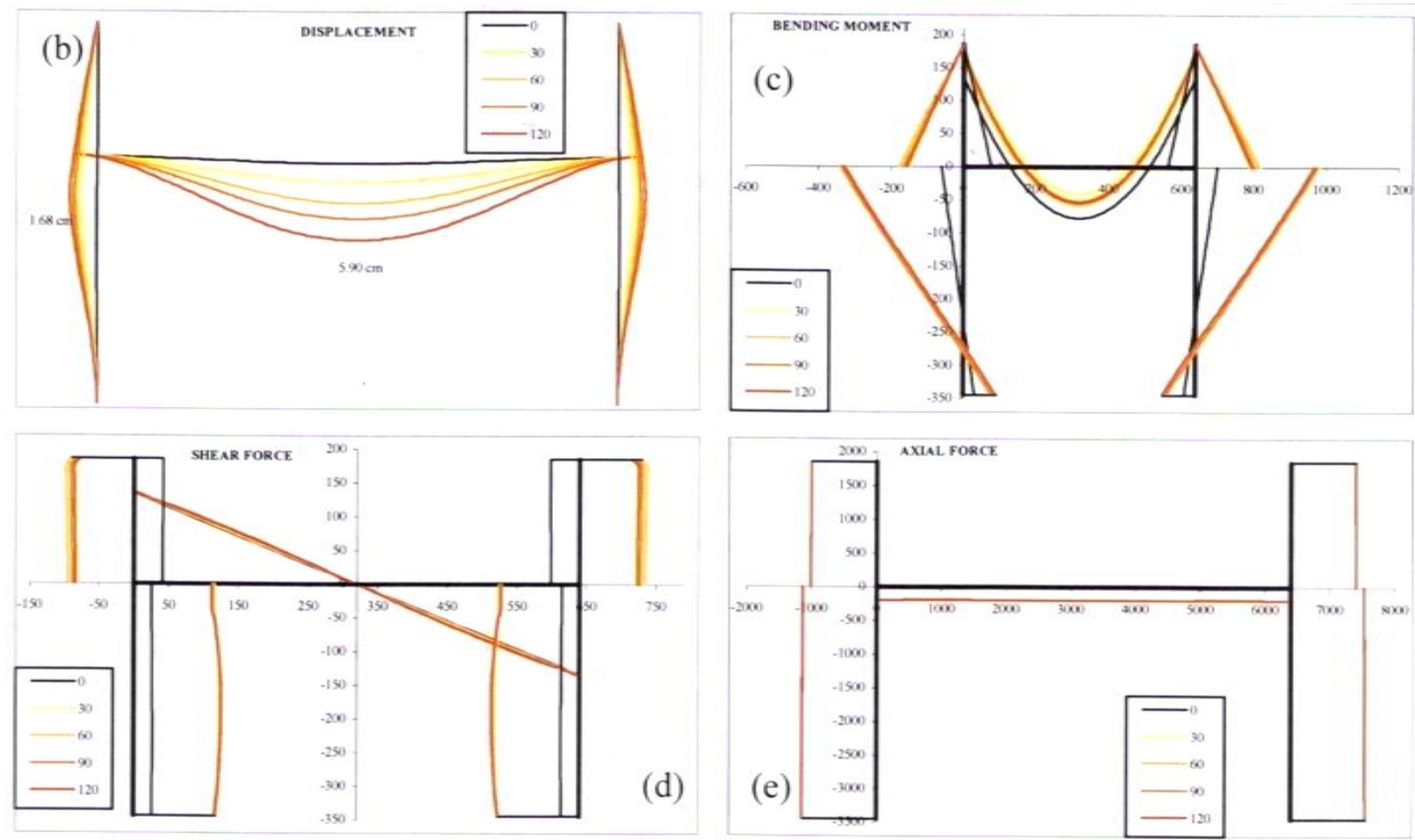

Figura 37 - Exemplo dos efeitos do aquecimento em pórtico de concreto armado analisado numericamente (RIVA, 2005). (a) Deslocamentos, (b) momentos fletores, (c) esforços cortantes e (d) esforços axiais

Entre os resultados observados na simulação do pórtico bidimensional da Figura 37 estão:

- os esforços cortantes e momentos fletores nos pilares aumentam consideravelmente nos primeiros 30 minutos do incêndio, por causa da expansão térmica da viga. Após 30 minutos, os esforços pouco aumentam, devido à degradação das propriedades da viga;

- nos pilares inferiores, foi observado aumento de aproximadamente sete vezes nos momentos fletores nos primeiros 30 minutos de incêndio, em relação aos momentos à temperatura ambiente. Nos pilares superiores, os momentos fletores mudam de sinal e seus valores mais que dobram em relação aos valores à temperatura ambiente;

- os esforços cortantes nos pilares inferiores correspondem a aproximadamente quatro vezes os valores à temperatura ambiente. Como consequência, um pilar com pouca armadura transversal pode apresentar falha prematura devido ao esforço cortante, como observado frequentemente em cenários de incêndios reais. 
Foi simulado também um pórtico igual ao anterior, mas com os pilares aquecidos em três faces. Os esforços induzidos pelas expansões térmicas resultaram menores, devido aos menores gradientes térmicos nos pilares.

Riva (2005) afirma que os efeitos do aquecimento nos esforços cortantes e momentos fletores nos pilares dependem também do tipo de fundação da edificação. Por exemplo, uma fundação composta por sapatas isoladas apresenta menor rigidez rotacional do que fundações de blocos sobre estacas. Consequentemente, os esforços em situação de incêndio seriam menores para a fundação composta por sapatas isoladas (FIB, 2008).

Em fase de projeto, as regras de detalhamento adotadas em estruturas sujeitas a sismos podem ser benéficas para estruturas em situação de incêndio. Um dos critérios diz respeito ao menor espaçamento entre estribos do pilar, o que aumenta sua resistência e ductilidade à flexocompressão além de colaborar no controle do spalling (KODUR et al., 2004).

Diversas questões ainda estão em aberto em relação ao comportamento da estrutura como um todo e situação de incêndio. Uma das dúvidas é em relação às curvas que representam o incêndio, pois os estudos são feitos considerando o incêndio-padrão na maioria dos casos. Mas cenários de incêndios reais podem ser bastante diferentes. A taxa de aquecimento inicial pode ser maior e há a fase de resfriamento, sendo que ambas as características podem induzir deformações e tensões adicionais às estruturas, especialmente aquelas com alto grau de hiperestaticidade (FLETCHER et al., 2007). Sendo assim, são necessários estudos mais aprofundados para verificar a segurança dos cálculos quando se utiliza curvas de incêndio-padrão.

A modelagem computacional de estruturas em situação de incêndio é bastante complexa, pois se deve considerar a interação entre os diversos elementos estruturais, o impacto de fenômenos microscópicos na estrutura e a variação espacial e temporal da exposição ao fogo, incluindo a fase de resfriamento. Já houve avanços na questão da modelagem de efeitos termomecânicos, mas o tratamento de fenômenos complexos, como os efeitos higrotérmicos e o spalling, ainda carecem de estudos conclusivos (FLETCHER et al., 2007).

Na prática, o colapso de uma estrutura em situação de incêndio é uma combinação de fatores e características da própria estrutura (restrições, vinculações entre os elementos, etc.) e esses tais fatores não podem ser considerados isoladamente. Casos reais de colapso de estruturas em situação de incêndio já foram atribuídos a falhas na continuidade das armaduras, falhas na execução, incapacidade da estrutura de resistir aos grandes 
deslocamentos horizontais devido à expansão térmica das lajes ou simplesmente perda do cobrimento das armaduras devido ao spalling (BAILEY, 2002).

Benmarce e Guenfoud (2005) estudaram as condições de contorno de pilares e os efeitos do aquecimento em elementos de concreto, tentando se aproximar dos efeitos observados na estrutura como um todo. Isso é importante, pois é fundamental compreender o papel de um elemento estrutural como parte de uma estrutura completa e investigar os esforços que esse elemento exerce no restante da estrutura durante um incêndio. Os testes mostraram que os esforços adicionais nos pilares foram relativamente baixos, da ordem de $15 \%$ da capacidade de carga dos pilares à temperatura ambiente. Os pilares testados possuíam seção transversal de $12,5 \mathrm{~cm} \times 12,5 \mathrm{~cm}$, altura de $1,80 \mathrm{~m}$ e foi utilizado concreto com resistência de $108 \mathrm{MPa}$. Essas dimensões são pequenas em se tratando de estruturas de concreto armado, além da resistência do concreto utilizado não ser tão freqüente em obras convencionais. Embora os resultados sejam interessantes, até mesmo pelo pioneirismo do estudo, não há certeza sobre a possibilidade de estendê-los a elementos de dimensões diferentes e/ou feitos com concreto de resistência normal. Os autores do estudo concluíram que mais estudos são necessários nessa área.

Martins e Rodrigues (2010) realizaram ensaios em laboratório e utilizaram simulações numéricas para estudar os efeitos das restrições impostas pela estrutura no comportamento de pilares de concreto armado em situação de incêndio. Foram testados diversos níveis de restrição. Conforme esperado, quanto maior a rigidez da estrutura conectada ao pilar, maiores são os esforços devidos às restrições à deformação axial e rotacional nos apoios. No entanto, os autores constataram apenas pequena redução no TRF para maiores níveis de restrição. Essa redução não foi maior porque, nesse ensaio, as restrições às deformações axial e rotacional aumentaram juntas. $\mathrm{O}$ aumento da restrição à deformação axial colabora para a redução do TRF, enquanto que o aumento da restrição rotacional colabora para o aumento do TRF.

Lie e Lin (1985) reportaram o ensaio de dois pilares com restrição total à deformação axial (pilares de rótulo II2 e II3 da Tabela 11). A expansão térmica do pilar foi continuamente compensada por aumento da carga aplicada. Embora a carga aplicada tenha atingido o dobro da carga inicial, devido à compensação, não foi constatada alteração significativa no TRF dos pilares ensaiados. Os autores afirmam, inclusive, que os efeitos das restrições às deformações térmicas dos pilares em situação de incêndio podem ser benéficos, caso o restante da estrutura possa redistribuir parte das cargas para outros pilares.

Uma questão importante é a ductilidade dos pilares. Pilares com baixa ductilidade podem ter sua capacidade resistente seriamente diminuída em situações excepcionais, como 
terremotos ou outros impactos violentos. Tais situações são, em muitos casos, seguidas de incêndios. Ensaios experimentais de pilares à temperatura ambiente mostraram aumento da ductilidade de pilares quando se adota menores espaçamentos entre estribos. Por outro lado, a resistência dos mesmos pilares praticamente não foi influenciada pelos diferentes espaçamentos (NĚMECĚK, PADEVĚT e BITTNAR, 2004). Assim, o uso de menores espaçamentos entre estribos pode ser benéfico para pilares em situações excepcionais, tanto à temperatura ambiente quanto em situação de incêndio.

O maior estudo já realizado sobre o comportamento da estrutura como um todo foi realizado em Cardington, Inglaterra, pelo Building Research Establishment (BRE). Um edifício de concreto armado de sete andares, em escala real, foi construído no interior de um hangar desativado (Figura 38). O edifício foi projetado para TRRF de 60 minutos, segundo o Eurocode 2 (EN 1992-1-2:2004). O combustível, composto por madeira, foi adotado de forma a representar a carga de incêndio de um típico edifício comercial de escritórios (Figura 39).

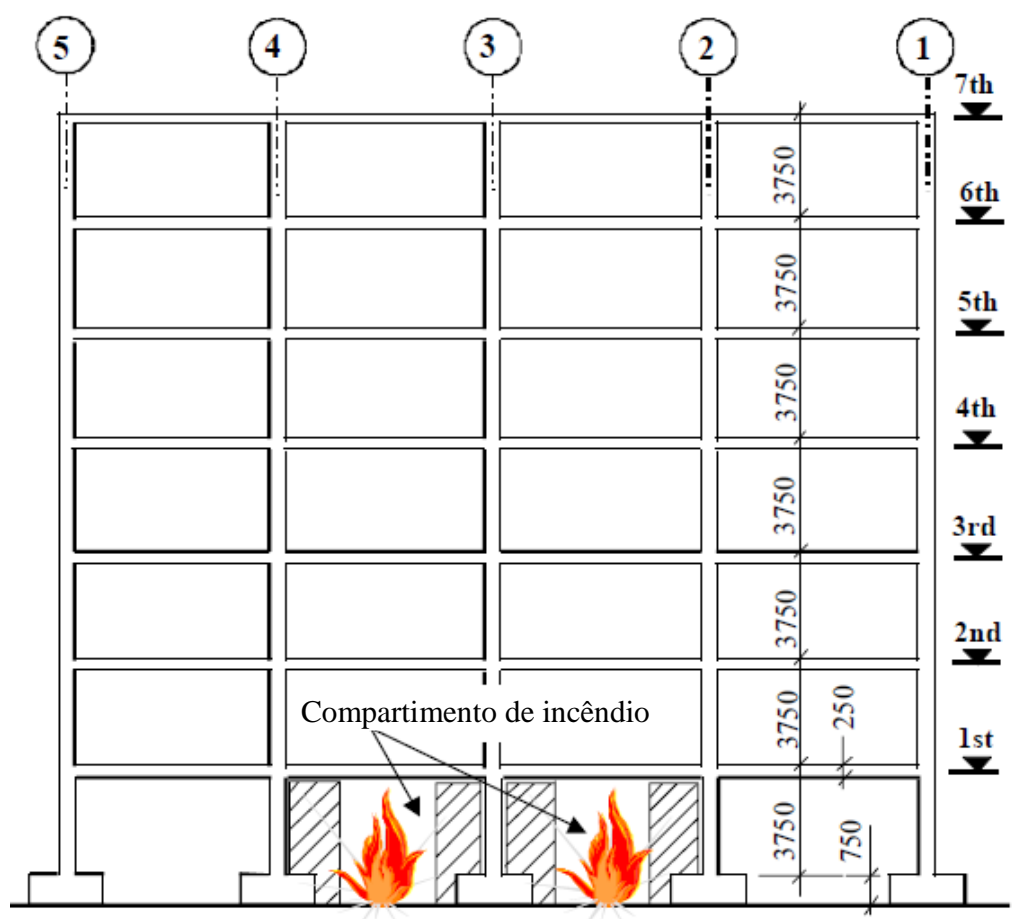

Figura 38 - Representação esquemática do edifício ensaiado em Cardington (BAILEY, 2002) 


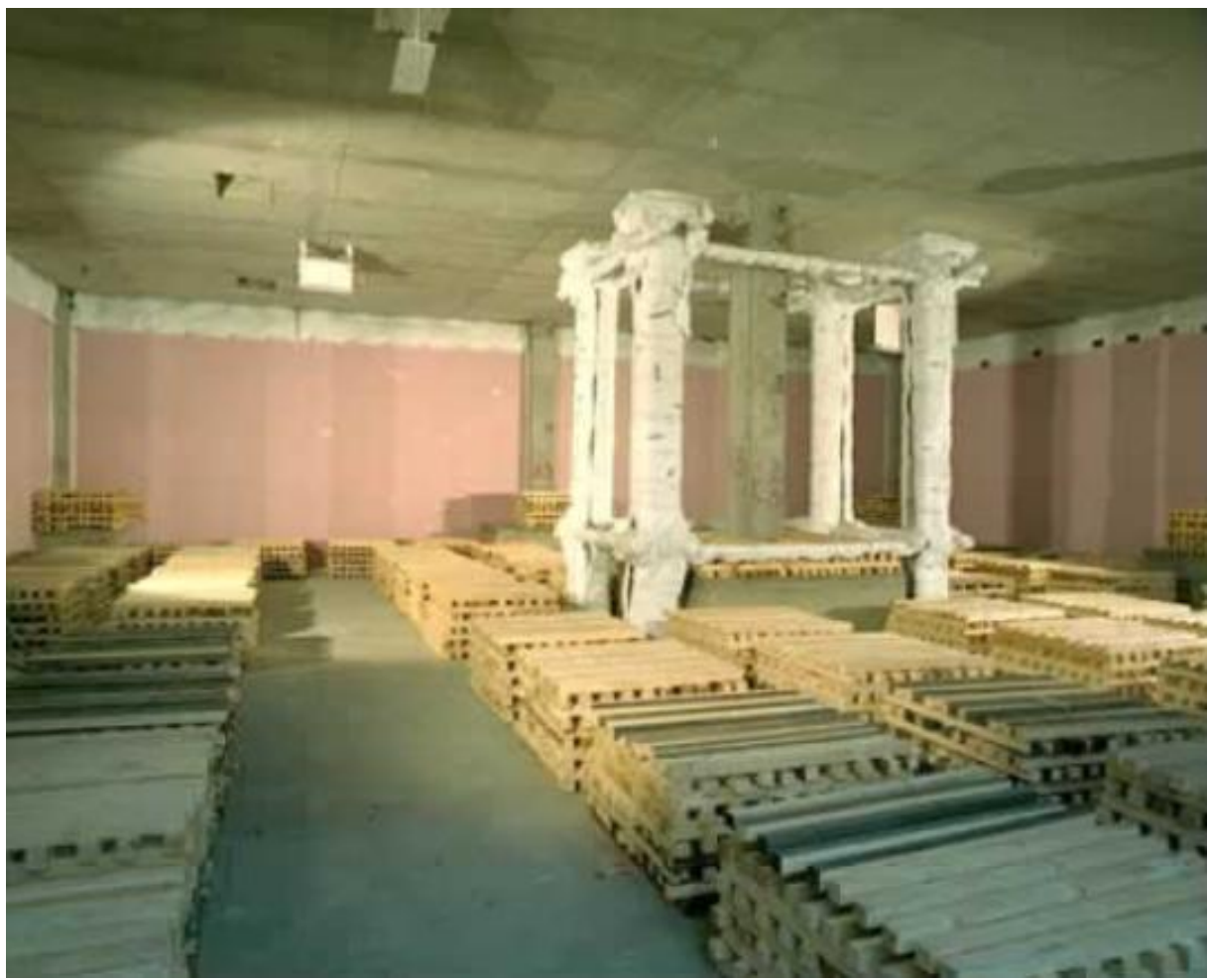

Figura 39 - Compartimento de incêndio antes do ensaio (BAILEY, 2002)

O ensaio consistiu em criar um incêndio, em um compartimento no piso térreo, em torno de um pilar feito com concreto de alta resistência. A exposição ao fogo não foi muito severa, mas serviu para indicar que o pilar se comportou muito bem, com poucos danos visíveis na sua superfície. O concreto do pilar possuía fibras de polipropileno na sua composição, que muito provavelmente contribuíram para esse desempenho. Entretanto, a laje do teto do compartimento, feita com concreto de resistência normal, apresentou spalling bastante intenso (Figura 40). Mesmo assim a laje não apresentou colapso, principalmente devido ao efeito compressivo de membrana, uma vez que a expansão térmica da laje estava restringida pela presença de outras partes da estrutura ainda relativamente frias. Esse efeito compressivo de membrana se manifesta para deslocamentos relativamente pequenos. Quando se considera grandes deslocamentos, o efeito de membrana à tração também pode suportar uma laje, desde que as barras de aço tenham resistência para tal. No caso do ensaio de Cardington, o spalling severo expôs as barras às altas temperaturas do incêndio, diminuindo sua resistência significativamente, portanto não se sabe como seria o comportamento daquela laje submetida a grandes deslocamentos (BAILEY, 2002). 


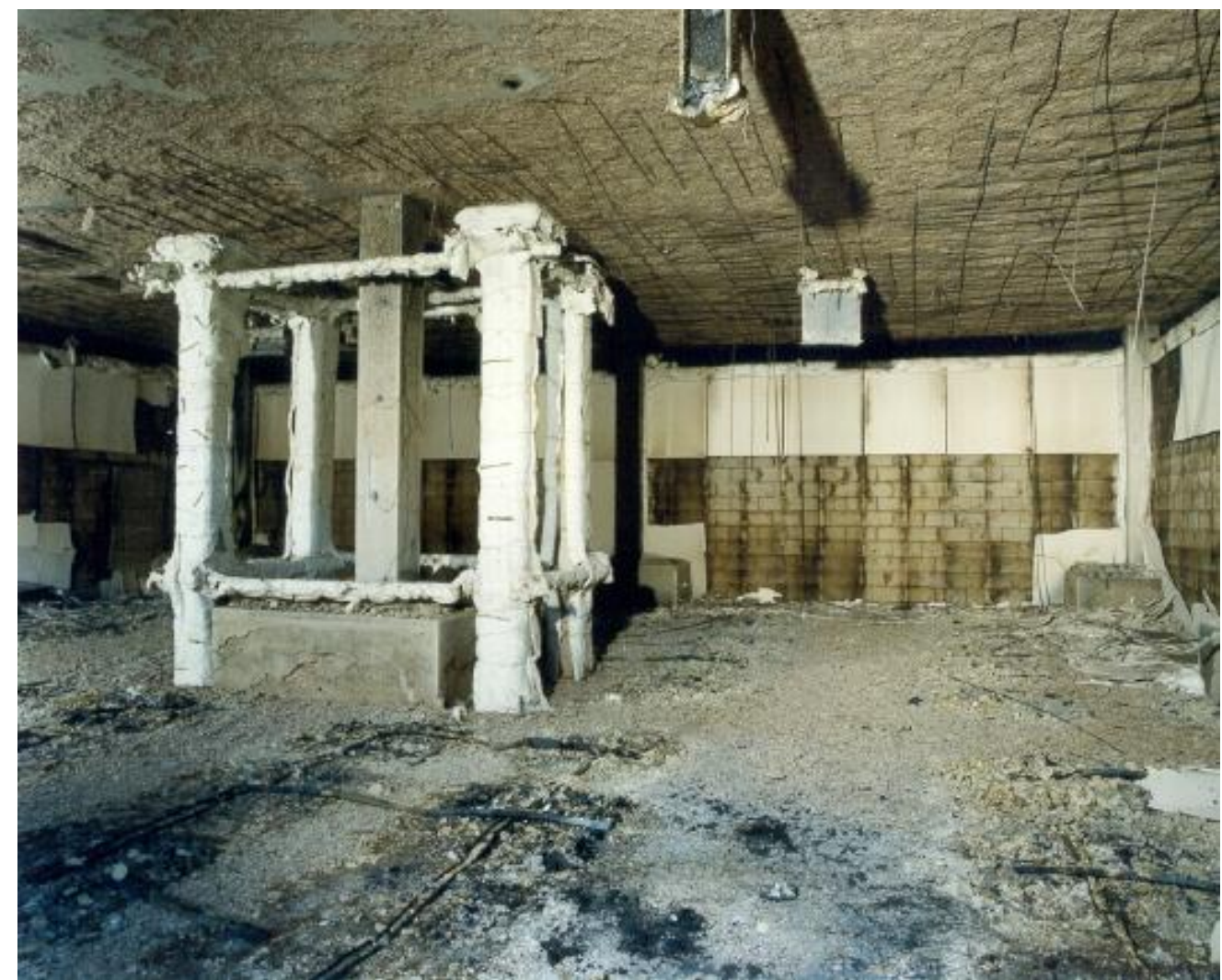

Figura 40 - Compartimento de incêndio após o ensaio (BAILEY, 2002)

A expansão térmica das lajes do teto do compartimento de incêndio foi significativa. No ensaio de Cardington, os pilares externos foram capazes de acomodar essas deformações, mas em outros casos de incêndios reais, a solicitação lateral nos pilares devido à expansão térmica das lajes foi a causa do colapso da estrutura. Observou-se também que a expansão térmicas das lajes foi irreversível após o resfriamento (BAILEY, 2002). 


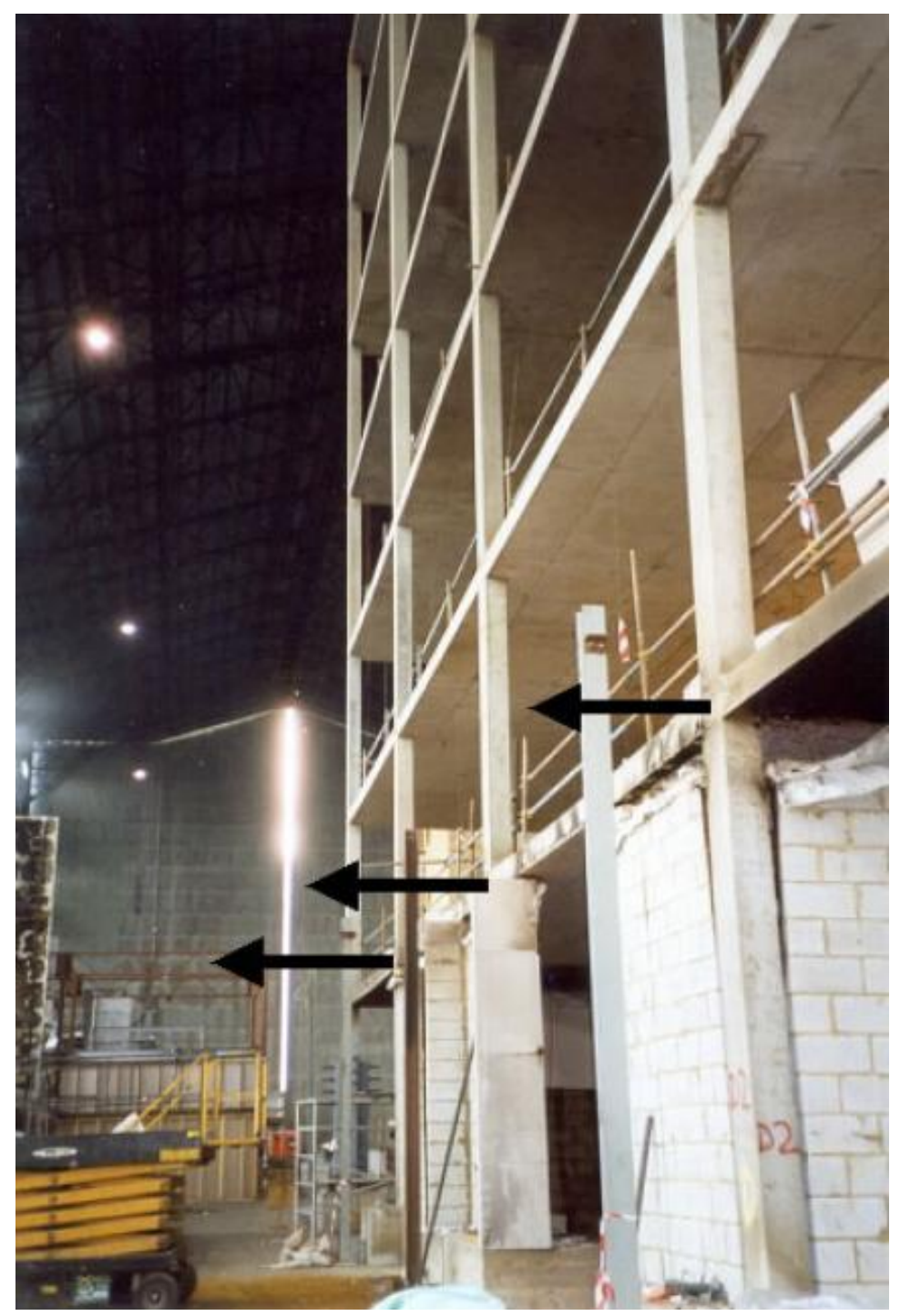

Figura 41 - Deslocamento lateral dos pilares externos devido à expansão térmica das lajes (BAILEY, 2002), que pode causar colapso prematuro das estruturas em situação de incêndio

Em simulações utilizando o programa Vulcan® (HUANG, BURGESS e PLANK, 2006), também foi detectado o mesmo comportamento de membrana das lajes observado nos ensaios de Cardington. Além disso, os pesquisadores notaram a tendência das vigas apresentaram esforços de tração significativos (nos primeiros 30 minutos de incêndio, os esforços de tração nas vigas podem triplicar em relação ao mesmo esforço à temperatura ambiente), dependendo obviamente das características do incêndio e das dimensões da seção transversal das vigas e lajes. Por fim, todas as simulações numéricas apresentaram colapso estrutural devido à instabilidade dos pilares. Os autores concluíram que prevenir o colapso dos pilares é essencial para a resistência da estrutura como um todo. Sendo assim, medidas de proteção são recomendáveis, especialmente contra o spalling. 
Os resultados do ensaio de Cardington foram utilizados em outras simulações com elementos finitos, que consideraram diversas hipóteses com respeito ao concreto em situação de incêndio (por exemplo, os efeitos do spalling foram desprezados) (CANISIUS, WALEED, MATTHEWS $^{38}, 2003$ apud FLETCHER et al., 2007). Mais estudos a respeito dos efeitos do fogo em estruturas completas seriam extremamente úteis.

Outras fontes de informação a respeito do comportamento de edifícios completos são os próprios incidentes de incêndios reais. Como exemplo, o incêndio da torre Windsor, em Madri (fevereiro de 2005) (CAPOTE et al. ${ }^{39}$, 2006 apud FLETCHER et al., 2007), entre outros incêndios que ocorreram ao redor do mundo. $\mathrm{O}$ principal desafio para compreender esses incidentes envolve a reprodução das condições reais no momento do incêndio. Nesses casos, ferramentas de modelagem avançada podem ser bastante úteis, aliadas a qualquer tipo de registro do incêndio, por exemplo, gravações em vídeo (FLETCHER et al., 2007).

Algumas formas de se obter melhor comportamento estrutural em situação de incêndio incluem a robustez da estrutura, continuidade das armaduras, redução do nível de carregamento e redistribuição de esforços quando há caminhos alternativos para as cargas. A continuidade das armaduras permite a redistribuição de esforços para as partes da estrutura com melhor resistência do que os elementos expostos ao fogo (FIB, 2007).

${ }^{38}$ CANISIUS, T. D. G.; WALEED, N.; MATTHEWS, S. L. Evaluation of effects of the fire test on Cardington concrete building. Proceedings, CIB Publication No. 290, Conference on Tall Buildings, p. 353360. Kuala Lumpur, Malásia, Outubro 2003.

${ }^{39}$ CAPOTE, J. A. et al. Analysis of thermal fields generated by natural fires on the structural elements of tall buildings. Proceedings. Intl. Cong. "Fire Safety in Tall Buildings", p. 93-109. Santander, Espanha, 2006. 


\section{AVALIAÇÃO DE ESTRUTURAS PÓS-INCÊNDIO}

A garantia da manutenção da capacidade portante de estruturas em situação de incêndio é fundamental para permitir a evacuação dos ocupantes da edificação e para as medidas de combate ao fogo. No entanto, como os incêndios possuem uma duração finita e, na maioria dos casos, as estruturas de concreto armado não apresentam colapso, deve-se avaliar a capacidade resistente residual das estruturas. Isso porque a decisão de demolir uma estrutura ou adotar medidas de reforço e recuperação são normalmente operações de alto custo (FIB, 2008).

As normas técnicas, até o presente momento, não trazem orientações sobre a avaliação de estruturas após uma situação de incêndio. Sendo assim, a avaliação da capacidade portante residual de estruturas de concreto envolve o conhecimento das propriedades residuais dos materiais, que são estimadas normalmente por meio de métodos de ensaio não destrutivos. Essa avaliação é importante, pois em alguns casos os elementos submetidos ao incêndio podem ter sofrido alterações nas suas propriedades mesmo sem apresentar danos visíveis na superfície.

\subsection{AÇO}

As propriedades dos aços (tanto os aços das armaduras passivas quanto os aços das armaduras ativas) quando aquecidos são razoavelmente bem conhecidas. No entanto, as suas propriedades residuais após o aquecimento foram até o momento pouco estudadas.

As possíveis explicações são que as propriedades dos aços laminados a quente (comumente utilizados nas armaduras passivas) são praticamente totalmente recuperadas após um ciclo de aquecimento a $500^{\circ} \mathrm{C}$, e perdem de 20 a $30 \%$ dos seus valores originais após um ciclo de aquecimento de $650-850^{\circ} \mathrm{C}$. Mesmo após o aquecimento, os aços laminados a quente ainda apresentam uma fase de escoamento bem definida (FIB, 2008).

Para aços das armaduras ativas, a perda de resistência sob temperaturas elevadas (acima de $550^{\circ} \mathrm{C}$ ) é elevada. Provavelmente a recuperação da sua resistência seria de pouca valia, pois a redução dos esforços de protensão durante o incêndio é tal que resulta em grandes danos à estrutura (FIB, 2008). 
Recentemente, Felicetti, Gambarova e Meda (2009) investigaram experimentalmente as propriedades residuais de barras de aço laminadas a quente após um ciclo de aquecimento. Os corpos de prova foram aquecidos até 200, 400, 550, 700 e $850^{\circ} \mathrm{C}$, após isso foram armazenados à temperatura ambiente por um período entre 90 e 120 dias. As barras que foram aquecidas acima de $550^{\circ} \mathrm{C}$ apresentaram queda significativa da resistência ao escoamento e resistência última (40-45\% e 30\%, respectivamente, para barras aquecidas até $850^{\circ} \mathrm{C}$ ).

\subsection{CONCRETO}

As propriedades residuais do concreto após um ciclo de aquecimento foram muito estudadas no passado, porque durante muitos anos os efeitos do aquecimento no concreto foram medidos em corpos de prova após o resfriamento. Ensaios desse tipo são muito mais simples de serem feitos se comparados aos ensaios envolvendo corpos de prova aquecidos. As principais propriedades estudadas foram: (a) resistência à compressão e à tração residual; (b) módulo de elasticidade residual; (c) recuperação da resistência; (d) deformação residual. Pesquisas recentes avaliaram também as propriedades relacionadas à fratura do concreto (FIB, 2008).

O Boletim 46 do fib (FIB, 2008) reuniu os principais resultados dos estudos sobre as propriedades residuais do concreto após um ciclo de aquecimento e as apresenta em detalhes, sendo alguns pontos relevantes discutidos nos parágrafos a seguir.

A maioria das alterações nas propriedades do concreto aquecido resulta das alterações físico-químicas, como evaporação da água da pasta de cimento e dos agregados, transformações na estrutura cristalina dos agregados à base de quartzo, dissociação do hidróxido de cálcio e descarbonatação dos agregados calcários. Esses efeitos, combinados à deformação diferencial da pasta de cimento e agregados, provocam microfissuração e degradação da microestrutura do concreto.

$\mathrm{Na}$ fase de resfriamento, poucos são os fatores que afetam as propriedades do concreto. Como a LITS não está mais presente (para mitigar os efeitos da incompatibilidade das deformações da pasta de cimento e agregados), ocorre ainda degradação das propriedades do concreto durante o resfriamento. A reidratação parcial da pasta de cimento após o resfriamento tem dois efeitos conflitantes: queda da resistência do concreto em curto prazo (um a dois meses) por causa da formação de hidróxido de cálcio a partir do calcário, com aumento de volume, e recuperação da resistência (que em alguns casos chega a ser total) em 
relação à resistência original, em longo prazo (um a dois anos após o resfriamento), por causa da reidratação do gel e dos grãos de cimento ainda não hidratados. A perda de resistência inicial também possuem uma natureza “estrutural”, uma vez que a absorção de umidade provoca expansão do concreto nas camadas mais externas, que são restringidas pelas camadas mais internas, resultando em tensões de compressão paralelas à superfície nas camadas externas e tensões de tração no núcleo do elemento estrutural (KHOURY ${ }^{40}, 1992$ apud FIB, 2008). Observou-se que a perda e recuperação da resistência são mais intensas nos concretos de resistência normal do que nos concretos de alta resistência, conforme mostra a Figura 42 (FELICETTI; GAMBAROVA, 1998 apud FIB, 2008).

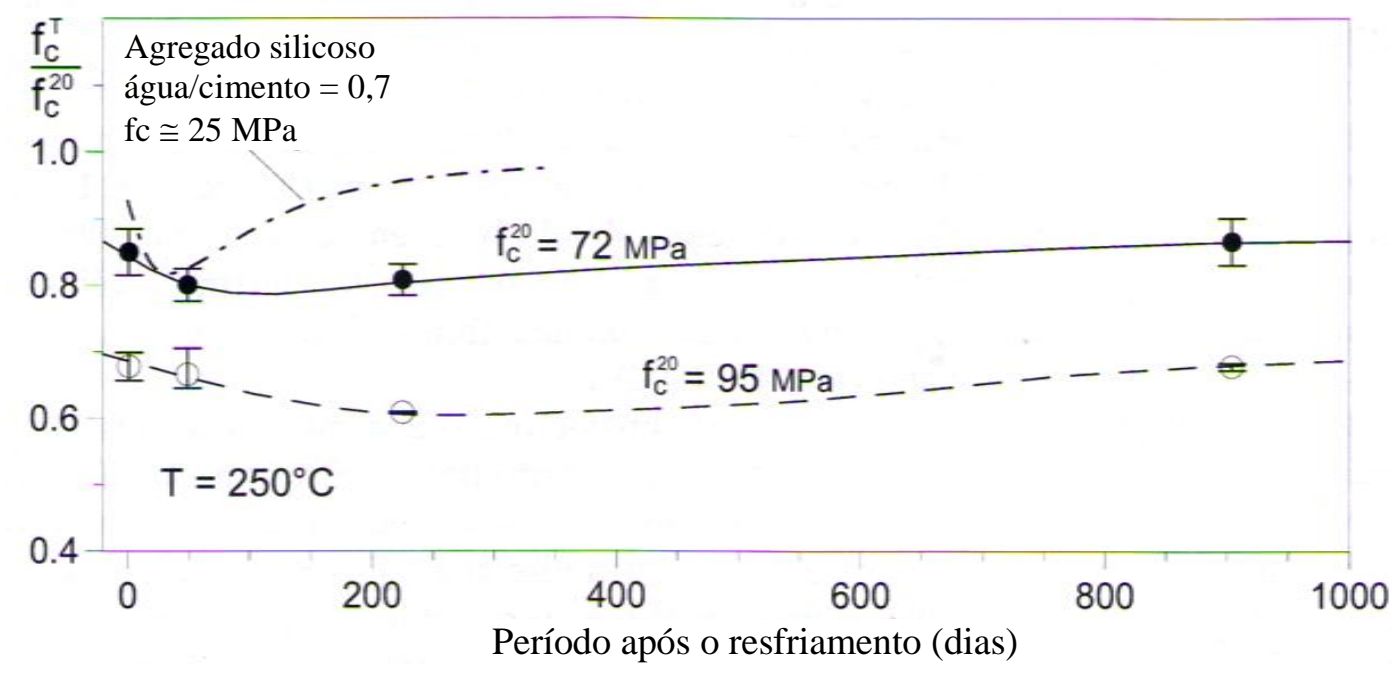

Figura 42 - Recuperação da resistência do concreto após um ciclo de aquecimento a $250^{\circ} \mathrm{C}$, em função do tempo decorrido a partir do resfriamento

Como uma primeira aproximação, as curvas tensão-deformação residual do concreto sob compressão podem ser obtidas a partir da curva proposta pelo Eurocode 2 (EN 1992-12:2004), mas considerando redução de 15 a 20\% na tensão de pico do concreto (FIB, 2008).

O Boletim 46 do fib (FIB, 2008) afirma que recuperação da resistência original do concreto pode ocorrer no período de 6 a 18 meses após o resfriamento.

Algumas pesquisas indicaram que o concreto com adição de fibras de aço pode apresentar melhores propriedades mecânicas residuais após o resfriamento. As melhoras são mais significativas para a resistência à flexão do que para a resistência à compressão dos elementos. A ductilidade residual é mantida, mesmo após vários ciclos de aquecimentoresfriamento (PLIYA, BEAUCOUR e NOUMOWÉ, 2010).

${ }^{40}$ KHOURY, G. A. Compressive strength of concrete at high temperatures: a reassessment. Magazine of Concrete Research 44, p. 291-309, 1992. 


\subsection{ENSAIOS NÃO DESTRUTIVOS}

Para permitir a avaliação dos danos aos materiais após um evento de incêndio, podem ser utilizados ensaios não destrutivos que fornecem estimativas da máxima temperatura alcançada localmente no concreto e nas barras de aço e as respectivas resistências residuais.

Devido à heterogeneidade do concreto, especialmente após uma situação de incêndio, é difícil avaliar as suas propriedades residuais pelos métodos convencionais de ensaios. Possíveis métodos de avaliação incluem estudo da resposta média do concreto do cobrimento, análise ponto a ponto de pequenos corpos de prova extraídos de diferentes profundidades do elemento estrutural e técnicas especiais, conforme apresentado na Tabela 5.

- Análise termodilatométrica (Thermo dilato-Metric Analysis - TMA)

- Análise termogravimétrica (ThermoGravimetric Analysis - TGA)

- Análise térmica diferencial (Differential Thermal Analysis - DTA)

Tabela 5 - Tipos de ensaios não destrutivos para avaliação do concreto após o incêndio (FIB, 2008)

\begin{tabular}{|c|c|c|}
\hline $\begin{array}{c}\text { Resposta média do concreto } \\
\text { do cobrimento }\end{array}$ & $\begin{array}{l}\text { Análise ponto a ponto de } \\
\text { pequenos corpos de prova }\end{array}$ & Técnicas especiais \\
\hline \multirow{3}{*}{$\begin{array}{l}\text { Martelo de Schmidt } \\
\text { Sensor Windsor } \\
\text { Ensaio CAPO } \\
\text { Fratura interna BRE }\end{array}$} & $\begin{array}{l}\text { Testes mecânicos em escala } \\
\text { reduzida }\end{array}$ & $\begin{array}{l}\text { Medição indireta da velocidade } \\
\text { do pulso ultrassônico }\end{array}$ \\
\hline & diferencial & Eco de impacto \\
\hline & (DTA) & Tomografia sônica \\
\hline $\begin{array}{l}\text { Velocidade do } \\
\text { ultrassônico }\end{array}$ & $\begin{array}{l}\text { Análise } \quad \text { termogravimétrica } \\
\text { (TGA) }\end{array}$ & $\begin{array}{l}\text { Análise modal das ondas de } \\
\text { superfície (MASW) }\end{array}$ \\
\hline & $\begin{array}{l}\text { Análise } \quad \text { termodilatométrica } \\
\text { (TMA) }\end{array}$ & Resistividade elétrica \\
\hline & Termoluminescência & \\
\hline & Porosimetria & \\
\hline & Colorimetria & \\
\hline & Análise da densidade & \\
\hline & Análises químicas & \\
\hline
\end{tabular}

Como a queda da resistência do concreto aquecido depende da composição do material e das características das fases de aquecimento e resfriamento, não é possível estabelecer uma correlação direta entre a resistência residual do concreto e a máxima temperatura alcançada pelo material durante o incêndio. Mas como é fundamental conhecer o valor da resistência do 
concreto para avaliar a capacidade resistente da estrutura, a sua avaliação é o objetivo dos métodos não destrutivos. Para o aço, o conhecimento da máxima temperatura alcançada pelo material permite estimar a sua resistência residual.

\subsubsection{Extração de corpos de prova}

Baseado nos ensaios de corpos de prova de concreto à temperatura ambiente, é intuitivo supor que a resistência residual possa ser estimada de modo análogo. No entanto, não é confiável estimar a resistência do concreto utilizando corpos de prova com resistência variável ao longo do seu volume.

Por outro lado, a extração de corpos de prova da estrutura submetida ao incêndio é normalmente o primeiro passo para a aplicação de diversos outros métodos de ensaio (colorimetria, porosimetria, análises químicas, etc.). Além disso, os corpos de prova permitem avaliar a profundidade dos danos sofridos pelo concreto (FIB, 2008).

\subsubsection{Martelo de Schmidt}

O ensaio do martelo de Schmidt (Figura 43) mede a dureza superficial do concreto, mas não existe relação direta entre esse parâmetro e a resistência residual do concreto. $\mathrm{O}$ instrumento só consegue avaliar a dureza média de uma camada de 20 a $30 \mathrm{~mm}$ de concreto, o que é insuficiente para o caso de concreto danificado pelo fogo. Devido à necessidade de uma superfície plana para a realização do ensaio e de grande número de medições por motivos estatísticos, esse ensaio geralmente não é adequado para estruturas muito danificadas pelo fogo devido à ocorrência do spalling (FIB, 2008).

Os resultados disponíveis na literatura apresentam significativa variabilidade, provavelmente devido às características da mistura do concreto e do seu teor de umidade. $\mathrm{O}$ ensaio do martelo de Schmidt é popular e fácil de ser realizado. Sua aplicação pode ser útil para uma estimativa rápida de regiões onde o concreto superficial perdeu de 30 a $50 \%$ de sua resistência original (FIB, 2008). 


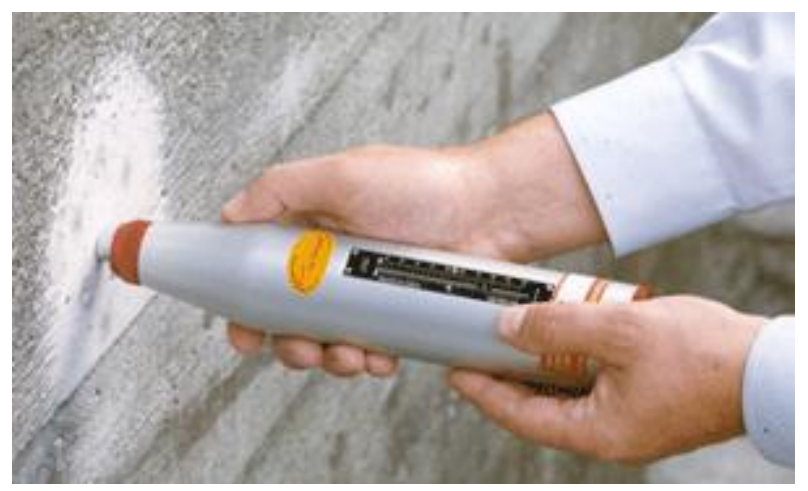

Figura 43 - Ensaio do martelo de Schmidt (POYESHYAR CO. LTD., 2011)

\subsubsection{Velocidade do pulso ultrassônico}

O ensaio utilizando a velocidade do pulso ultrassônico (Figura 44) requer uma superfície plana para sua aplicação, ou seja, só pode ser utilizado em elementos que não sofreram spalling. O método é particularmente adequado para avaliação da resistência do concreto de lajes e da extensão dos danos ao concreto causados por um incêndio localizado.

Ao contrário da prática usual, as cabeças de transmissão e recepção dos pulsos ultrassônicos podem ser posicionadas do mesmo lado dos elementos estruturais (método indireto). Diversas medições são feitas, aumentando-se a distância entre os sensores a cada medição. Analisando as características dos gráficos que relacionam a distância entre os sensores e o tempo de recepção do pulso, pode-se estimar a severidade e profundidade dos danos causados no concreto pelo incêndio (FIB, 2008).

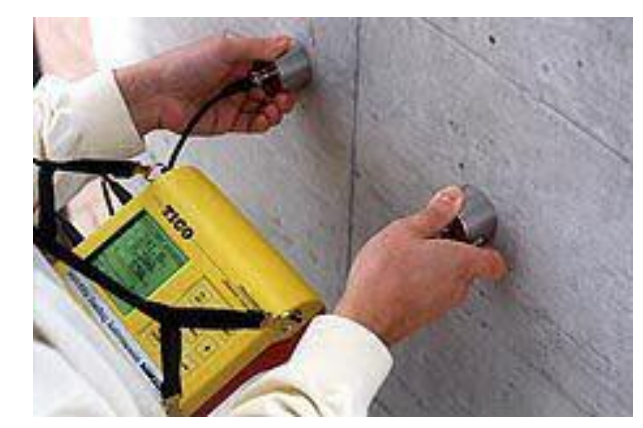

Figura 44 - Ensaio de velocidade do pulso ultrassônico (DYWIDAG-SYSTEMS INTL., 2011) 


\subsubsection{Sensor Windsor}

Desenvolvido nos Estados Unidos há aproximadamente 40 anos atrás, o método consiste em atirar um sensor de aço contra o elemento estrutural (Figura 45). Mede-se em seguida o comprimento do sensor que ficou exposto e correlaciona-se com a resistência à compressão do concreto. O ensaio é simples e rápido de ser realizado e pode ser feito em superfícies que sofreram spalling, desde que estejam razoavelmente planas. O método pode ser usado para determinar o perfil das resistências do concreto cortado em diferentes camadas. A correlação dos resultados do teste com a resistência residual do concreto é sensivelmente melhor se comparada aos métodos descritos anteriormente, sendo mais confiável caso os resultados sejam calibrados por meio de ensaios com concreto não afetado pelo incêndio. Na literatura não existem curvas de calibração do método específicas para a avaliação da resistência residual do concreto submetido ao incêndio (FIB, 2008).

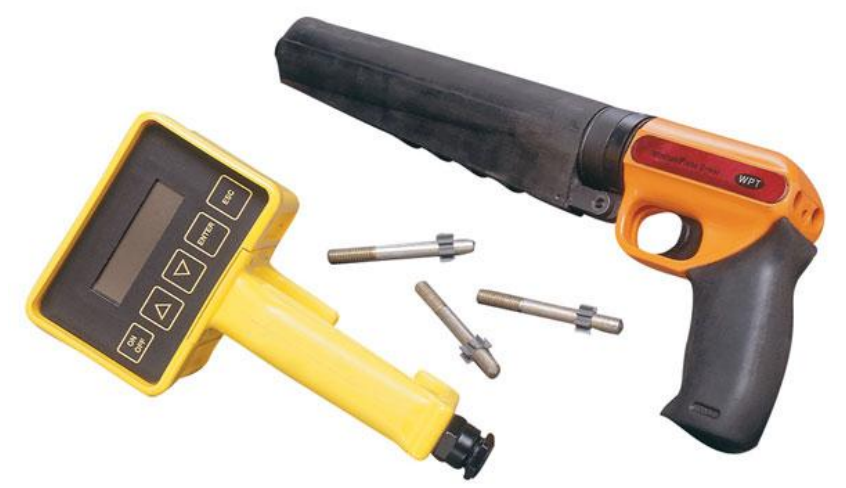

Figura 45 - Sensor Windsor (TEST MARK INDUSTRIES, 2011)

\subsubsection{Ensaio de fratura interna BRE e ensaio CAPO}

O ensaio de fratura interna BRE (Building Research Establishment) consiste em fazer um furo de $6 \mathrm{~mm}$ de diâmetro, no qual é inserido um pino de ancoragem com luva expansiva à profundidade de $20 \mathrm{~mm}$ (Figura 46). O torque necessário para extrair o pino permite estimar a resistência residual do concreto, dado por um gráfico de calibração do instrumento. A dispersão dos resultados desse método é razoavelmente elevada. Resultados mais confiáveis podem ser obtidos caso se disponha de dados de calibração do mesmo concreto que está sendo 
ensaiado. As estimativas do ensaio de fratura interna BRE são menos confiáveis que os resultados do ensaio com o sensor Windsor (FIB, 2008).

O ensaio CAPO (cut and pull-out) foi desenvolvido na Dinamarca há aproximadamente 25 anos atrás. O método é similar ao ensaio de fratura interna BRE. Um anel expansível é posicionado no interior de um furo e é extraído pelo instrumento do ensaio (Figura 47). O ensaio CAPO permite melhor controle do cone de fratura do concreto, fornecendo resultados menos dispersos. É possível avaliar a resistência média da camada superficial do concreto (10 a $15 \mathrm{~mm}$ de espessura) (FIB, 2008).

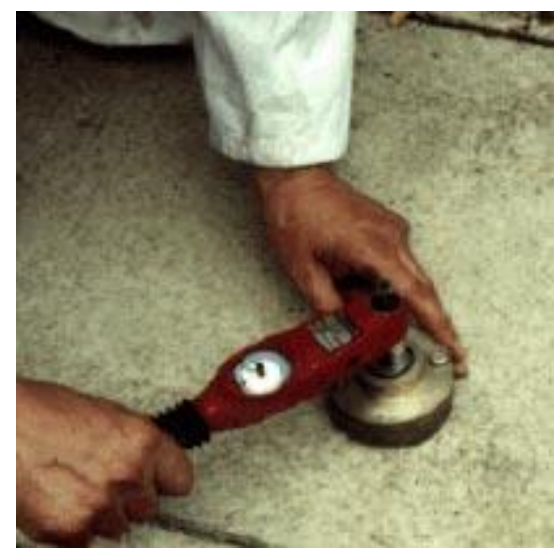

Figura 46 - Ensaio de fratura interna BRE (IMPACT TEST EQUIPMENT LTD., 2010)

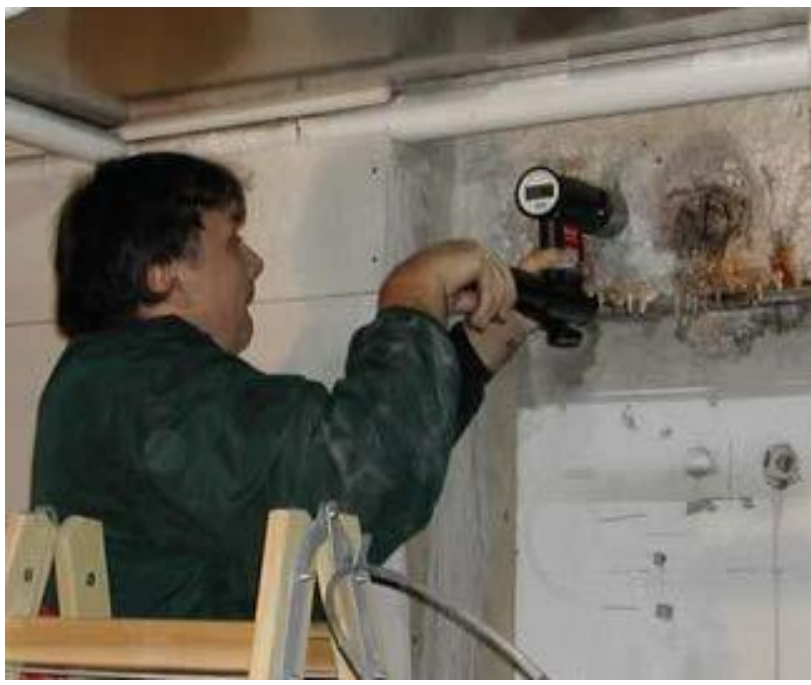

(a)

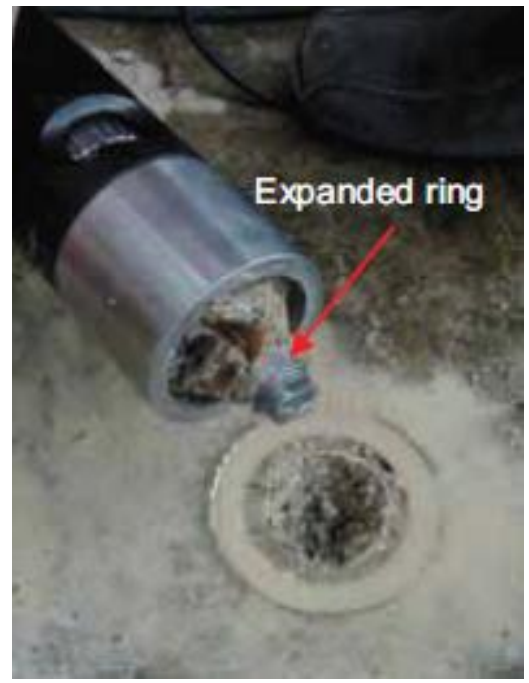

(b)

Figura 47 - (a) Ensaio CAPO; (b) cone de concreto extraído pelo anel expansível (GERMANN INSTRUMENTS A/S, 2009) 


\subsubsection{Colorimetria}

Um método tradicional para a avaliação dos danos causados no concreto pelo fogo consiste na avaliação visual das cores do material (Figura 48). As cores do concreto em função do aumento da temperatura variam do normal ao rosa ou vermelho $\left(300-600^{\circ} \mathrm{C}\right)$, cinza esbranquiçado $\left(600-900^{\circ}\right.$ C) e castanho-amarelado $\left(900-1000^{\circ}\right.$ C). A coloração rosa avermelhada mostra a presença de compostos de ferro nos agregados, que oxidam nessa faixa de temperaturas $\left(300-600^{\circ} \mathrm{C}\right)$. A intensidade da mudança das cores depende do tipo de agregado, sendo mais pronunciadas para agregados silicosos e menos para agregados calcários e ígneos (SHORT, PURKISS e GUISE, 2001). Mesmo não havendo correlação direta das cores com a resistência do concreto, detectar as alterações de cores é de grande interesse, pois indicam reduções mais significativas da resistência do concreto (FIB, 2008).

A avaliação das cores do concreto submetido ao incêndio pode ser feita por meio de colorímetros ou microscopia ótica combinada com análise digital das imagens. Pesquisas recentes na Universidade de Milão propuseram um método de análise colorimétrica usando câmeras fotográficas digitais convencionais. Além de acessível, uma única fotografia permite analisar o perfil de cores do concreto em diferentes profundidades, além de permitir análise em separado da argamassa e dos agregados graúdos (FELICETTI, 2006).

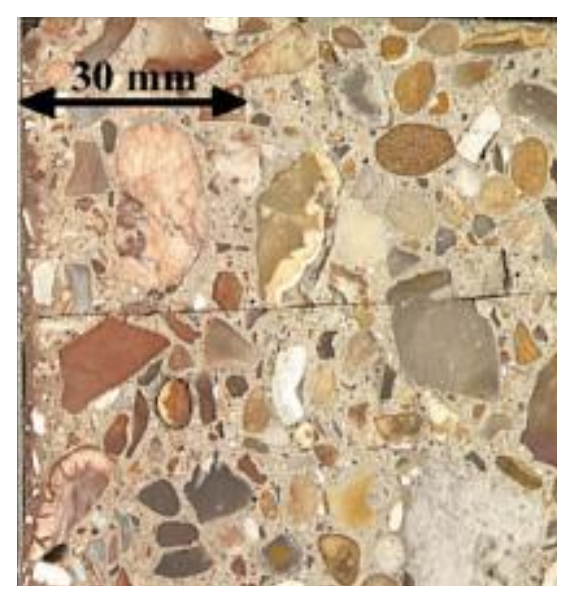

Figura 48 - Seção polida de uma amostra de concreto aquecido pela face esquerda, onde nota-se alteração da coloração em relação ao núcleo (SHORT, PURKISS e GUISE, 2001) 


\subsubsection{Termoluminescência}

A termoluminescência é a emissão de luz visível quando se aquece determinados minerais, incluindo quartzo e feldspato. A curva que correlaciona a luz emitida em função da temperatura para um determinado material depende do histórico de temperaturas e radiação experimentados pelo material (BUNGEY ${ }^{41}, 1982$ apud FIB, 2008).

Para concreto submetido ao incêndio, o ensaio consiste em medir a termoluminescência residual de pequenas amostras de areia extraídas por perfuração do concreto. A maior redução da termoluminescência ocorre na faixa de 300 a $500^{\circ} \mathrm{C}$, ou seja, quando a resistência do concreto começa a reduzir de forma mais acelerada. Uma das vantagens do método é danificar muito pouco o elemento estrutural. Além disso, pode-se estimar a resistência de diversas camadas de concreto a partir da superfície do elemento. Por outro lado, a realização desse ensaio requer equipamentos especiais (Figura 49) e profissionais experientes (FIB, 2008).

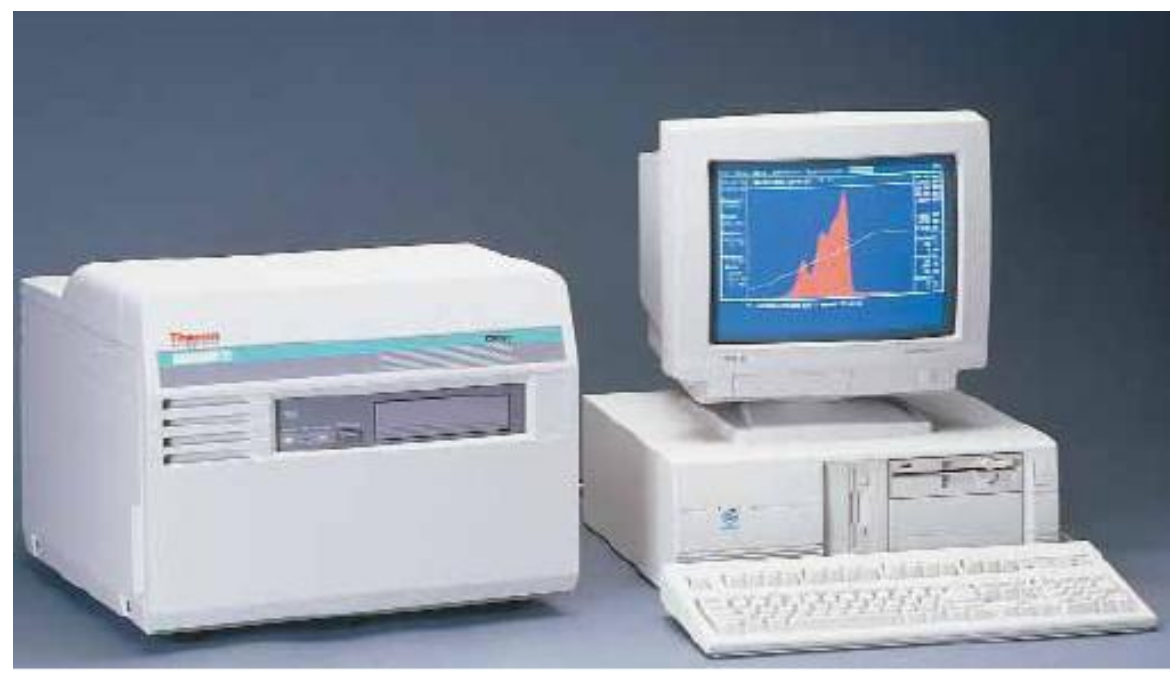

Figura 49 - Equipamento de medição automática da termoluminescência do concreto (TLD, 2010)

\subsubsection{Ensaio de carbonatação}

A profundidade de carbonatação do concreto pode ser medida borrifando-se uma solução de fenolftaleína e medindo-se a profundidade da zona não colorida (Figura 50). A profundidade da carbonatação depende da severidade do incêndio. Informações sobre a

\footnotetext{
${ }^{41}$ BUNGEY, J. H. The testing of concrete in structures. Surrey University Press, New York, 1982.
} 
durabilidade residual do concreto podem ser obtidas medindo-se a profundidade de carbonatação dos elementos alguns anos após o incêndio e comparando-se à profundidade de carbonatação de elementos da mesma idade, mas que não foram afetados pelo incêndio (FIB, 2008).

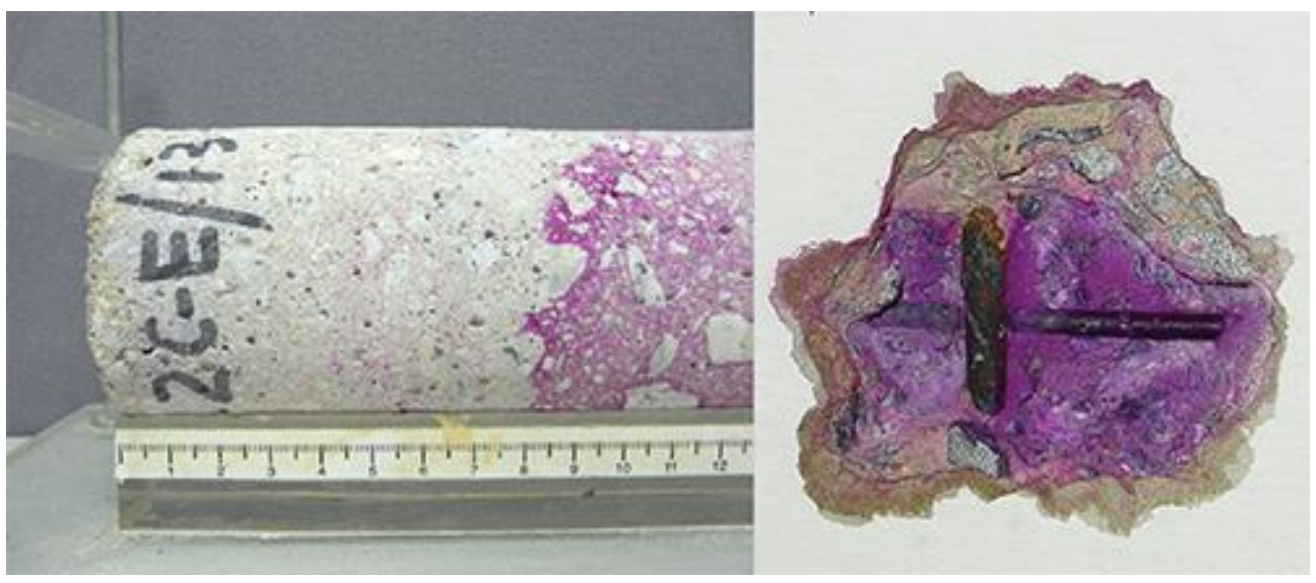

Figura 50 - Ensaio de profundidade da carbonatação do concreto (AL TECHNOLOGIES LTD., 2011)

\subsubsection{Análise química}

A análise química permite determinar a quantidade residual de água combinada em cimentos endurecidos ou o teor residual de cloretos no concreto.

A análise para determinar a quantidade de água residual de água combinada foi desenvolvida no Japão há aproximadamente 50 anos atrás e é utilizada ainda hoje. Extrai-se o pó de concreto de diversas profundidades do elemento estrutural. Após a separação da areia o pó de cimento é aquecido para determinar a quantidade residual de água combinada. A partir da relação entre a quantidade residual de água combinada e a máxima temperatura medida (ou esperada), os perfis de temperaturas podem ser traçados e as reduções de resistência do concreto podem ser estimadas (FIB, 2008).

Os íons cloreto podem atacar o concreto durante e após o incêndio devido à decomposição de plásticos contendo policloretos (PVC, por exemplo). Os cloretos existem inicialmente na superfície do concreto (5 a $10 \mathrm{~mm}$ de profundidade). Devido à difusão, os íons de cloreto podem migrar para camadas mais internas do elemento, causando corrosão localizada nas armaduras. Os métodos de ensaio disponíveis comercialmente incluem titulação potenciométrica, fluorescência de raios-x e análises de cloretos (FIB, 2008). 


\subsubsection{Difração de raios-x}

A avaliação de amostras de argamassa de cimento endurecida mostra a presença de compostos hidratados, como a portlandita $\left(\mathrm{Ca}(\mathrm{OH})_{2}\right)$, silicato de cálcio hidratado $(\mathrm{C}-\mathrm{S}-\mathrm{H})$, etringita e quartzo. Os resultados de difração de raios-x são comparados a certos padrões, que variam conforme a temperatura alcançada pelo concreto, permitindo avaliar posteriormente a redução da resistência do concreto (FIB, 2008).

\subsubsection{Ensaios físico-químicos e mecânicos}

Diversos métodos de ensaio são baseados em ensaios de pequenas amostras de concreto extraídas de diferentes profundidades de um elemento estrutural. Os seguintes métodos, aplicados por laboratórios especializados, são baseados nas transformações físicoquímicas do concreto (FIB, 2008):

- Análise termodilatométrica (Thermo dilato-Metric Analysis - TMA)

- Análise termogravimétrica (ThermoGravimetric Analysis - TGA)

- Análise térmica diferencial (Differential Thermal Analysis - DTA)

Muitas das transformações físico-químicas do concreto induzidas pela temperatura são irreversíveis. Portanto, durante um segundo aquecimento de um concreto já danificado por um incêndio, não ocorrem transformações significativas no concreto até que temperatura máxima atingida no primeiro aquecimento seja superada pelo segundo aquecimento. As transformações que ocorrem no concreto durante o segundo aquecimento podem ser obtidas por meio de medições do comprimento (TMA), massa (TGA) e temperatura (DTA) (FIB, 2008).

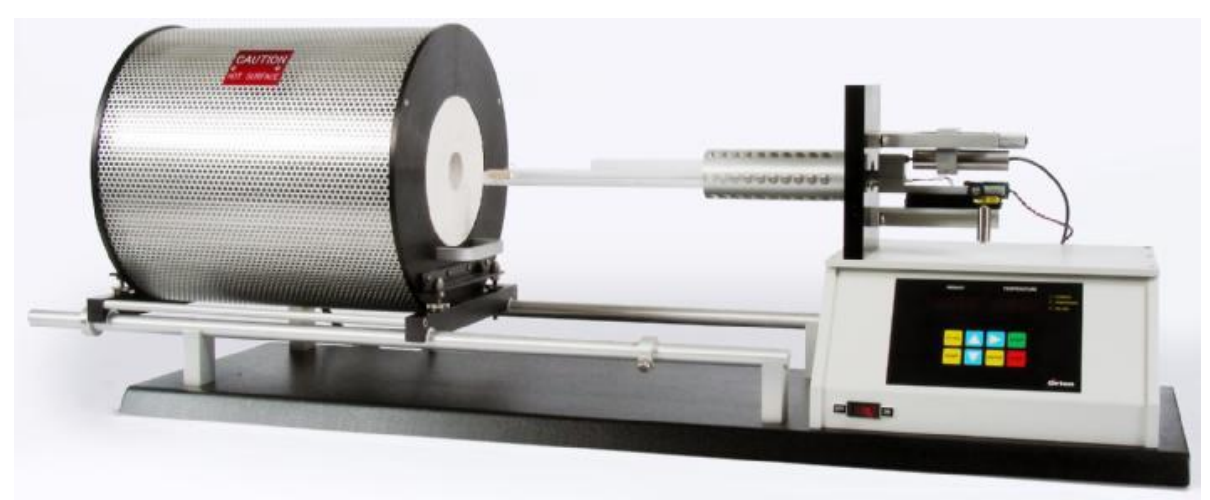

Figura 51 - Equipamento para ensaio termodilatométrico (ORTON, 2010) 


\subsubsection{Resistência à furação}

Alguns dos métodos descritos anteriormente iniciam pela coleta de amostras do concreto a diferentes profundidades. Esse procedimento pode ser bastante trabalhoso para estruturas muito danificadas pelo incêndio, pois é necessário coletar muitas amostras para análise.

Um método bastante promissor e muito mais rápido de ser realizado, baseado na medição da resistência à furação numa única etapa, foi proposto por Felicetti (2006). Uma furadeira de impacto é recomendada de modo a prevenir o desgaste e o superaquecimento da broca.

Para concreto submetido ao incêndio, um bom indicador da integridade do material é a energia dissipada por unidade de comprimento perfurada $(\mathrm{J} / \mathrm{mm})$. Uma correlação entre a esse parâmetro e a resistência à compressão residual do concreto é difícil de ser obtida, devido à forte influência de outras propriedades como energia de fratura e dureza dos agregados. No entanto, a resistência à furação possui significado em termos relativos, ou seja, quando os valores medidos são comparados aos resultados do concreto original (não submetido ao incêndio). Pode-se assim estimar a profundidade da camada de concreto danificada pelo aquecimento. Esse método produz resultados confiáveis, principalmente para concretos severamente danificados pelo incêndio (resistência residual do concreto inferior a $70 \%$ da sua resistência original) (FIB, 2008).

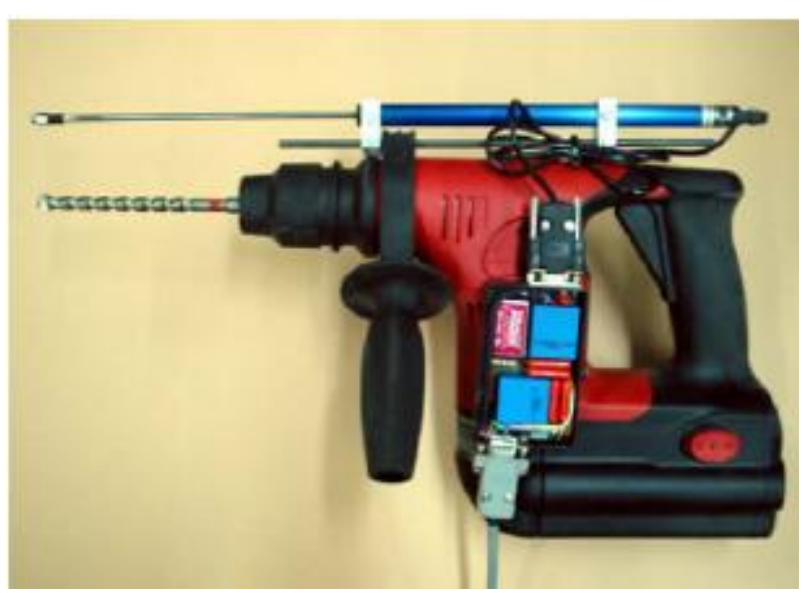

(a)

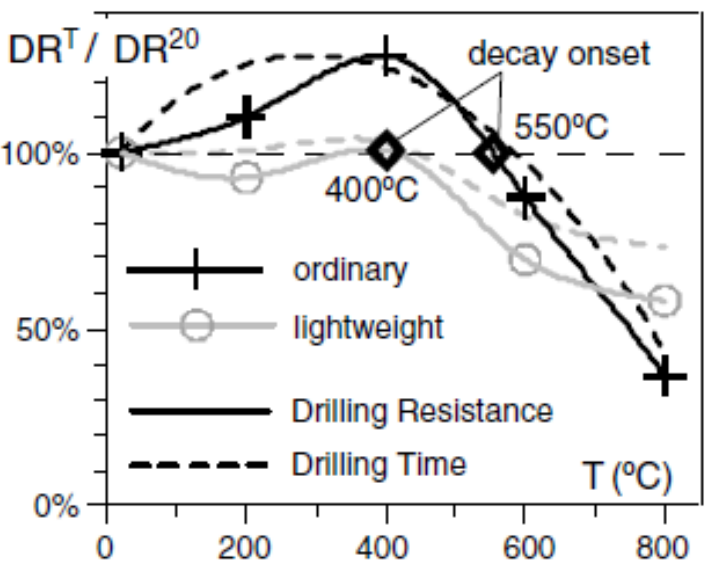

(b)

Figura 52 - (a) Furadeira instrumentada para a medição da resistência à furação do concreto submetido a temperaturas elevadas; (b) efeito das temperaturas elevadas na resistência e tempo de furação

(FELICETTI, 2006) 


\subsubsection{Outros métodos}

Além dos diversos métodos não destrutivos para análise das propriedades residuais do concreto após o incêndio, outros métodos foram sugeridos (FIB, 2008).

A porosimetria por intrusão de mercúrio é normalmente utilizada para medir o volume dos poros no concreto, pois a quantidade e o tamanho médio dos poros aumentam com a exposição do concreto a temperaturas elevadas.

Técnicas de análise digital de imagens permitem medir a densidade de microfissuras (comprimento total de fissuras por unidade de área), o que permite estimar a máxima temperatura alcançada pelo concreto durante o incêndio.

Outra técnica proposta foi o escaneamento longitudinal ultrassônico de núcleos de concreto, com o emissor e o receptor localizados em posições diametralmente opostas.

Um método proposto recentemente (BENEDETTI; MANGONI ${ }^{42}, 2005$ apud FIB, 2008) para a avaliação da resistência à compressão residual do concreto é o Ensaio de Disco (disk punching-test). Uma amostra de concreto submetido ao incêndio é cortada em finos discos, a diferentes profundidades a partir da superfície do elemento estrutural. Cada disco é então ensaiado sob compressão. Apesar do nome do ensaio em inglês sugerir um ensaio de punção, o efeito que se manifesta é análogo ao fendilhamento.
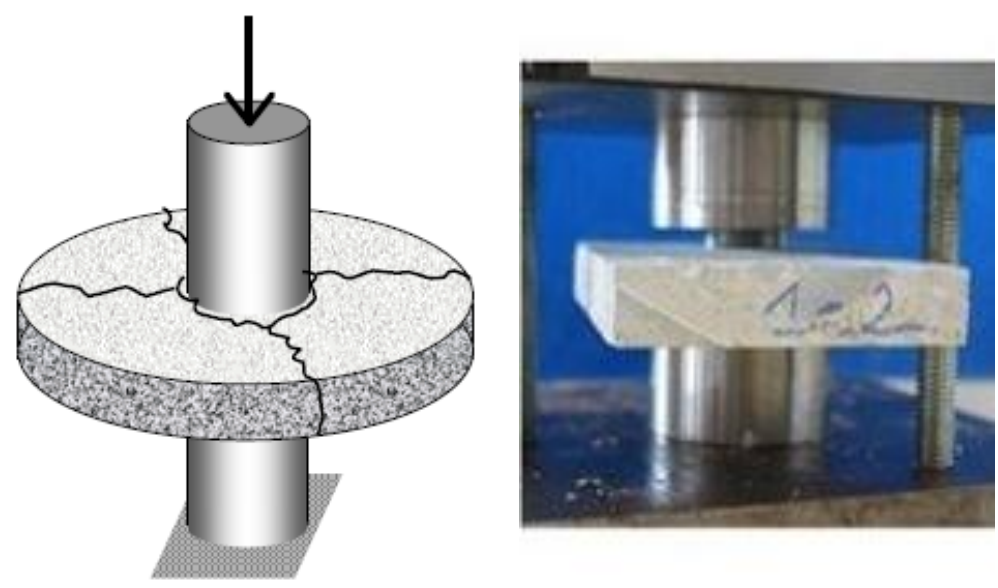

Figura 53 - Ensaio de disco de concreto (BENEDETTI; MANGONI ${ }^{47}, 2005$ apud FIB, 2008)

${ }^{42}$ BENEDETTI, A.; MANGONI, E. Damage assessment in actual fire situations by means of nondestructive techniques and concrete tests. Proc. Int. Workshop "Fire Design of Concrete Structures: What now? What next?, p. 231-239. Milão, dez. 2004. 


\subsection{REPAROS DE ESTRUTURAS APÓS UM INCÊNDIO}

Após um incêndio, quando for possível, deve-se inspecionar a edificação em busca de dados que permitam decidir as ações a serem tomadas, que podem variar entre pequenos reparos até a demolição total da estrutura. A tomada de decisões envolve questões relacionadas à segurança da estrutura e ao custo-benefício de cada possível solução.

A avaliação de uma estrutura submetida ao incêndio é composta pelas seguintes etapas (FIB, 2008):

- coleta de dados sobre o incêndio e suas consequências;

- avaliação dos danos devido ao fogo e às ações de combate ao fogo;

- $\quad$ classificação dos danos;

- identificação e seleção dos métodos de reparo apropriados.

\subsubsection{Coleta de dados}

Após um incêndio, quando o compartimento incendiado for acessível, todas as evidências devem ser observadas e registradas. Em especial, a localização e o estado (aparência) dos materiais podem fornecer indicativos da máxima temperatura alcançada durante o incêndio. A Tabela 6 apresenta algumas informações a respeito dos efeitos causados nos materiais sob temperaturas elevadas. 
Tabela 6 - Efeitos das altas temperaturas nos materiais normalmente encontrados em edificações (FIB, 2008)

\begin{tabular}{|c|c|c|c|}
\hline Substância & Exemplos & Condições & $\begin{array}{l}\text { Temperatura } \\
\text { aproximada }\left[{ }^{\circ} \mathrm{C}\right]\end{array}$ \\
\hline Poliestireno & $\begin{array}{l}\text { Embalagens de alimentos, } \\
\text { luminárias, puxadores, carcaças } \\
\text { de equipamentos eletrônicos }\end{array}$ & $\begin{array}{l}\text { Colapso } \\
\text { Amolecimento } \\
\text { Derretimento }\end{array}$ & $\begin{array}{l}120 \\
120-140 \\
150-180\end{array}$ \\
\hline Polietileno & $\begin{array}{l}\text { Sacolas, garrafas, tubulações, } \\
\text { embalagens }\end{array}$ & $\begin{array}{l}\text { Encolhimento } \\
\text { Amolecimento e derretimento }\end{array}$ & $\begin{array}{l}120 \\
120-140\end{array}$ \\
\hline Polimetil-metacrilato & coberturas, & $\begin{array}{l}\text { Amolecimento } \\
\text { Formação de bolhas }\end{array}$ & $\begin{array}{l}130-200 \\
250\end{array}$ \\
\hline PVC & $\begin{array}{l}\text { Cabos, tubulações, dutos, forros, } \\
\text { perfis, puxadores, maçanetas, } \\
\text { utilidades domésticas, } \\
\text { brinquedos, garrafas }\end{array}$ & $\begin{array}{l}\text { Degradação } \\
\text { Fumaça } \\
\text { Cor marrom } \\
\text { Carbonização }\end{array}$ & $\begin{array}{l}100 \\
150 \\
200 \\
400-500\end{array}$ \\
\hline Celulose & Madeira, papel, algodão & Cor escura & $200-300$ \\
\hline Soldas & Junções de tubulações & Derretimento & 250 \\
\hline Chumbo & $\begin{array}{l}\text { Tubulações, itens sanitários, } \\
\text { brinquedos }\end{array}$ & $\begin{array}{l}\text { Derretimento } \\
\text { Arredondamento de bordas } \\
\text { Formação de gotas }\end{array}$ & $300-350$ \\
\hline $\begin{array}{l}\text { Alumínio e ligas } \\
\text { leves }\end{array}$ & $\begin{array}{l}\text { Fixações, partes mecânicas, } \\
\text { utensílios }\end{array}$ & $\begin{array}{l}\text { Amolecimento } \\
\text { Derretimento } \\
\text { Formação de gotas }\end{array}$ & $\begin{array}{l}400 \\
650 \\
650\end{array}$ \\
\hline Vidro & Utensílios, garrafas & $\begin{array}{l}\text { Amolecimento, } \\
\text { arredondamento de bordas }\end{array}$ & $\begin{array}{l}500-600 \\
800\end{array}$ \\
\hline Prata & Joias, talheres & $\begin{array}{l}\text { Derretimento } \\
\text { Formação de gotas }\end{array}$ & 950 \\
\hline Latão & $\begin{array}{l}\text { Cadeados, torneiras, maçanetas, } \\
\text { grampos }\end{array}$ & $\begin{array}{l}\text { Derretimento } \\
\text { nas bordas), formação de } \\
\text { gotas }\end{array}$ & $900-1000$ \\
\hline Cobre & $\begin{array}{l}\text { Cabos elétricos, elementos } \\
\text { decorativos }\end{array}$ & Derretimento & $1000-1100$ \\
\hline Ferro fundido & Radiadores, tubulação & $\begin{array}{l}\text { Derretimento } \\
\text { Formação de gotas }\end{array}$ & $1100-1200$ \\
\hline Zinco & $\begin{array}{l}\text { Itens sanitários, calhas, } \\
\text { tubulações de descida de águas } \\
\text { pluviais }\end{array}$ & $\begin{array}{l}\text { Formação de gotas } \\
\text { Derretimento }\end{array}$ & $\begin{array}{l}400 \\
420\end{array}$ \\
\hline Bronze & $\begin{array}{l}\text { Janelas, guarnições, } \\
\text { campainhas, ornamentos }\end{array}$ & $\begin{array}{l}\text { Arredondamento dos cantos, } \\
\text { formação de gotas }\end{array}$ & $\begin{array}{l}900 \\
900-1000\end{array}$ \\
\hline Tintas & & $\begin{array}{l}\text { Deterioração } \\
\text { Destruição }\end{array}$ & $\begin{array}{l}100 \\
250 \\
\end{array}$ \\
\hline Madeira & & Queima, formação de cinzas & 240 \\
\hline
\end{tabular}

\subsubsection{Danos no concreto}

Um método de determinar a profundidade dos danos causados pelo incêndio nos elementos de concreto é quebrar com cuidado pequenas partes de alguns elementos, camada por camada. Outra possibilidade é extrair pequenos corpos de prova e analisar suas cores. A profundidade da zona descolorida corresponde, aproximadamente, à isoterma de $300^{\circ} \mathrm{C}$ (FIB, 
2008). Podem ser usados também os métodos de ensaios não destrutivos apresentados no item 6.3 deste trabalho.

\subsubsection{Danos nas armaduras}

As deformações residuais nas armaduras ativas e passivas devem ser verificadas e mapeadas. As partículas de fumaça e fuligem devem ser analisadas, pois podem induzir à corrosão. Recomenda-se extrair pequenos corpos de prova para ensaio em laboratório, onde se consegue determinar a relação tensão-deformação completa do material. A medição da dureza no local pode, em muitos casos, ser suficiente para fornecer as informações necessárias a respeito da resistência residual das barras da armadura. Análises metalográficas são necessárias apenas em casos especiais (FIB, 2008).

\subsubsection{Diagnóstico}

Em muitos casos, as estruturas de concreto podem ser reparadas, mesmo quando submetidas a incêndios severos. Obviamente, é importante comparar os custos dos reparos com os custos da reconstrução (parcial ou total) dos elementos afetados.

Para estruturas de concreto, é possível definir "fatores de dano", ou seja, atribui-se um valor para esse fator dependendo da máxima temperatura alcançada localmente durante o incêndio, conforme mostra a Tabela 7.

Tabela 7 - Fatores de dano para estruturas de concreto (FIB, 2008)

\begin{tabular}{cc}
\hline Temperatura máxima alcançada $\left[{ }^{\mathbf{0}} \mathbf{C}\right]$ & Fator de dano \\
\hline$\leq 100$ & 1,00 \\
\hline $100-300$ & 0,85 \\
\hline $300-500$ & 0,40 \\
\hline$>500$ & 0,00 \\
\hline
\end{tabular}

A resistência do aço das armaduras passivas praticamente não é afetada para temperaturas de no máximo $400^{\circ} \mathrm{C}$. Quando a temperatura máxima do incêndio supera os $400^{\circ} \mathrm{C}$, a resistência residual do aço deve ser avaliada. Caso seja necessário reforçar a estrutura, barras complementares podem ser previstas (FIB, 2008). 
As estruturas protendidas são geralmente mais sensíveis aos efeitos do aquecimento do que as estruturas de concreto armado. Isso depende do tipo da seção transversal dos elementos e do sistema de protensão (elementos pré-tensionados são mais sensíveis aos efeitos do aquecimento que elementos pós-tensionados). É sempre necessário avaliar criteriosamente a capacidade portante residual das estruturas protendidas após um incêndio, pois o aço das armaduras ativas é bastante sensível aos efeitos das temperaturas elevadas. Os reparos podem incluir mudança do sistema estrutural (de concreto protendido para concreto armado) ou adição de cabos de protensão complementares (FIB, 2008).

\subsubsection{Classificação dos danos}

Os efeitos das temperaturas elevadas em estruturas de concreto podem ser classificados conforme a severidade, permitindo planejar diferentes ações corretivas para a edificação (FIB, 2008):

- $\quad$ somente reparos;

- combinação de reparos e reconstrução parcial;

- $\quad$ mudança de uso;

- demolição total e reconstrução.

A Tabela 8 apresenta as classes de severidade dos danos causados pelo incêndio em estruturas de concreto. 
Tabela 8 - Classes de danos causados pelo incêndio em estruturas de concreto (FIB, 2008)

\begin{tabular}{|c|c|c|}
\hline Classe & Caracterização & Descrição \\
\hline 1 & $\begin{array}{l}\text { Dano estético, } \\
\text { superficial }\end{array}$ & $\begin{array}{l}\text { Caracterizado por depósitos de fuligem e descoloração, podendo ser } \\
\text { removidos com uma lavagem em muitos casos. Pode ser necessário } \\
\text { substituir alguns revestimentos. Odores podem ser removidos com produtos } \\
\text { químicos específicos. }\end{array}$ \\
\hline 2 & $\begin{array}{l}\text { Dano técnico, } \\
\text { superficial }\end{array}$ & $\begin{array}{l}\text { Danos na superfície e revestimentos dos elementos estruturais. Pouco } \\
\text { spalling no concreto e corrosão em elementos metálicos desprotegidos. } \\
\text { Superfícies pintadas podem ser reparadas. Acabamentos à base de plásticos } \\
\text { podem ser substituídos. Danos pequenos devido ao spalling podem ser } \\
\text { ignorados ou resolvidos com pequenos reparos. }\end{array}$ \\
\hline 3 & $\begin{array}{l}\text { Dano estrutural, } \\
\text { superficial }\end{array}$ & $\begin{array}{l}\text { Há spalling e alguma fissuração do concreto, superfícies de madeira } \\
\text { levemente carbonizadas, alguma deformação em superfícies metálicas ou } \\
\text { corrosão moderada. Os reparos são semelhantes aos descritos na Classe } 2 \text {. }\end{array}$ \\
\hline 4 & $\begin{array}{l}\text { Dano estrutural, } \\
\text { seção transversal }\end{array}$ & $\begin{array}{l}\text { Maior ocorrência de spalling e fissuração na alma de vigas com seção I, } \\
\text { flanges deformadas e seções transversais parcialmente carbonizadas em } \\
\text { elementos de madeira, plásticos degradados. Observam-se também grandes } \\
\text { deformações da estrutura que reduzem a capacidade portante e afetam o } \\
\text { posicionamento dos subsistemas da edificação. Esse comportamento } \\
\text { manifesta-se principalmente em estruturas metálicas. }\end{array}$ \\
\hline 5 & $\begin{array}{l}\text { Danos estruturais de } \\
\text { elementos } \\
\text { componentes }\end{array}$ & $\begin{array}{l}\text { Danos severos em elementos estruturais e componentes, com falhas } \\
\text { localizadas e grandes deformações. Spalling generalizado, armaduras } \\
\text { expostas e zonas comprimidas são afetadas. Deformações permanentes em } \\
\text { estruturas metálicas devido à redução da capacidade portante. Elementos de } \\
\text { madeira podem ter as seções transversais totalmente carbonizadas. } \\
\text { Diminuição da resistência dos materiais. Os danos da Classe } 5 \text { normalmente } \\
\text { resultam na demolição da estrutura, sem possibilidade de reparos. }\end{array}$ \\
\hline
\end{tabular}

\subsubsection{Métodos de reparo}

O Boletim 46 do fib apresenta em detalhes os critérios e métodos de reparos possíveis de serem feitos em estruturas danificadas por um incêndio, descritos brevemente a seguir.

O principal objetivo dos reparos em estruturas após um incêndio é recuperar as características originais dos elementos estruturais e sua capacidade portante, conforme os seguintes passos:

- as armaduras devem ser reparadas e protegidas, as seções transversais dos elementos de concreto devem ser recompostas até suas dimensões originais;

- a estrutura recuperada deve ter a mesma durabilidade residual que possuía antes do incêndio;

- a estrutura recuperada deve ter a mesma capacidade portante que possuía antes do incêndio;

- a estrutura recuperada deve atender aos mesmos requisitos de segurança contra incêndio que possuía antes do incêndio. 
Dependendo da classe de danos (FIB, 2008), os reparos devem ser feitos utilizando as seguintes técnicas:

- limpeza e recuperação estética;

- reparo das superfícies de concreto (com tintas, graute, etc.);

- reparo dos elementos de concreto e recuperação das dimensões originais;

- reposição de elementos estruturais (no caso de estruturas metálicas ou estruturas pré-fabricadas);

- adoção de reforços (por exemplo, usando mantas de fibra de vidro ou fibra de carbono coladas à estrutura);

- $\quad$ instalação de novos equipamentos de detecção e combate ao incêndio;

- tratamento das fissuras no concreto com resinas poliméricas ou nata de cimento;

- demolição (parcial ou total) e reconstrução da estrutura.

Para elementos de concreto, as camadas que foram aquecidas acima de $300^{\circ} \mathrm{C}$ devem ser removidas (por meio de cinzelamento e limpeza com jatos de areia e água) e posteriormente reconstituídas. Devem ser previstos meios de garantir a boa aderência dos materiais novos com a estrutura existente, para garantir o bom desempenho estrutural conforme o projeto original. 


\section{MÉTODOS DE CÁLCULO}

A resistência ao fogo de estruturas de concreto pode ser avaliada pelos seguintes métodos:

- métodos tabulares (prescritivos);

- métodos de cálculo simplificados;

- métodos de cálculo avançados;

- ensaios de elementos isolados;

- ensaios de estruturas completas em escala real.

A Figura 54 apresenta os diversos procedimentos que podem ser utilizados para a análise de estruturas em situação de incêndio, segundo o Eurocode 1 (EN-1991-1-2:2004). 


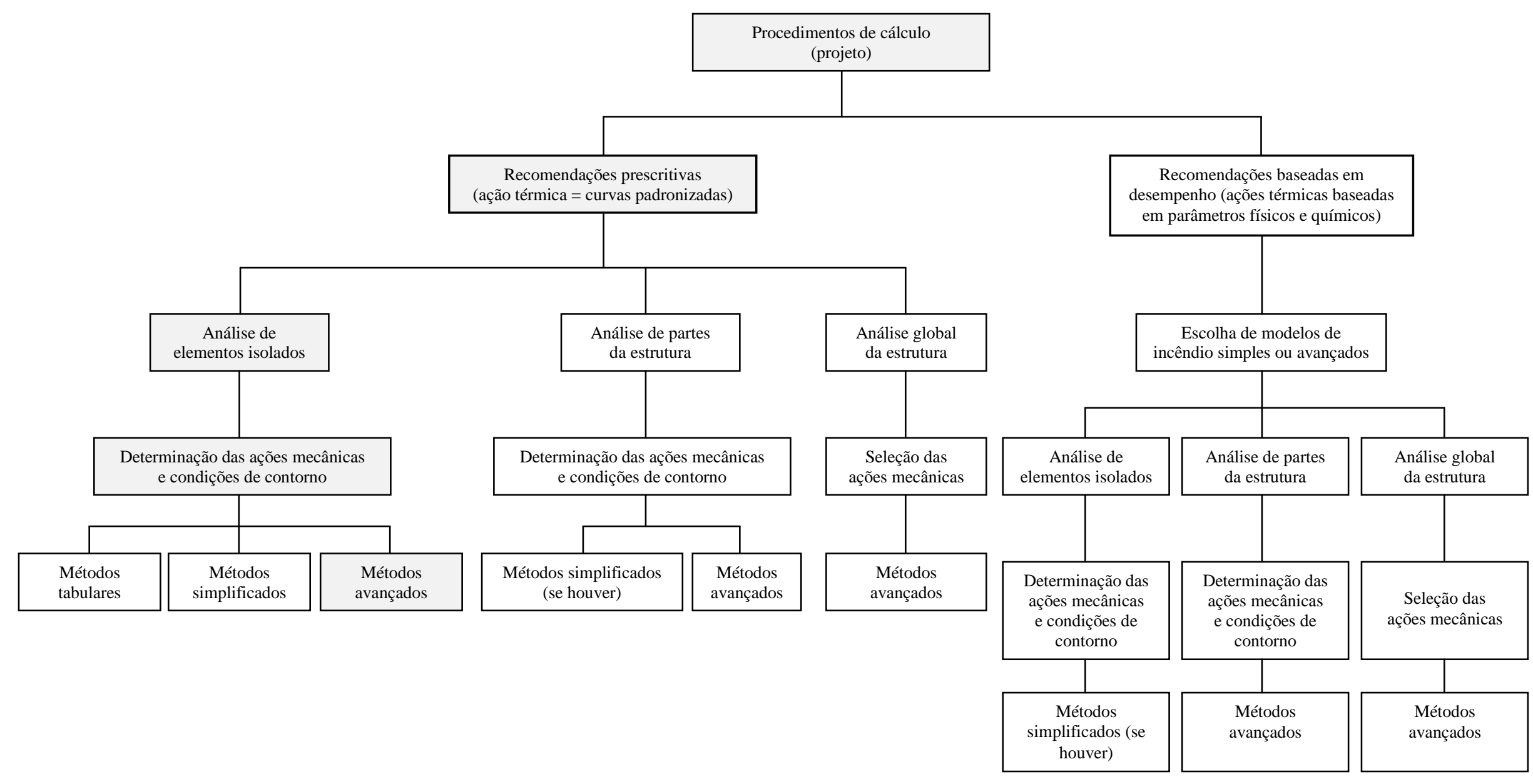

Figura 54 - Procedimentos para análise de estruturas em situação de incêndio recomendados pelo Eurocode 1 (EN-1991-1-2:2004), destacando o procedimento utilizado neste trabalho 


\subsection{MÉTODOS TABULARES}

A prática atual para projeto de estruturas em situação de incêndio ainda é fortemente baseada na aplicação de métodos tabulares contidos em normas técnicas. O engenheiro atende a diversos requisitos predeterminados baseados no tempo requerido de resistência ao fogo (TRRF) desejado. Embora os métodos tabulares sejam os mais simples, rápidos e baratos de serem aplicados, são bastante restritivos e normalmente excessivamente a favor da segurança, resultando em estruturas antieconômicas (FIB, 2007). Essas deficiências tem motivado o estudo e aplicação mais amplas de normas baseadas em desempenho. Além disso, os métodos tabulares só permitem a verificação de elementos isolados em situação de incêndio.

Os dados dos métodos tabulares consideram a exposição ao fogo segundo a curva ISO 834 (ISO, 1990), para TRRF iguais a 30, 60, 90, 120, 180 e 240 minutos no caso do Eurocode 2 (EN 1992-1-2:2004), e para TRRF iguais a 30, 60, 90, 120, 180 minutos no projeto de revisão da norma ABNT NBR 15200:2004. São dadas as dimensões mínimas dos elementos para cada TRRF, incluindo a distância do eixo das armaduras à face aquecida mais próxima. Não são fornecidos valores para valores intermediários de TRRF, mas permite-se interpolação linear entre os valores. Morris, Read e Cooke ${ }^{43}$ (1988 apud FIB (2007) afirmam que, se uma dimensão de um elemento é inferior ao mínimo especificado nas tabelas, e não sendo possível aumentar as dimensões desse elemento, a resistência ao fogo pode ser atendida mediante aplicação de algum tipo de proteção térmica na estrutura. Informações sobre aplicação e manutenção de sistemas de isolamento térmico, bem como seus efeitos na resistência ao fogo de elementos de concreto, não são dados pelo Eurocode 2 (EN 1992-1-2:2004), mas podem ser encontradas na literatura científica (SILVA (2004), CUOGHI e FIGUEIREDO (2007)). A norma ABNT NBR 15200:2004, no seu item 7.2 - Método tabular, permite considerar o efeito dos revestimentos térmicos no cálculo das espessuras mínimas e distâncias das barras longitudinais à face aquecida mais próxima $\left(\mathrm{c}_{1}\right)$.

O manual de projeto de estruturas de concreto em situação de incêndio da Suécia apresenta tabelas que servem também para curvas de incêndio paramétricas, além do incêndio-padrão (ANDERBERG, Y., PETTERSON, O. ${ }^{44}, 1992$ apud FIB, 2007).

\footnotetext{
${ }^{43}$ MORRIS, W. A., READ, R. E. H., COOKE, G. M. E. Guidelines for the construction of fireresisting structural elements. Building Research Establishment Report BR 128, 1988, pp. 39.

${ }_{44}$ ANDERBERG, Y. PETTERSON, O. Manual on fire engineering design of concrete structures. Swedish Board for Building Research, 1992.
} 


\subsection{MÉTODOS SIMPLIFICADOS}

\subsubsection{Análise da seção transversal}

O método da redução da seção transversal (ou seção efetiva) é conhecido por proporcionar resultados satisfatórios sob flexão simples, mas sua validade no caso de flexão composta ainda não está completamente provada, mesmo que alguns resultados mostrem que esse método é a favor da segurança (FIB, 2008).

A seção 4.2.1 da norma europeia Eurocode 2 (EN 1992-1-2:2004) fornece as diretrizes para o cálculo da capacidade última de seções transversais em situação de incêndio. Os métodos simplificados disponíveis nessa mesma norma são o Método da Isoterma de $500^{\circ} \mathrm{C} \mathrm{e}$ Método das Zonas (anexos B.1 e B.2, respectivamente). Embora sejam ditos simplificados, ambos necessitam de análise térmica da seção transversal. $\mathrm{O}$ anexo A da mesma norma fornece diagramas de distribuição de temperaturas em pilares conforme o TRRF para algumas poucas seções, que podem ser utilizados nos métodos simplificados citados.

\subsubsection{Método da isoterma de $500^{\circ} \mathrm{C}$}

A hipótese básica do Método da Isoterma de $500^{\circ} \mathrm{C}$ consiste em reduzir a seção transversal excluindo o concreto com temperatura superior a $500^{\circ} \mathrm{C}$ (Figura 55, Figura 56 e Figura 57). O concreto restante é considerado como tendo resistência e módulo de elasticidade iguais aos à temperatura ambiente. As barras de aço são consideradas na sua totalidade, sendo suas propriedades mecânicas calculadas conforme a temperatura no centro de cada barra, obtida da análise térmica da seção transversal. Esse método foi originalmente sugerido em 1976 pelo pesquisador Yngve Anderberg, no trabalho Fire-exposed hyperstatic concrete structures - Na experimental and theoretical study (FIB, 2007) e está presente no Anexo B do Eurocode 2 (EN 1992-1-2:2004).

O Método da Isoterma de $500^{\circ} \mathrm{C}$ é aplicável para qualquer curva de incêndio, desde que se disponha dos dados de análise térmica da seção transversal desejada e que a distribuição de temperaturas seja similar àquela obtida considerando incêndio-padrão. Curvas de incêndio que não cumpram com esse critério invalidam a aplicação do método. O Método da Isoterma de $500^{\circ} \mathrm{C}$ é válido para elementos submetidos à flexão simples ou flexão normal composta (vigas e pilares). Alerta-se, no entanto, que o método foi desenvolvido 
originalmente para elementos submetidos à flexão simples, nas quais a ruptura é geralmente comandada pelo escoamento do aço. A extensão para casos de flexocompressão, embora permitida pelo Eurocode 2 (EN 1992-1-2:2004), ainda é um assunto em discussão e deve ser considerado com bastante cuidado (FIB, 2008). Outra limitação se refere ao tipo de agregado, pois o método foi baseado em elementos de concreto feitos com agregado silicoso, por isso não se recomenda a aplicação do método para concretos feitos com outros agregados.

Estudos publicados no Boletim 46 do fib (FIB, 2008) mostram que o método da Isoterma de $500^{\circ} \mathrm{C}$ possui baixa concordância com o método iterativo-incremental ou "exato" (seção 7.3.2 deste trabalho), especialmente para maiores tempos de exposição ao fogo. A concordância piora à medida que aumenta o esforço axial. Ambos os métodos melhoram a concordância para seções transversais robustas, visto que estas seções são menos sensíveis à temperatura. Os estudos concluíram ainda que a capacidade resistente sob compressão simples é superestimada pelo método da Isoterma de $500^{\circ} \mathrm{C}$.

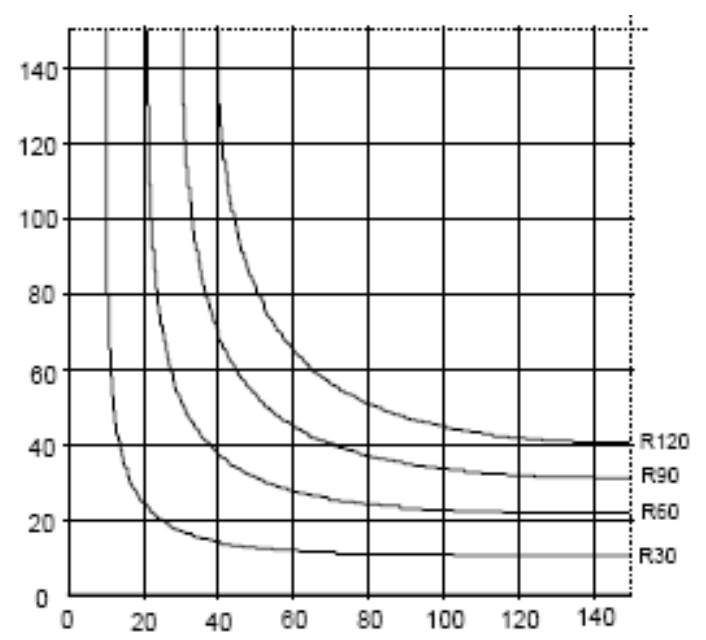

Figura 55 - Isotermas de $500^{\circ} \mathrm{C}$ em seção de concreto de $300 \mathrm{~mm}$ x $300 \mathrm{~mm}$ para $1 / 4$ da seção transversal, considerando a simetria (EN 1992-1-2:2004) 


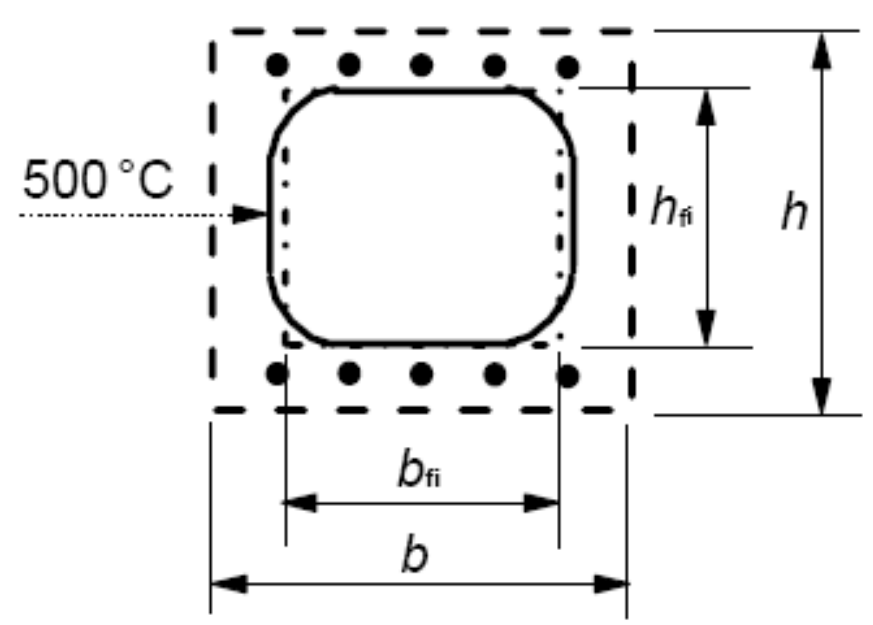

Figura 56 - Seção reduzida pela isoterma de $500^{\circ} \mathrm{C}$ (EN 1992-1-2:2004)

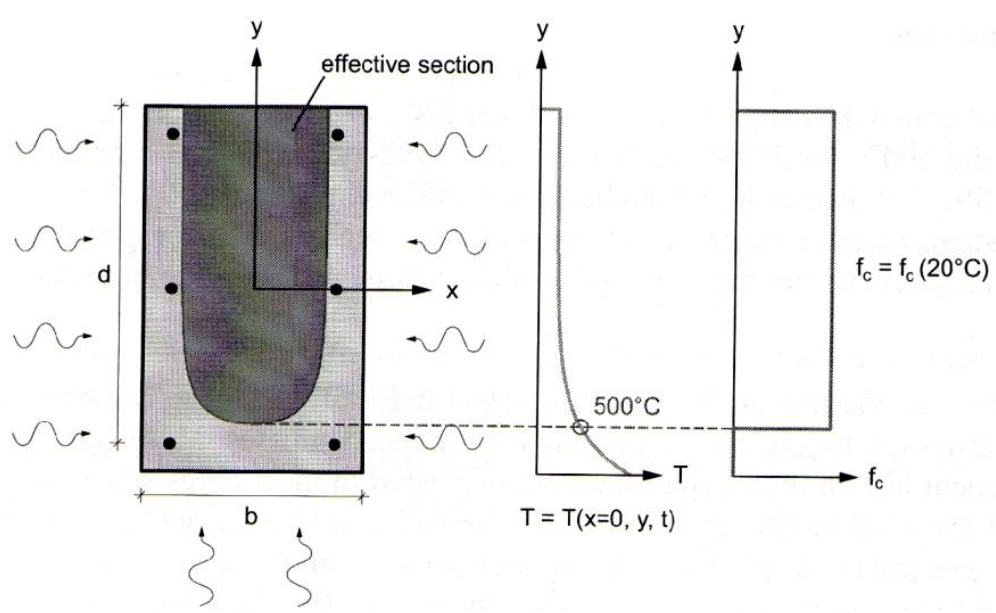

Figura 57 - Aplicação do Método da Isoterma de $500^{\circ} \mathrm{C}$ aplicado em seção retangular aquecida em três faces (FIB, 2008)

\subsubsection{Método das zonas}

O Método das Zonas (anexo B.2 do Eurocode 2 (EN 1992-1-2:2004)) é baseado na mesma filosofia do Método da Isoterma de $500^{\circ} \mathrm{C}$, mas considera a seção transversal subdividida em diversas zonas, conforme a distribuição de temperaturas. Esse método foi sugerido em 1985 pelo pesquisador Kristian Hertz, no trabalho Analyses of prestressed concrete structures exposed to fire. Embora seja mais trabalhoso que o Método da Isoterma de $500^{\circ} \mathrm{C}$, seus resultados são mais precisos especialmente para pilares (flexocompressão). O Método das Zonas é válido somente para seções aquecidas segundo a curva de incêndiopadrão ISO 834 (1975), e pode ser aplicado a vigas, pilares, lajes e paredes (Figura 58). 
Basicamente, a seção transversal é dividida em um número $(n \geq 3)$ de zonas paralelas de igual espessura (elementos retangulares). Calcula-se a temperatura média da zona pela posição de seu centroide, segundo análise térmica prévia. As propriedades mecânicas do concreto (resistência à compressão e módulo de elasticidade) são calculadas para cada zona segundo sua respectiva temperatura média (EN 1992-1-2:2004).

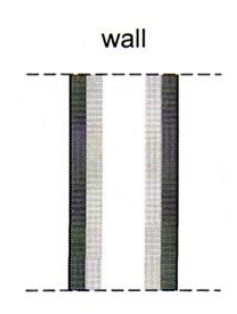

rectangular beam

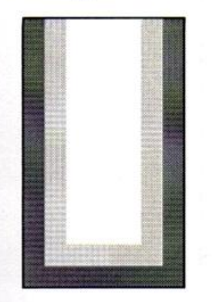

Figura 58 - Exemplos de aplicação do Método das Zonas (FIB, 2008).

\subsubsection{Método A do Eurocode 2 (EN 1992-1-2:2004)}

O Método A do Eurocode 2 (EN 1992-1-2:2004) é um método empírico, consistindo numa expressão que retorna o tempo de resistência ao fogo (TRF) de um pilar submetido à flexão normal composta (FNC), dadas as suas características geométricas, dos materiais e do carregamento.

O Método A foi desenvolvido considerando os resultados dos ensaios de 76 pilares provenientes de 5 laboratórios (ver item 7.2.6 deste trabalho). Posteriormente, foram ensaiados 4 pilares de seção circular, feitos com concreto de alta resistência. Os seus resultados foram incorporados ao banco de dados, totalizando 80 pilares, mas o método não precisou ser modificado, pois apresentou resultados satisfatórios para esses últimos pilares (FRANSSEN, 2001).

O Método A foi calibrado por meio de modelagem numérica com auxílio do software SAFIR ${ }^{\circledR}$, desenvolvido pela Universidade de Liège para a análise de estruturas em situação de incêndio considerando as não linearidades geométrica e dos materiais (COSTA, 2006). As 
análises numéricas serviram para identificar os parâmetros que influenciam no tempo de resistência ao fogo (TRF) dos pilares ensaiados. Os parâmetros identificados foram: comprimento, cobrimento, dimensões da seção transversal, número de barras longitudinais e nível de carregamento. A proposta do Método A foi apresentada no SiF 2000 - First International Workshop Structures in Fire, realizado em Copenhagen em 2000 (FRANSSEN, 2000).

O Eurocode 2 (EN 1992-1-2:2004) apresenta o Método A no seu item 5.3.2. Segundo essa norma, o método pode ser aplicado a pilares de concreto armado ou concreto protendido de estruturas de nós fixos. A expressão para o cálculo do TRF do pilar em minutos (segundo a curva de incêndio-padrão ISO 834 (1975)) é definida pela eq. (48).

$$
R=120 .\left(\frac{R_{\eta f i}+R_{a}+R_{l}+R_{b}+R_{n}}{120}\right)^{1,8}
$$

Onde:

$\mathrm{R}$ = tempo de resistência ao fogo [minutos] do pilar de concreto;

$\mathrm{R}_{\eta \mathrm{fi}}=$ componente da resistência ao fogo, função do nível de carregamento;

$\mathrm{R}_{\mathrm{a}}=$ componente da resistência ao fogo, função da posição das barras dentro da seção de concreto;

$\mathrm{R}_{\ell}=$ componente da resistência ao fogo, função do comprimento efetivo;

$\mathrm{R}_{\mathrm{b}}=$ componente da resistência ao fogo, função da largura efetiva da seção transversal;

$\mathrm{R}_{\mathrm{n}}=$ componente da resistência ao fogo, função da quantidade de barras de aço.

Conforme mencionado, o método pode ser aplicado a pilares de estruturas de nós fixos, ou seja, nas quais os efeitos de segunda ordem global não sejam significativos (conforme item 15.4.2 da norma ABNT NBR 6118:2003). Recomenda-se que o coeficiente $\gamma_{z}$ da estrutura (item 15.5.3 da mesma norma) seja no máximo igual a 1,3 (SILVA, 2008).

A componente da resistência ao fogo, função do nível de carregamento é definida pela eq. (49). 


$$
R_{\eta f i}=83 \cdot\left[1-\eta_{f i} \cdot\left(\frac{1+\omega}{\frac{0,85}{\alpha_{c c}}+\omega}\right)\right]
$$

Onde:

$\eta_{\mathrm{fi}}=$ fator de redução para o nível de carregamento em situação de incêndio (eq. (50));

$\omega=$ taxa mecânica para a situação normal de projeto (eq. (51));

$\alpha_{c c}=$ coeficiente relacionado aos efeitos de carregamento de longa duração (tomado com valor 0,85 para situações usuais).

O fator de redução para o nível de carregamento em situação de incêndio é dado pela eq. (50).

$$
\eta f i=\frac{N_{d, f i}}{N_{R d}}
$$

Onde:

$\mathrm{N}_{\mathrm{d}, \mathrm{fi}}=$ valor de cálculo da ação axial atuante em situação de incêndio [kN];

$\mathrm{N}_{\mathrm{Rd}}=$ valor de cálculo do esforço axial resistente à temperatura ambiente [kN].

$\mathrm{O}$ valor de $\eta_{\mathrm{fi}}$, quando não calculado explicitamente, pode ser adotado igual a 0,7 (EN 1992-1-2:2004 e ABNT NBR 15200:2004).

Apesar do Método A aparentar ser de uso imediato, é necessário saber o valor de cálculo do esforço axial resistente à temperatura ambiente $\left(\mathrm{N}_{\mathrm{Rd}}\right)$, o que exige uma etapa adicional de cálculos analíticos. Os cálculos de $\mathrm{N}_{\mathrm{Rd}}$ (à temperatura ambiente) devem incluir os efeitos da não linearidade geométrica $\left(2^{\mathrm{a}}\right.$ ordem $)$ e excentricidade inicial igual à excentricidade de $\mathrm{N}_{\mathrm{d} \text {,fi }}$ (SILVA, 2008), devendo estar de acordo com as prescrições da norma ABNT NBR 6118:2003.

A taxa mecânica para a situação normal de projeto é definida pela eq. (51).

$$
\omega=\frac{A_{s} \cdot f_{y d}}{A_{c} \cdot f_{c d}}
$$


Onde:

$\mathrm{A}_{\mathrm{s}}=$ área de aço total das armaduras longitudinais $\left[\mathrm{m}^{2}\right]$;

$\mathrm{f}_{\mathrm{yd}}=$ valor de cálculo da resistência à tração do aço $[\mathrm{kPa}]$;

$\mathrm{A}_{\mathrm{c}}=$ área da seção transversal de concreto $\left[\mathrm{m}^{2}\right]$;

$\mathrm{f}_{\mathrm{cd}}=$ valor de cálculo da resistência à compressão do concreto $[\mathrm{kPa}]$.

O Eurocode 2 (EN 1992-1-2:2004) apresenta o limite $A_{s} / A_{c} \leq 0,04$.

Apresenta-se a seguir comentários sobre o fator dado pela eq. (52).

$$
\frac{1+\omega}{\frac{0,85}{\alpha_{c c}}+\omega}
$$

Costa (2006) explicou que o fator dado pela eq. (52), da componente $\mathrm{R}_{\eta \mathrm{fi}}$ (eq. (49)) de resistência ao fogo, não constava na formulação original do Método A. Ele foi sugerido durante o processo de revisão da norma Eurocode 2 (EN 1992-1-2:2004) como fator de ajuste ao fator de redução para o nível de carregamento $\left(\eta_{\mathrm{fi}}\right)$ quando os efeitos do carregamento de longa duração $\left(\alpha_{c c}\right)$ são considerados no cálculo da resistência do concreto, o que ocorre em situações usuais (eq. (53)).

$$
f_{c d}=\alpha_{c c} \cdot \frac{f_{c k}}{\gamma c}
$$

Como a norma Eurocode 2 (EN 1992-1-2:2004), no seu item 3.1.6, permite projeto de elementos à temperatura ambiente usando coeficiente $\alpha_{\mathrm{cc}}=1$, quando se utiliza esse valor no Método $\mathrm{A}$, a componente $\mathrm{R}_{\eta \text { fi }}$ resulta maior, elevando também o tempo de resistência ao fogo calculado para o pilar. Costa (2006) apresentou a dedução do fator de correção para $\alpha_{c c}$, considerando a capacidade resistente de pilares curtos com carregamento axial centrado. A correção do valor de cálculo do esforço resistente usando o coeficiente usual para o efeito de carregamento de longa duração $\left(\alpha_{c c}=0,85\right)$ ou qualquer $\alpha_{c c} \neq 0,85$ é feita pela correlação entre as eqs. (54) e (55).

$$
N_{R d}=f_{y d} \cdot A_{s}+\alpha_{c c} \cdot f_{c d} \cdot A_{c}
$$




$$
N_{R d, m}=f_{y d} \cdot A_{s}+0,85 \cdot f_{c d} \cdot A_{c}
$$

Dividindo-se a eq. (54) pela eq. (55), tem a relação da eq. (56).

$$
\frac{N_{R d}}{N_{R d, m}}=\frac{f_{y d} \cdot A_{s}+\alpha_{c c} \cdot f_{c d} \cdot A_{c}}{f_{y d} \cdot A_{s}+0,85 \cdot f_{c d} \cdot A_{c}}=\frac{\frac{f_{y d} \cdot A_{s}}{f_{c d} \cdot A_{c}}+\frac{\alpha_{c c} \cdot f_{c d} \cdot A_{c}}{f_{c d} \cdot A_{c}}}{\frac{f_{y d} \cdot A_{s}}{f_{c d} \cdot A_{c}}+\frac{0,85 \cdot f_{c d} \cdot A_{c}}{f_{c d} \cdot A_{c}}}=\frac{\omega+\alpha_{c c}}{\omega+0,85}
$$

Por último, normaliza-se o coeficiente $\alpha_{c c}$ do numerador, conforme a eq. (57)

$$
\frac{N_{R d}}{N_{R d, m}}=\frac{\omega+\alpha_{c c}}{\omega+0,85}=\frac{\omega+1}{\omega+\frac{0,85}{\alpha_{c c}}}
$$

Para pilares esbeltos, determinar o coeficiente de correção seria mais difícil, mas o coeficiente de correção dado pela eq. (57) cobre o valor máximo da correlação possível para pilares (DOTREPPE, 2003). As tabelas do Método A presentes no Eurocode 2 (EN 1992-12:2004) foram calculadas para $\alpha_{\mathrm{cc}}=1$ (COSTA, 2006).

A componente da resistência ao fogo, função da posição das barras dentro da seção de concreto é dada pela eq. (58)

$$
R_{a}=1,60 .\left(c_{1}-30\right)
$$

Onde:

$c_{1}=$ distância entre o centroide das barras de aço longitudinais e a face aquecida mais próxima [mm];

O Eurocode 2 (EN 1992-1-2:2004) limita o valor de $c_{1}$ à seguinte faixa de valores: $25 \mathrm{~mm} \leq \mathrm{c}_{1} \leq 80 \mathrm{~mm}$. Quando as barras longitudinais estão dispostas em camadas, $\mathrm{c}_{1}$ é a distância média das barras longitudinais à face aquecida do pilar ( $\left.\mathrm{c}_{1 \mathrm{~m}}\right)$ (SILVA, 2008). O valor de c1m deve ser o menor dos seguintes valores (eq. (59)): 


$$
c_{1 m} \leq\left\{\begin{array}{l}
\frac{\sum c_{1 x i} A_{s i}}{\sum A_{s i}} \\
\frac{\sum c_{1 y i} A_{s i}}{\sum A_{s i}}
\end{array}\right.
$$

Onde:

$\mathrm{c}_{1 \mathrm{xi}}$ e $\mathrm{c}_{1 \mathrm{yi}}=$ distância do centroide da barra $\mathrm{i}$, de área $\mathrm{A}_{\mathrm{si}}$, à face aquecida mais próxima $[\mathrm{mm}]$.

Como exemplo de aplicação da eq. (59), considere-se a seção transversal de um pilar conforme mostra a Figura 59.

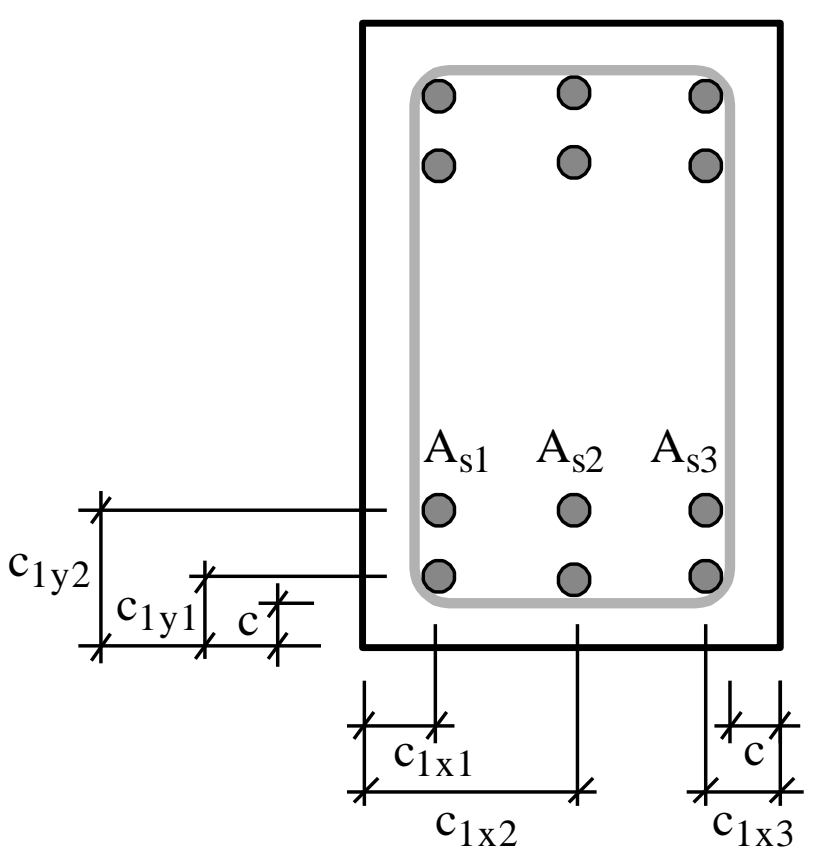

Figura 59 - Seção transversal de um pilar com barras longitudinais em camadas (SILVA, 2008).

Supondo que o pilar seja aquecido nas 4 faces, os valores de $c_{1 x m}$ e $c_{1 y m}$ são dados pelas eqs. (60) e (61).

$$
\begin{gathered}
c_{1 x m}=\frac{c_{1 x 1} A_{s 1}+c_{1 x 2} A_{s 2}+c_{1 x 3} A_{s 3}}{A_{s 1}+A_{s 2}+A_{s 3}} \\
c_{1 y m}=\frac{\left(c_{1 y 1}+c_{1 y 2}\right)\left(A_{s 1}+A_{s 2}+A_{s 3}\right)}{2\left(A_{s 1}+A_{s 2}+A_{s 3}\right)}
\end{gathered}
$$


Se todas as barras tiverem diâmetros iguais, as eqs. (60) e (61) resultam nas eqs. (62) e (63).

$$
\begin{gathered}
c_{1 x m}=\frac{2 c_{1 x 1}+c_{1 x 2}}{3} \\
c_{1 y m}=\frac{c_{1 y 1}+c_{1 y 2}}{2}
\end{gathered}
$$

A componente da resistência ao fogo, função do comprimento efetivo do pilar em situação de incêndio é dada pela eq. (64).

$$
R_{\ell}=9,6 .\left(5-\ell_{0, f i}\right)
$$

Onde:

$\ell_{0, \mathrm{fi}}=$ comprimento efetivo do pilar em situação de incêndio [m];

Para estruturas contraventadas, nas quais os pavimentos são compartimentados verticalmente e o TRRF é superior a 30 minutos, o comprimento efetivo do pilar em situação de incêndio $\left(\ell_{0, \mathrm{fi}}\right)$ pode ser adotado como $0,5 . \ell$ para os lances intermediários (entre pisos) e

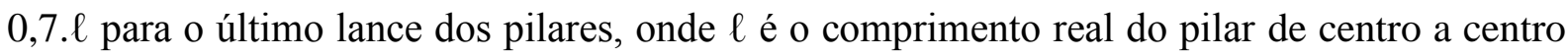
dos pisos (Figura 60). Essas hipóteses admitem que o pilar sob ação do fogo esteja engastado nos pisos inferior e superior. Isso é justificado considerando que os pisos estejam relativamente mais frios que o pilar e, portanto, mantendo certa rigidez e garantindo as condições de vinculação admitidas. A suposição das extremidades do pilar perfeitamente engastadas é um assunto divergente entre diversos pesquisadores, sendo aceita por alguns e rejeitada por outros (SILVA, 2008), mas recomendada pelo Eurocode 2 (EN 1992-1-2:2004). A mesma norma limita ainda o comprimento $\ell_{0, \text { fi }}$ ao máximo de 3 metros para aplicação do Método A. O projeto de revisão da norma ABNT NBR 15200:2004 sugere novas limitações para $\ell_{0, \mathrm{fi}}$, dependendo do nível de carregamento do pilar em situação de incêndio: $\ell_{0, \mathrm{fi}} \leq 2,00 \mathrm{~m}$ ou $\ell_{0, \mathrm{fi}} \leq 3,70 \mathrm{~m}$ e $\eta_{\mathrm{fi}} \leq 0,9-0,1 \ell_{0, \mathrm{fi}}$. Tais limitações só são válidas quando se utiliza métodos tabulares ou simplificados. 


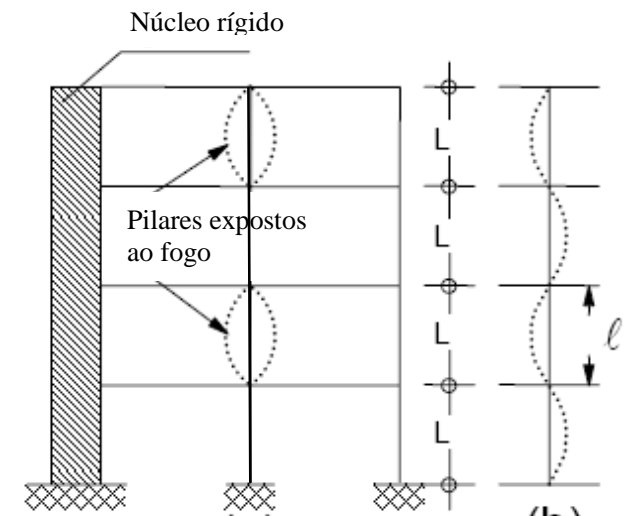

(a)

(b)

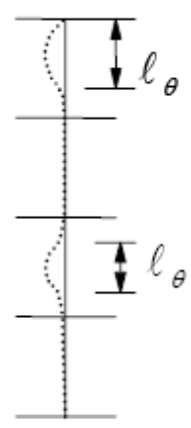

(c)

Figura 60 - Comprimentos efetivos de pilares em pórticos contraventados (a) seções ao longo do edifício,

(b) modo de deformação à temperatura ambiente e (c) modo de deformação em situação de incêndio (SILVA, 2008)

A componente da resistência ao fogo, função da largura efetiva da seção transversal, é dada pela eq. (65).

$$
R_{b}=0,09 \cdot b^{\prime}
$$

Onde:

$$
\begin{aligned}
& b^{\prime}=\left\{\begin{array}{cc}
\frac{2 . b \cdot h}{b+h} & \rightarrow \text { para seção transversal retangular } \\
\phi & \rightarrow \text { para seção transversal circular }
\end{array}\right. \\
& \mathrm{b}=\text { largura da seção transversal de pilar retangular [mm]; } \\
& \mathrm{h}=\text { comprimento da seção transversal de pilar retangular [mm]; } \\
& \phi=\text { diâmetro da seção transversal de pilar redondo [mm]. }
\end{aligned}
$$

O Eurocode 2 (EN 1992-1-2:2004) apresenta as seguintes limitações para as variáveis da eq. (65): $\mathrm{h} / \mathrm{b} \leq 1,5$ (para pilares retangulares) e $200 \mathrm{~mm} \leq \mathrm{b}^{\prime} \leq 450 \mathrm{~mm}$.

A componente da resistência ao fogo, função da quantidade de barras de aço é definida pela eq. (66).

$$
R_{n}=\left\{\begin{array}{cc}
0 & \rightarrow \text { para } \mathrm{n}=4 \\
12 & \rightarrow \text { para } \mathrm{n}>4
\end{array}\right.
$$


Onde:

$\mathrm{n}=$ quantidade total de barras longitudinais na seção transversal do pilar.

O Eurocode 2 (EN 1992-1-2:2004) sugere também limites para a excentricidade do carregamento de $1^{\mathrm{a}}$ ordem, definido pela expressão da eq. (67).

$$
e_{1}=\frac{M_{0 E d, f i}}{N_{0 E d, f i}} \leq e_{\text {máx }}
$$

Onde:

$\mathrm{e}_{1}=$ excentricidade de $1^{\mathrm{a}}$ ordem em situação de incêndio;

$\mathrm{M}_{0 \mathrm{Ed}, \mathrm{fi}}=$ momento fletor de cálculo do momento fletor atuante em uma direção, em situação de incêndio;

$\mathrm{N}_{0 \mathrm{Ed}, \mathrm{fi}}=$ esforço axial de cálculo em situação de incêndio;

$\mathrm{e}_{\text {máx }}=$ excentricidade máxima, dentro do intervalo $0,15 . \mathrm{h}$ (ou b) $\leq \mathrm{e}_{\text {máx }} \leq 0,4 . \mathrm{h}$ (e b). A

excentricidade máxima recomendada pelo Eurocode 2 (EN 1992-1-2:2004) é $\mathrm{e}_{\text {máx }}=0,15 . \mathrm{h}($ ou b);

A partir da expressão básica do método (eq. (48)), podem ser construídas tabelas que relacionam o TRF do pilar a dimensões mínimas e certos níveis de carregamento em situação de incêndio. Uma tabela com tais características é apresentada no item 5.3.2 do Eurocode 2 (EN 1992-1-2:2004). Silva (2008) fez uma análise crítica do Método A e sugeriu um método alternativo para ser incorporada à norma ABNT NBR 15200:2004.

É importante lembrar que a ocorrência do fenômeno de spalling deve ser evitada, de modo a garantir a eficiência dos métodos de cálculo, incluindo o Método A. Para isso, o Eurocode 2 (EN 1992-1-2:2004), no item 4.5 - Spalling, recomenda que a umidade livre no concreto seja inferior a 3\% e que, quando a distância das barras longitudinais à face aquecida mais próxima $\left(\mathrm{c}_{1}\right)$ for igual ou superior a $70 \mathrm{~mm}$, deve-se prever armadura de reforço da superfície (armadura de pele), com barras de diâmetro $\phi \geq 4 \mathrm{~mm}$ e espaçamento $\mathrm{s} \leq 100 \mathrm{~mm}$.

Por fim, alguns comentários e recomendações feitas por Franssen (2000), autor do Método A, são aqui apresentadas. Apesar do Método A ter sido proposto na forma de uma expressão que permite o cálculo do TRF de pilares segundo uma combinação qualquer das variáveis de entrada, o modelo em si pertence à classe dos métodos tabulares. A expressão da eq. (48) foi obtida por meio de ajuste de curvas (best fit), não sendo baseada em qualquer 
condição de equilíbrio. Por isso, o campo de aplicação do método restringe-se, para cada parâmetro, aos valores avaliados experimentalmente. Todas as limitações de parâmetros apresentadas anteriormente devem ser respeitadas.

\subsubsection{Método B do Eurocode 2 (EN 1992-1-2:2004)}

O item 5.3.3 do Eurocode 2 (EN 1992-1-2:2004) apresenta o Método B, desenvolvido pelo engenheiro espanhol José Maria Izquierdo (SILVA, 2008), utilizando o método de cálculo descrito no anexo B.3 da mesma norma. O Método B foi validado por meio de comparação com resultados experimentais, sendo um pouco mais conservador que o Método A descrito anteriormente (ver item 6.2.4 deste trabalho).

O Método B era válido somente para pilares de seção transversal quadrada, sendo alvo de críticas nos documentos de base do Eurocode 2 (DOTREPPE, 2004). Na última revisão do Eurocode 2 (EN 1992-1-2:2004), no entanto, o Método B é apresentado como válido para pilares retangulares e circulares, assim como o Método A.

As tabelas do Método B, presentes no item 5.3.3 e Anexo C do Eurocode 2 (EN 19921-2:2004), fornecem os valores mínimos (em mm) da largura dos pilares ( $b_{\text {mín }}$ ) e da distância entre as barras longitudinais à face aquecida mais próxima (a), para TRRF igual a 30, 60, 90, 120, 180 e 240 minutos. As variáveis de entrada são o nível de carregamento (n), a excentricidade de $1^{\mathrm{a}}$ ordem em situação de incêndio (e), o parâmetro de esbeltez do pilar em situação de incêndio $\left(\lambda_{\mathrm{fi}}\right)$ e a taxa mecânica de armadura $(\omega)$. No cálculo das tabelas, foi levado em consideração a não linearidade geométrica.

\subsubsection{Origem dos dados e análise do Método A}

Conforme mencionado anteriormente, o Método A foi proposto com base no resultado dos ensaios de 76 pilares. Posteriormente, os resultados de outros 4 pilares foram incluídos ao banco de dados, mas sem modificar o método originalmente proposto, totalizando 80 pilares. Cinco laboratórios foram responsáveis pelos ensaios, conforme mostra a Tabela 9. 
Tabela 9 - Laboratórios cujos experimentos serviram de base ao Método A do Eurocode 2 (EN 1992-12:2004) (COSTA, 2006).

\begin{tabular}{lcc}
\hline \multicolumn{1}{c}{ Laboratório } & País & $\begin{array}{c}\text { Pilares } \\
\text { ensaiados }\end{array}$ \\
\hline $\begin{array}{l}\text { Laboratório de Segurança Contra Incêndio da Universidade de Ghent e } \\
\text { Laboratório Magnel de Pesquisas de Concreto da Universidade de Ghent (RUG) }\end{array}$ & Bélgica & 12 \\
\hline Laboratório de Pontes e Engenharia Estrutural da Universidade de Liège (Ulg) & Bélgica & 8 \\
\hline Laboratório da Universidade Técnica de Braunschweig (TUBr) & Alemanha & 39 \\
\hline National Research Council of Canada (NRCC) & Canadá & 21 \\
\hline & Total & 80 \\
\hline
\end{tabular}

Costa (2006) reuniu e organizou as informações relevantes sobre esses 80 pilares (geometria, materiais e carregamentos). A pesquisadora precisou recorrer a diversas referências para reunir os dados de cada pilar, sendo que muitas vezes os dados estavam ausentes ou eram apresentados de maneira implícita. Houve situações em que os dados de um mesmo pilar eram contraditórios entre as referências consultadas. As características geométricas, dos materiais e dos carregamentos dos pilares descritos por Holmberg e Anderberg (1993), Franssen (2000), Franssen (2001), Franssen e Dotreppe (2003) e Dotreppe, J. -C. et al. ${ }^{45}$ (1996, apud COSTA, 2006) e reunidas por Costa (2006) são apresentadas na Tabela 10.

Costa (2006) fez uma avaliação criteriosa do Método A. Primeiro, recalculou o esforço normal resistente dos pilares à temperatura ambiente, utilizando os valores de resistência dos materiais medidos dos pilares ensaiados. Em seguida, recalculou o TRF dos 80 pilares segundo o Método A do Eurocode 2 (EN 1992-1-2:2004), apresentado anteriormente no item 7.2.4.

A maior dispersão dos resultados foi com relação aos pilares ensaiados pela Universidade Técnica de Braunshweig (TUBr), os quais possuem elevada esbeltez e dados imprecisos, como o valor do diâmetro das barras e o comprimento efetivo devido às condições de ensaio (COSTA, 2006). Franssen (2001) afirmou que alguns dos pilares ensaiados pela TUBr possuíam um dos lados engastados, justificando assim a adoção do comprimento efetivo $\ell_{0, \mathrm{fi}}=0,7 . \ell_{0}$ nos seus cálculos. Já Holmberg e Anderberg (1993) consideraram os comprimentos nominal e efetivo iguais, evidenciando que há confusão sobre o comprimento efetivo real desse grupo de 39 pilares. Costa (2006) concluiu que, para a calibração do Método A, ao que tudo indica, o comprimento efetivo $\ell_{0, \mathrm{fi}}=0,7 . \ell_{0}$ parece ter sido usado no

${ }^{45}$ DOTREPPE, J. -C. et al. Experimental research on the determination of the main parameters affecting the behaviour of reinforced concrete columns under fire conditions. Magazine of concrete research. Issue 49, No. 179. London: Thomas Telford Services Ltd., 1996. 
cálculo da componente de resistência ao fogo devido ao carregamento (eq. (49)) e o comprimento nominal $\ell_{0}$ parece ter sido usado no cálculo da componente de resistência ao fogo devido ao comprimento efetivo do pilar em situação de incêndio (eq. (64)).

A média da relação entre os resultados teóricos e experimentais da resistência ao fogo dos pilares investigados por Franssen (2001) foi $\mathrm{TRF}_{\text {calc }} / \mathrm{TRF}_{\text {experimental }}=1,19$, com desvio padrão de 0,38 e coeficiente de variação de 0,32 . Para os resultados calculados por Costa (2006), a relação entre os resultados teóricos e experimentais da resistência ao fogo dos 80 pilares foi $\mathrm{TRF}_{\text {calc }} / \mathrm{TRF}_{\text {experimental }}=1,18$ com desvio padrão de 0,42 e coeficiente de variação de 0,38 .

Verificou-se, por fim, que o Método A do Eurocode 2 (EN 1992-1-2:2004) foi calibrado para fornecer resultados limiares de segurança e, por vezes, ligeiramente contra a segurança. Portanto, esse método deve ser usado com cuidado, evitando adaptações, que poderiam reduzir significativamente sua confiabilidade (COSTA, 2006).

Em pesquisas recentes realizadas na Universidade de Coimbra, foram ensaiados oito pilares de concreto armado com restrição às deformações axiais e rotacionais (MARTINS e RODRIGUES, 2010). Os resultados fornecidos pelo Método A do Eurocode 2 (EN 1992-12:2004) foram excessivamente conservadores em relação aos valores de TRF medidos experimentalmente. 
Tabela 10 - Características geométricas, dos materiais e dos carregamentos dos pilares de concreto armado utilizados no modelo de cálculo do Método A do Eurocode 2 (EN 1992-1-2:2004) (COSTA, 2006)

\begin{tabular}{|c|c|c|c|c|c|c|c|c|c|c|c|c|c|c|c|c|c|c|c|c|c|c|c|}
\hline \multirow[b]{2}{*}{ País } & \multirow[b]{2}{*}{ Universidade } & \multirow[b]{2}{*}{ no } & \multirow[b]{2}{*}{ Lab. } & \multirow[b]{2}{*}{ Rótulo } & \multicolumn{3}{|c|}{ Seção transversal } & \multirow[b]{2}{*}{$\mathrm{L}(\mathrm{m})$} & \multirow[b]{2}{*}{ Modelo } & \multirow[b]{2}{*}{$\begin{array}{c}\mathrm{c} \\
(\mathrm{mm})\end{array}$} & \multicolumn{5}{|c|}{ Armaduras } & \multirow[b]{2}{*}{$\begin{array}{c}\mathrm{a} \\
(\mathrm{mm})\end{array}$} & \multicolumn{3}{|c|}{ Materiais } & \multicolumn{3}{|c|}{ Excentricidades } & \multirow[b]{2}{*}{$\begin{array}{l}\mathrm{N}_{\mathrm{Sd}, \mathrm{fi}} \\
(\mathrm{kN})\end{array}$} \\
\hline & & & & & $\begin{array}{c}\mathrm{b} \\
(\mathrm{cm}) \\
\end{array}$ & $\begin{array}{c}\mathrm{h} \\
(\mathrm{cm}) \\
\end{array}$ & $\begin{array}{l}\text { Área } \\
\left(\mathrm{cm}^{2}\right)\end{array}$ & & & & $\mathrm{n}$ & $\begin{array}{c}\phi \\
(\mathrm{mm})\end{array}$ & $\begin{array}{c}\text { As } \\
\left(\mathrm{cm}^{2}\right) \\
\end{array}$ & $\begin{array}{c}\rho= \\
\mathrm{A}_{\mathrm{s}} / \mathrm{A}_{\mathrm{c}} \\
\end{array}$ & $\begin{array}{l}\phi, \text { est. } \\
(\mathrm{mm}) \\
\end{array}$ & & $\begin{array}{c}\mathrm{f}_{\mathrm{c}} \\
(\mathrm{MPa}) \\
\end{array}$ & $\begin{array}{c}f_{y} \\
(\mathrm{MPa}) \\
\end{array}$ & agregado & $\begin{array}{r}\mathrm{e}_{\text {sup }} \\
(\mathrm{cm}) \\
\end{array}$ & $\begin{array}{r}\mathrm{e}_{\text {inf }} \\
(\mathrm{cm}) \\
\end{array}$ & $\begin{array}{c}\mathrm{e}_{1} \\
(\mathrm{~cm}) \\
\end{array}$ & \\
\hline Bélgica & Ghent & 1 & RUG & $31 \mathrm{~B}$ & 30 & 30 & 900,0 & 3,81 & $\mathrm{BA}^{*}$ & 25 & 4 & 16 & 8,04 & $0,89 \%$ & 6 & 33 & 33,9 & 576 & silicoso* & 0 & 0 & 0 & 950 \\
\hline Bélgica & Ghent & 2 & RUG & $31 \mathrm{C}$ & 30 & 30 & 900,0 & 3,81 & $\mathrm{BA}^{*}$ & 25 & 4 & 16 & 8,04 & $0,89 \%$ & 6 & 33 & 35,4 & 576 & silicoso* & 0 & 0 & 0 & 622 \\
\hline Bélgica & Ghent & 3 & RUG & $31 \mathrm{D}$ & 30 & 30 & 900,0 & 3,81 & $\mathrm{BA}^{*}$ & 25 & 4 & 16 & 8,04 & $0,89 \%$ & 6 & 33 & 36,5 & 576 & silicoso* & 2 & 2 & 2 & 220 \\
\hline Bélgica & Ghent & 4 & RUG & $31 \mathrm{E}$ & 30 & 30 & 900,0 & 3,81 & $\mathrm{BA}^{*}$ & 25 & 4 & 16 & 8,04 & $0,89 \%$ & 6 & 33 & 33,4 & 576 & silicoso* & -2 & 2 & 0,8 & 664 \\
\hline Bélgica & Ghent & 5 & RUG & $32 \mathrm{~A}$ & 30 & 30 & 900,0 & 3,81 & $\mathrm{BA}^{*}$ & 25 & 4 & 16 & 8,04 & $0,89 \%$ & 6 & 48 & 36,6 & 576 & silicoso* & 2 & 2 & 2 & 349 \\
\hline Bélgica & Ghent & 6 & RUG & $34 \mathrm{~A}$ & 30 & 30 & 900,0 & 3,81 & $\mathrm{BA}^{*}$ & 25 & 8 & 16 & 16,08 & $1,79 \%$ & 6 & 33 & 35,9 & 576 & silicoso* & 2 & 2 & 2 & 370 \\
\hline Bélgica & Ghent & 7 & RUG & $31 \mathrm{~F}$ & 30 & 30 & 900,0 & 3,81 & $\mathrm{BA}^{*}$ & 25 & 4 & 16 & 8,04 & $0,89 \%$ & 6 & 33 & 29,3 & 576 & silicoso* & 0 & 0 & 0 & 422 \\
\hline Bélgica & Ghent & 8 & RUG & $41 \mathrm{~A}$ & 40 & 40 & 1600,0 & 3,81 & $\mathrm{BA}^{*}$ & 25 & 8 & 16 & 16,08 & $1,01 \%$ & 8 & 33 & 29,6 & 576 & silicoso* & 2 & 2 & 2 & 1650 \\
\hline Bélgica & Ghent & 9 & RUG & $21 \mathrm{~A}$ & 30 & 20 & 600,0 & 3,81 & $\mathrm{BA}^{*}$ & 25 & 6 & 12 & 6,79 & $1,13 \%$ & 8 & 31 & 31,1 & 493 & silicoso* & 2 & 2 & 2 & 300 \\
\hline Bélgica & Ghent & 10 & RUG & 21B & 30 & 20 & 600,0 & 3,81 & $\mathrm{BA}^{*}$ & 25 & 6 & 12 & 6,79 & $1,13 \%$ & 8 & 31 & 29,6 & 493 & silicoso* & 2 & 2 & 2 & 178 \\
\hline Bélgica & Ghent & 11 & RUG & $22 \mathrm{~A}$ & 30 & 20 & 600,0 & 3,81 & $\mathrm{BA}^{*}$ & 25 & 6 & 12 & 6,79 & $1,13 \%$ & 8 & 41 & 32,5 & 493 & silicoso* & 2 & 2 & 2 & 283 \\
\hline Bélgica & Ghent & 12 & RUG & $22 \mathrm{~B}$ & 30 & 20 & 600,0 & 3,81 & $\mathrm{BA}^{*}$ & 25 & 6 & 12 & 6,79 & $1,13 \%$ & 8 & 41 & 32,4 & 493 & silicoso* & 2 & 2 & 2 & 334 \\
\hline Bélgica & Liège & 13 & Ulg & $31 \mathrm{BC}$ & 30 & 30 & 900,0 & 2,1 & BA* & 25 & 4 & 16 & 8,04 & $0,89 \%$ & 6 & 33 & 29,3 & 576 & silicoso* & 0 & 0 & 0 & 1270 \\
\hline Bélgica & Liège & 14 & Ulg & $31 \mathrm{CC}$ & 30 & 30 & 900,0 & 2,1 & $\mathrm{BA}^{*}$ & 25 & 4 & 16 & 8,04 & $0,89 \%$ & 6 & 33 & 28,6 & 576 & silicoso* & 0 & 0 & 0 & 803 \\
\hline Bélgica & Liège & 15 & Ulg & $21 \mathrm{BC}$ & 30 & 20 & 600,0 & 2,1 & $\mathrm{BA}^{*}$ & 25 & 6 & 12 & 6,79 & $1,13 \%$ & 8 & 31 & 30,6 & 493 & silicoso* & 0 & 0 & 0 & 611 \\
\hline Bélgica & Liège & 16 & Ulg & $22 \mathrm{BC}$ & 30 & 20 & 600,0 & 2,1 & $\mathrm{BA}^{*}$ & 25 & 6 & 12 & 6,79 & $1,13 \%$ & 8 & 41 & 27,3 & 493 & silicoso* & 0 & 0 & 0 & 620 \\
\hline Alemanha & Braunschweig & 17 & TUBr & 1 & 30 & 30 & 900,0 & 3,76 & $\mathrm{BA}^{*}$ & 28 & 6 & 20 & 18,85 & $2,09 \%$ & NF* & 38 & 24,1 & 487 & silicoso* & 3 & 3 & 3 & 710 \\
\hline Alemanha & Braunschweig & 18 & TUBr & 2 & 30 & 30 & 900,0 & 3,76 & $\mathrm{BA}^{*}$ & $28^{*}$ & 6 & $20^{*}$ & 18,85 & $2,09 \%$ & NF* & 38 & 24,1 & 487 & silicoso* & 0 & 0 & 0 & 930 \\
\hline Alemanha & Braunschweig & 19 & TUBr & 3 & 30 & 30 & 900,0 & 3,76 & $\mathrm{BA}^{*}$ & $28^{*}$ & 6 & $20^{*}$ & 18,85 & $2,09 \%$ & $\mathrm{NF}^{*}$ & 38 & 24,1 & 487 & silicoso* & 0 & 0 & 0 & 930 \\
\hline Alemanha & Braunschweig & 20 & TUBr & 4 & 30 & 30 & 900,0 & 4,76 & $\mathrm{BA}^{*}$ & $28^{*}$ & 6 & $20^{*}$ & 18,85 & $2,09 \%$ & $\mathrm{NF}^{*}$ & 38 & 24,1 & 487 & silicoso* & 3 & 3 & 3 & 650 \\
\hline Alemanha & Braunschweig & 21 & TUBr & 5 & 30 & 30 & 900,0 & 4,76 & $\mathrm{BA}^{*}$ & $28^{*}$ & 6 & $20^{*}$ & 18,85 & $2,09 \%$ & NF* & 38 & 24,1 & 487 & silicoso* & 0 & 0 & 0 & 880 \\
\hline Alemanha & Braunschweig & 22 & TUBr & 6 & 30 & 30 & 900,0 & 5,76 & $\mathrm{BA}^{*}$ & $28^{*}$ & 6 & $20 *$ & 18,85 & $2,09 \%$ & $\mathrm{NF}^{*}$ & 38 & 24,1 & 487 & silicoso* & 3 & 3 & 3 & 600 \\
\hline Alemanha & Braunschweig & 23 & TUBr & 7 & 30 & 30 & 900,0 & 5,76 & $\mathrm{BA}^{*}$ & $28^{*}$ & 6 & $20^{*}$ & 18,85 & $2,09 \%$ & NF* & 38 & 24,1 & 487 & silicoso* & 0 & 0 & 0 & 800 \\
\hline Alemanha & Braunschweig & 24 & TUBr & 8 & 20 & 20 & 400,0 & 3,76 & $\mathrm{BA}^{*}$ & $28^{*}$ & 4 & $20^{*}$ & 12,57 & $3,14 \%$ & $\mathrm{NF}^{*}$ & 38 & 24,1 & 487 & silicoso* & 0 & 0 & 0 & 420 \\
\hline Alemanha & Braunschweig & 25 & TUBr & 9 & 20 & 20 & 400,0 & 3,76 & $\mathrm{BA}^{*}$ & $28^{*}$ & 4 & $20^{*}$ & 12,57 & $3,14 \%$ & NF* & 38 & 24,1 & 487 & silicoso* & 0 & 0 & 0 & 420 \\
\hline Alemanha & Braunschweig & 26 & TUBr & 10 & 20 & 20 & 400,0 & 4,76 & $\mathrm{BA}^{*}$ & $28^{*}$ & 4 & 20 & 12,57 & $3,14 \%$ & NF* & 38 & 24,1 & 487 & silicoso* & 0 & 0 & 0 & 340 \\
\hline Alemanha & Braunschweig & 27 & TUBr & 11 & 30 & 30 & 900,0 & 4,76 & $\mathrm{BA}^{*}$ & $28^{*}$ & 6 & 20 & 18,85 & $2,09 \%$ & $\mathrm{NF}^{*}$ & 38 & 30,7 & 462 & silicoso* & 3 & 3 & 3 & 650 \\
\hline Alemanha & Braunschweig & 28 & TUBr & 12 & 30 & 30 & 900,0 & 4,76 & $\mathrm{BA}^{*}$ & $28^{*}$ & 6 & 20 & 18,85 & $2,09 \%$ & NF* & 38 & 30,7 & 462 & silicoso* & 3 & 3 & 3 & 650 \\
\hline Alemanha & Braunschweig & 29 & TUBr & 13 & 30 & 30 & 900,0 & 4,76 & $\mathrm{BA}^{*}$ & $28 *$ & 6 & 20 & 18,85 & $2,09 \%$ & $\mathrm{NF}^{*}$ & 38 & 30,7 & 462 & silicoso* & 1,5 & 1,5 & 1,5 & 740 \\
\hline Alemanha & Braunschweig & 30 & TUBr & 14 & 20 & 20 & 400,0 & 4,76 & $\mathrm{BA}^{*}$ & $28^{*}$ & 4 & 20 & 12,57 & $3,14 \%$ & NF* & 38 & 30,7 & 462 & silicoso* & 1 & 1 & 1 & 280 \\
\hline Alemanha & Braunschweig & 31 & TUBr & 15 & 20 & 20 & 400,0 & 4,76 & $\mathrm{BA}^{*}$ & $28^{*}$ & 4 & 20 & 12,57 & $3,14 \%$ & NF* & 38 & 30,7 & 462 & silicoso* & 2 & 2 & 2 & 240 \\
\hline Alemanha & Braunschweig & 32 & TUBr & 16 & 30 & 30 & 900,0 & 4,76 & $\mathrm{BA}^{*}$ & $28^{*}$ & 6 & 20 & 18,85 & $2,09 \%$ & NF* & 38 & 30,7 & 462 & silicoso* & 9 & 9 & 9 & 460 \\
\hline Alemanha & Braunschweig & 33 & TUBr & 17 & 30 & 30 & 900,0 & 4,76 & $\mathrm{BA}^{*}$ & $28^{*}$ & 6 & 20 & 18,85 & $2,09 \%$ & NF* & 38 & 30,7 & 462 & silicoso* & 15 & 15 & 15 & 362 \\
\hline Alemanha & Braunschweig & 34 & TUBr & 18 & 20 & 20 & 400,0 & 4,76 & $\mathrm{BA}^{*}$ & $28^{*}$ & 4 & $20^{*}$ & 12,57 & $3,14 \%$ & $\mathrm{NF}^{*}$ & 38 & 30,7 & 462 & silicoso* & 6 & 6 & 6 & 170 \\
\hline Alemanha & Braunschweig & 35 & TUBr & 19 & 20 & 20 & 400,0 & 4,76 & $\mathrm{BA}^{*}$ & $28^{*}$ & 4 & 20 & 12,57 & $3,14 \%$ & NF* & 38 & 30,7 & 462 & silicoso* & 10 & 10 & 10 & 130 \\
\hline Alemanha & Braunschweig & 36 & TUBr & 20 & 30 & 30 & 900,0 & 2,66 & $\mathrm{BA}^{*}$ & $28^{*}$ & 6 & $20^{*}$ & 18,85 & $2,09 \%$ & NF* & 38 & 33,2 & 458 & silicoso* & 3 & 3 & 3 & 845 \\
\hline $\begin{array}{l}\text { Alemanha } \\
\text { continua }\end{array}$ & Braunschweig & 37 & TUBr & 21 & 30 & 30 & 900,0 & 2,66 & $\mathrm{BA}^{*}$ & $28^{*}$ & 6 & $20^{*}$ & 18,85 & $2,09 \%$ & $\mathrm{NF}^{*}$ & 38 & 33,2 & 418 & silicoso $^{*}$ & 5 & 5 & 5 & 780 \\
\hline
\end{tabular}


continuação

\begin{tabular}{|c|c|c|c|c|c|c|c|c|c|c|c|c|c|c|c|c|c|c|c|c|c|c|c|}
\hline \multirow[b]{2}{*}{ País } & \multirow[b]{2}{*}{ Universidade } & \multirow[b]{2}{*}{ no. } & \multirow[b]{2}{*}{ Lab. } & \multirow[b]{2}{*}{ Rótulo } & \multicolumn{3}{|c|}{ Seção transversal } & \multirow[b]{2}{*}{$\begin{array}{c}\mathrm{L} \\
(\mathrm{m})\end{array}$} & \multirow[b]{2}{*}{ Modelo } & \multirow[b]{2}{*}{$\begin{array}{c}\mathrm{c} \\
(\mathrm{mm})\end{array}$} & \multicolumn{5}{|c|}{ Armaduras } & \multirow[b]{2}{*}{$\begin{array}{c}\mathrm{a} \\
(\mathrm{mm})\end{array}$} & \multicolumn{3}{|c|}{ Materiais } & \multicolumn{3}{|c|}{ Excentricidades } & \multirow[b]{2}{*}{$\begin{array}{l}\mathrm{N}_{\mathrm{Sd}, \mathrm{f}} \\
(\mathrm{kN})\end{array}$} \\
\hline & & & & & $\begin{array}{c}\mathrm{b} \\
(\mathrm{cm}) \\
\end{array}$ & $\begin{array}{c}\mathrm{h} \\
(\mathrm{cm}) \\
\end{array}$ & $\begin{array}{l}\text { Área } \\
\left(\mathrm{cm}^{2}\right)\end{array}$ & & & & $\mathrm{n}$ & $\begin{array}{c}\phi \\
(\mathrm{mm}) \\
\end{array}$ & $\begin{array}{c}\text { As } \\
\left(\mathrm{cm}^{2}\right)\end{array}$ & $\begin{array}{c}\rho= \\
\mathrm{A}_{\mathrm{s}} / \mathrm{A}_{\mathrm{c}} \\
\end{array}$ & $\begin{array}{l}\phi \text {,est. } \\
(\mathrm{mm})\end{array}$ & & $\begin{array}{c}\mathrm{f}_{\mathrm{c}} \\
(\mathrm{MPa}) \\
\end{array}$ & $\begin{array}{c}\mathrm{f}_{\mathrm{y}} \\
(\mathrm{MPa}) \\
\end{array}$ & agregado & $\begin{array}{c}\mathrm{e}_{\text {sup }} \\
(\mathrm{cm}) \\
\end{array}$ & $\begin{array}{c}\mathrm{e}_{\text {inf }} \\
(\mathrm{cm}) \\
\end{array}$ & $\begin{array}{c}\mathrm{e}_{1} \\
(\mathrm{~cm}) \\
\end{array}$ & \\
\hline Alemanha & Braunschweig & 38 & TUBr & 25 & 20 & 20 & 400,0 & 5,76 & $\mathrm{BA}^{*}$ & $28^{*}$ & 4 & $20^{*}$ & 12,57 & $3,14 \%$ & $\mathrm{NF}^{*}$ & 38 & 32,4 & 443 & silicoso* & 1 & 1 & 1 & 208 \\
\hline Alemanha & Braunschweig & 39 & TUBr & 26 & 30 & 30 & 900,0 & 3,33 & $\mathrm{BA}^{*}$ & $28^{*}$ & 6 & $20^{*}$ & 18,85 & $2,09 \%$ & $\mathrm{NF}^{*}$ & 38 & 30,7 & 433 & silicoso* & 1,5 & 1,5 & 1,5 & 735 \\
\hline Alemanha & Braunschweig & 40 & TUBr & 27 & 30 & 30 & 900,0 & 3,33 & BA* $^{*}$ & $28^{*}$ & 6 & $20^{*}$ & 18,85 & $2,09 \%$ & $\mathrm{NF}^{*}$ & 38 & 43,2 & 544 & silicoso* & 15 & 15 & 15 & 355 \\
\hline Alemanha & Braunschweig & 41 & TUBr & 28 & 30 & 30 & 900,0 & 4,76 & $\mathrm{BA}^{*}$ & $28^{*}$ & 6 & $20^{*}$ & 18,85 & $2,09 \%$ & $\mathrm{NF}^{*}$ & 38 & 31,5 & 499 & silicoso* & $-1,5$ & 1,5 & 0,6 & 735 \\
\hline Alemanha & Braunschweig & 42 & TUBr & 29 & 30 & 30 & 900,0 & 4,76 & BA* $^{*}$ & $28^{*}$ & 6 & $20^{*}$ & 18,85 & $2,09 \%$ & $\mathrm{NF}^{*}$ & 38 & 38,2 & 449 & silicoso* & -3 & 3 & 1,2 & 645 \\
\hline Alemanha & Braunschweig & 43 & TUBr & 30 & 30 & 30 & 900,0 & 4,76 & BA* $^{*}$ & $28^{*}$ & 6 & $20^{*}$ & 18,85 & $2,09 \%$ & $\mathrm{NF}^{*}$ & 38 & 38,2 & 404 & silicoso* & 0,5 & 0,5 & 0,5 & 1224 \\
\hline Alemanha & Braunschweig & 44 & TUBr & 31 & 30 & 30 & 900,0 & 3,76 & BA* & $28^{*}$ & 6 & 20 & 18,85 & $2,09 \%$ & $\mathrm{NF}^{*}$ & 38 & 42,3 & 452 & silicoso* & 0,5 & 0,5 & 0,5 & 1695 \\
\hline Alemanha & Braunschweig & 45 & TUBr & 37 & 30 & 30 & 900,0 & 4,7 & BA* & $28^{*}$ & 6 & $20^{*}$ & 18,85 & $2,09 \%$ & $\mathrm{NF}^{*}$ & 38 & 34,9 & 505 & silicoso* & 0,5 & 0,5 & 0,5 & 1548 \\
\hline Alemanha & Braunschweig & 46 & TUBr & 38 & 30 & 30 & 900,0 & 4,7 & BA* $^{*}$ & $28 *$ & 6 & $20 *$ & 18,85 & $2,09 \%$ & $\mathrm{NF}^{*}$ & 38 & 31,5 & 503 & silicoso* & 1 & 1 & 1 & 970 \\
\hline Alemanha & Braunschweig & 47 & TUBr & 39 & 30 & 30 & 900,0 & 4,7 & BA* $^{*}$ & $28^{*}$ & 6 & $20^{*}$ & 18,85 & $2,09 \%$ & $\mathrm{NF}^{*}$ & 38 & 31,5 & 526 & silicoso* & 1 & 1 & 1 & 1308 \\
\hline Alemanha & Braunschweig & 48 & TUBr & 40 & 30 & 30 & 900,0 & 4,7 & $\mathrm{BA}^{*}$ & $28^{*}$ & 6 & $20^{*}$ & 18,85 & $2,09 \%$ & $\mathrm{NF}^{*}$ & 38 & 31,5 & 503 & silicoso* & 15 & 15 & 15 & 280 \\
\hline Alemanha & Braunschweig & 49 & TUBr & 41 & 30 & 30 & 900,0 & 4,7 & $\mathrm{BA}^{*}$ & $28^{*}$ & 6 & $20^{*}$ & 18,85 & $2,09 \%$ & $\mathrm{NF}^{*}$ & 38 & 31,5 & 526 & silicoso* & 15 & 15 & 15 & 465 \\
\hline Alemanha & Braunschweig & 50 & TUBr & 42 & 20 & 20 & 400,0 & 5,71 & $\mathrm{BA}^{*}$ & $23^{*}$ & 6 & $14 *$ & 9,24 & $2,31 \%$ & $\mathrm{NF}^{*}$ & 30 & 41,5 & 480 & silicoso* & 10 & 10 & 10 & 140 \\
\hline Alemanha & Braunschweig & 51 & TUBr & 43 & 20 & 20 & 400,0 & 5,71 & $\mathrm{BA}^{*}$ & $23^{*}$ & 6 & $14 *$ & 9,24 & $2,31 \%$ & $\mathrm{NF}^{*}$ & 30 & 41,5 & 477 & silicoso* & 1 & 1 & 1 & 245 \\
\hline Alemanha & Braunschweig & 52 & TUBr & 44 & 20 & 20 & 400,0 & 5,71 & BA* $^{*}$ & $23^{*}$ & 6 & $14 *$ & 9,24 & $2,31 \%$ & $\mathrm{NF}^{*}$ & 30 & 41,5 & 480 & silicoso* & 5 & 5 & 5 & 172 \\
\hline Alemanha & Braunschweig & 53 & TUBr & 45 & 20 & 20 & 400,0 & 5,71 & $\mathrm{BA}^{*}$ & $23^{*}$ & 6 & $14 *$ & 9,24 & $2,31 \%$ & $\mathrm{NF}^{*}$ & 30 & 41,5 & 482 & silicoso* & 1 & 1 & 1 & 175 \\
\hline Alemanha & Braunschweig & 54 & TUBr & 46 & 20 & 20 & 400,0 & 5,71 & $\mathrm{BA}^{*}$ & $23 *$ & 6 & $14 *$ & 9,24 & $2,31 \%$ & $\mathrm{NF}^{*}$ & 30 & 41,5 & 485 & silicoso* & 5 & 5 & 5 & 122 \\
\hline Alemanha & Braunschweig & 55 & TUBr & 47 & 20 & 20 & 400,0 & 5,71 & BA* $^{*}$ & $23^{*}$ & 6 & $14 *$ & 9,24 & $2,31 \%$ & $\mathrm{NF}^{*}$ & 30 & 41,5 & 478 & silicoso* & 1 & 1 & 1 & 128 \\
\hline Canadá & --- & 56 & NRCC & I2 & 30,5 & 30,5 & 930,3 & 3,8 & BE* & $48^{*}$ & 4 & $25,5^{*}$ & 20,43 & $2,20 \%$ & $\mathrm{NF}^{*}$ & 60,75 & 36,9 & 444 & silicoso & 0 & 0 & 0 & 1333 \\
\hline Canadá & --- & 57 & NRCC & I3 & 30,5 & 30,5 & 930,3 & 3,8 & BE* & $48^{*}$ & 4 & $25,5^{*}$ & 20,43 & $2,20 \%$ & $\mathrm{NF}^{*}$ & 60,75 & 34,2 & 444 & silicoso & 0 & 0 & 0 & 800 \\
\hline Canadá & --- & 58 & NRCC & I4 & 30,5 & 30,5 & 930,3 & 3,8 & BE* & $48^{*}$ & 4 & $25,5^{*}$ & 20,43 & $2,20 \%$ & $\mathrm{NF}^{*}$ & 60,75 & 35,1 & 444 & silicoso & 0 & 0 & 0 & 711 \\
\hline Canadá & --- & 59 & NRCC & I6 & 20,3 & 20,3 & 412,1 & 3,8 & BE* & $48^{*}$ & 4 & 20 & 12,57 & $3,05 \%$ & $\mathrm{NF}^{*}$ & 58 & 42,3 & 442 & silicoso & 0 & 0 & 0 & 169 \\
\hline Canadá & --- & 60 & NRCC & I7 & 30,5 & 30,5 & 930,3 & 3,8 & BE* & $48^{*}$ & 4 & $25,5^{*}$ & 20,43 & $2,20 \%$ & $\mathrm{NF}^{*}$ & 60,75 & 36,1 & 444 & silicoso & 0 & 0 & 0 & 1067 \\
\hline Canadá & ---- & 61 & NRCC & I8 & 30,5 & 30,5 & 930,3 & 3,8 & BE* & $48^{*}$ & 4 & $25,5^{*}$ & 20,43 & $2,20 \%$ & $\mathrm{NF}^{*}$ & 60,75 & 34,8 & 444 & silicoso & 0 & 0 & 0 & 1778 \\
\hline Canadá & --- & 62 & NRCC & I9 & 30,5 & 30,5 & 930,3 & 3,8 & BE* & $48^{*}$ & 4 & $25,5^{*}$ & 20,43 & $2,20 \%$ & $\mathrm{NF}^{*}$ & 60,75 & 38,3 & 444 & silicoso & 0 & 0 & 0 & 1333 \\
\hline Canadá & --- & 63 & NRCC & II2 & 30,5 & 30,5 & 930,3 & 3,8 & BE* & $48^{*}$ & 4 & $25,5^{*}$ & 20,43 & $2,20 \%$ & $\mathrm{NF}^{*}$ & 60,75 & 43,6 & 444 & silicoso & 0 & 0 & 0 & 1044 \\
\hline Canadá & --- & 64 & NRCC & II3 & 30,5 & 30,5 & 930,3 & 3,8 & BE* & $48^{*}$ & 4 & $25,5^{*}$ & 20,43 & $2,20 \%$ & $\mathrm{NF}^{*}$ & 60,75 & 35,4 & 444 & silicoso & 0 & 0 & 0 & 916 \\
\hline Canadá & --- & 65 & NRCC & III & 30,5 & 30,5 & 930,3 & 3,8 & BE* & $48^{*}$ & 4 & $25,5^{*}$ & 20,43 & $2,20 \%$ & $\mathrm{NF}^{*}$ & 60,75 & 52,9 & 444 & silicoso & 0 & 0 & 0 & 1178 \\
\hline Canadá & --- & 66 & NRCC & II5 & 30,5 & 30,5 & 930,3 & 3,8 & BE* & $48^{*}$ & 4 & $25,5^{*}$ & 20,43 & $2,20 \%$ & $\mathrm{NF}^{*}$ & 60,75 & 49,5 & 444 & silicoso & 0 & 0 & 0 & 1067 \\
\hline Canadá & ---- & 67 & NRCC & II8 & 30,5 & 30,5 & 930,3 & 3,8 & BE* & $48^{*}$ & 8 & $25,5^{*}$ & 40,86 & $4,39 \%$ & $\mathrm{NF}^{*}$ & 60,75 & 42,6 & 444 & silicoso & 0 & 0 & 0 & 978 \\
\hline Canadá & --- & 68 & NRCC & III & 30,5 & 30,5 & 930,3 & 3,8 & BE* & $48^{*}$ & 8 & $25,5^{*}$ & 40,86 & $4,39 \%$ & $\mathrm{NF}^{*}$ & 60,75 & 37,1 & 444 & silicoso & 0 & 0 & 0 & 1333 \\
\hline Canadá & --- & 69 & NRCC & II10 & 40,6 & 40,6 & 1648,4 & 3,8 & BE* & $48^{*}$ & 8 & $25,5^{*}$ & 40,86 & $2,48 \%$ & $\mathrm{NF}^{*}$ & 60,75 & 38,8 & 444 & silicoso & 0 & 0 & 0 & 2418 \\
\hline Canadá & --- & 70 & NRCC & II11 & 40,6 & 40,6 & 1648,4 & 3,8 & BE* & 48 & 8 & $32 *$ & 64,34 & $3,90 \%$ & $\mathrm{NF}^{*}$ & 64,15 & 38,4 & 414 & silicoso & 0 & 0 & 0 & 2795 \\
\hline Canadá & --- & 71 & NRCC & II12 & 40,6 & 40,6 & 1648,4 & 3,8 & BE* & $64,15^{*}$ & 8 & $32 *$ & 64,34 & $3,90 \%$ & $\mathrm{NF}^{*}$ & 80,15 & 46,2 & 414 & silicoso & 0 & 0 & 0 & 2978 \\
\hline Canadá & --- & 72 & NRCC & III1 & 30,5 & 30,5 & 930,3 & 3,8 & $\mathrm{AE}^{*}$ & $48^{*}$ & 4 & $25,5^{*}$ & 20,43 & $2,20 \%$ & $\mathrm{NF}^{*}$ & 60,75 & 39,6 & 444 & silicoso & 0 & 0 & 0 & 800 \\
\hline Canadá & --- & 73 & NRCC & III2 & 30,5 & 30,5 & 930,3 & 3,8 & $\mathrm{AE}^{*}$ & $48^{*}$ & 4 & $25,5^{*}$ & 20,43 & $2,20 \%$ & $\mathrm{NF}^{*}$ & 60,75 & 39,2 & 444 & silicoso & 0 & 0 & 0 & 1000 \\
\hline Canadá & --- & 74 & NRCC & III3 & 30,5 & 30,5 & 930,3 & 3,8 & BE* & $56,75^{*}$ & 4 & $25,5^{*}$ & 20,43 & $2,20 \%$ & $\mathrm{NF}^{*}$ & 60,75 & 39,9 & 444 & calcáreo & 2,5 & 2,5 & 2,5 & 1000 \\
\hline Canadá & --- & 75 & NRCC & III5 & 30,5 & 45,7 & 1393,9 & 3,8 & $\mathrm{BE}^{*}$ & $48,1^{*}$ & 8 & $22 *$ & 30,41 & $2,18 \%$ & $\mathrm{NF}^{*}$ & 59,1 & 42,5 & 414 & silicoso & 0 & 0 & 0 & 1413 \\
\hline Canadá & --- & 76 & NRCC & III14 & 30,5 & 30,5 & 930,3 & 3,8 & $\mathrm{AE}^{*}$ & $56,75^{*}$ & 4 & $25,5^{*}$ & 20,43 & $2,20 \%$ & $\mathrm{NF}^{*}$ & 60,75 & 37,9 & 444 & silicoso & 2,5 & 0 & 1 & 1178 \\
\hline
\end{tabular}

continua 
conclusão

\begin{tabular}{|c|c|c|c|c|c|c|c|c|c|c|c|c|c|c|c|c|c|c|c|c|c|c|c|}
\hline \multirow[b]{2}{*}{ País } & \multirow[b]{2}{*}{ Universidade } & \multirow[b]{2}{*}{ no. } & \multirow[b]{2}{*}{ Lab. } & \multirow[b]{2}{*}{ Rótulo } & \multicolumn{3}{|c|}{ Seção transversal } & \multirow[b]{2}{*}{$\mathrm{L}(\mathrm{m})$} & \multirow[b]{2}{*}{ Modelo } & \multirow[b]{2}{*}{$\mathrm{c}(\mathrm{mm})$} & \multicolumn{5}{|c|}{ Armaduras } & \multirow[b]{2}{*}{$\begin{array}{c}\mathrm{a} \\
(\mathrm{mm})\end{array}$} & \multicolumn{3}{|c|}{ Materiais } & \multicolumn{3}{|c|}{ Excentricidades } & \multirow[b]{2}{*}{$\begin{array}{l}N_{\text {sd,fi }} \\
(\mathrm{kN})\end{array}$} \\
\hline & & & & & $\begin{array}{c}\mathrm{b} \\
(\mathrm{cm}) \\
\end{array}$ & $\begin{array}{c}\mathrm{h} \\
(\mathrm{cm}) \\
\end{array}$ & $\begin{array}{l}\text { Área } \\
\left(\mathrm{cm}^{2}\right)\end{array}$ & & & & $\mathrm{n}$ & $\begin{array}{c}\phi \\
(\mathrm{mm})\end{array}$ & $\begin{array}{c}\text { As } \\
\left(\mathrm{cm}^{2}\right)\end{array}$ & $\begin{array}{c}\rho= \\
\mathrm{A}_{\mathrm{s}} / \mathrm{A}_{\mathrm{c}}\end{array}$ & $\begin{array}{l}\phi, \text { est. } \\
(\mathrm{mm})\end{array}$ & & $\begin{array}{c}\mathrm{f}_{\mathrm{c}} \\
(\mathrm{MPa})\end{array}$ & $\begin{array}{c}\mathrm{f}_{\mathrm{y}} \\
(\mathrm{MPa})\end{array}$ & agregado & $\begin{array}{c}\mathrm{e}_{\text {sup }} \\
(\mathrm{cm})\end{array}$ & $\begin{array}{c}\mathrm{e}_{\mathrm{inf}} \\
(\mathrm{cm})\end{array}$ & $\begin{array}{c}\mathrm{e}_{1} \\
(\mathrm{~cm}) \\
\end{array}$ & \\
\hline Bélgica & ège & 77 & Ulg & $\mathrm{C} 1$ & $\phi 30$ & $\phi 30$ & 706,9 & 2,1 & $\mathrm{BA}^{*}$ & 30 & 6 & 12 & 6,79 & $0,96 \%$ & 8 & 44 & 60 & 500 & silicoso* & 0 & 0 & 0 & 1260 \\
\hline Bélgica & Liège & 78 & Ulg & $\mathrm{C} 2$ & $\phi 30$ & $\phi 30$ & 706,9 & 2,1 & BA* & 30 & 6 & 12 & 6,79 & $0,96 \%$ & 8 & 44 & 60 & 500 & silicoso* & 0 & 0 & 0 & 1770 \\
\hline Bélgica & Liège & 79 & Ulg & $\mathrm{C} 3$ & $\phi 30$ & $\phi 30$ & 706,9 & 2,1 & BA* & 30 & 6 & 20 & 18,85 & $2,67 \%$ & 8 & 48 & 60 & 500 & silicoso* & 0 & 0 & 0 & 1450 \\
\hline Bélgica & Liège & 80 & Ulg & C4 & $\phi 30$ & $\phi 30$ & 706,9 & 2,1 & $\mathrm{BA}^{*}$ & 30 & 6 & 20 & 18,85 & $2,67 \%$ & 8 & 48 & 60 & 500 & silicoso* & 0 & 0 & 0 & 1900 \\
\hline
\end{tabular}

* dados em itálico calculados ou deduzidos, por estarem ausentes nas referências consultadas por (COSTA, 2006)

* modelos de cálculo: biapoiado (BA), biengastado (BE) e apoiado-engastado (AE)

* NF: valor não fornecido nas referências consultadas por Costa (2006) 


\subsubsection{Outros métodos simplificados}

Na literatura especializada é possível encontrar diversos métodos simplificados para o cálculo do TRF de pilares de concreto em situação de incêndio.

Tan e Yao (2003) propuseram um método simplificado para o cálculo o TRF de pilares retangulares de concreto armado em situação de incêndio submetidos à flexão composta normal ou oblíqua, baseado no método do ACI (ACI, 2006) para o cálculo de pilares de concreto à temperatura ambiente. $\mathrm{O}$ método proposto divide-se em três etapas: (1) determinar os fatores de redução da resistência e do módulo de elasticidade dos materiais sob temperaturas elevadas para um dado tempo de incêndio; (2) calcular o nível de excentricidade do carregamento (pequena ou grande excentricidade) e o fator de ampliação dos momentos finais; (3) utilizando um processo de tentativa e erro, determinar a carga de falha do pilar e compará-la ao carregamento aplicado em situação de incêndio. Para cada etapa, os autores deduziram as expressões a serem aplicadas, calibrando-as com auxílio do software SAFIR®. Apesar de o método dispensar consultas a gráficos e tabelas de distribuição de temperaturas na seção transversal, sua aplicação é trabalhosa, devido ao processo de tentativa e erro. $\mathrm{O}$ método foi validado pelos autores calculando-se o TRF de 64 pilares (submetidos à flexão normal composta) e comparando os valores aos resultados dos ensaios experimentais desses mesmos pilares. Foram comparados também os valores do TRF de 68 pilares submetidos à flexão normal oblíqua, calculados pelo método proposto e calculados pelo software SAFIR®. Nesse caso, não foi possível fazer comparações com resultados experimentais devido à falta de dados confiáveis. As análises mostraram que o método proposto ficou a favor da segurança para os grupos de pilares estudados.

O método anteriormente descrito foi estendido para pilares aquecidos em 1, 2 ou 3 faces (TAN e YAO, 2004). As etapas para o cálculo dos pilares são as mesmas do método anterior, com algumas modificações. Os redutores de resistência e módulo de elasticidade dos materiais foram modificados. Foi incluído um novo processo de cálculo da excentricidade final do carregamento, que varia conforme o número de faces exposta ao fogo. Para pilares aquecidos em 1 ou 3 faces, a excentricidade do carregamento varia somente em uma direção, ou seja, os pilares ficam submetidos à flexão normal composta. Para pilares aquecidos em duas faces adjacentes, a variação da excentricidade do carregamento ocorre em duas direções no plano da seção transversal do pilar, resultando em um caso de flexão composta oblíqua. Dependendo da situação, a excentricidade final pode até mesmo mudar de sinal em relação à excentricidade inicial do carregamento, caso o carregamento esteja aplicado na região da 
seção transversal oposta às faces aquecidas. As deformações térmicas são as responsáveis por essa inversão. Tal efeito foi incluído na formulação proposta por Tan e Yao (2004). Devido à falta de resultados de ensaios experimentais de pilares em situação de incêndio aquecidos em 1, 2 ou 3 faces, os resultados do método proposto foram comparados aos resultados do software SAFIR®, para uma ampla gama de pilares (diversos índices de esbeltez, excentricidades iniciais do carregamento, dimensões da seção transversal, resistência do concreto, cobrimentos e tempos de exposição ao fogo). Segundo os autores, o método proposto ficou a favor da segurança para o grupo de pilares avaliado.

Outros métodos simplificados foram sugeridos por Wade et al. (1997) e Wu, Tang e Wang (2007).

\subsubsection{Método simplificado de Kodur e Raut (2009)}

Avaliando-se os métodos simplificados alternativos propostos na literatura, considerou-se oportuno apresentar com maiores detalhes o método proposto por Kodur e Raut (2009). Inicialmente, foram avaliados os parâmetros que influenciam o tempo de resistência ao fogo de pilares de concreto armado. Com o auxílio de um software de análises estatísticas (seu nome não foi informado pelos autores), foram traçadas curvas da variação do TRF dos pilares em função desses parâmetros. Kodur e Raut (2009) identificaram os seguintes parâmetros como relevantes para o TRF de pilares de concreto armado:

- Nível de carregamento: é mais importante do que o valor absoluto do carregamento normal aplicado ao pilar, pois representa o nível das tensões às quais o pilar está submetido. O TRF decresce com o aumento do nível de carregamento;

- Índice de esbeltez: as propriedades geométricas do pilar (principalmente as dimensões da seção transversal, comprimento e condições de vinculação do pilar) afetam o TRF dos pilares. Isso se deve ao fator do pilar tornar-se mais susceptível à instabilidade com o decréscimo da rigidez sob temperaturas elevadas. O nível de carregamento e o índice de esbeltez estão inter-relacionados em relação à influência no TRF do pilar;

- Cobrimento: maiores cobrimentos retardam o aumento da temperatura nas barras de aço. Esse fator possui influência moderada no TRF de pilares de concreto armado; 
- Taxa geométrica de armaduras: maiores taxas geométricas de armaduras diminuem o TRF dos pilares, pois a resistência do aço diminui mais rapidamente que a resistência do concreto sob temperaturas elevadas. Esse fator possui influência moderada no TRF de pilares de concreto armado;

- Tipo de agregado: pilares de concreto feito com agregados calcários apresentam TRF aproximadamente $10 \%$ superior que pilares de concreto feito com agregados silicosos. Esse fator possui influência moderada no TRF de pilares de concreto armado;

- Excentricidade do carregamento: carregamentos aplicados com maiores excentricidades diminuem significativamente o TRF de pilares de concreto armado. Esse efeito se deve aos momentos adicionais aplicados ao pilar por esse carregamento. Isso favorece a instabilidade do pilar, que possui rigidez reduzida sob temperaturas elevadas;

- Resistência do concreto: para concretos de resistência normal (inferior a $70 \mathrm{MPa}$, aproximadamente), esse parâmetro possui influência moderada no TRF dos pilares. Essa influência se manifesta no nível de carregamento, pois o esforço normal resistente do pilar depende da resistência do concreto.

O spalling não foi considerado como um dos parâmetros que influenciam nos valores do TRF, pois, segundo os autores, a literatura indica claramente que o spalling não é significativo em pilares de concreto com resistência normal.

O método proposto é semelhante ao Método A do Eurocode 2 (EN 1992-1-2:2004) quanto à forma de aplicação. A partir das análises paramétricas dos diversos fatores que influenciam o tempo de resistência ao fogo de pilares de concreto armado, os autores propuseram a seguinte expressão empírica (eq. (68)):

$$
R=C_{t} \cdot\left[8 \cdot k_{c p} \cdot k_{e c} \cdot\left(30-\left(S_{R}+5\right) \cdot\left(L_{R}-0,2\right)\right)\right]^{0,94}
$$

Onde:

$\mathrm{R}$ : tempo de resistência ao fogo do pilar [min.];

$\mathrm{C}_{\mathrm{t}}$ : constante dependendo do tipo de agregado utilizado no concreto. Possui valor igual a 1,0 para agregados silicosos e 1,1 para agregados calcários;

$\mathrm{S}_{\mathrm{R}}$ : índice de esbeltez do pilar [adimensional]; 
$\mathrm{L}_{\mathrm{R}}$ : nível de carregamento do pilar [adimensional].

O índice de esbeltez SR do pilar é definido pela eq. (69).

$$
S_{R}=\frac{L_{e}}{r}
$$

Onde:

$\mathrm{L}_{\mathrm{e}}$ : comprimento efetivo do pilar em situação de incêndio [m];

r: raio de giração $[\mathrm{m}]$.

O raio de giração é definido convencionalmente conforme mostra a eq. (70).

$$
r=\sqrt{\frac{I}{A}}
$$

Onde:

I: momento de inércia do pilar $\left[\mathrm{m}^{4}\right]$;

A: área da seção transversal do pilar $\left[\mathrm{m}^{2}\right]$.

O nível de carregamento LR do pilar é definido pela eq. (71).

$$
L_{R}=\frac{P}{P_{c a p}}
$$

Onde:

P: esforço normal aplicado ao pilar em situação de incêndio $[\mathrm{kN}]$;

$\mathrm{P}_{\text {cap }}$ : esforço normal resistente do pilar à temperatura ambiente $[\mathrm{kN}]$.

O esforço normal resistente do pilar em à temperatura ambiente é calculado segundo as orientações da norma ACI 318 (ACI, 2006), desconsiderando os efeitos de segunda ordem do pilar, conforme mostra a eq. (72).

$$
P_{c a p}=0,8 \cdot\left(0,85 \cdot A_{c} \cdot f_{c}^{\prime}+A_{s} \cdot f_{y}\right)
$$


Onde:

$\mathrm{A}_{\mathrm{c}}$ : área de concreto da seção transversal $\left[\mathrm{m}^{2}\right]$;

$\mathrm{f}^{\prime}$ : : resistência característica do concreto $\left[\mathrm{kN} / \mathrm{m}^{2}\right]$;

$\mathrm{A}_{\mathrm{s}}$ : área total de aço na seção transversal $\left[\mathrm{m}^{2}\right]$;

$\mathrm{f}_{\mathrm{y}}$ : resistência ao escoamento do aço $\left[\mathrm{kN} / \mathrm{m}^{2}\right]$.

O parâmetro $\mathrm{k}_{\mathrm{cp}}$ da eq. (68) é definido pela eq. (73).

$$
k_{c p}=\frac{\left\lfloor\left(C_{e}-82\right) \cdot\left(S_{p}+10,5\right)+870\right\rfloor}{390}
$$

Onde:

$\mathrm{C}_{\mathrm{e}}$ : cobrimento nominal de concreto $[\mathrm{mm}]$;

$\mathrm{S}_{\mathrm{p}}$ : taxa geométrica de armaduras na seção transversal [\%];

O parâmetro $\mathrm{k}_{\mathrm{ec}}$ da eq. (68) é definido pela eq..

$$
\begin{array}{cc}
k_{e c}=1 & \text { para Ec }=0 \\
k_{e c}=\frac{\left[\left(S_{R}-243\right) \cdot(E c-768)-83250\right]}{99880} & \text { para Ec } \neq 0
\end{array}
$$

Onde:

Ec: excentricidade de aplicação do carregamento [mm];

Como o método foi proposto com base na análise de dados experimentais, é necessário definir limites de aplicabilidade para esse método (KODUR e RAUT, 2009):

a) tempo de resistência ao fogo: 60-240 minutos;

b) pilares expostos ao incêndio-padrão segundo a curva ISO 834 (ISO, 1990) ou ASTM E119 (ASTM, 2000);

c) resistência do concreto aos 28 dias $\left(\mathrm{f}^{\prime} \mathrm{c}\right): 25-70 \mathrm{MPa}$;

d) dimensões do pilar (retangular ou circular): 20-60 cm;

e) taxa geométrica de armaduras: $1-4 \%$;

f) comprimento efetivo dos pilares: $200-450 \mathrm{~cm}$; 
g) excentricidade do carregamento axial: $0-0,75 . b$, onde $b$ é a dimensão da seção transversal na direção da excentricidade;

h) concretos feitos com agregados silicosos ou calcários.

Kodur e Raut (2009) aplicaram o método proposto em diversos pilares e compararam os resultados aos dados experimentais. Os valores do TRF calculados pelo método proposto ficaram na maioria dos casos a favor da segurança. Os autores verificaram que o método proposto apresentou valores de TRF contra a segurança para alguns pilares (TRF inferior a 60 minutos) e valores de TRF excessivamente conservadores para pilares com TRF superior a 240 minutos. No entanto, essa constatação não é preocupante, pois a maioria dos casos práticos apresenta TRRF entre 60 e 240 minutos, por isso essa limitação foi incorporada ao método proposto, conforme apresentado anteriormente.

Para pilares com maiores dimensões da seção transversal (até $60 \mathrm{~cm}$ ), os resultados do método proposto foram comparados aos resultados do TRF de pilares de concreto armado calculados pelo software SAFIR®, devido à falta de resultados experimentais. O método proposto por Kodur e Raut (2009) novamente apresentou resultados a favor da segurança para esses pilares.

A vantagem do método proposto em relação ao Método A do Eurocode 2 (EN 1992-12:2004) é em relação à consideração explícita da excentricidade de aplicação do carregamento no método proposto. Apesar do Método B do Eurocode 2 (EN 1992-1-2:2004) considerar a excentricidade de aplicação do carregamento, seus resultados são considerados muito conservadores. Recomenda-se fazer um estudo comparativo entre o método proposto por Kodur e Raut (2009) e os Métodos A e B do Eurocode 2 (EN 1992-1-2:2004), para avaliar a confiabilidade dos resultados, e também o conservadorismo, dos três métodos.

\subsection{MÉTODOS AVANÇADOS}

O projeto de estruturas em situação de incêndio utilizando métodos de cálculo avançados são um meio eficaz, normalmente com boa relação custo-benefício e mais flexíveis que os métodos prescritivos (tabulares). Um determinado problema pode ser estudado sob diferentes cenários de incêndio, materiais, geometrias, carregamentos e condições de apoio. Esses estudos podem ser feitos em períodos de tempo relativamente curtos, permitindo melhor compreensão do comportamento da estrutura durante o incêndio até o colapso. Além 
disso, as analises numéricas permitem simular condições difíceis de reproduzir em ensaios de laboratório (FIB, 2007).

Os primeiros estudos sobre modelagem geralmente representaram a resposta termomecânica do concreto por meio da extensão dos modelos baseados em isotermas para incorporar a dependência térmica nas propriedades do concreto. Na maioria dos programas comerciais de elementos finitos, as propriedades mecânicas dos materiais como resistência e módulo de elasticidade são simplesmente relacionadas à temperatura. No entanto, esse procedimento não considera as mudanças irreversíveis que os materiais experimentam no decorrer do incêndio (FLETCHER et al., 2007). É necessário compreender com clareza as limitações e o campo de validade de cada programa para que sejam usados de acordo com suas potencialidades, evitando o risco de tirar conclusões com base em algoritmos inadequados ao problema em estudo. Essas afirmações tem por objetivo alertar para o uso coerente dos programas disponíveis no mercado ou apresentados em trabalhos acadêmicos, como nesta dissertação.

Como uma das iniciativas para o desenvolvimento de métodos de cálculo avançados de pilares em situação de incêndio, numa pesquisa do Swedish Board for Testing em Borås, Suécia, num processo de colaboração entre o Lund Institute of Technology e a Technischen Universität Braunschweig, foram ensaiados em laboratório três pilares de concreto armado aquecidos em três faces, no início da década de 1980. Os cálculos computacionais em alguns casos concordaram e em outros casos divergiram dos resultados experimentais. Segundo os autores da pesquisa, os problemas em se prever adequadamente o comportamento dos pilares em situação de incêndio se deveram aos modelos analíticos do concreto e do aço (ANDERBERG e HAKSEVER, 1981). Outras questões levantadas na pesquisa foram a influência do histórico de carregamento da peça e a consideração da taxa de aquecimento, que poderiam ter efeito significativo nos cálculos.

O programa especializado Vulcan ${ }^{\circledR}$ tem sido progressivamente desenvolvido ao longo da última década na Universidade de Sheffield, Inglaterra, para modelagem tridimensional do comportamento de estruturas de concreto e aço em situação de incêndio (BAILEY, BURGESS e PLANK, 1996; CAI, BURGESS e PLANK, 2003; HUANG, BURGESS e PLANK, 1999; HUANG, BURGESS e PLANK, 2003; HUANG, BURGESS e PLANK, 2006; NAJJAR e BURGESS, 1996). Nesse programa, um elemento finito não linear (material e geométrico) e composto por diversas camadas foi desenvolvido para analisar lajes de concreto armado sob temperaturas elevadas. Também um elemento finito tridimensional de 3 nós, mais robusto e adequado para simular seções transversais genéricas, foi desenvolvido 
para modelar pórticos de concreto armado e aço em situação de incêndio. Para ambos os elementos finitos, a seção transversal da peça é dividida em diversos segmentos, e a cada qual pode ser atribuída uma temperatura, material e propriedades termomecânicas diferentes. Os modelos incorporam ainda diversos fenômenos típicos de estruturas em situação de incêndio, como expansão térmica, deformações transientes, degradação das curvas tensão-deformação, falha dos elementos de concreto por fissuração ou esmagamento e escoamento do aço (HUANG, BURGESS e PLANK, 2003).

Muito recentemente, Huang, Burgess e Plank (2009) reformularam o elemento finito não linear tridimensional do software Vulcan ${ }^{\circledR}$ para torná-lo mais robusto e incorporar os efeitos do spalling. Para isso, considerou-se na discretização da seção transversal a possibilidade de haver um "elemento nulo" (void element, conforme denominado pelos autores), ou seja, com resistência térmica, resistência mecânica e rigidez nulos.

O software SAFIR ${ }^{\circledR}$, desenvolvido na Universidade de Liège, realiza a análise termoestrutural de estruturas de concreto, aço, madeira e alumínio. O programa realiza a análise térmica considerando as curvas de incêndio-padrão ou considerando curvas inseridas pelo usuário, considerando as propriedades térmicas dos materiais. Para a análise estrutural, o programa disponibiliza elementos de treliça, vigas ou placas, todos apropriados para análises bidimensionais ou tridimensionais considerando a não linearidade geométrica. Os diferentes elementos podem ser combinados num único modelo. Não é possível considerar propriedades mecânicas dos materiais além daquelas predefinidas no programa. A fluência do concreto é modelada de forma implícita por meio dos modelos constitutivos e não são considerados os efeitos do spalling (FRANSSEN, 2005).

O software CONFIRE® modela as estruturas de concreto em situação de incêndio utilizando elementos de viga com três graus de liberdade por nó. São consideradas as propriedades termomecânicas do aço e do concreto. As parcelas de deformação do concreto sob temperaturas elevadas foram programadas de forma explícita. O programa leva em conta a não linearidade geométrica e dos materiais (ANDERBERG e FORSÉN, 1982).

No desenvolvimento de métodos de cálculo avançados, são levantadas diversas questões que influenciam diretamente na modelagem e nos resultados desses métodos. Por exemplo, o modo de aplicação do carregamento nos cálculos computacionais é uma questão ainda pouco discutida. Segundo alguns autores, negligenciar o histórico de carregamento geralmente resulta em maior rigidez à compressão e menor deformação axial nos cálculos analíticos (ANDERBERG e HAKSEVER, 1981). 
O comportamento real do concreto armado em situação de incêndio é controlado pelo histórico de estados de tensões multiaxiais, temperaturas e teores de umidade (KHOURY, 2000b; GEORGALI e TSAKIRIDIS, 2005). A consideração desse histórico pode ser significativa no caso de elementos em situação de incêndio submetidos à flexocompressão, nos quais a distribuição de tensões internas muda continuamente ao longo do tempo. $\mathrm{O}$ concreto deve ser considerado como um sistema multifásico, no qual os vazios estão parcialmente preenchidos com líquidos e gases compostos de ar e vapor d'água. Para simular realisticamente o comportamento do concreto sob ações complexas, o modelo numérico deve considerar a transferência de calor e massa acoplada à análise mecânica.

\subsubsection{Análise térmica}

Para os métodos avançados, o primeiro passo é determinar a distribuição de temperaturas na seção transversal do elemento em estudo, para diversos tempos de exposição ao fogo. Em modelos de cálculo integrados, a distribuição de temperaturas é calculada considerando as propriedades mecânicas e teores de umidade dos elementos, para cada incremento de tempo. A análise térmica proporciona a resposta final quanto à função de isolamento, mas não para a capacidade portante nem a resposta completa para a função de separação (estanqueidade) (FIB, 2007).

O Anexo A do Eurocode 2 parte 1-2 (EN 1992-1-2:2004) e Costa (2008) fornecem os diagramas de distribuição de temperaturas para algumas seções transversais de concreto submetidas ao incêndio-padrão segundo a curva ISO 834 (ISO, 1990) (Figura 61). Há na literatura diagramas calculados segundo curvas paramétricas de incêndio (ANDERBERG ${ }^{46}$, 1992 apud FIB, 2007).

Como normalmente se considera que a temperatura dos gases é uniforme no compartimento, as temperaturas são constantes ao longo do eixo do elemento estrutural, sendo necessário somente análise térmica bidimensional na seção transversal. Geralmente é desprezada também a influência do restante da estrutura próxima aos apoios do elemento (FIB, 2007).

O conhecimento da distribuição de temperaturas na seção transversal é o primeiro passo para a avaliação do comportamento de estruturas em situação de incêndio. A

${ }^{46}$ ANDERBERG, Y. Manual on fire engineering design of concrete structures - temperature appendix. Swedish Board for Building Research, 1992. 
temperatura dos gases pode exceder os $1000^{\circ} \mathrm{C}$ com relativa facilidade. No entanto, como o concreto possui baixa condutividade térmica, os gradientes de temperaturas nas camadas mais externas são elevados, enquanto que as temperaturas nas camadas mais internas permanecem relativamente baixas (FIB, 2007).

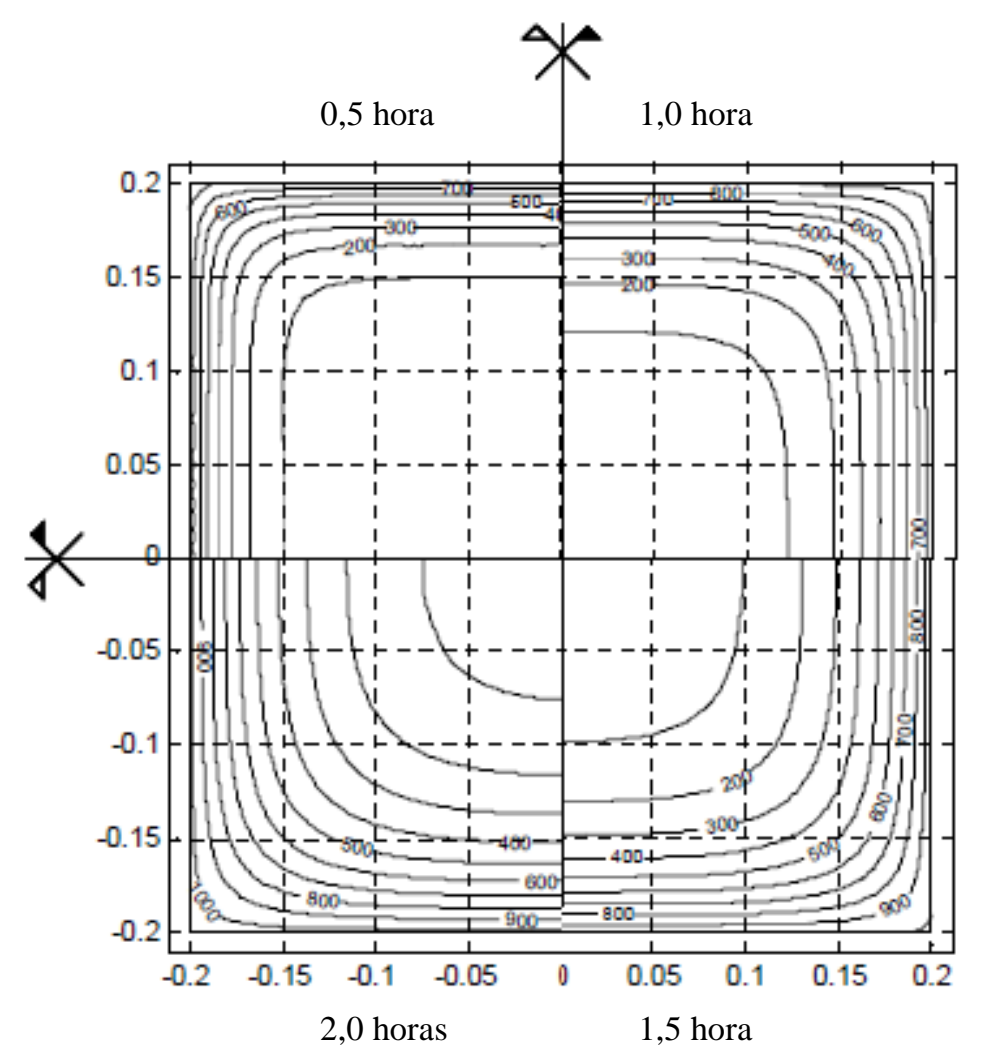

Figura 61 - Distribuição das isotermas numa seção transversal de concreto de 40 x $40 \mathrm{~cm}$, para diversos tempos de exposição ao incêndio-padrão (COSTA, 2008)

\subsubsection{Análise termo-mecânica}

Neste procedimento a análise térmica e a análise mecânica são feitas em etapas distintas. Primeiro é feita a análise térmica abrangendo toda a duração do incêndio. Em seguida é feita a análise mecânica, que utiliza os resultados da análise térmica como dados de entrada. Não se consideram os efeitos da umidade nem a interdependência entre as análises. No entanto, estudos de validação desse procedimento mostraram que é possível calcular com razoável precisão o comportamento de elementos estruturais simples. É importante que os modelos considerem a LITS (conforme item 4.1.6.4 deste trabalho). Uma vez considerada a LITS, pode-se dispensar a consideração da fluência transiente, sem grandes prejuízos à 
precisão dos resultados. A falta de análise envolvendo transporte de umidade impossibilita a avaliação do spalling. Dependendo da formulação do elemento finito adotado, é possível calcular a perda da capacidade resistente da peça devido à formação de fissuras (FIB, 2007).

A análise termo-mecânica é utilizada em programas de elementos finitos (Vulcan®, SAFIR®, etc.) e foi adotada no método deste trabalho.

\subsubsection{Análise termo-hidro-mecânica abrangente}

A análise termo-hidro-mecânica abrangente é o tipo de análise mais sofisticada na área de estruturas de concreto em situação de incêndio, considerando as três parcelas de forma acoplada. O procedimento é iterativo e pode prever o spalling explosivo. A possibilidade de avaliar o transporte de umidade no concreto é importante na análise de reatores nucleares, por exemplo. Na maioria dos casos práticos, no entanto, métodos mais simples são suficientes para a análise de estruturas de concreto em situação de incêndio (FIB, 2007).

Um modelo avançado chamado HITECOSP (High Temperature Concrete Spalling) foi sugerido em 1999, num trabalho de cooperação entre o ENEA de Roma, Itália, e o Imperial College de Londres, Inglaterra (Figura 62). Nesse modelo o concreto foi considerado como um material multifásico, composto de uma fase sólida, duas fases gasosas e três fases líquidas. Foram incluídos os efeitos de danos (por exemplo, fissuração) na permeabilidade do concreto e as não linearidades devido à temperatura. Foram incorporadas as mudanças de fase físico-químicas, tais como hidratação-desidratação, evaporação-condensação e adsorçãodessorção. As mudanças de fase do concreto foram incluídas diretamente no modelo do material, nos seus mecanismos de transporte. A fusão e evaporação das fibras de polipropileno foram modeladas como mudanças de fases (FIB, 2007).

O comportamento completo do concreto foi modelado, incluindo as fases elástica, inelástica, plástica e fraturas. $\mathrm{O}$ modelo físico foi baseado em experimentos realizados por laboratórios europeus como parte do programa HITECO. Pela primeira vez foi incorporado num modelo o comportamento do concreto à tração direta, assim como características do comportamento de concretos de alta resistência e ultra-alta resistência. Considerou-se a fase de fluidos formada por água, vapor e ar seco. A parcela de água divide-se em água livre e água nos tubos capilares do concreto. A água quimicamente associada foi considerada como parte da fase sólida, até ser liberada durante o aquecimento. A fase sólida pode sofrer 
deformação elástica, plástica, térmica, fluência ("básica" e transiente), retração e fissuração. O modelo é explicado em detalhes por Khoury et al. (2002) e Schrefler et al. (2002).

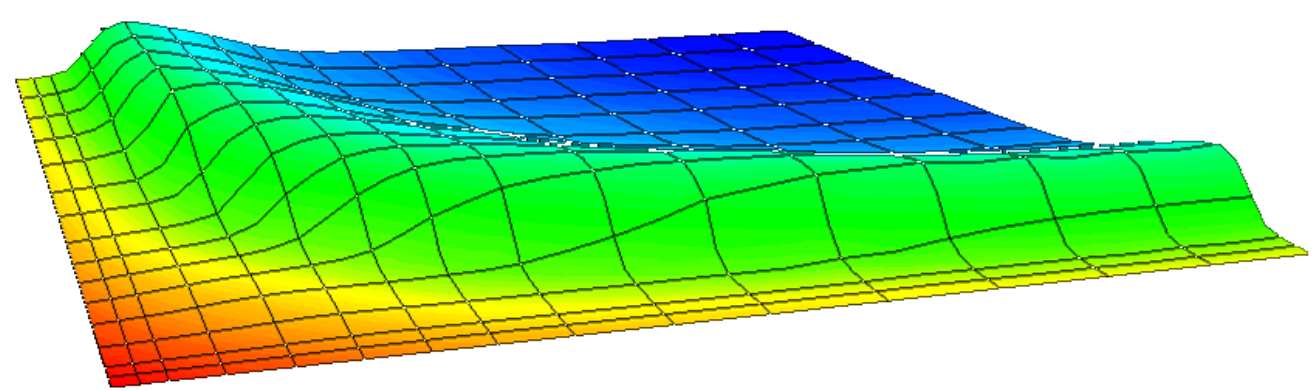

Figura 62 - Distribuição de temperaturas e pressões nos poros de uma seção de concreto calculados pelo software HITECOSP (ENEA; PADOVA UNIVERSITY, 1999)

Um modelo avançado e termodinamicamente consistente foi proposto por Stabler ${ }^{47}$ (2000 apud FLETCHER et al., 2007). Os efeitos da elevação da temperatura foram incluídos por meio de um modelo de dano térmico e as equações de equilíbrio térmico e mecânico foram resolvidas considerando-as totalmente acopladas. Entretanto, os efeitos higrotérmicos e a fluência térmica transiente não foram incluídos no modelo, e esses são fenômenos importantes nos cálculos da resposta ao aquecimento. Tenchev e Purnell (2005) desenvolveram um modelo numérico de transferência de calor e massa no qual todas as fases são explicitamente modeladas, mas sem qualquer acoplamento mecânico. Esse último aspecto seria uma extensão natural, visto que a desidratação e o transporte de massa sob temperaturas elevadas que influenciam nas alterações das propriedades mecânicas do material e na perda de coesão e rigidez. Há outros modelos higrotermomecânicos, que consideram esses efeitos completamente acoplados, disponíveis na literatura (KHOURY, 2000b; KHOURY et al., 2002; GRASBERGER e MESCHKE ${ }^{48}, 2000$ apud FLETCHER et al., 2007; ULM, COUSSY e BAZANT, 1999).

${ }^{47}$ STABLER, J. Computational modeling of thermo-mechanical damage and plasticity in concrete. Ph. D. Thesis, Dept. of Civil Engineering, University of Queensland, Australia, 2000.

${ }^{48}$ GRASBERGER, S.; MESCHKE, G. A hygral-thermal-poroplastic damage model for the durability analyses of concrete structures. Proceedings. European Congress Computational Methods in Applied Sciences \& Engineering, Barcelona, Espanha, 2000. 


\subsubsection{Métodos baseados em limitação das deformações}

Para a determinação do diagrama de interação esforço normal x momento resistentes no estado limite último (ELU) à temperatura ambiente, adota-se o método baseado na limitação das deformações, a partir do conhecido diagrama de domínios de deformação da norma ABNT NBR6118:2003 (Figura 63).

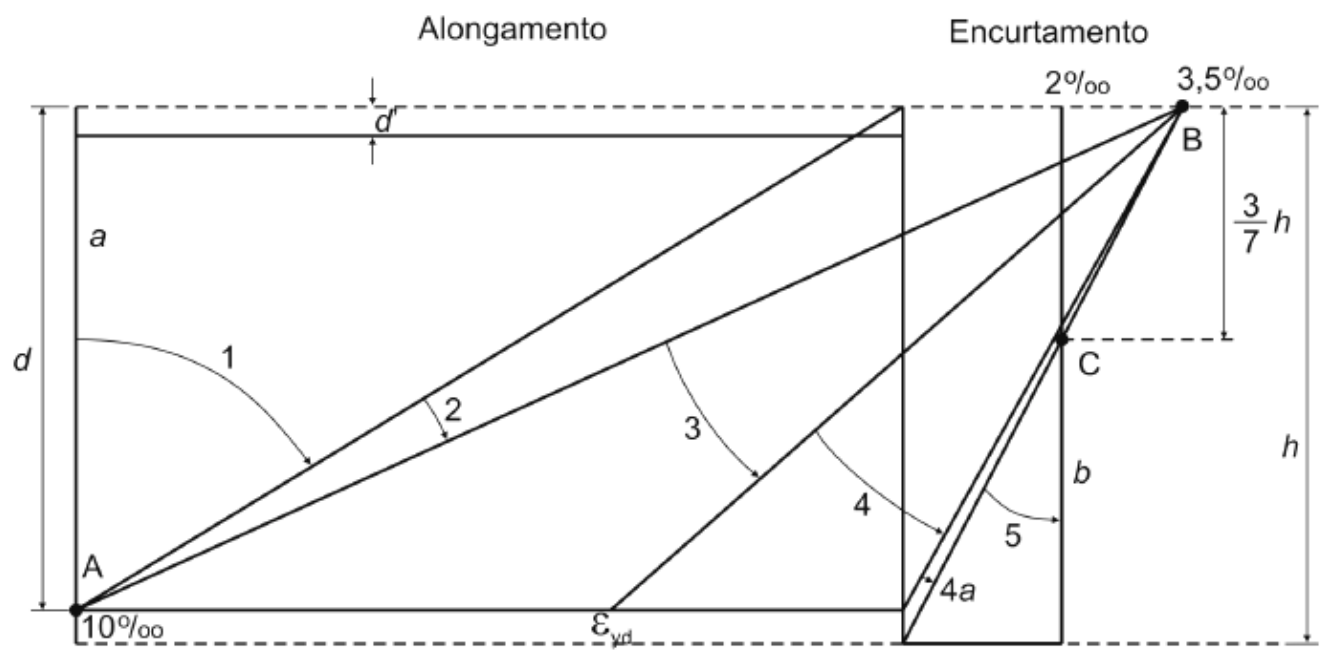

Figura 63 - Domínios de deformação no ELU (ABNT NBR 6118:2003)

No caso de projeto de estruturas de concreto armado em situação de incêndio é natural pensar, num primeiro momento, de forma análoga. No entanto, tal abordagem não pode ser diretamente aplicada, como será explicado a seguir.

O Boletim 46 do fib (FIB, 2008) explica que análises não lineares com limitação das deformações não podem ser feitas utilizando os diagramas tensão-deformação com ramo descendente do Eurocode 2 (EN 1992-1-2:2004). Isso porque as deformações últimas em um dos materiais (aço ou concreto) geralmente não correspondem à capacidade resistente última da seção transversal. Na verdade, quando a deformação última é atingida na fibra de concreto mais solicitada, a maior parte da seção transversal já atingiu a zona de descarregamento, ou seja, as tensões já são inferiores à tensão máxima $f_{c}$.

Os diagramas de interação esforço normal x momento fletor da Figura 65 foram obtidos por meio de análise não linear com limitação das deformações (no entanto, os valores das deformações últimas adotadas não são citados pelo Boletim 46 do fib) utilizando três diferentes curvas tensão deformação para o concreto, conforme mostra a Figura 64. Os resultados são claramente diferentes ao utilizar as três relações constitutivas, e a capacidade 
resistente da seção transversal é fortemente subestimada quando se utiliza a curva do Eurocode 2 (EN 1992-1-2:2004), ou seja, com ramo descendente.

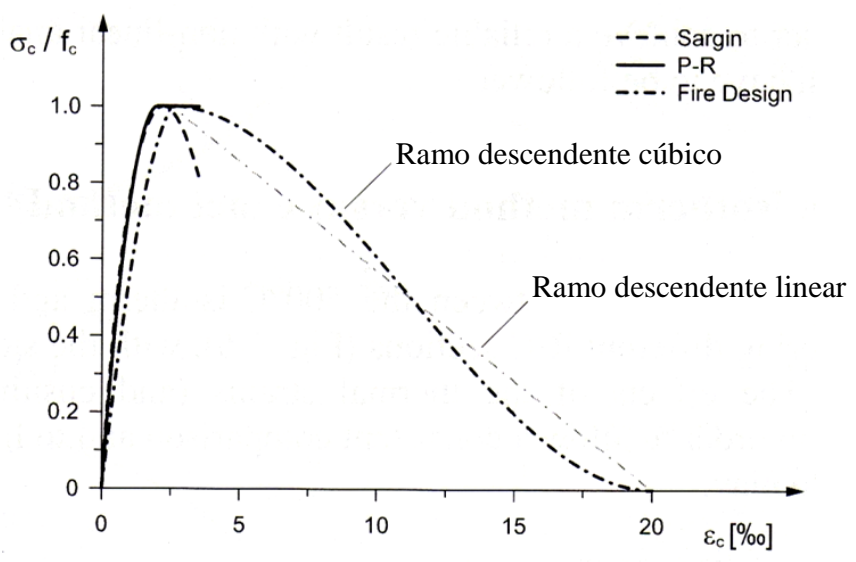

Figura 64 - Curvas tensão-deformação do concreto sob temperaturas elevadas (FIB, 2008). Linha tracejada: modelo de Sargin; linha cheia: parábola-retângulo; linha traço-ponto: modelo constitutivo do Eurocode 2 (EN 1992-1-2:2004)

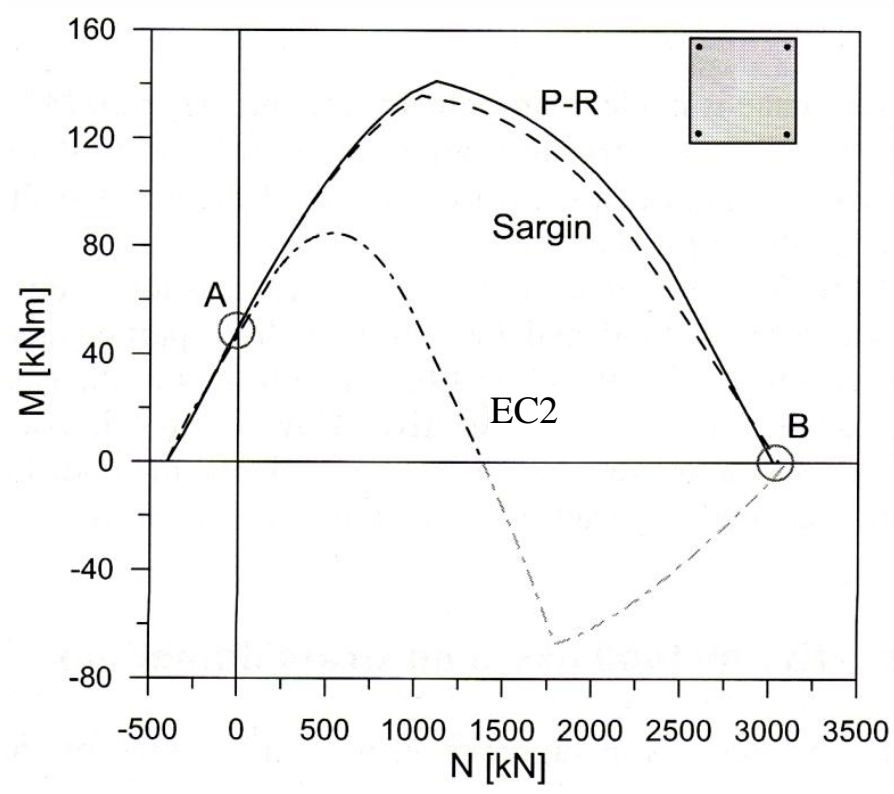

Figura 65 - Diagramas de interação esforço normal $x$ momento fletor para uma seção transversal quadrada $\left(30 \mathrm{~cm} \times 30 \mathrm{~cm}, 4\right.$ barras de $16 \mathrm{~mm}$ de diâmetro, $f_{c}=30 \mathrm{MPa}, f_{\mathrm{y}}=500 \mathrm{MPa}$, cobrimento $3 \mathrm{~cm}$ ) obtidos por análise não linear, utilizando 3 diferentes curvas tensão-deformação (FIB, 2008)

Embora a capacidade resistente à flexão simples (ponto $\mathrm{A}$ da Figura 65) e à compressão simples (ponto B da Figura 65) sejam quase os mesmos para as três relações constitutivas (as diferenças no ponto B dependem da tensão máxima do aço), é importante lembrar que a parte negativa da curva traço-ponto não possui significado físico. A estimativa para menos da capacidade resistente da seção transversal é evitada se a relação tensão- 
deformação do Eurocode 2 (EN 1992-1-2:2004) for utilizada adequadamente em análise não linear, ou seja, sem limitação das deformações.

As evidências apresentadas anteriormente mostram claramente que, mediante utilização de curvas tensão-deformação em função da temperatura adequadas (com ramo descendente limitado ou sem ramo descendente), é possível fazer análises não lineares simples ao invés do procedimento iterativo-incremental (definição dos esforços resistentes últimos a partir do diagrama momento-curvatura), conforme mostra a Figura 66. Tais curvas, como por exemplo, a curva parábola-retângulo da Figura 64, não representam o real comportamento do concreto e devem então ser validadas comparando-as a procedimento iterativo-incrementais ou resultados de ensaios, como foi originalmente feito para a curva parábola-retângulo utilizada atualmente para projeto à temperatura ambiente.

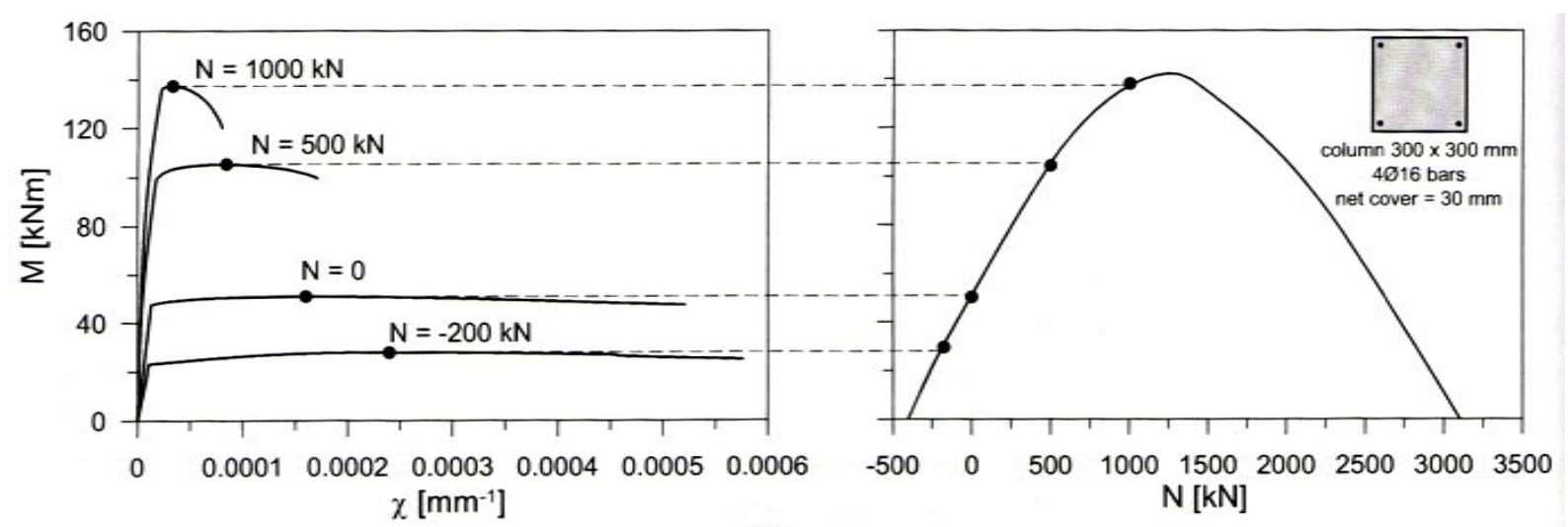

(a)

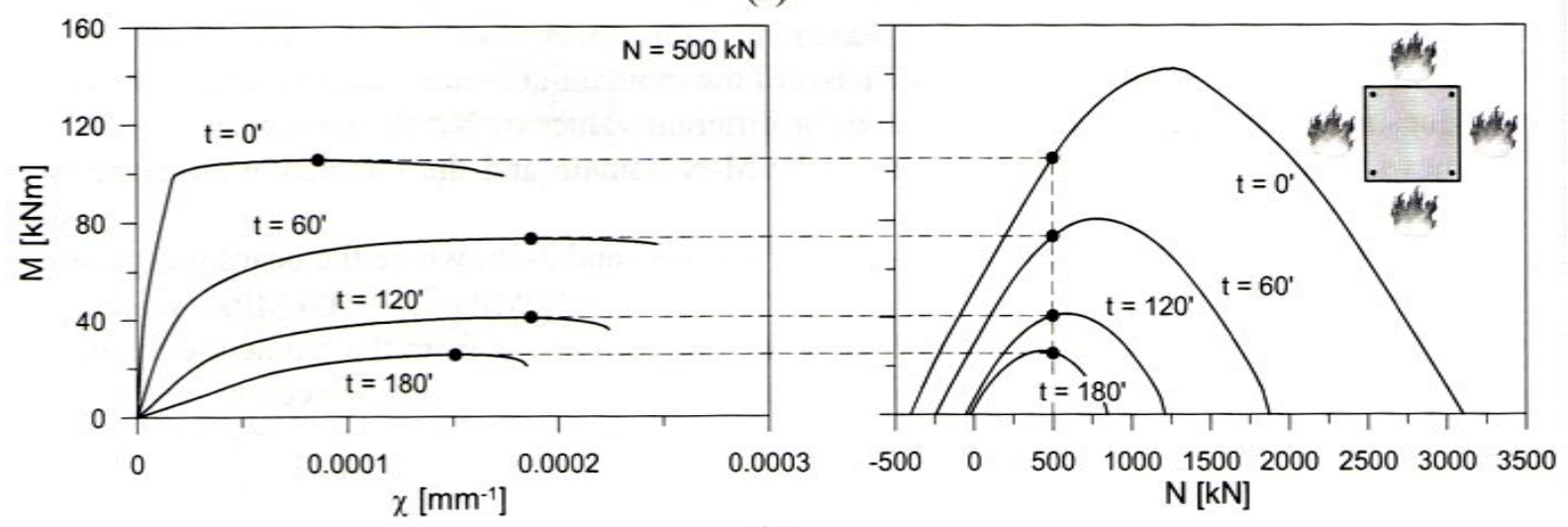

(b)

Figura 66 - Processo iterativo-incremental para obtenção dos esforços resistentes últimos de pilares (a) à temperatura ambiente e (b) para diferentes tempos de exposição ao fogo

O Boletim 46 do fib (FIB, 2008) apresenta uma proposta de extensão do método com limitação das deformações (normalmente utilizado para projeto à temperatura ambiente) para projeto de estruturas de concreto em situação de incêndio (Figura 67). O procedimento foi 
originalmente proposto por Meda, Gambarova e Bonomi (2002). Para cada duração de incêndio, considera-se um diagrama de domínios de deformações no estado limite último, adotando as deformações últimas no concreto $\left(\varepsilon_{\mathrm{cu}}^{\mathrm{T}}\right)$ e no aço $\left(\varepsilon_{\mathrm{su}}^{\mathrm{T}}\right)$. Uma vez que o concreto se torna mais dútil com o aumento da temperatura, é suficiente que se respeite as deformações últimas ao longo do plano mais frio (e, portanto, menos dútil) da seção transversal. Dessa forma, as deformações últimas em qualquer outro ponto da seção transversal são automaticamente respeitadas. No caso de seção transversal quadrada aquecida nas quatro faces, o plano mais frio é o plano médio (Figura 67-a).

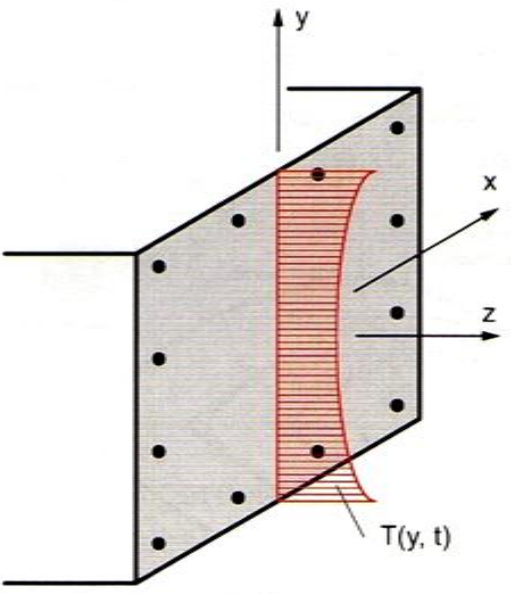

(a)

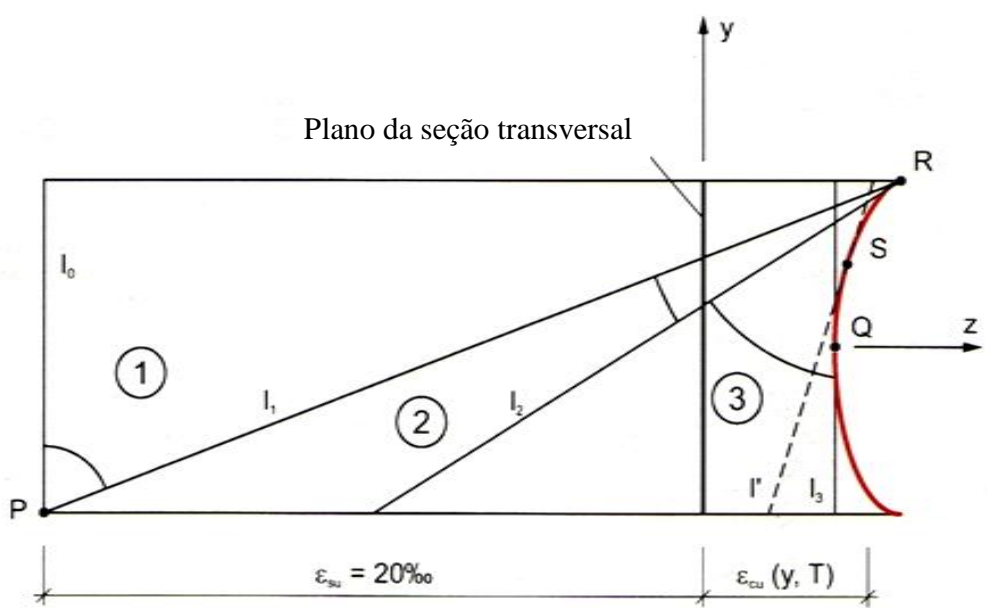

(b)

Figura 67 - (a) Perfil de temperaturas ao longo do plano médio de seção transversal quadrada aquecida nas quatro faces e (b) domínios de deformação para o ELU (FIB, 2008)

De forma análoga à análise não linear à temperatura ambiente, os domínios de deformação são divididos conforme segue (Figura 67-b):

- Domínio 1: varia desde a linha $1_{0}$, que representa a falha por tração pura, até a linha $\mathrm{l}_{1}$, que corresponde à deformação última no aço (ponto $\mathrm{P}$ ) juntamente com deformação última no concreto (ponto R). O ponto fixo (pivô) é o ponto $\mathrm{P}$.

- Domínio 2: variando da linha $1_{1}$ até a linha $l_{2}$ (com pivô no ponto $\mathrm{R}$ ), até que o perfil de deformações tangencie o perfil de deformações últimas do concreto. $\mathrm{O}$ perfil de deformações gira em torno do ponto fixo $\mathrm{R}$.

- Domínio 3: variando da linha 12 até a linha 13. Não há ponto fixo para os perfis de deformação, mas o pivô $\mathrm{S}$ se move ao longo do perfil de deformações últimas do concreto, que varia entre os pontos $\mathrm{R}$ e $\mathrm{Q}$.

Uma vez que no Domínio 3 o pivô se move, este método foi batizado de "Método do Pivô Móvel” (MEDA, GAMBAROVA e BONOMI, 2002). É importante notar que, enquanto o gradiente de temperaturas for baixo na periferia da seção transversal, o Domínio 2 existe, mas desaparece quando o gradiente de temperaturas se torna elevado (geralmente o gradiente 
de temperaturas cresce com o aumento da temperatura). Para perfis de deformação lineares ao longo do plano médio da seção transversal, a deformação em qualquer ponto pode ser calculada, assumindo a hipótese da seção transversal permanecer plana. Como consequência, as tensões podem ser calculadas usando as curvas tensão-deformação para cada ponto e os esforços resistentes últimos $\left(\mathrm{N}_{\mathrm{u}}\right.$ e $\left.\mathrm{M}_{\mathrm{u}}\right)$ podem ser calculados por meio de integração das tensões.

As curvas tensão-deformação em função da temperatura descritas a seguir foram obtidas por meio de ajuste de curvas aplicado ao diagrama de interação $\mathrm{N}_{\mathrm{u}}-\mathrm{M}_{\mathrm{u}}$ previamente calculados pelo método iterativo-incremental, para diferentes durações de incêndio. Para cada curva tensão-deformação, os dois parâmetros determinados por meio de ajuste de curvas são a tensão máxima $\mathrm{f}_{\mathrm{c}}^{\mathrm{T}}$ e a deformação máxima $\varepsilon_{\mathrm{cu}}^{\mathrm{T}}$, enquanto que a deformação $\varepsilon_{\mathrm{c} 1}^{\mathrm{T}}$ correspondente à tensão máxima foi assumida idêntica aos valores sugeridos pelo Eurocode 2 (EN 1992-1-2:2004). Foram testadas diversas seções transversais (quadrada, retangular e circular, conforme a Figura 68), sempre aquecidas em todas as faces de modo a garantir a simetria.

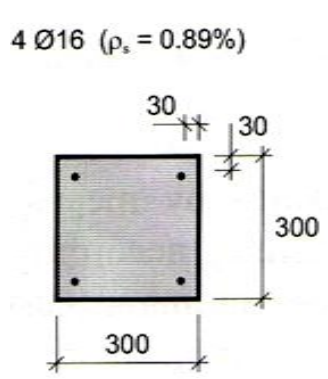

Seção 1

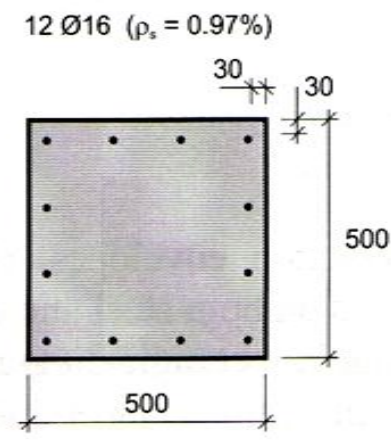

Seção 2

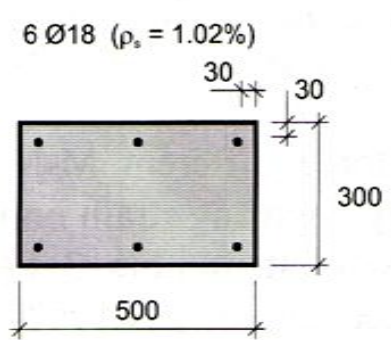

Seção 3

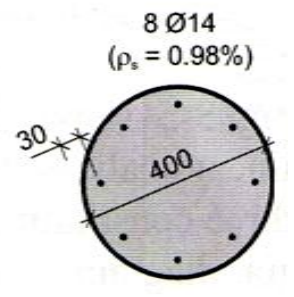

Seção 4

Figura 68 - Seções transversais estudadas (FIB, 2008)

A Figura 69 e Figura 70 apresentam os diagramas tensão-deformação resultantes, comparados às curvas propostas pelo Eurocode 2 (EN 1992-1-2:2004), as quais possuem ramo descendente. 


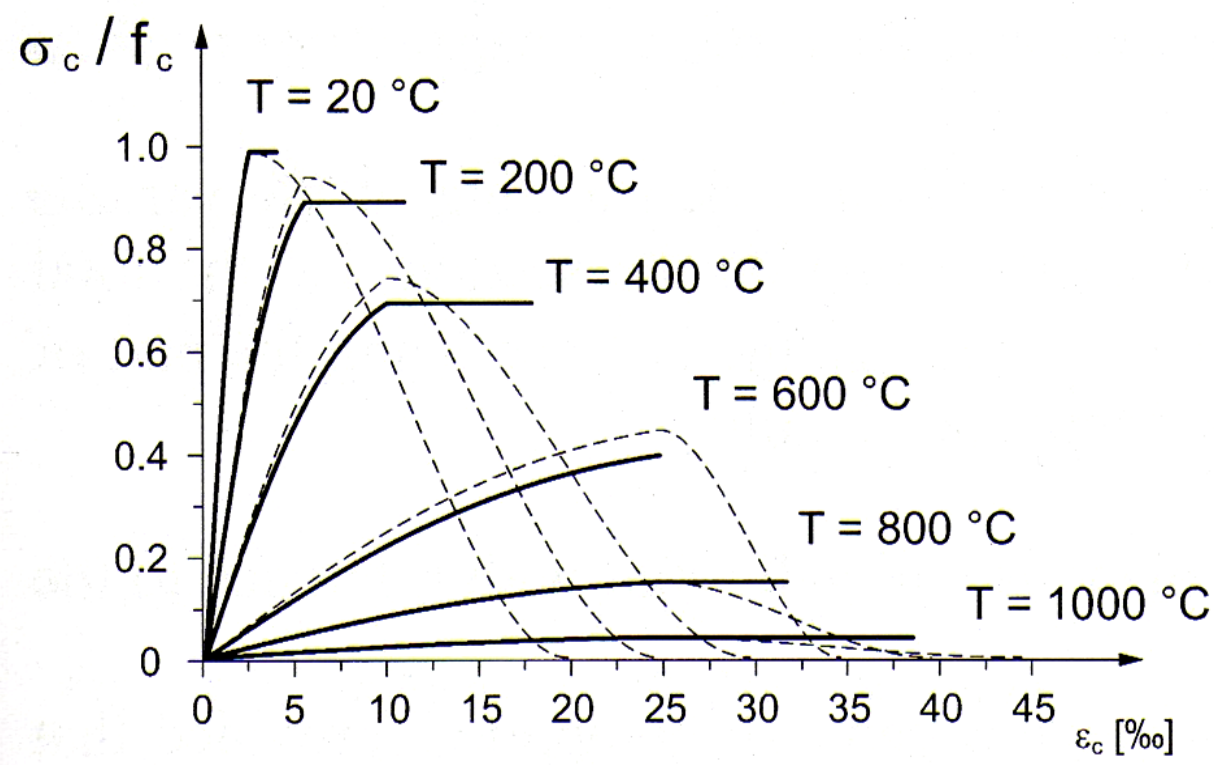

Figura 69 - Curvas tensão-deformação do concreto em função da temperatura, para uso em análises com limitação das deformações (linhas contínuas) e curvas propostas pelo Eurocode 2 (EN 1992-1-2:2004) (linhas tracejadas) para uso em análises iterativo-incrementais (FIB, 2008)

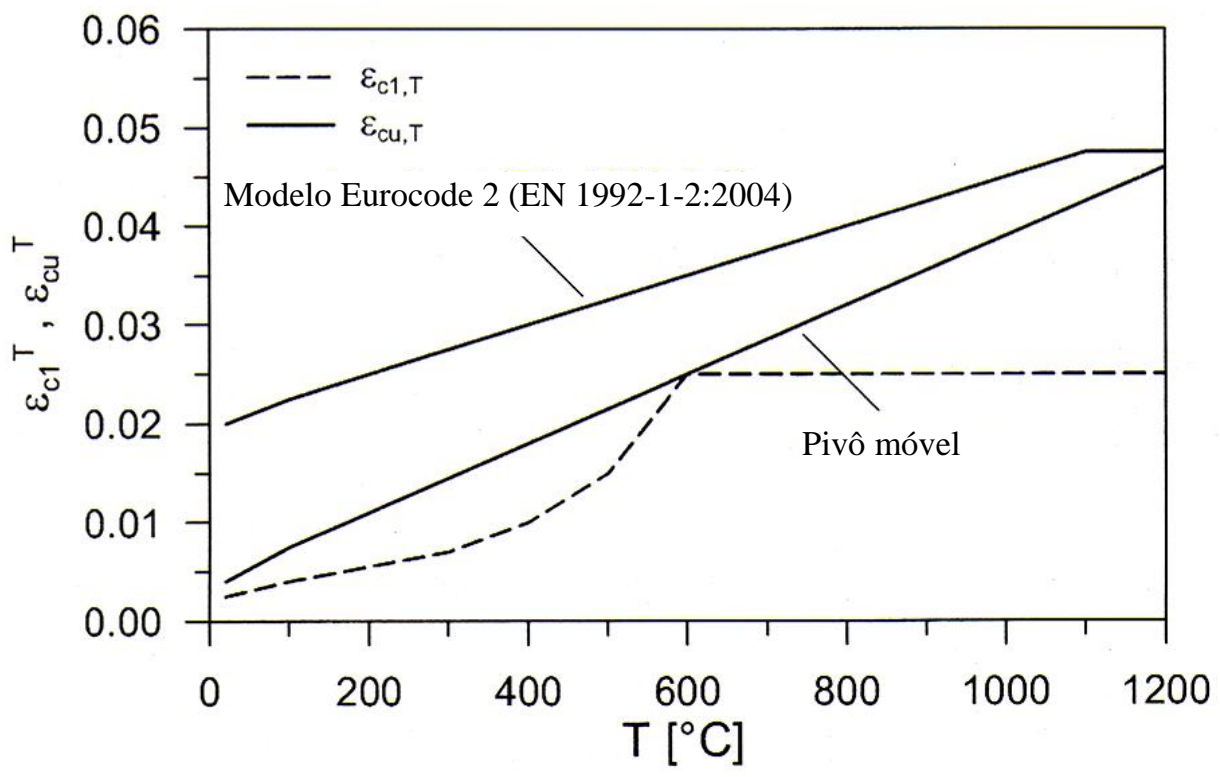

Figura 70 - Deformação de pico e deformação última das curvas tensão-deformação obtidas para os métodos com limitação das deformações (FIB, 2008)

É importante destacar que as curvas propostas (monotônicas) possuem tensão de pico constante para deformações maiores que $\varepsilon_{\mathrm{c} 1}{ }^{\mathrm{T}} \mathrm{e}$ as deformações últimas $\varepsilon_{\mathrm{cu}}{ }^{\mathrm{T}}$ menores que as das curvas do Eurocode 2 (EN 1992-1-2:2004).

Os resultados obtidos para a Seção 1 (Figura 68) com o método proposto são comparados aos obtidos pelo método iterativo-incremental na Figura 71. 


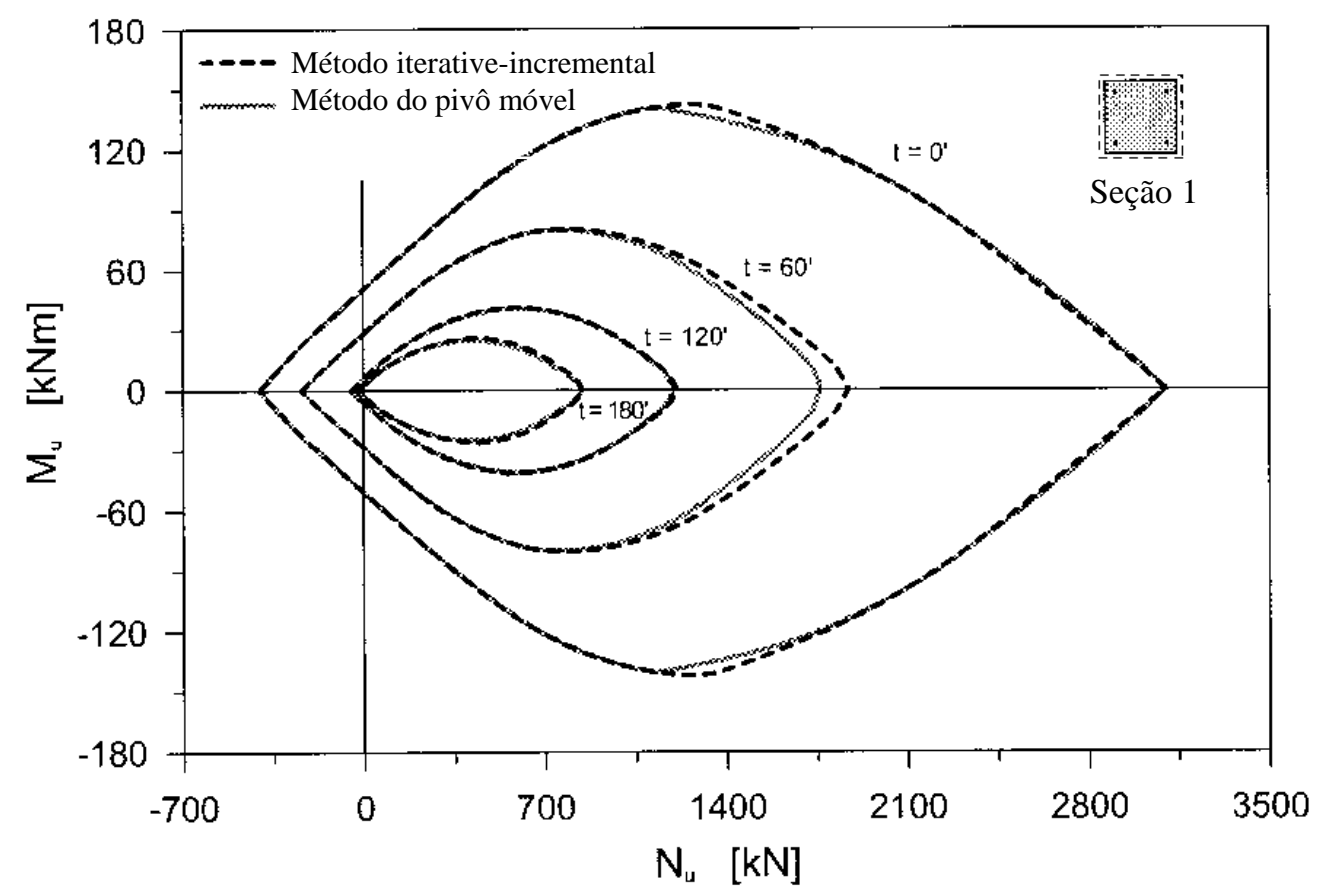

Figura 71 - Diagrama de interação esforço normal $x$ momento fletor resistentes $\left(N_{u}-M_{u}\right)$ para a Seção 1 aquecida nas quatro faces (FIB, 2008)

Verifica-se que, especialmente para os maiores tempos de duração de incêndio, há muito boa concordância entre os métodos.

Os resultados obtidos para a Seção 2 (Figura 68) com o método proposto são comparados aos obtidos pelo método iterativo-incremental na Figura 72. 


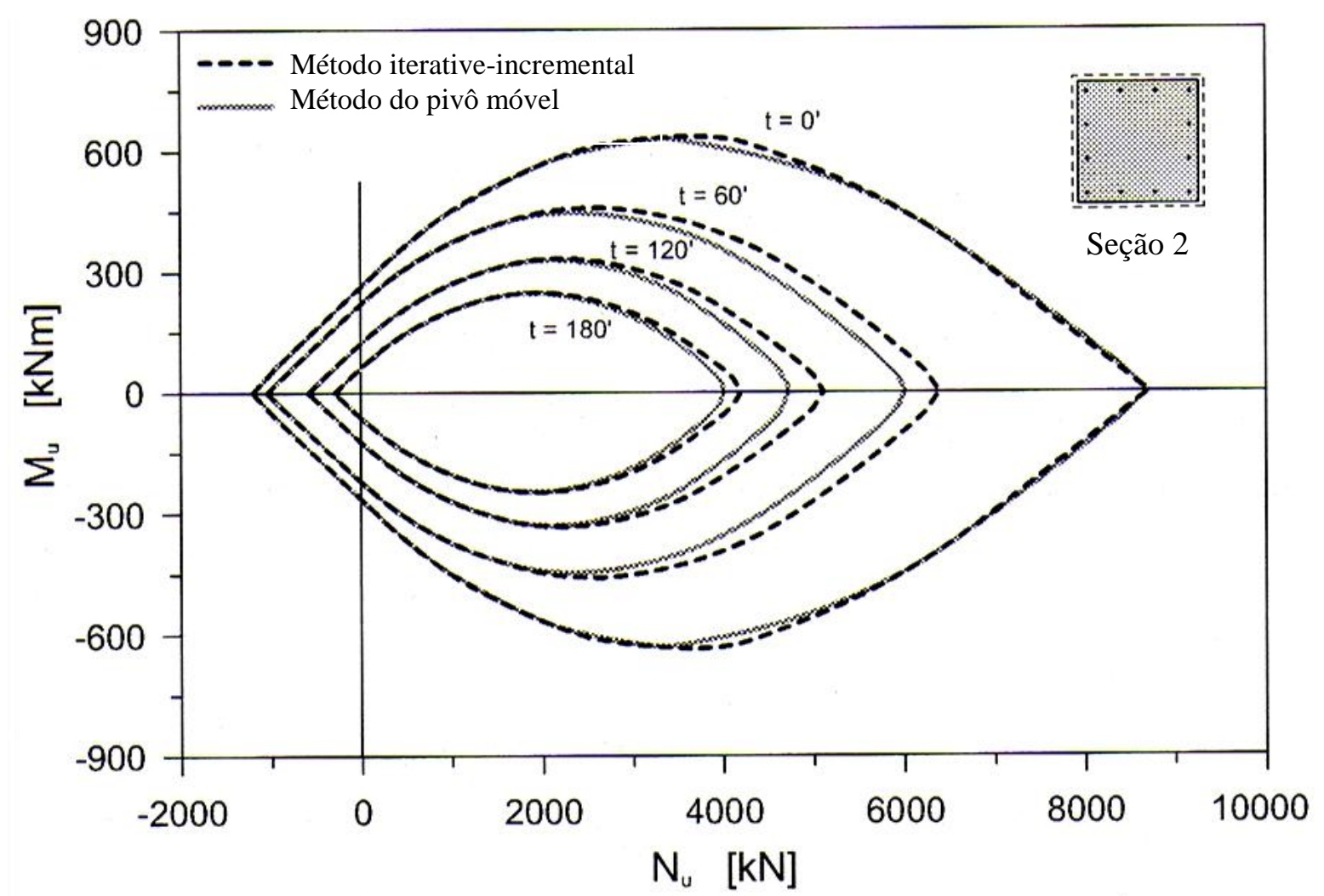

Figura 72 - Diagrama de interação esforço normal $x$ momento fletor resistentes $\left(N_{u}-M_{u}\right)$ para a Seção 2 aquecida nas quatro faces (FIB, 2008)

Para o caso da Seção 2, nota-se também muito boa concordância entre os métodos, especialmente para incêndios com duração superior a 120 minutos.

É importante destacar que o método aqui descrito, com limitação das deformações, ficou sempre a favor da segurança, ao menos nos exemplos apresentados. Outras seções devem ser exaustivamente testadas de modo a garantir a eficácia do método em qualquer situação possível de existir na prática.

\subsection{ENSAIOS EM LABORATÓRIO}

O ensaio de elementos isolados ou mesmo estruturas completas em situação de incêndio é muito mais trabalhoso e caro se comparado aos métodos analíticos. A um elemento de concreto que esteja dentro do campo de validade de um ensaio válido pode ser atribuído um tempo de resistência ao fogo, desde que o elemento possua materiais, esquema construtivo, nível de carregamento e condições de apoio similares ao corpo de prova utilizado no ensaio. Em alguns casos, acredita-se que um elemento em situação de incêndio quando na 
estrutura real tenha desempenho superior do que o mesmo elemento quando ensaiado isoladamente em laboratório. Em outras situações, o desempenho do elemento na estrutura pode ser pior, devido às deformações térmicas (FIB, 2007).

Algumas vantagens dos ensaios sobre os métodos prescritivos são que os primeiros proporcionam indicativos da distribuição de temperaturas e deflexões nos elementos, assim como falhas no detalhamento que não seriam facilmente descobertas sem os ensaios.

Entretanto, os resultados dos ensaios são influenciados pelas características dos aparelhos e métodos empregados, o que tem motivado discussões em comitês internacionais que buscam a uniformização dos métodos de ensaio a nível mundial (FIB, 2007).

Mais informações sobre ensaios, em especial os ensaios em escala real feitos pelo Building Research Establishment (BRE) em Cardington, Inglaterra, são apresentados no item 7.5.4 deste trabalho.

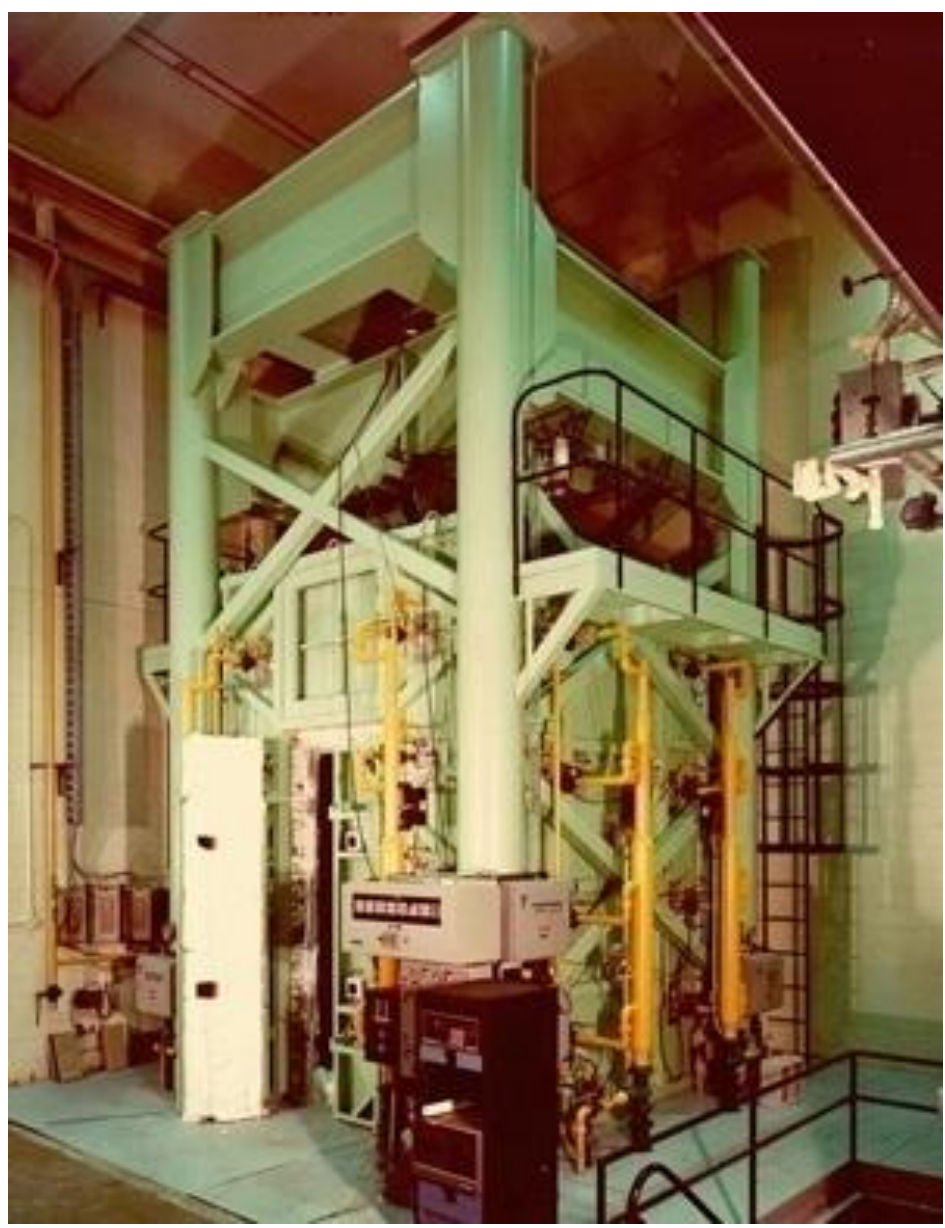

Figura 73 - Forno do NRCC para ensaio de pilares em escala real em situação de incêndio com atuação do carregamento (NRCC, 2009) 


\subsection{MÉTODO DESTE TRABALHO - FNC-FOGO}

Descreve-se a seguir as hipóteses e etapas de cálculo do método desenvolvido neste trabalho, denominado FNC-FOGO, para o cálculo de pilares de concreto armado em situação de incêndio submetidos à flexão normal composta. O método FNC-FOGO realiza a etapa de análise mecânica do pilar, considerando a não linearidade dos materiais, a atuação das deformações térmicas e a não linearidade geométrica do problema, baseado nas relações momento-curvatura. Todo o processo foi programado utilizando o software MATLAB®.

A etapa de análise térmica não é calculada pelo método FNC-FOGO, por isso utilizouse como dados de entrada campos de temperaturas na seção transversal de concreto previamente calculados utilizando-se o programa SuperTempCalc®. Os campos de temperaturas foram calculados segundo a curva de incêndio-padrão ISO 834 (ISO, 1990), considerando as propriedades térmicas do concreto dadas pelo Eurocode 2 (EN 1992-12:2004).

\subsubsection{Hipóteses gerais}

Considerando as diversas conclusões obtidas em pesquisas anteriores ((BAMONTE e LO MONTE, 2010) (BRATINA, CAS, et al., 2005) (CAI, BURGESS e PLANK, 2003) (CAPUA e MARI, 2007) (GERNAY e FRANSSEN, 2010)), foram estabelecidas as hipóteses básicas a serem adotadas no método FNC-FOGO, conforme segue:

1) hipótese de Bernoulli (seção permanece plana após as deformações) para as deformações totais;

2) hipótese de haver somente pequenas rotações e pequenas deformações ao longo do pilar, o que é usual para elementos de concreto;

3) não são consideradas as restrições à deformação axial do pilar;

4) as propriedades dos materiais sob temperaturas elevadas são calculadas segundo o Eurocode 2 (EN 1992-1-2:2004), nos centros geométricos de cada elemento discretizado na seção transversal;

5) o campo de tensões na seção transversal não influencia a análise térmica, por isso a análise termomecânica é desacoplada, ou seja, é feita em duas etapas: análise térmica + análise mecânica, utilizando o campo de temperaturas calculado na etapa anterior; 
6) estado uniaxial de tensão nas fibras da seção transversal;

7) os esforços axiais e tangenciais são considerados desacoplados;

8) as deformações devido ao esforço cortante são desconsideradas;

9) há perfeita aderência entre as barras de aço e o concreto;

10) seção transversal permanece íntegra durante todo o processo, ou seja, desconsidera-se a atuação do spalling;

11) a resistência à tração do concreto não é considerada;

12)a LITS é considerada de maneira implítica, por meio do uso do modelo constitutivo do concreto proposto pelo Eurocode 2 (EN 1992-1-2:2004);

13) a seção transversal deve ser simétrica em relação a cada um dos eixos principais, tanto em relação à distribuição das barras de aço quanto em relação ao campo de temperaturas.

\subsubsection{Cálculo dos esforços resistentes na seção transversal}

O cálculo dos esforços resistentes da seção transversal é razoavelmente simples. Para isso, é necessário conhecer os dados dos materiais (aço e concreto) e a deformação em qualquer ponto da seção transversal. Considerando que o foco deste trabalho é a flexão normal composta, a seção transversal deve possuir ao menos um eixo de simetria (em relação à geometria, em relação à distribuição e área das barras de aço e em relação à distribuição de temperaturas).

A seção transversal é discretizada numa matriz de fibras (ou prismas) de concreto e aço, submetidas apenas a tensões uniaxiais de tração ou compressão. O esforço normal e momento fletor resistentes $\left(\mathrm{N}_{\mathrm{Rd}, \mathrm{fi}}\right.$ e $\left.\mathrm{M}_{\mathrm{Rd}, \mathrm{fi}}\right)$ resultam do somatório da contribuição de todas as fibras.

As barras de aço são consideradas segundo a posição do seu centro de gravidade (CG), assumindo que a área de cada barra esteja concentrada nesse ponto. Os esforços resistentes são calculados em relação ao centro de esforços (CE) da seção transversal, normalmente posicionado no centro de gravidade (CG) da mesma. Exemplos de discretização da seção transversal são mostrados na Figura 74. 


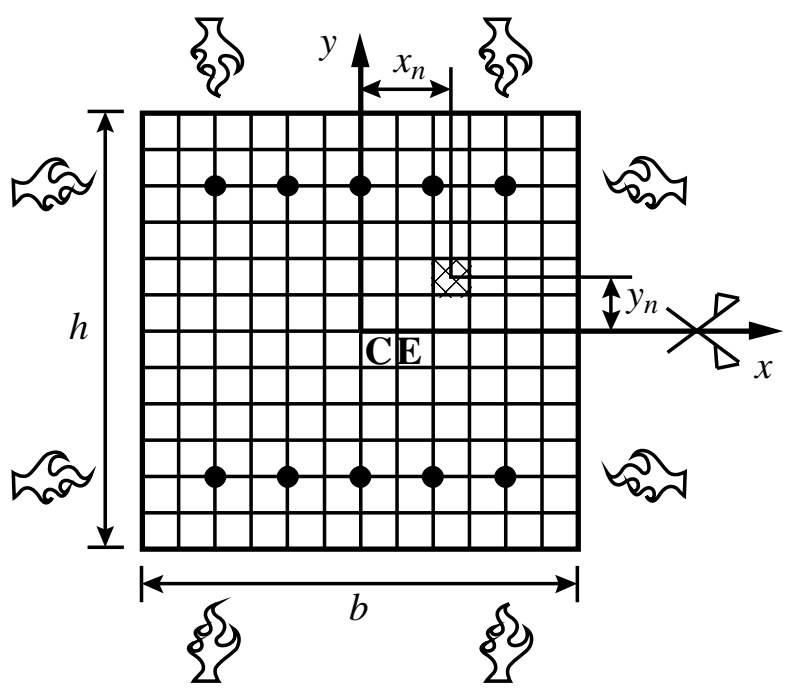

(a)

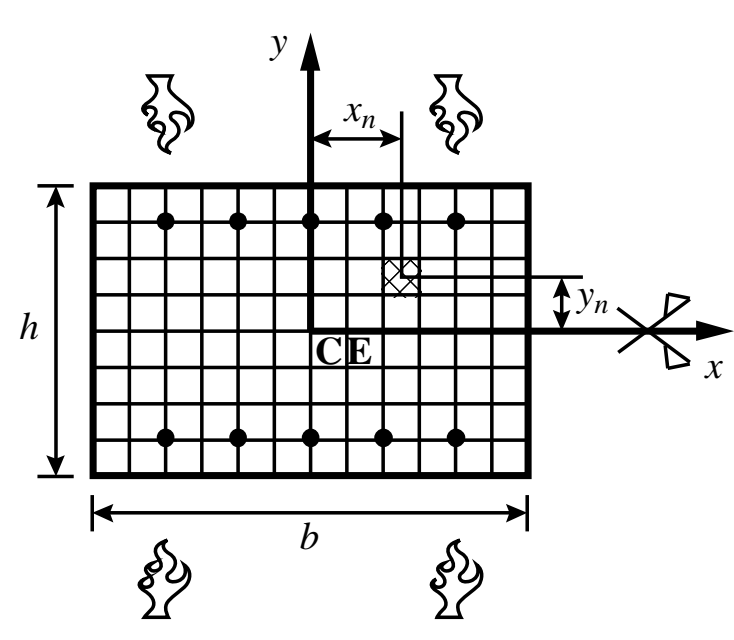

(b)

Figura 74 - Exemplos de discretização em fibras da seção transversal do pilar de concreto armado em situação de incêndio, aquecido simetricamente em (a) 4 faces e (b) 2 faces

A análise termomecânica é feita em duas etapas: análise térmica e posterior análise mecânica, utilizando o campo de temperaturas calculado na etapa anterior.

O primeiro passo consiste em determinar, para um dado tempo de exposição ao fogo, a temperatura no centro de gravidade de cada fibra. Neste trabalho, as temperaturas foram calculadas por meio de interpolação linear bidimensional a partir de campos de temperaturas previamente calculados.

Conhecidas as temperaturas de cada fibra, inicia-se a segunda etapa, calculando-se os parâmetros relativos ao concreto:

a) deformação térmica linear específica $\varepsilon_{\mathrm{c}}(\theta)$ (item 0 deste trabalho);

b) parâmetros da curva tensão-deformação: redutor $\mathrm{f}_{\mathrm{c}, \theta} / \mathrm{f}_{\mathrm{ck}}$, deformações $\varepsilon_{\mathrm{c} 1, \theta} \mathrm{e}$ $\varepsilon_{\mathrm{cu}, \theta}$ (item 4.1.4 deste trabalho).

Para o aço, os parâmetros a serem calculados são:

a) deformação térmica linear específica $\varepsilon_{\mathrm{s}}(\theta)$ (item 0 deste trabalho);

b) parâmetros da curva tensão-deformação: redutores $\mathrm{f}_{\mathrm{sp}, \theta} / \mathrm{f}_{\mathrm{yk}}, \mathrm{f}_{\mathrm{sy}, \theta} / \mathrm{f}_{\mathrm{yk}}$ e $\mathrm{E}_{\mathrm{s}, \theta} / \mathrm{E}_{\mathrm{s}}$, deformações $\varepsilon_{\mathrm{sy}, \theta}, \varepsilon_{\mathrm{st}, \theta}$ e $\varepsilon_{\mathrm{su}, \theta}$ (item 4.2.2 deste trabalho).

A descrição das etapas seguintes segue as convenções da Figura 75. 


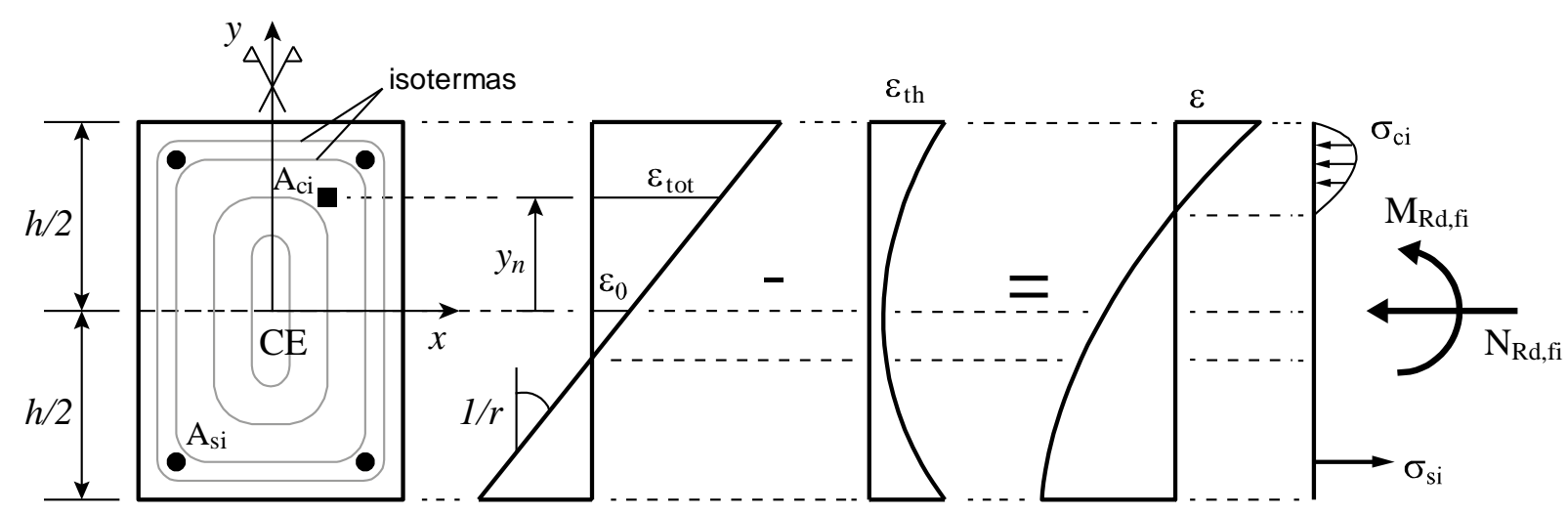

Figura 75 - Convenções para o cálculo dos esforços resistentes da seção transversal

A deformação linear específica total $\varepsilon_{\text {tot }}$ numa fibra genérica situada a uma distância $y$ do CE da seção transversal é definida pela eq. (75).

$$
\varepsilon_{t o t}=\varepsilon_{0}+\frac{1}{r} y
$$

Onde:

$\varepsilon_{0}$ : deformação linear específica da fibra situada no CE da seção transversal;

$1 / \mathrm{r}$ : curvatura $\left[\mathrm{m}^{-1}\right]$.

As variáveis $\varepsilon_{0}$ e $1 /$ r são dados de entrada do problema.

Adotando as conclusões do item 0 deste trabalho, a deformação térmica linear específica de cada fibra $\left(\varepsilon_{\text {th }}\right)$ é descontada da deformação total $\left(\varepsilon_{\text {tot }}\right)$, conforme a eq. $(76)$.

$$
\varepsilon=\varepsilon_{t o t}-\varepsilon_{t h}
$$

Conhecida a deformação linear específica $\varepsilon$ para cada fibra, a tensão $\sigma(\varepsilon)$ pode ser calculada utilizando os diagramas tensão-deformação dados pelo Eurocode 2 (EN 1992-12:2004), conforme os itens 4.1.4 e 4.2.2 deste trabalho.

Genericamente, os esforços resistentes da seção transversal podem ser calculados pelas eqs. (77) e (78). 


$$
\begin{gathered}
N_{R d, f i}=\iint \sigma(\varepsilon) d x d y \\
M_{R d, f i}=\iint \sigma(\varepsilon) y d x d y
\end{gathered}
$$

Sem prejuízos significativos à precisão numérica, as integrais acima podem ser divididas segundo os materiais componentes (concreto e aço). Além disso, como a área de armadura normalmente é pequena com relação à área de concreto, adota-se a simplificação usual de não descontar a área das armaduras da área bruta de concreto. Ou seja, considera-se que a área efetiva de concreto é igual à área da seção bruta. Considerando tais hipóteses, as eqs. (77) e (78) reduzem-se a simples somatórios, conforme mostram as eqs. (79) e (80).

$$
\begin{gathered}
N_{R d, f i}=\sum_{i=1}^{n c} \sigma_{c i, \theta}\left(\varepsilon_{c i}\right) A_{c i}+\sum_{i=1}^{n s} \sigma_{s i, \theta}\left(\varepsilon_{s i}\right) A_{s i} \\
M_{R d, f i}=\sum_{i=1}^{n c} \sigma_{c i, \theta}\left(\varepsilon_{c i}\right) y A_{c i}+\sum_{i=1}^{n s} \sigma_{s i, \theta}\left(\varepsilon_{s i}\right) y A_{s i}
\end{gathered}
$$

Onde:

$n c$ : número de fibras de concreto na seção transversal discretizada;

$n s:$ número de fibras (barras) de aço na seção transversal discretizada;

$\sigma_{\mathrm{ci}, \theta}:$ tensão na fibra de concreto $i\left[\mathrm{~N} / \mathrm{m}^{2}\right]$;

$\varepsilon_{\mathrm{ci}, \theta}$ : deformação linear específica na fibra de concreto $i$;

$\sigma_{\mathrm{si}, \theta}$ : tensão na fibra de aço $i\left[\mathrm{~N} / \mathrm{m}^{2}\right]$;

$\varepsilon_{\mathrm{si}, \theta}:$ deformação linear específica na fibra de aço $i$;

$\mathrm{A}_{\mathrm{ci}}$ : área da fibra de concreto $i\left[\mathrm{~m}^{2}\right]$.

$\mathrm{A}_{\mathrm{si}}$ : área da fibra (barra) de aço $i\left[\mathrm{~m}^{2}\right]$.

Os resultados das eqs. (79) e (80) são o esforço normal e momento fletor resistentes $\left(\mathrm{N}_{\mathrm{Rd}, \mathrm{fi}}\right.$ e $\left.\mathrm{M}_{\mathrm{Rd}, \mathrm{fi}}\right)$ para uma dada deformação linear específica $\varepsilon_{0}$ e uma dada curvatura 1/r.

O processo de cálculo aqui descrito é explicado em detalhes por França (1984) e Mendes Neto (2009), para o caso de seções de concreto armado à temperatura ambiente. 


\subsubsection{Cálculo do diagrama momento-curvatura}

Utilizando o processo descrito no item anterior, são calculados os pares de esforços resistentes $\mathrm{N}_{\mathrm{Rd}, \mathrm{fi}}$ e $\mathrm{M}_{\mathrm{Rd}, \mathrm{fi}}$ para uma faixa de valores de deformação linear específica no $\mathrm{CE}$ da seção transversal $\left(\varepsilon_{0}\right)$ e curvaturas $(1 / \mathrm{r})$. Unindo-se os pontos de uma mesma curvatura, obtém-se o diagrama mostrado pela Figura 76.

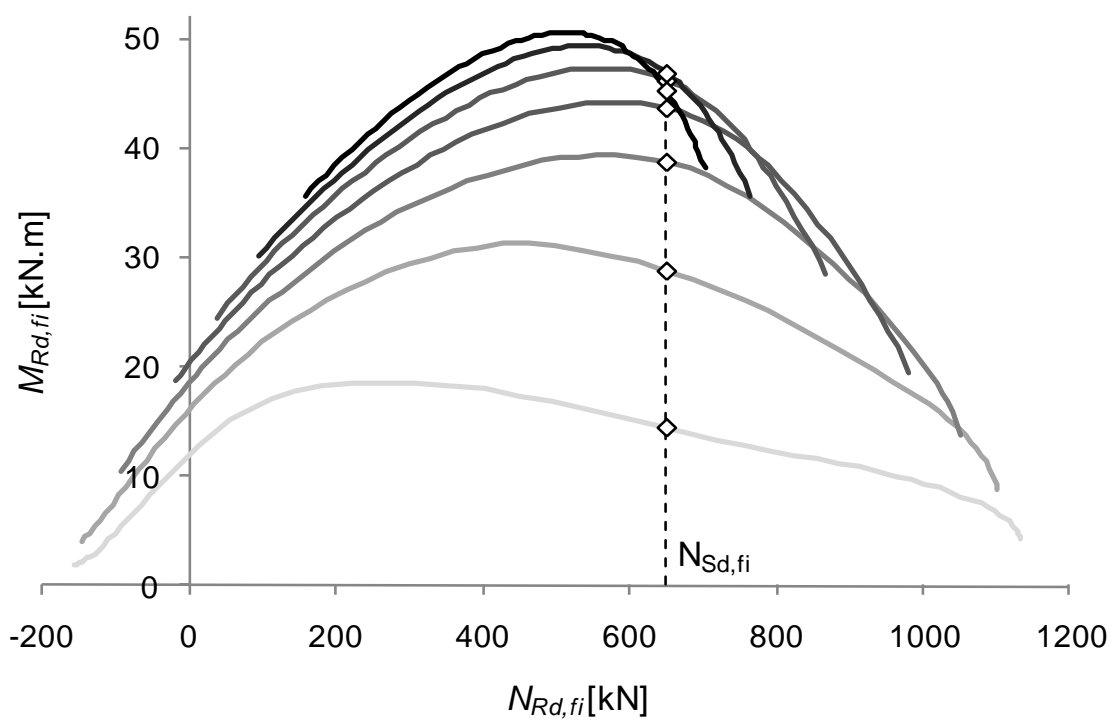

Figura 76 - Exemplo de gráfico esforço normal - momento resistente $\left(\mathbf{N}_{\mathbf{R d}, \mathrm{f}}-\mathbf{M}_{\mathbf{R d}, \mathrm{fi}}\right)$

O diagrama momento-curvatura é obtido pela leitura dos pontos correspondentes ao esforço normal solicitante $\mathrm{N}_{\mathrm{Sd}, \mathrm{fi}}$ (Figura 76). Assim, obtém-se o diagrama mostrado na Figura 77. 


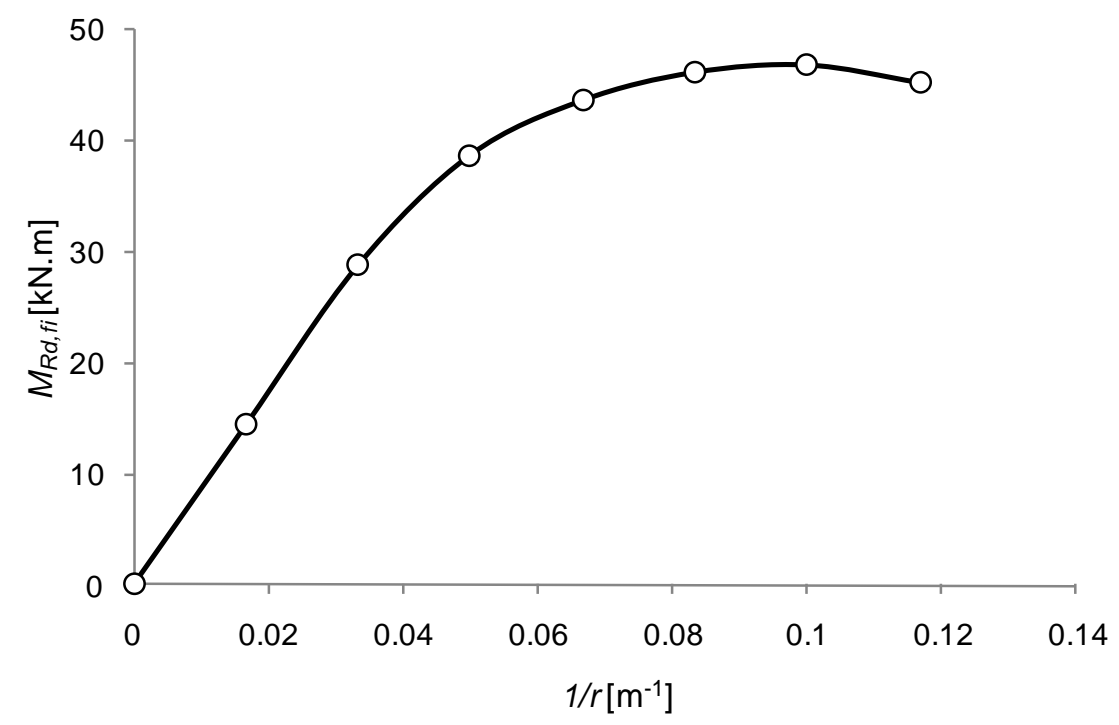

Figura 77 - Exemplo de diagrama momento-curvatura para um dado $\mathbf{N}_{\mathrm{Sd}, \mathrm{fi}}$

Como exemplo qualitativo, a Figura 78 apresenta os diagramas momento-curvatura para um mesmo pilar submetido a diversos tempos de exposição ao fogo.

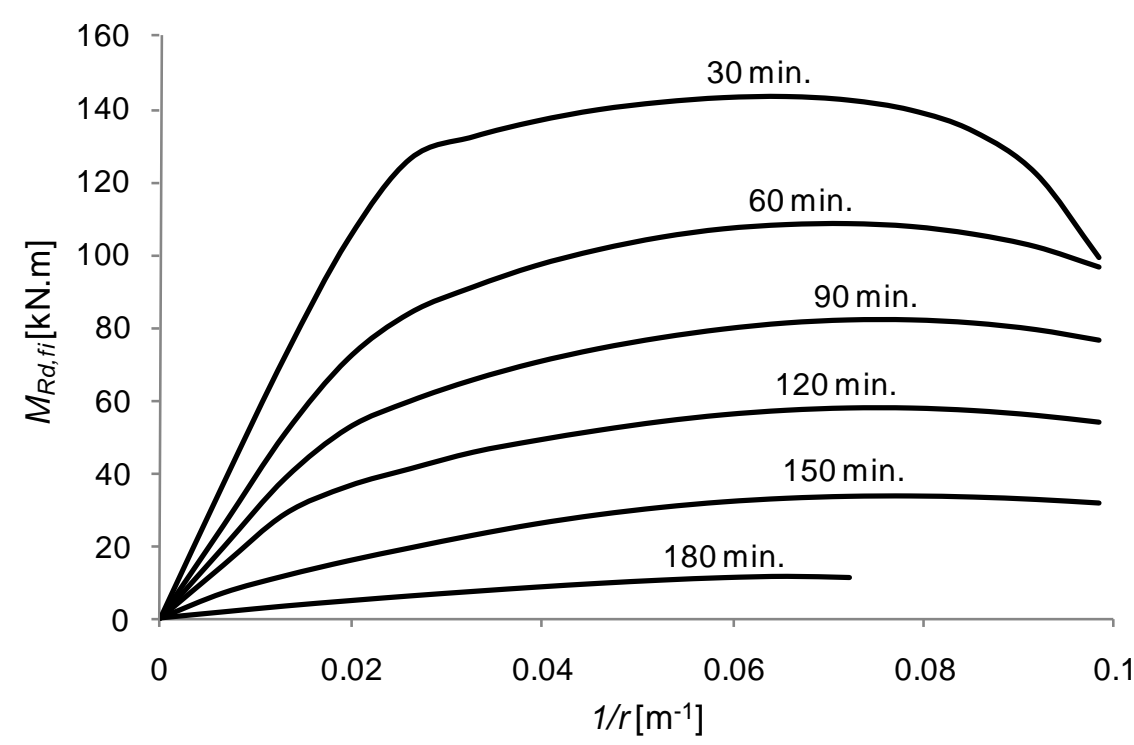

Figura 78 - Exemplo de diagramas momento-curvatura para diversos tempos de exposição ao fogo

Quando se calcula pilares de concreto armado em situação de incêndio adotando o modelo de elemento isolado, costuma-se desprezar a influência das restrições à deformação longitudinal do pilar. Portanto, para cada tempo de exposição ao fogo desejado, basta calcular um único diagrama momento-curvatura. 
É importante esclarecer que as deformações das fibras não são limitadas ao longo dos cálculos para obtenção do diagrama momento-curvatura. Ou seja, o conceito de domínios de deformações últimas para o concreto e aço (vide item 17.2.2 da norma ABNT NBR 6116:2003) não foi considerado neste trabalho. Como o objetivo foi comparar os resultados dos cálculos analíticos aos resultados de ensaios experimentais, foi necessário considerar as deformações sem limitações. O esgotamento da capacidade resistente da seção transversal (trecho decrescente do diagrama momento-curvatura, após o pico, mostrado na Figura 77) resulta das relações tensão-deformação dos materiais, nos quais se observa diminuição das tensões para deformações elevadas. No entanto, o Eurocode 2 (EN 1992-1-2:2004), no item 4.3.3, determina que as deformações no estado limite último devem ser limitadas conforme necessário para garantir a compatibilidade entre as diversas partes da estrutura, mas não apresenta nenhuma indicação sobre valores dessas limitações.

\subsubsection{Integração numérica}

O cálculo dos deslocamentos transversais de um pilar submetido à flexão normal composta é realizado pelo processo de integração numérica por iterações sucessivas. O processo permite considerar de maneira adequada a não linearidade geométrica para o problema em estudo. Além disso, é particularmente útil para análise de barras com comportamento inelástico à flexão, que é o caso de peças de concreto armado. Descreve-se a seguir a base teórica e os passos do processo.

Considere-se um pilar em balanço, engastado na base e livre no topo, submetido à flexocompressão normal (Figura 79).

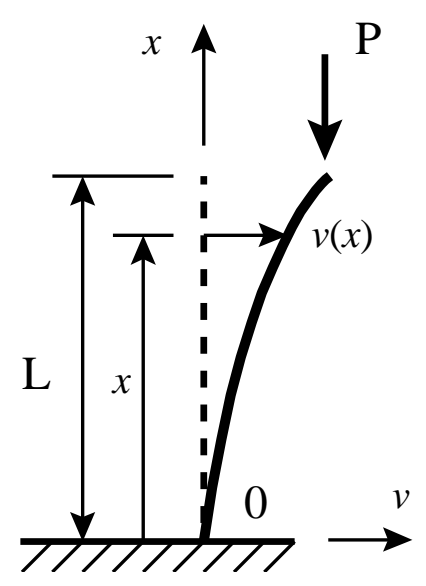

Figura 79 - Integração numérica de pilar em balanço 
A equação de equilíbrio do pilar na posição deformada é expressa pela eq. (81).

$$
M(x)=M_{1}(x)+P \cdot\left[v_{L}-v(x)\right]
$$

A parcela $\mathrm{M}_{1}(\mathrm{x})$ é a equação do diagrama de momentos fletores de $1^{\mathrm{a}}$ ordem ao longo do pilar. Esse diagrama pode ter qualquer forma e pode ter origem em esforços adicionais aplicados ao pilar (alguns casos básicos são apresentados na Figura 80), excentricidade no ponto de aplicação da carga axial $\mathrm{P}$ ou combinações quaisquer de ambos os carregamentos.
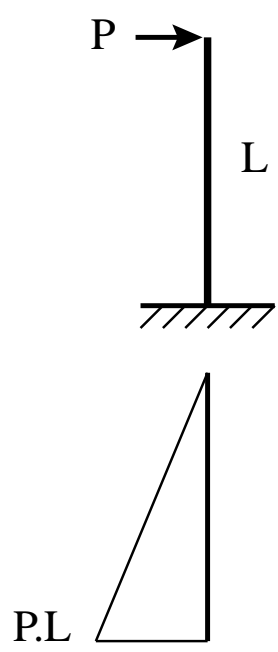
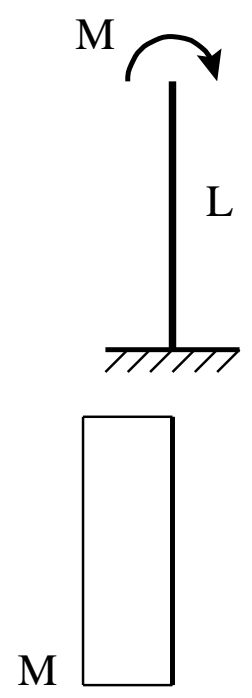
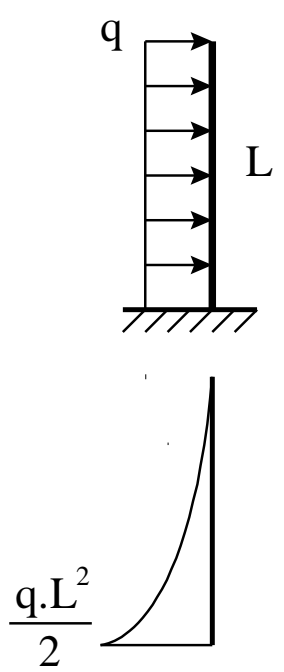

Figura 80 - Alguns casos básicos de esforços aplicados em um pilar em balanço e seus respectivos diagramas de momentos fletores de $\mathbf{1}^{\mathrm{a}}$ ordem $\left(\mathrm{M}_{1}\right)$

De acordo com a Geometria Diferencial, a curvatura ao longo do eixo $x$ é expressa pela eq. (82).

$$
\frac{1}{r}(x)= \pm \frac{v^{\prime \prime}(x)}{\left[1+\left(\left(v^{\prime}(x)\right)^{2}\right)\right]^{3 / 2}}
$$

Para pilares de concreto armado, admite-se a hipótese de haver somente pequenas rotações e pequenos deslocamentos. Portanto, a parcela $\left(v^{\prime}(x)\right)^{2}$ é muito pequena se comparada à unidade, o que resulta na aproximação expressa pela eq. (83).

$$
\frac{1}{r}(x) \cong-v^{\prime \prime}(x)
$$


As rotações $v^{\prime}(x)$ ao longo do eixo da barra são obtidas integrando-se a eq. (83), conforme mostra a eq. (84).

$$
\int v^{\prime \prime}(x) d x=v^{\prime}(x)+A
$$

Inserindo a eq. (83) na eq. (84), tem-se a seguinte relação (eq. (85)):

$$
v^{\prime}(x)+A=\varphi(x)+A=\int_{0}^{L}\left[\frac{1}{r}(x)\right] d x
$$

Os deslocamentos $v(x)$ ao longo do pilar são finalmente obtidos integrando-se a eq. (85), conforme mostra a eq. (86).

$$
\int\left[v^{\prime}(x)+A\right] d x=\int[\varphi(x)+A] d x=v(x)+A x+B
$$

As condições de contorno de um pilar em balanço implicam em rotação e deslocamentos nulos na extremidade engastada, condição expressa pelas eqs. (87) e (88).

$$
\begin{aligned}
& v^{\prime}(0)=0 \\
& v(0)=0
\end{aligned}
$$

Dessa forma, as constantes de integração A e B da eq. (86) são anuladas.

As curvas $v(x)$ de pilares em balanço ou biapoiados possuem a mesma forma, pois dependem unicamente do diagrama de momentos fletores ao longo do pilar. Sendo assim, para calcular um pilar biapoiado basta modificar as condições de contorno e aplicá-las à eq. (86). As seguintes condições de contorno são válidas para um pilar biapoiado (eqs.(89) a (91)):

$$
\begin{gathered}
v^{\prime}(0) \neq 0 \\
v^{\prime}(L) \neq 0 \\
v(0)=v(L)=0
\end{gathered}
$$


Para aplicar as condições de contorno acima, é oportuno avaliar a questão de maneira mais prática. Conforme mencionado, a curva $v(x)$ depende unicamente do diagrama de momentos fletores, assim o pilar pode ser calculado considerando o modelo em balanço e, ao final do processo, aplica-se uma rotação de corpo rígido de modo a respeitar as condições de contorno (Figura 81).
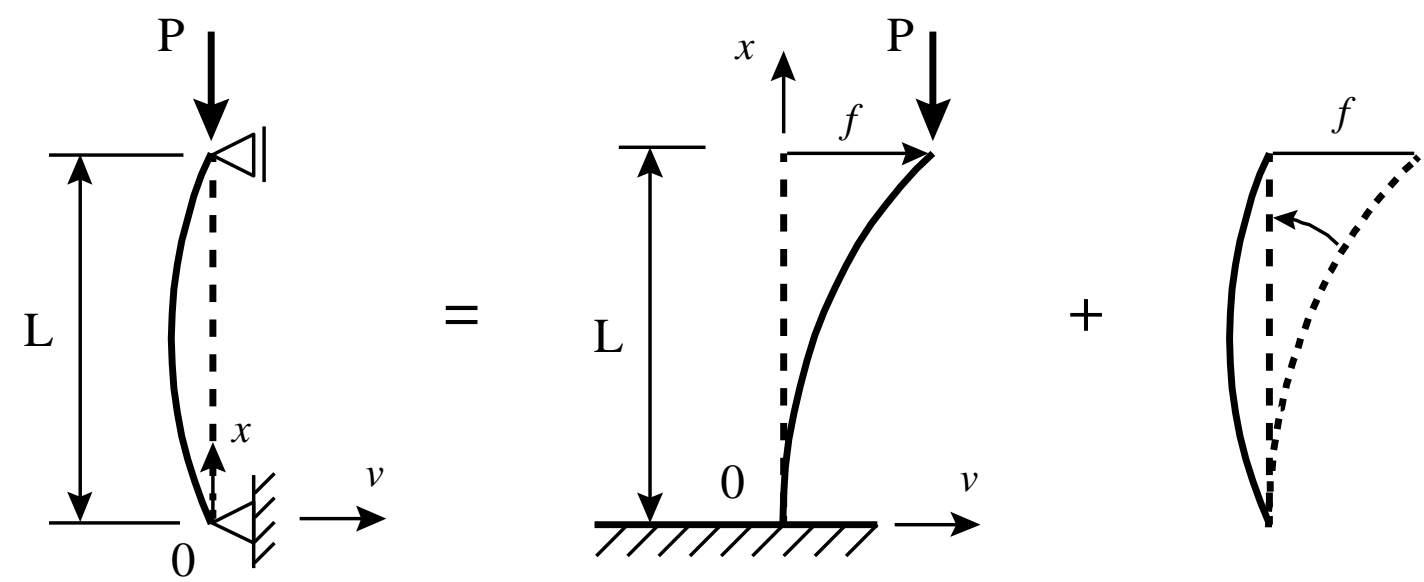

Figura 81 - Método da integração numérica para pilar biapoiado

Considerando $f$ o deslocamento na extremidade livre do pilar em balanço, a constante de integração A da eq. (86) assume o valor mostrado na eq. (92). A constante de integração B da eq. (86) é imediatamente anulada quando se considera a eq. (91).

$$
A=\frac{f}{L}
$$

Para programação computacional do método anteriormente descrito, é conveniente dividir o pilar em diversos segmentos. Todos os dados de cada etapa (momentos fletores, curvaturas, rotações e deslocamentos) são calculados somente nas extremidades de cada segmento (nós). A Figura 82 exemplifica um pilar em balanço dividido em $n$ segmentos iguais. 


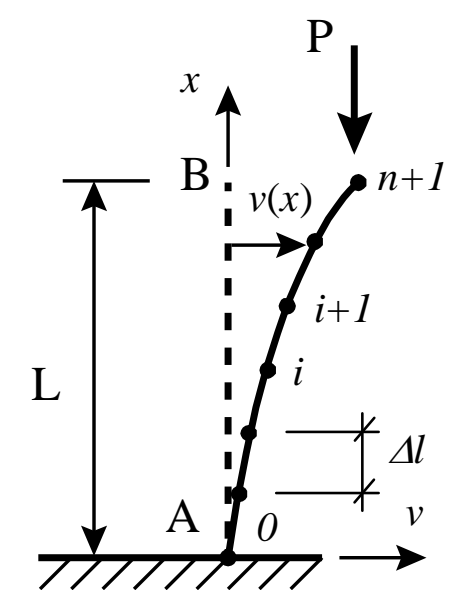

Figura 82 - Divisão do pilar em balanço em $n$ segmentos iguais

Todas as integrais apresentadas anteriormente podem então ser calculadas numericamente para cada nó do pilar. Adotando, por exemplo, a integração pelo método dos trapézios, as integrais das eqs. (85) e (86) resultam conforme segue (eqs. (93) a (95)).

$$
\begin{gathered}
\varphi_{i+1}=v_{i+1}^{\prime}=v_{i}^{\prime}+\left(\frac{1}{r_{i}}+\frac{1}{r_{i+1}}\right) \cdot \frac{\Delta l}{2} \\
v_{i+1}=v_{i}+\left(\varphi_{i}+\varphi_{i+1}\right) \cdot \frac{\Delta l}{2} \\
\Delta l=\frac{L}{n}
\end{gathered}
$$

Lembra-se que as equações acima servem para o cálculo de um pilar em balanço. Para um pilar biapoiado deve-se efetuar a correção apresentada anteriormente.

Outro método de integração numérica que pode ser usado é a Quadratura de GaussLobatto, adotada no programa computacional desenvolvido nessa dissertação. Sua principal vantagem, se comparado à Quadratura de Gauss, é considerar os extremos do intervalo de integração com seus valores originais.

Uma vez obtidos os valores dos deslocamentos $v(x)$ finais ao longo do pilar, o diagrama de momentos fletores deve ser atualizado utilizando a eq. (81). O processo de cálculo descrito anteriormente deve ser repetido sucessivamente até a ocorrência de uma das seguintes situações: 
a) convergência dos deslocamentos calculados, ou seja, a variação dos deslocamentos transversais de cada ponto entre uma iteração e outra é inferior a uma certa tolerância (dado de entrada);

b) um ou mais pontos do pilar apresenta valor de momento fletor em módulo superior ao máximo momento fletor suportado pela seção transversal naquele ponto (falha por esgotamento da capacidade resistente da seção transversal). Esse momento corresponde ao pico do diagrama momento-curvatura;

c) o número máximo de iterações (dado de entrada) é atingido sem que se verifique a condição de convergência. Neste caso, considera-se que houve falha do pilar por instabilidade.

7.5.4.1. Processo para pilares apoiado-engastado e biengastado

A partir do método da integração numérica descrito no item anterior, criou-se um processo adicional para o cálculo de pilares biengastados e apoiados no topo e engastados na base (apoiado-engastado).

O processo consiste em encontrar o valor de momentos fletores que, aplicados a uma ou ambas as extremidades do pilar, conduzem a rotações nulas nessas extremidades, o que é a condição de contorno de uma extremidade engastada. Os passos para a aplicação do processo são (Figura 83):

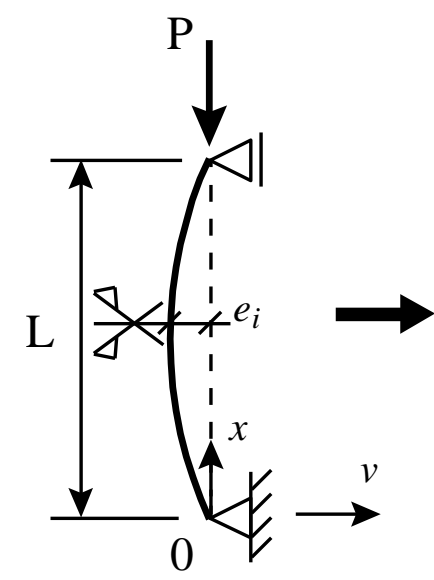

(a)

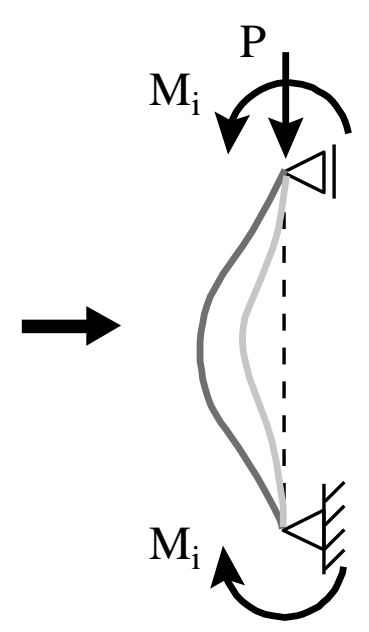

(c)

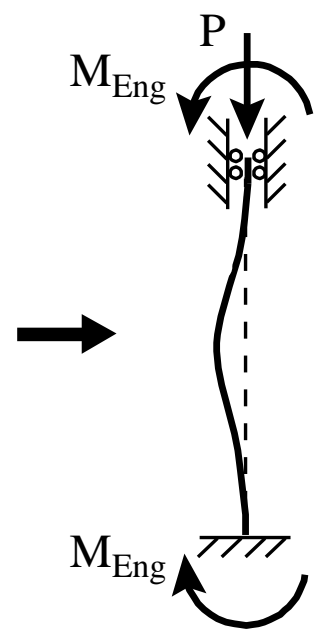

(d)

Figura 83 - Passos para o cálculo dos deslocamentos transversais de um pilar biengastado. (a) Modelo inicial adotado na $1^{\mathrm{a}}$ iteração, (b) rotações calculadas nas extremidades, (c) aplicação de momentos nas extremidades para cálculo do diagrama momento-rotação (d) e modelo final do pilar 
1) cálculo inicial considerando o pilar biapoiado ( ${ }^{\mathrm{a}}$ iteração). Para pilares biengastados é fundamental que o diagrama de momentos fletores de $1^{\mathrm{a}}$ ordem não seja constante. Sugere-se que na $1^{\mathrm{a}}$ iteração o pilar seja calculado com uma pequena excentricidade no meio do vão (nesse trabalho constatou-se que uma excentricidade de $0,01 \mathrm{~cm}$ foi suficiente para um pilar convencional);

2) considerando a configuração deformada do pilar calculada na etapa anterior, uma subrrotina aplica uma faixa de momentos fletores nas extremidades do pilar e registra as rotações nessas extremidades. Cria-se assim um diagrama momentorotação, exemplificado na Figura 84;

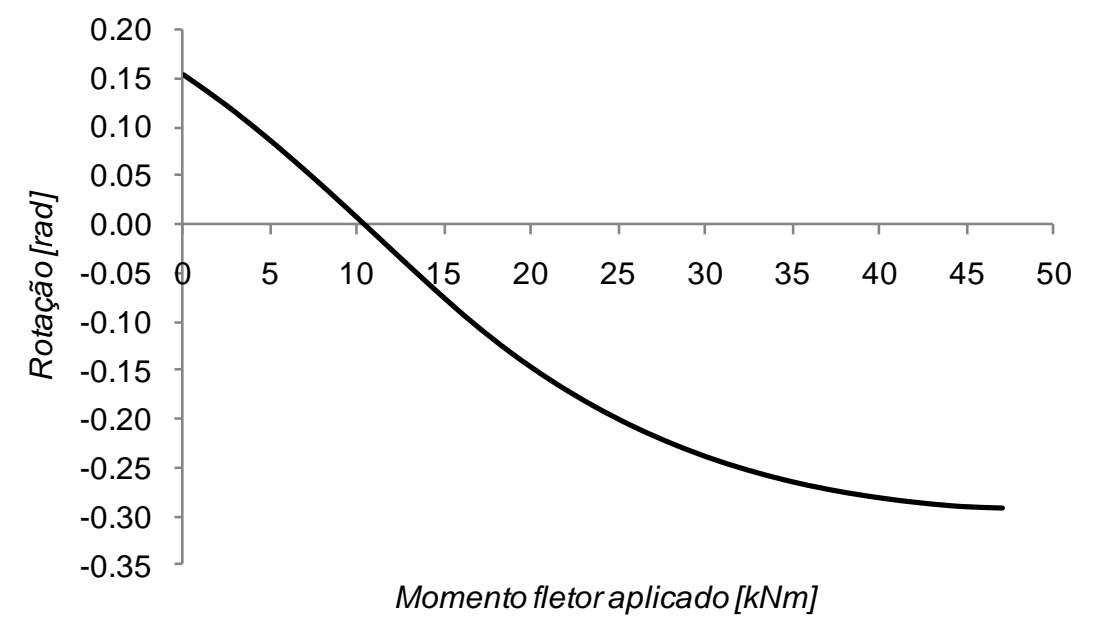

Figura 84 - Exemplo de diagrama momento-rotação na extremidade do pilar

3) pesquisa-se no diagrama momento-rotação o valor dos momentos aplicados nas extremidades que resultam em rotação nula nessas extremidades;

4) cálculo da posição deformada do pilar incluindo os momentos de engastamento aplicados nas extremidades;

5) considerando a configuração deformada do pilar calculada na etapa anterior, calcula-se novamente o pilar com modelo biapoiado ( $2^{\mathrm{a}}$ iteração);

6) os passos 2 a 5 são repetidos até que se verifique um dos critérios de convergência apresentados no item anterior.

Por fim, é importante esclarecer que o processo aqui descrito teve como premissa a hipótese de haver somente pequenas rotações e pequenos deslocamentos (eq. (83)). Por isso, quanto maior o número de subdivisões do pilar, melhor a precisão numérica dos resultados, se 
comparados aos resultados obtidos pelo mesmo processo sem essa aproximação. Para o caso específico deste trabalho, verificou-se que o vão de pilares biapoiados deve ser dividido em, ao menos, 10 partes iguais para se obter satisfatória precisão nos cálculos. Para pilares biengastados e apoiado-engastado, verificou-se a necessidade de dividir o vão em, ao menos, 50 partes iguais, pois o desempenho desses modelos depende da avaliação precisa das rotações nas extremidades do pilar.

\subsubsection{Processo iterativo de cálculo do TRF}

A sequência de cálculos dos itens 7.5.1 ao 7.5.4 apresentados anteriormente fornecem como resultado final a confirmação (ou não) da ruptura de um pilar, para um determinado tempo de exposição ao fogo, segundo os critérios estabelecidos no item 7.5.4 deste trabalho.

Para o cálculo do TRF de um pilar, a sequência de cálculos foi inserida num processo iterativo baseado no método da bisseção. Arbitra-se, nos dados de entrada, um intervalo de tempos de exposição ao fogo a ser pesquisado. O programa verifica qual dos dois valores apresenta ruptura teórica do pilar e repete a pesquisa, tomando como novo intervalo de pesquisa a metade do intervalo arbitrado inicialmente. $\mathrm{O}$ processo é repetido iterativamente até atingir a convergência para o valor final do TRF, respeitando uma dada precisão.

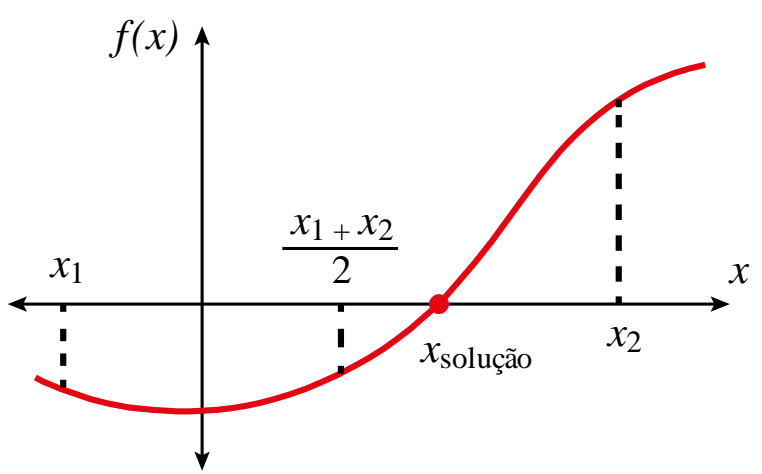

(a)

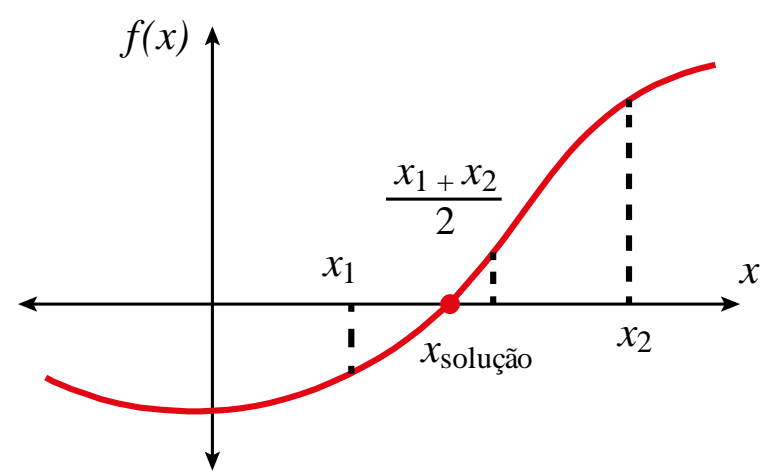

(b)

Figura 85 - Método da bisseção. (a) $1^{\mathrm{a}}$ iteração, com intervalo de pesquisa da solução arbitrado; (b) $2^{\mathrm{a}}$ iteração, com novo intervalo de pesquisa da solução 


\section{APLICAÇÃO DO MÉTODO FNC-FOGO E ANÁliSE DOS RESULTADOS}

O Método FNC-FOGO foi aplicado ao cálculo do TRF de pilares de concreto armado em situação de incêndio submetidos à flexão normal composta, para posterior comparação com o TRF dos mesmos pilares medido experimentalmente.

Foram analisados pilares aquecidos de forma simétrica, desconsiderando possíveis restrições à deformação axial do pilar.

\subsection{PILARES USADOS NA CALIBRAÇÃO DO MÉTODO A (EN 1992-1-2:2004)}

Conforme apresentado no item 7.2.4 deste trabalho, o Método A do Eurocode 2 (EN 1992-1-2:2004) foi desenvolvido e calibrado com base nos valores de TRF obtidos nos ensaios experimentais de 76 pilares. Como o Método A é bastante difundido, tanto pela presença no Eurocode 2 (EN 1992-1-2:2004) quanto pela presença no projeto de revisão da norma ABNT NBR 15200:2004, julgou-se oportuno avaliar o desempenho do método FNCFOGO para esse grupo de pilares.

As informações relevantes sobre cada um dos 76 pilares (geometria, características dos materiais, carregamentos e condições de apoio) foram reunidas por Costa (2006) e utilizadas neste estudo.

Os resultados dos TRFs são apresentados na Tabela 11. Além dos TRFs medidos experimentalmente, apresentam-se os TRFs calculados por Costa (2006) segundo o Método A do Eurocode 2 (EN 1992-1-2:2004) e os TRFs calculados analiticamente neste trabalho utilizando o método FNC-FOGO. 
Tabela 11 - TRF medidos e calculados dos pilares utilizados na calibração do Método A do Eurocode 2 (EN 1992-1-2:2004)

\begin{tabular}{|c|c|c|c|c|c|c|c|c|c|c|c|c|c|c|c|c|c|c|c|c|c|}
\hline \multirow[b]{2}{*}{ no. } & \multirow[b]{2}{*}{ Lab. } & \multirow[b]{2}{*}{ Rótulo } & \multicolumn{2}{|c|}{ Seção transv. } & \multirow[b]{2}{*}{$\mathrm{L}(\mathrm{m})$} & \multirow[b]{2}{*}{$\begin{array}{c}\mathrm{c} \\
(\mathrm{mm})\end{array}$} & \multicolumn{5}{|c|}{ Armaduras } & \multirow[b]{2}{*}{$\begin{array}{c}\mathrm{a} \\
(\mathrm{mm})\end{array}$} & \multicolumn{3}{|c|}{ Materiais } & \multirow[b]{2}{*}{$e / b$} & \multirow[b]{2}{*}{$\begin{array}{l}\mathrm{N}_{\mathrm{Sd}, \mathrm{fi}} \\
(\mathrm{kN})\end{array}$} & \multicolumn{4}{|c|}{ TRF (min) } \\
\hline & & & $\begin{array}{c}\mathrm{b} \\
(\mathrm{cm})\end{array}$ & $\begin{array}{c}\mathrm{h} \\
(\mathrm{cm})\end{array}$ & & & $\mathrm{n}$ & $\begin{array}{c}\phi \\
(\mathrm{mm})\end{array}$ & $\begin{array}{c}\text { As } \\
\left(\mathrm{cm}^{2}\right)\end{array}$ & $\begin{array}{c}\rho= \\
A_{s} / A_{c}\end{array}$ & $\begin{array}{l}\phi, \text { est. } \\
\text { (mm) }\end{array}$ & & $\begin{array}{c}\mathrm{f}_{\mathrm{c}} \\
(\mathrm{MPa})\end{array}$ & $\begin{array}{c}\mathrm{f}_{\mathrm{y}} \\
(\mathrm{MPa})\end{array}$ & agregado & & & Teste & $\begin{array}{l}\text { COSTA(2006) } \\
\text { Mét. A EC2 }\end{array}$ & $\begin{array}{c}\text { TRF1* } \\
\text { analítico }\end{array}$ & $\begin{array}{c}\text { TRF2* } \\
\text { analítico }\end{array}$ \\
\hline 1 & RUG & $31 \mathrm{~B}$ & 30 & 30 & 3,81 & 25 & 4 & 16 & 8,04 & $0,89 \%$ & 6 & 33 & 33,9 & 576 & silicoso* & 0,00 & 950 & 61 & 56 & 58,2 & 118,0 \\
\hline 2 & RUG & $31 \mathrm{C}$ & 30 & 30 & 3,81 & 25 & 4 & 16 & 8,04 & $0,89 \%$ & 6 & 33 & 35,4 & 576 & silicoso* & 0,00 & 622 & 120 & 80 & 79,8 & 129,7 \\
\hline 3 & RUG & 31D & 30 & 30 & 3,81 & 25 & 4 & 16 & 8,04 & $0,89 \%$ & 6 & 33 & 36,5 & 576 & silicoso* & 0,07 & 220 & 125 & 107 & 87,5 & 169,0 \\
\hline 4 & RUG & $31 \mathrm{E}$ & 30 & 30 & 3,81 & 25 & 4 & 16 & 8,04 & $0,89 \%$ & 6 & 33 & 33,4 & 576 & silicoso* & 0,07 & 664 & 128 & 70 & 76,1 & 121,0 \\
\hline 5 & RUG & $32 \mathrm{~A}$ & 30 & 30 & 3,81 & 25 & 4 & 16 & 8,04 & $0,89 \%$ & 6 & 48 & 36,6 & 576 & silicoso* & 0,07 & 349 & 123 & 136 & 99,2 & 141,0 \\
\hline 6 & RUG & $34 \mathrm{~A}$ & 30 & 30 & 3,81 & 25 & 8 & 16 & 16,08 & $1,79 \%$ & 6 & 33 & 35,9 & 576 & silicoso* & 0,07 & 370 & 126 & 116 & 112,8 & 151,3 \\
\hline 7 & RUG & $31 \mathrm{~F}$ & 30 & 30 & 3,81 & 25 & 4 & 16 & 8,04 & $0,89 \%$ & 6 & 33 & 29,3 & 576 & silicoso* & 0,00 & 422 & 116 & 89 & 96,4 & 152,3 \\
\hline 8 & RUG & $41 \mathrm{~A}$ & 40 & 40 & 3,81 & 25 & 8 & 16 & 16,08 & $1,01 \%$ & 8 & 33 & 29,6 & 576 & silicoso* & 0,05 & 1650 & 93 & 73 & 80,3 & 127,2 \\
\hline 9 & RUG & $21 \mathrm{~A}$ & 30 & 20 & 3,81 & 25 & 6 & 12 & 6,79 & $1,13 \%$ & 8 & 31 & 31,1 & 493 & silicoso* & 0,10 & 300 & 60 & 58 & 26,1 & 48,8 \\
\hline 10 & RUG & 21B & 30 & 20 & 3,81 & 25 & 6 & 12 & 6,79 & $1,13 \%$ & 8 & 31 & 29,6 & 493 & silicoso* & 0,10 & 178 & 120 & 83 & 41,3 & 72,0 \\
\hline 11 & RUG & $22 \mathrm{~A}$ & 30 & 20 & 3,81 & 25 & 6 & 12 & 6,79 & $1,13 \%$ & 8 & 41 & 32,5 & 493 & silicoso* & 0,10 & 283 & 60 & 77 & 32,9 & 54,7 \\
\hline 12 & RUG & $22 \mathrm{~B}$ & 30 & 20 & 3,81 & 25 & 6 & 12 & 6,79 & $1,13 \%$ & 8 & 41 & 32,4 & 493 & silicoso* & 0,10 & 334 & 120 & 64 & 27,1 & 44,4 \\
\hline 13 & Ulg & $31 \mathrm{BC}$ & 30 & 30 & 2,1 & 25 & 4 & 16 & 8,04 & $0,89 \%$ & 6 & 33 & 29,3 & 576 & silicoso* & 0,00 & 1270 & 63 & 67 & 50,7 & 99,3 \\
\hline 14 & Ulg & $31 \mathrm{CC}$ & 30 & 30 & 2,1 & 25 & 4 & 16 & 8,04 & $0,89 \%$ & 6 & 33 & 28,6 & 576 & silicoso* & 0,00 & 803 & 123 & 97 & 113,3 & 149,3 \\
\hline 15 & Ulg & $21 \mathrm{BC}$ & 30 & 20 & 2,1 & 25 & 6 & 12 & 6,79 & $1,13 \%$ & 8 & 31 & 30,6 & 493 & silicoso* & 0,00 & 611 & 107 & 85 & 73,5 & 82,6 \\
\hline 16 & Ulg & $22 \mathrm{BC}$ & 30 & 20 & 2,1 & 25 & 6 & 12 & 6,79 & $1,13 \%$ & 8 & 41 & 27,3 & 493 & silicoso* & 0,00 & 620 & 97 & 101 & 78,5 & 79,7 \\
\hline 17 & TUBr & 1 & 30 & 30 & 3,76 & 28 & 6 & 20 & 18,85 & $2,09 \%$ & $\mathrm{NF}$ & 38 & 24,1 & 487 & silicoso* & 0,10 & 710 & 86 & 99 & 71,4 & 61,0 \\
\hline 18 & TUBr & 2 & 30 & 30 & 3,76 & $28^{*}$ & 6 & $20^{*}$ & 18,85 & $2,09 \%$ & $\mathrm{NF}$ & 38 & 24,1 & 487 & silicoso* & 0,00 & 930 & 84 & 98 & 65,5 & 104,8 \\
\hline 19 & TUBr & 3 & 30 & 30 & 3,76 & $28^{*}$ & 6 & $20^{*}$ & 18,85 & $2,09 \%$ & $\mathrm{NF}$ & 38 & 24,1 & 487 & silicoso* & 0,00 & 930 & 138 & 98 & 65,5 & 104,8 \\
\hline 20 & TUBr & 4 & 30 & 30 & 4,76 & $28^{*}$ & 6 & $20^{*}$ & 18,85 & $2,09 \%$ & $\mathrm{NF}$ & 38 & 24,1 & 487 & silicoso* & 0,10 & 650 & 63 & 91 & 64,8 & 79,5 \\
\hline 21 & TUBr & 5 & 30 & 30 & 4,76 & $28^{*}$ & 6 & $20 *$ & 18,85 & $2,09 \%$ & $\mathrm{NF}$ & 38 & 24,1 & 487 & silicoso* & 0,00 & 880 & 108 & 89 & 93,5 & 83,4 \\
\hline 22 & TUBr & 6 & 30 & 30 & 5,76 & $28^{*}$ & 6 & $20^{*}$ & 18,85 & $2,09 \%$ & $\mathrm{NF}$ & 38 & 24,1 & 487 & silicoso* & 0,10 & 600 & 61 & 82 & 52,6 & 70,0 \\
\hline 23 & TUBr & 7 & 30 & 30 & 5,76 & $28^{*}$ & 6 & $20^{*}$ & 18,85 & $2,09 \%$ & $\mathrm{NF}$ & 38 & 24,1 & 487 & silicoso* & 0,00 & 800 & 58 & 83 & 64,4 & 78,4 \\
\hline 24 & TUBr & 8 & 20 & 20 & 3,76 & $28^{*}$ & 4 & $20^{*}$ & 12,57 & $3,14 \%$ & NF & 38 & 24,1 & 487 & silicoso* & 0,00 & 420 & 58 & 68 & 66,9 & 53,3 \\
\hline 25 & TUBr & 9 & 20 & 20 & 3,76 & $28^{*}$ & 4 & $20^{*}$ & 12,57 & $3,14 \%$ & $\mathrm{NF}$ & 38 & 24,1 & 487 & silicoso* & 0,00 & 420 & 66 & 68 & 66,9 & 53,3 \\
\hline 26 & TUBr & 10 & 20 & 20 & 4,76 & $28^{*}$ & 4 & 20 & 12,57 & $3,14 \%$ & $\mathrm{NF}$ & 38 & 24,1 & 487 & silicoso* & 0,00 & 340 & 48 & 66 & 44,3 & 54,9 \\
\hline 27 & TUBr & 11 & 30 & 30 & 4,76 & $28^{*}$ & 6 & 20 & 18,85 & $2,09 \%$ & $\mathrm{NF}$ & 38 & 30,7 & 462 & silicoso* & 0,10 & 650 & 80 & 103 & 63,8 & 86,5 \\
\hline 28 & TUBr & 12 & 30 & 30 & 4,76 & $28^{*}$ & 6 & 20 & 18,85 & $2,09 \%$ & $\mathrm{NF}$ & 38 & 30,7 & 462 & silicoso* & 0,10 & 650 & 69 & 103 & 63,8 & 86,5 \\
\hline 29 & TUBr & 13 & 30 & 30 & 4,76 & $28^{*}$ & 6 & 20 & 18,85 & $2,09 \%$ & $\mathrm{NF}$ & 38 & 30,7 & 462 & silicoso* & 0,05 & 740 & 85 & 104 & 68,5 & 89,7 \\
\hline 30 & TUBr & 14 & 20 & 20 & 4,76 & $28^{*}$ & 4 & 20 & 12,57 & $3,14 \%$ & $\mathrm{NF}$ & 38 & 30,7 & 462 & silicoso* & 0,05 & 280 & 49 & 75 & 42,5 & 46,7 \\
\hline 31 & TUBr & 15 & 20 & 20 & 4,76 & $28^{*}$ & 4 & 20 & 12,57 & $3,14 \%$ & $\mathrm{NF}$ & 38 & 30,7 & 462 & silicoso* & 0,10 & 240 & 36 & 74 & 40,2 & 47,0 \\
\hline 32 & TUBr & 16 & 30 & 30 & 4,76 & $28^{*}$ & 6 & 20 & 18,85 & $2,09 \%$ & $\mathrm{NF}$ & 38 & 30,7 & 462 & silicoso* & 0,30 & 460 & 75 & 92 & 53,8 & 72,6 \\
\hline 33 & TUBr & 17 & 30 & 30 & 4,76 & $28^{*}$ & 6 & 20 & 18,85 & $2,09 \%$ & $\mathrm{NF}$ & 38 & 30,7 & 462 & silicoso* & 0,50 & 362 & 65 & 99 & 47,8 & 62,8 \\
\hline 34 & TUBr & 18 & 20 & 20 & 4,76 & $28^{*}$ & 4 & $20^{*}$ & 12,57 & $3,14 \%$ & $\mathrm{NF}$ & 38 & 30,7 & 462 & silicoso* & 0,30 & 170 & 49 & 65 & 34,9 & 46,3 \\
\hline 35 & TUBr & 19 & 20 & 20 & 4,76 & $28^{*}$ & 4 & 20 & 12,57 & $3,14 \%$ & $\mathrm{NF}$ & 38 & 30,7 & 462 & silicoso* & 0,50 & 130 & 53 & 128 & 35,0 & 46,6 \\
\hline 36 & TUBr & 20 & 30 & 30 & 2,66 & $28^{*}$ & 6 & $20^{*}$ & 18,85 & $2,09 \%$ & $\mathrm{NF}$ & 38 & 33,2 & 458 & silicoso* & 0,10 & 845 & 111 & 123 & 100,8 & 121,1 \\
\hline 37 & TUBr & 21 & 30 & 30 & 2,66 & $28^{*}$ & 6 & $20^{*}$ & 18,85 & $2,09 \%$ & NF & 38 & 33,2 & 418 & silicoso* & 0,17 & 780 & 125 & 129 & 84,2 & 102,2 \\
\hline 38 & TUBr & 25 & 20 & 20 & 5,76 & $28^{*}$ & 4 & $20^{*}$ & 12,57 & $3,14 \%$ & $\mathrm{NF}$ & 38 & 32,4 & 443 & silicoso* & 0,05 & 208 & 40 & 72 & 48,6 & 315 \\
\hline
\end{tabular}

continua 
conclusão

\begin{tabular}{|c|c|c|c|c|c|c|c|c|c|c|c|c|c|c|c|c|c|c|c|c|c|}
\hline \multirow[b]{2}{*}{ no. } & \multirow[b]{2}{*}{ Lab. } & \multirow[b]{2}{*}{ Rótulo } & \multicolumn{2}{|c|}{ Seção transv. } & \multirow[b]{2}{*}{$\mathrm{L}(\mathrm{m})$} & \multirow[b]{2}{*}{$\mathrm{c}(\mathrm{mm})$} & \multicolumn{5}{|c|}{ Armaduras } & \multirow[b]{2}{*}{$\begin{array}{c}\mathrm{a} \\
(\mathrm{mm})\end{array}$} & \multicolumn{3}{|c|}{ Materiais } & \multirow[b]{2}{*}{$e / b$} & \multirow[b]{2}{*}{$\begin{array}{l}\mathrm{N}_{\mathrm{Sd}, \mathrm{fi}} \\
(\mathrm{kN})\end{array}$} & \multicolumn{4}{|c|}{ TRF (min) } \\
\hline & & & $\begin{array}{c}\mathrm{b} \\
(\mathrm{cm})\end{array}$ & $\begin{array}{c}\mathrm{h} \\
(\mathrm{cm})\end{array}$ & & & $\mathrm{n}$ & $\begin{array}{c}\phi \\
(\mathrm{mm})\end{array}$ & $\begin{array}{c}\text { As } \\
\left(\mathrm{cm}^{2}\right)\end{array}$ & $\begin{array}{c}\rho= \\
A_{s} / A_{c}\end{array}$ & $\begin{array}{l}\phi, \text { est. } \\
(\mathrm{mm})\end{array}$ & & $\begin{array}{c}\mathrm{f}_{\mathrm{c}} \\
(\mathrm{MPa})\end{array}$ & $\begin{array}{c}\mathrm{f}_{\mathrm{y}} \\
(\mathrm{MPa})\end{array}$ & agregado & & & Teste & $\begin{array}{l}\text { COSTA(2006) } \\
\text { Mét. A EC2 }\end{array}$ & $\begin{array}{c}\text { TRF1* } \\
\text { analítico }\end{array}$ & $\begin{array}{c}\text { TRF2* } \\
\text { analítico }\end{array}$ \\
\hline 39 & TUBr & 26 & 30 & 30 & 3,33 & $28^{*}$ & 6 & $20^{*}$ & 18,85 & $2,09 \%$ & NF & 38 & 30,7 & 433 & silicoso* & 0,05 & 735 & 160 & 124 & 118,1 & 131,2 \\
\hline 40 & TUBr & 27 & 30 & 30 & 3,33 & $28^{*}$ & 6 & $20^{*}$ & 18,85 & $2,09 \%$ & $\mathrm{NF}$ & 38 & 43,2 & 544 & silicoso* & 0,50 & 355 & 89 & 136 & 81,1 & 84 \\
\hline 41 & TUBr & 28 & 30 & 30 & 4,76 & $28^{*}$ & 6 & $20^{*}$ & 18,85 & $2,09 \%$ & NF & 38 & 31,5 & 499 & silicoso* & 0,05 & 735 & 93 & 112 & 71,9 & 93,1 \\
\hline 42 & TUBr & 29 & 30 & 30 & 4,76 & $28^{*}$ & 6 & $20 *$ & 18,85 & $2,09 \%$ & NF & 38 & 38,2 & 449 & silicoso* & 0,10 & 645 & 135 & 124 & 64,2 & 93,8 \\
\hline 43 & TUBr & 30 & 30 & 30 & 4,76 & $28^{*}$ & 6 & $20 *$ & 18,85 & $2,09 \%$ & NF & 38 & 38,2 & 404 & silicoso* & 0,02 & 1224 & 48 & 85 & 56,2 & 70,3 \\
\hline 44 & TUBr & 31 & 30 & 30 & 3,76 & $28^{*}$ & 6 & 20 & 18,85 & $2,09 \%$ & $\mathrm{NF}$ & 38 & 42,3 & 452 & silicoso* & 0,02 & 1695 & 57 & 79 & 47,1 & 73,2 \\
\hline 45 & TUBr & 37 & 30 & 30 & 4,7 & $28^{*}$ & 6 & $20^{*}$ & 18,85 & $2,09 \%$ & NF & 38 & 34,9 & 505 & silicoso* & 0,02 & 1548 & 38 & 62 & 47,6 & 56,7 \\
\hline 46 & TUBr & 38 & 30 & 30 & 4,7 & $28^{*}$ & 6 & $20 *$ & 18,85 & $2,09 \%$ & NF & 38 & 31,5 & 503 & silicoso* & 0,03 & 970 & 55 & 91 & 65,5 & 78,5 \\
\hline 47 & TUBr & 39 & 30 & 30 & 4,7 & $28^{*}$ & 6 & $20^{*}$ & 18,85 & $2,09 \%$ & NF & 38 & 31,5 & 526 & silicoso* & 0,03 & 1308 & 57 & 67 & 42,6 & 60,1 \\
\hline 48 & TUBr & 40 & 30 & 30 & 4,7 & $28^{*}$ & 6 & $20^{*}$ & 18,85 & $2,09 \%$ & NF & 38 & 31,5 & 503 & silicoso* & 0,50 & 280 & 49 & 116 & 67,8 & 76,2 \\
\hline 49 & TUBr & 41 & 30 & 30 & 4,7 & $28^{*}$ & 6 & $20 *$ & 18,85 & $2,09 \%$ & NF & 38 & 31,5 & 526 & silicoso* & 0,50 & 465 & 50 & 79 & 40,1 & 52 \\
\hline 50 & TUBr & 42 & 20 & 20 & 5,71 & $23^{*}$ & 6 & $14 *$ & 9,24 & $2,31 \%$ & NF & 30 & 41,5 & 480 & silicoso* & 0,50 & 140 & 31 & 77 & 13,7 & 61 \\
\hline 51 & TUBr & 43 & 20 & 20 & 5,71 & $23 *$ & 6 & $14 *$ & 9,24 & $2,31 \%$ & NF & 30 & 41,5 & 477 & silicoso* & 0,05 & 245 & 40 & 70 & 20,2 & 38,1 \\
\hline 52 & TUBr & 44 & 20 & 20 & 5,71 & $23^{*}$ & 6 & $14^{*}$ & 9,24 & $2,31 \%$ & NF & 30 & 41,5 & 480 & silicoso* & 0,25 & 172 & 35 & 68 & 17,7 & 28,6 \\
\hline 53 & TUBr & 45 & 20 & 20 & 5,71 & $23^{*}$ & 6 & $14 *$ & 9,24 & $2,31 \%$ & NF & 30 & 41,5 & 482 & silicoso* & 0,05 & 175 & 49 & 84 & 29,4 & 50,5 \\
\hline 54 & TUBr & 46 & 20 & 20 & 5,71 & $23^{*}$ & 6 & $14 *$ & 9,24 & $2,31 \%$ & NF & 30 & 41,5 & 485 & silicoso* & 0,25 & 122 & 52 & 83 & 28,1 & 46,4 \\
\hline 55 & TUBr & 47 & 20 & 20 & 5,71 & $23 *$ & 6 & $14 *$ & 9,24 & $2,31 \%$ & NF & 30 & 41,5 & 478 & silicoso* & 0,05 & 128 & 72 & 94 & 38,1 & 63,1 \\
\hline 56 & NRCC & $\mathrm{I} 2$ & 30,5 & 30,5 & 3,8 & $48^{*}$ & 4 & $25,5^{*}$ & 20,43 & $2,20 \%$ & NF & 60,75 & 36,9 & 444 & silicoso & 0,00 & 1333 & 170 & 177 & 142,6 & 171,3 \\
\hline 57 & NRCC & I3 & 30,5 & 30,5 & 3,8 & $48^{*}$ & 4 & $25,5 *$ & 20,43 & $2,20 \%$ & $\mathrm{NF}$ & 60,75 & 34,2 & 444 & silicoso & 0,00 & 800 & 218 & 210 & 216,2 & 225,1 \\
\hline 58 & NRCC & I4 & 30,5 & 30,5 & 3,8 & $48^{*}$ & 4 & $25,5 *$ & 20,43 & $2,20 \%$ & NF & 60,75 & 35,1 & 444 & silicoso & 0,00 & 711 & 220 & 218 & 235,6 & 241,7 \\
\hline 59 & NRCC & I6 & 20,3 & 20,3 & 3,8 & $48^{*}$ & 4 & 20 & 12,57 & $3,05 \%$ & NF & 58 & 42,3 & 442 & silicoso & 0,00 & 169 & 185 & 209 & 144,6 & 158,1 \\
\hline 60 & NRCC & I7 & 30,5 & 30,5 & 3,8 & $48^{*}$ & 4 & $25,5 *$ & 20,43 & $2,20 \%$ & NF & 60,75 & 36,1 & 444 & silicoso & 0,00 & 1067 & 208 & 193 & 178 & $\begin{array}{l}194,9 \\
\end{array}$ \\
\hline 61 & NRCC & I8 & 30,5 & 30,5 & 3,8 & $48^{*}$ & 4 & $25,5 *$ & 20,43 & $2,20 \%$ & NF & 60,75 & 34,8 & 444 & silicoso & 0,00 & 1778 & 146 & 145 & 88 & 124 \\
\hline 62 & NRCC & I9 & 30,5 & 30,5 & 3,8 & $48^{*}$ & 4 & $25,5 *$ & 20,43 & $2,20 \%$ & NF & 60,75 & 38,3 & 444 & silicoso & 0,00 & 1333 & 187 & 179 & 146,9 & 174,8 \\
\hline 63 & NRCC & II2 & 30,5 & 30,5 & 3,8 & $48^{*}$ & 4 & $25,5 *$ & 20,43 & $2,20 \%$ & NF & 60,75 & 43,6 & 444 & silicoso & 0,00 & 1044 & 201 & 204 & 206,1 & 218 \\
\hline 64 & NRCC & II3 & 30,5 & 30,5 & 3,8 & $48^{*}$ & 4 & $25,5 *$ & 20,43 & $2,20 \%$ & NF & 60,75 & 35,4 & 444 & silicoso & 0,00 & 916 & 210 & 203 & 198,8 & 212,1 \\
\hline 65 & NRCC & II4 & 30,5 & 30,5 & 3,8 & $48^{*}$ & 4 & $25,5^{*}$ & 20,43 & $2,20 \%$ & NF & $\begin{array}{l}60,75 \\
\end{array}$ & 52,9 & 444 & silicoso & 0,00 & 1178 & 227 & 206 & 213,5 & 224,1 \\
\hline 66 & NRCC & II5 & 30,5 & 30,5 & 3,8 & $48^{*}$ & 4 & $25,5^{*}$ & 20,43 & $2,20 \%$ & NF & 60,75 & 49,5 & 444 & silicoso & 0,00 & 1067 & 234 & 209 & 219,8 & 228,9 \\
\hline 67 & NRCC & II8 & 30,5 & 30,5 & 3,8 & $48^{*}$ & 8 & $25,5 *$ & 40,86 & $4,39 \%$ & NF & 60,75 & 42,6 & 444 & silicoso & 0,00 & 978 & 252 & 249 & 252 & 255,6 \\
\hline 68 & NRCC & II9 & 30,5 & 30,5 & 3,8 & $48^{*}$ & 8 & $25,5 *$ & 40,86 & $4,39 \%$ & NF & 60,75 & 37,1 & 444 & silicoso & 0,00 & 1333 & 225 & 225 & 205,4 & 209,2 \\
\hline 69 & NRCC & III0 & 40,6 & 40,6 & 3,8 & $48^{*}$ & 8 & $25,5 *$ & 40,86 & $2,48 \%$ & NF & 60,75 & 38,8 & 444 & silicoso & 0,00 & 2418 & 262 & 229 & 228,6 & 297,4 \\
\hline 70 & NRCC & II11 & 40,6 & 40,6 & 3,8 & 48 & 8 & $32 *$ & 64,34 & $3,90 \%$ & $\mathrm{NF}$ & 64,15 & 38,4 & 414 & silicoso & 0,00 & 2795 & 285 & 241 & 233,5 & 299,9 \\
\hline 71 & NRCC & II12 & 40,6 & 40,6 & 3,8 & $64,15^{*}$ & 8 & $32 *$ & 64,34 & $3,90 \%$ & NF & 80,15 & 46,2 & 414 & silicoso & 0,00 & 2978 & 213 & 312 & 262,1 & 284 \\
\hline 72 & NRCC & III1 & 30,5 & 30,5 & 3,8 & $48^{*}$ & 4 & $25,5^{*}$ & 20,43 & $2,20 \%$ & NF & $\begin{array}{l}60,75 \\
\end{array}$ & 39,6 & 444 & silicoso & 0,00 & 800 & 242 & 186 & 190,6 & 201,9 \\
\hline 73 & NRCC & III2 & 30,5 & 30,5 & 3,8 & $48^{*}$ & 4 & $25,5 *$ & 20,43 & $2,20 \%$ & NF & 60,75 & 39,2 & 444 & silicoso & 0,00 & 1000 & 220 & 170 & 167,6 & 180,4 \\
\hline 74 & NRCC & III3 & 30,5 & 30,5 & 3,8 & $56,75^{*}$ & 4 & $25,5 *$ & 20,43 & $2,20 \%$ & NF & 60,75 & 39,9 & 444 & calcáreo & 0,08 & 1000 & 181 & 123 & 185 & 184,9 \\
\hline 75 & NRCC & III5 & 30,5 & 45,7 & 3,8 & $48,1^{*}$ & 8 & $22 *$ & 30,41 & $2,18 \%$ & NF & 59,1 & 42,5 & 414 & silicoso & 0,00 & 1413 & 356 & 244 & 272,5 & 308 \\
\hline 76 & NRCC & III14 & 30,5 & 30,5 & 3,8 & $56,75^{*}$ & 4 & $25,5^{*}$ & 20,43 & $2,20 \%$ & $\mathrm{NF}$ & 60,75 & 37,9 & 444 & silicoso & 0,08 & 1178 & 183 & 146 & 121,7 & 128,8 \\
\hline
\end{tabular}

*valores em itálico foram calculados ou deduzidos, por estarem ausentes nas referências consultadas por (COSTA, 2006)

*TRF1: resultados analíticos calculados pelo método FNC-FOGO considerando as deformações térmicas

*TRF2: resultados analíticos calculados pelo método FNC-FOGO desconsiderando as deformações térmicas 
A Figura 86 apresenta a comparação entre os valores de TRF obtidos experimentalmente e os obtidos analiticamente pelo método FNC-FOGO (valores da coluna TRF1 da Tabela 11).

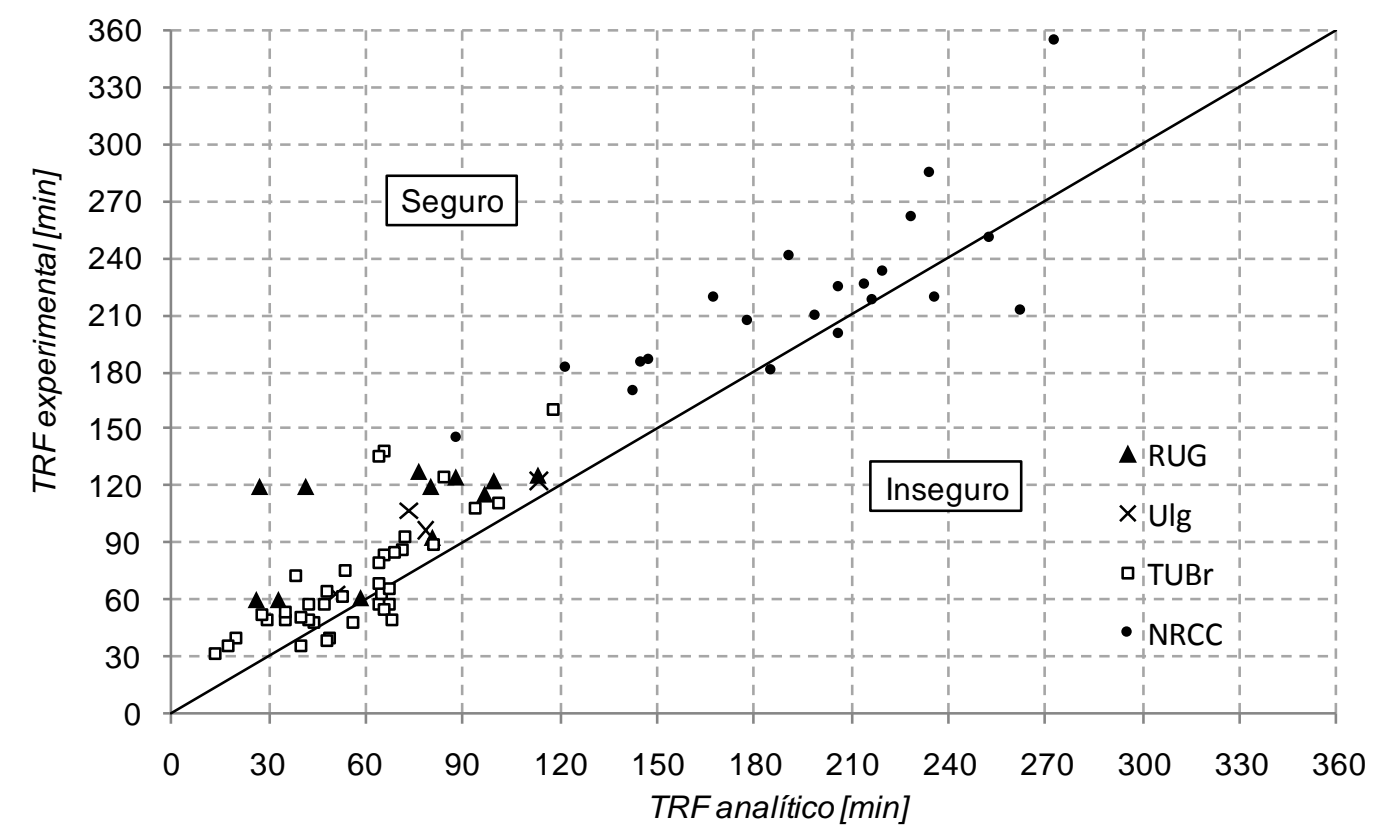

Figura 86 - Comparação entre o TRF obtido experimentalmente e o TRF1 obtido analiticamente pelo método FNC-FOGO

Esse grupo de pilares foi calculado considerando a deformação térmica e utilizando coeficientes redutores da resistência do aço diferentes para tração e compressão.

Avaliando a segurança do método FNC-FOGO em relação aos 76 pilares calculados, 62 pilares $(81,6 \%)$ ficaram a favor da segurança, ou seja, apresentaram relação $\mathrm{TRF} 1_{\text {analítico }} / \mathrm{TRF}_{\text {teste }} \leq 1$, conforme mostra a Figura 87.

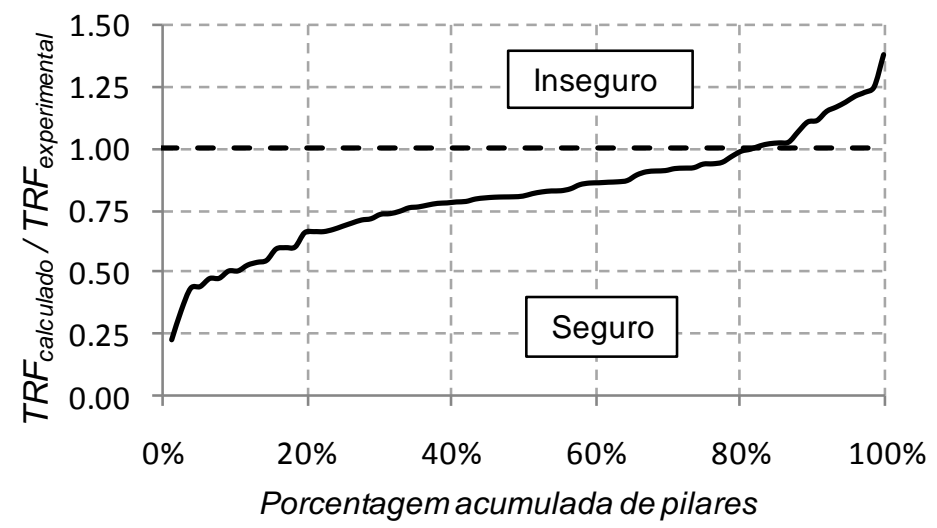

Figura 87 - Avaliação da segurança do método FNC-FOGO considerando os valores de TRF1 da Tabela 11 
A média da relação entre os resultados analíticos e os resultados experimentais (TRF $\left.1_{\text {analítico }} / \mathrm{TRF}_{\text {teste }}\right)$ resultou 0,82 , com desvio-padrão de 0,22 e coeficiente de variação igual a 0,27. Nos cálculos feitos por Costa (2006), aplicando o Método A do Eurocode 2 (EN 1992-1-2:2004) ao mesmo grupo de pilares, a média da relação entre os resultados analíticos e os resultados experimentais $\left(\mathrm{TRF}_{\text {calculado }} / \mathrm{TRF}_{\text {teste }}\right)$ resultou 1,18 , com desvio-padrão de 0,43 e coeficiente de variação igual a 0,36.

Dentre os 14 pilares que resultaram contra a segurança quando calculados pelo método FNC-FOGO, 4 foram ensaiados pelo NRCC e os outros 10 foram ensaiados pela TUBr.

Na Figura 86 é possível observar que um dos pilares ensaiados pelo NRCC (rótulo II12, ver Tabela 11) resultou excessivamente contra a segurança quando calculados pelo método FNC-FOGO. No relatório do ensaio experimental (LIN et al., 1992) consta que o ensaio deste pilar não foi completado devido a um mal funcionamento do forno, o que justifica a discrepância observada entre os valores de $\mathrm{TRF}\left(\mathrm{TRF}_{\text {teste }}=213\right.$ minutos $\mathrm{e}$ $\mathrm{TRF}_{\text {analítico }}=245$ minutos). $\mathrm{O}$ TRF calculado para o mesmo pilar segundo o Método A do Eurocode 2 (EN 1992-1-2:2004) resultou 312 minutos (COSTA, 2006), ficando ainda mais contra a segurança.

Conforme mencionado, do grupo de 39 pilares ensaiados pelo $\mathrm{TUBr}, 10$ resultaram ligeiramente contra a segurança quando calculados pelo método FNC-FOGO. A Figura 88 apresenta a comparação entre os valores de TRF experimentais e analíticos do grupo de pilares ensaiados pelo TUBr.

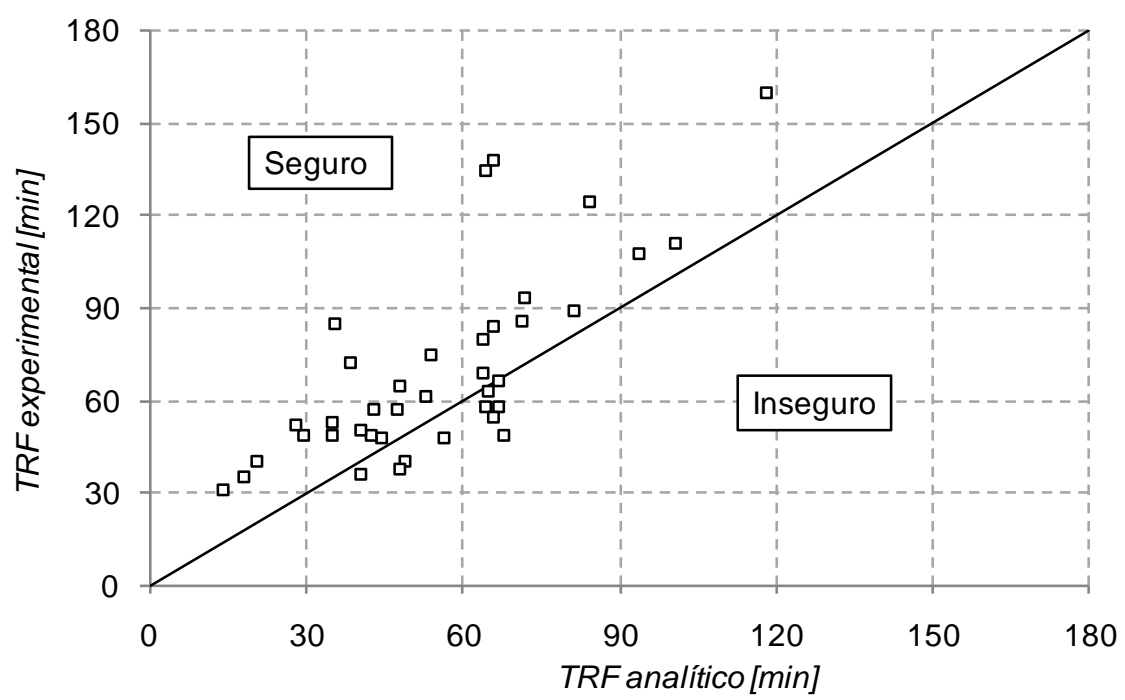

Figura 88 - Comparação entre o TRF obtido experimentalmente e o TRF1 obtido analiticamente pelo método FNC-FOGO com modelo biapoiado, pilares ensaiados pela TUBr 
A média da relação entre os resultados analíticos e os resultados experimentais resultou 0,83, com desvio-padrão de 0,25 e coeficiente de variação igual a 0,30. A pior relação TRF $1_{\text {analítico }} / \mathrm{TRF}_{\text {teste }}$ foi de 1,38 (TRF calculado $38 \%$ superior ao TRF experimental). Embora o grupo de 39 pilares ensaiados pela TUBr corresponda à metade dos pilares utilizados na calibração do Método A do Eurocode 2 (EN 1992-1-2:2004), a sua base de dados não é totalmente confiável, apresentando incertezas e dados incompletos (COSTA, 2006; FRANSSEN, 2001), conforme discutido anteriormente no item 7.2.6 deste trabalho.

Uma das incertezas em relação aos pilares ensaiados pela TUBr é com relação ao comprimento efetivo dos mesmos. Franssen (2001) afirma que alguns desses pilares possuíam restrição à rotação em uma das extremidades (modelo apoiado-engastado), justificando assim a consideração do comprimento efetivo do pilar em situação de incêndio $\ell_{\mathrm{fi}}=0,7 \cdot \ell_{0}$. Essa questão foi investigada por Costa (2006) e é avaliada também neste trabalho. A Tabela 12 apresenta os valores de TRF medidos experimentalmente, os calculados por Costa (2006) utilizando o Método A do Eurocode 2 (EN 1992-1-2:2004) e os calculados analiticamente neste trabalho pelo método FNC-FOGO, considerando os modelos de cálculo biapoiado e apoiado-engastado. 
Tabela 12 - TRF medidos e calculados dos pilares ensaiados pela TUBr

\begin{tabular}{|c|c|c|c|c|c|c|c|c|c|c|c|c|c|c|c|c|c|c|c|c|c|c|}
\hline \multirow[b]{2}{*}{ no. } & \multirow[b]{2}{*}{ Lab. } & \multirow[b]{2}{*}{ Rótulo } & \multicolumn{2}{|c|}{ Seção transv. } & \multirow[b]{2}{*}{$\mathrm{L}(\mathrm{m})$} & \multirow{2}{*}{$\begin{array}{c}\mathrm{c} \\
(\mathrm{mm} \\
)\end{array}$} & \multicolumn{5}{|c|}{ Armaduras } & \multirow[b]{2}{*}{$\begin{array}{c}\mathrm{a} \\
(\mathrm{mm})\end{array}$} & \multicolumn{3}{|c|}{ Materiais } & \multirow[b]{2}{*}{$e / b$} & \multirow[b]{2}{*}{$\begin{array}{l}\mathrm{N}_{\mathrm{Sd}, \mathrm{fi}} \\
(\mathrm{kN})\end{array}$} & \multirow{2}{*}{$\begin{array}{l}\text { TRF } \\
\text { Teste } \\
\text { (min) }\end{array}$} & \multicolumn{2}{|c|}{ TRF AE* (min) } & \multicolumn{2}{|c|}{ TRF BA* (min) } \\
\hline & & & $\begin{array}{c}\mathrm{b} \\
(\mathrm{cm})\end{array}$ & $\begin{array}{c}\mathrm{h} \\
(\mathrm{cm})\end{array}$ & & & $\mathrm{n}$ & $\begin{array}{c}\phi \\
(\mathrm{mm})\end{array}$ & $\begin{array}{c}\text { As } \\
\left(\mathrm{cm}^{2}\right)\end{array}$ & $\begin{array}{c}\rho= \\
A_{s} / A_{c}\end{array}$ & $\begin{array}{l}\phi, \text { est. } \\
(\mathrm{mm})\end{array}$ & & $\begin{array}{c}\mathrm{f}_{\mathrm{c}} \\
(\mathrm{MPa})\end{array}$ & $\begin{array}{c}\mathrm{f}_{\mathrm{y}} \\
(\mathrm{MPa})\end{array}$ & agregado & & & & $\begin{array}{l}\text { COSTA(2006) } \\
\text { Mét. A EC2 }\end{array}$ & $\begin{array}{c}\text { TRF3 } \\
\text { analítico }\end{array}$ & $\begin{array}{c}\text { COSTA(2006) } \\
\text { Mét. A EC2 }\end{array}$ & $\begin{array}{c}\text { TRF4 } \\
\text { analítico }\end{array}$ \\
\hline 17 & TUBr & 1 & 30 & 30 & 3,76 & 28 & 6 & 20 & 18,85 & $2,09 \%$ & $\mathrm{NF}$ & 38 & 24,1 & 487 & silicoso* & 0,10 & 710 & 86 & 99 & 62,3 & 75 & 69,5 \\
\hline 18 & TUBr & 2 & 30 & 30 & 3,76 & $28^{*}$ & 6 & $20^{*}$ & 18,85 & $2,09 \%$ & $\mathrm{NF}$ & 38 & 24,1 & 487 & silicoso* & 0,00 & 930 & 84 & 98 & 114,4 & 77 & 104,7 \\
\hline 19 & TUBr & 3 & 30 & 30 & 3,76 & $28^{*}$ & 6 & $20^{*}$ & 18,85 & $2,09 \%$ & $\mathrm{NF}$ & 38 & 24,1 & 487 & silicoso* & 0,00 & 930 & 138 & 98 & 114,4 & 77 & 104,7 \\
\hline 20 & TUBr & 4 & 30 & 30 & 4,76 & $28^{*}$ & 6 & $20^{*}$ & 18,85 & $2,09 \%$ & $\mathrm{NF}$ & 38 & 24,1 & 487 & silicoso* & 0,10 & 650 & 63 & 91 & 74,7 & 61 & 63,6 \\
\hline 21 & TUBr & 5 & 30 & 30 & 4,76 & $28^{*}$ & 6 & $20^{*}$ & 18,85 & $2,09 \%$ & $\mathrm{NF}$ & 38 & 24,1 & 487 & silicoso* & 0,00 & 880 & 108 & 89 & 106 & 63 & 74,4 \\
\hline 22 & TUBr & 6 & 30 & 30 & 5,76 & $28^{*}$ & 6 & $20^{*}$ & 18,85 & $2,09 \%$ & $\mathrm{NF}$ & 38 & 24,1 & 487 & silicoso* & 0,10 & 600 & 61 & 82 & 68,6 & 45 & 52,0 \\
\hline 23 & TUBr & 7 & 30 & 30 & 5,76 & $28^{*}$ & 6 & $20^{*}$ & 18,85 & $2,09 \%$ & $\mathrm{NF}$ & 38 & 24,1 & 487 & silicoso* & 0,00 & 800 & 58 & 83 & 74,5 & 52 & 63,6 \\
\hline 24 & TUBr & 8 & 20 & 20 & 3,76 & $28^{*}$ & 4 & $20^{*}$ & 12,57 & $3,14 \%$ & $\mathrm{NF}$ & 38 & 24,1 & 487 & silicoso* & 0,00 & 420 & 58 & 68 & 74,5 & 43 & 67,9 \\
\hline 25 & TUBr & 9 & 20 & 20 & 3,76 & $28^{*}$ & 4 & $20^{*}$ & 12,57 & $3,14 \%$ & $\mathrm{NF}$ & 38 & 24,1 & 487 & silicoso* & 0,00 & 420 & 66 & 68 & 74,5 & 43 & 67,9 \\
\hline 26 & TUBr & 10 & 20 & 20 & 4,76 & $28^{*}$ & 4 & 20 & 12,57 & $3,14 \%$ & $\mathrm{NF}$ & 38 & 24,1 & 487 & silicoso* & 0,00 & 340 & 48 & 66 & 80,3 & 23 & 44,3 \\
\hline 27 & TUBr & 11 & 30 & 30 & 4,76 & $28^{*}$ & 6 & 20 & 18,85 & $2,09 \%$ & $\mathrm{NF}$ & 38 & 30,7 & 462 & silicoso* & 0,10 & 650 & 80 & 103 & 83,3 & 72 & 63,1 \\
\hline 28 & TUBr & 12 & 30 & 30 & 4,76 & $28^{*}$ & 6 & 20 & 18,85 & $2,09 \%$ & $\mathrm{NF}$ & 38 & 30,7 & 462 & silicoso* & 0,10 & 650 & 69 & 103 & 83,3 & 72 & 63,1 \\
\hline 29 & TUBr & 13 & 30 & 30 & 4,76 & $28^{*}$ & 6 & 20 & 18,85 & $2,09 \%$ & $\mathrm{NF}$ & 38 & 30,7 & 462 & silicoso* & 0,05 & 740 & 85 & 104 & 128,3 & 75 & 67,7 \\
\hline 30 & TUBr & 14 & 20 & 20 & 4,76 & $28^{*}$ & 4 & 20 & 12,57 & $3,14 \%$ & $\mathrm{NF}$ & 38 & 30,7 & 462 & silicoso* & 0,05 & 280 & 49 & 75 & 76,8 & 29 & 40,9 \\
\hline 31 & TUBr & 15 & 20 & 20 & 4,76 & $28^{*}$ & 4 & 20 & 12,57 & $3,14 \%$ & $\mathrm{NF}$ & 38 & 30,7 & 462 & silicoso* & 0,10 & 240 & 36 & 74 & 77,1 & 32 & 39,7 \\
\hline 32 & TUBr & 16 & 30 & 30 & 4,76 & $28^{*}$ & 6 & 20 & 18,85 & $2,09 \%$ & $\mathrm{NF}$ & 38 & 30,7 & 462 & silicoso* & 0,30 & 460 & 75 & 92 & 78,8 & 64 & 53,4 \\
\hline 33 & TUBr & 17 & 30 & 30 & 4,76 & $28^{*}$ & 6 & 20 & 18,85 & $2,09 \%$ & $\mathrm{NF}$ & 38 & 30,7 & 462 & silicoso* & 0,50 & 362 & 65 & 99 & 76,5 & 78 & 47,6 \\
\hline 34 & TUBr & 18 & 20 & 20 & 4,76 & $28^{*}$ & 4 & $20^{*}$ & 12,57 & $3,14 \%$ & $\mathrm{NF}$ & 38 & 30,7 & 462 & silicoso* & 0,30 & 170 & 49 & 65 & 73,6 & 43 & 34,9 \\
\hline 35 & TUBr & 19 & 20 & 20 & 4,76 & $28^{*}$ & 4 & 20 & 12,57 & $3,14 \%$ & $\mathrm{NF}$ & 38 & 30,7 & 462 & silicoso* & 0,50 & 130 & 53 & 128 & 73,5 & 57 & 35,0 \\
\hline 36 & TUBr & 20 & 30 & 30 & 2,66 & $28^{*}$ & 6 & $20^{*}$ & 18,85 & $2,09 \%$ & $\mathrm{NF}$ & 38 & 33,2 & 458 & silicoso* & 0,10 & 845 & 111 & 123 & 145,3 & 88 & 96,7 \\
\hline 37 & TUBr & 21 & 30 & 30 & 2,66 & $28^{*}$ & 6 & $20^{*}$ & 18,85 & $2,09 \%$ & $\mathrm{NF}$ & 38 & 33,2 & 418 & silicoso* & 0,17 & 780 & 125 & 129 & 139,2 & 95 & 80,6 \\
\hline 38 & TUBr & 25 & 20 & 20 & 5,76 & $28 *$ & 4 & $20^{*}$ & 12,57 & $3,14 \%$ & $\mathrm{NF}$ & 38 & 32,4 & 443 & silicoso* & 0,05 & 208 & 40 & 72 & 47,1 & 26 & 48,6 \\
\hline 39 & TUBr & 26 & 30 & 30 & 3,33 & $28^{*}$ & 6 & $20^{*}$ & 18,85 & $2,09 \%$ & $\mathrm{NF}$ & 38 & 30,7 & 433 & silicoso* & 0,05 & 735 & 160 & 124 & 164,5 & 103 & 114,7 \\
\hline 40 & TUBr & 27 & 30 & 30 & 3,33 & $28^{*}$ & 6 & $20^{*}$ & 18,85 & $2,09 \%$ & $\mathrm{NF}$ & 38 & 43,2 & 544 & silicoso* & 0,50 & 355 & 89 & 136 & 107,8 & 118 & 80,0 \\
\hline 41 & TUBr & 28 & 30 & 30 & 4,76 & $28^{*}$ & 6 & $20^{*}$ & 18,85 & $2,09 \%$ & $\mathrm{NF}$ & 38 & 31,5 & 499 & silicoso* & 0,05 & 735 & 93 & 112 & 99,2 & 84 & 71,2 \\
\hline 42 & TUBr & 29 & 30 & 30 & 4,76 & $28^{*}$ & 6 & $20^{*}$ & 18,85 & $2,09 \%$ & $\mathrm{NF}$ & 38 & 38,2 & 449 & silicoso* & 0,10 & 645 & 135 & 124 & 125,6 & 95 & 63,8 \\
\hline 43 & TUBr & 30 & 30 & 30 & 4,76 & $28^{*}$ & 6 & $20^{*}$ & 18,85 & $2,09 \%$ & $\mathrm{NF}$ & 38 & 38,2 & 404 & silicoso* & 0,02 & 1224 & 48 & 85 & 96,2 & 59 & 55,2 \\
\hline 44 & TUBr & 31 & 30 & 30 & 3,76 & $28^{*}$ & 6 & 20 & 18,85 & $2,09 \%$ & $\mathrm{NF}$ & 38 & 42,3 & 452 & silicoso* & 0,02 & 1695 & 57 & 79 & 60,6 & 58 & 57,8 \\
\hline 45 & TUBr & 37 & 30 & 30 & 4,7 & $28 *$ & 6 & $20^{*}$ & 18,85 & $2,09 \%$ & $\mathrm{NF}$ & 38 & 34,9 & 505 & silicoso* & 0,02 & 1548 & 38 & 62 & 61,4 & 39 & 42,4 \\
\hline 46 & TUBr & 38 & 30 & 30 & 4,7 & $28^{*}$ & 6 & $20^{*}$ & 18,85 & $2,09 \%$ & $\mathrm{NF}$ & 38 & 31,5 & 503 & silicoso* & 0,03 & 970 & 55 & 91 & 63,9 & 64 & 61,6 \\
\hline 47 & TUBr & 39 & 30 & 30 & 4,7 & $28^{*}$ & 6 & $20^{*}$ & 18,85 & $2,09 \%$ & $\mathrm{NF}$ & 38 & 31,5 & 526 & silicoso* & 0,03 & 1308 & 57 & 67 & 58,8 & 42 & 41,9 \\
\hline 48 & TUBr & 40 & 30 & 30 & 4,7 & $28^{*}$ & 6 & $20^{*}$ & 18,85 & $2,09 \%$ & $\mathrm{NF}$ & 38 & 31,5 & 503 & silicoso* & 0,50 & 280 & 49 & 116 & 126,7 & 93 & 67,3 \\
\hline 49 & TUBr & 41 & 30 & 30 & 4,7 & $28^{*}$ & 6 & $20^{*}$ & 18,85 & $2,09 \%$ & $\mathrm{NF}$ & 38 & 31,5 & 526 & silicoso* & 0,50 & 465 & 50 & 79 & 94,7 & 60 & 39,8 \\
\hline 50 & TUBr & 42 & 20 & 20 & 5,71 & $23 *$ & 6 & $14 *$ & 9,24 & $2,31 \%$ & $\mathrm{NF}$ & 30 & 41,5 & 480 & silicoso* & 0,50 & 140 & 31 & 77 & 44,4 & 55 & 13,8 \\
\hline 51 & TUBr & 43 & 20 & 20 & 5,71 & $23 *$ & 6 & $14^{*}$ & 9,24 & $2,31 \%$ & $\mathrm{NF}$ & 30 & 41,5 & 477 & silicoso* & 0,05 & 245 & 40 & 70 & 47,6 & 31 & 20,1 \\
\hline 52 & TUBr & 44 & 20 & 20 & 5,71 & $23 *$ & 6 & $14^{*}$ & 9,24 & $2,31 \%$ & $\mathrm{NF}$ & 30 & 41,5 & 480 & silicoso* & 0,25 & 172 & 35 & 68 & 46,7 & 47 & 17,7 \\
\hline 53 & TUBr & 45 & 20 & 20 & 5,71 & $23 *$ & 6 & $14^{*}$ & 9,24 & $2,31 \%$ & $\mathrm{NF}$ & 30 & 41,5 & 482 & silicoso* & 0,05 & 175 & 49 & 84 & 61 & 46 & 29,4 \\
\hline 54 & TUBr & 46 & 20 & 20 & 5,71 & $23 *$ & 6 & $14 *$ & 9,24 & $2,31 \%$ & $\mathrm{NF}$ & 30 & 41,5 & 485 & silicoso* & 0,25 & 122 & 52 & 83 & 59,2 & 59 & 28,1 \\
\hline 55 & TUBr & 47 & 20 & 20 & 5,71 & $23^{*}$ & 6 & $14 *$ & 9,24 & $2,31 \%$ & $\mathrm{NF}$ & 30 & 41,5 & 478 & silicoso* & 0,05 & 128 & 72 & 94 & 75 & 58 & 38,1 \\
\hline
\end{tabular}

*valores em itálico foram calculados ou deduzidos, por estarem ausentes nas referências consultadas por (COSTA, 2006). Modelos de cálculo: biapoiado (BA) e apoiado-engastado (AE). 
A Figura 89 apresenta a comparação entre os valores de TRF obtidos experimentalmente e os obtidos analiticamente pelo método FNC-FOGO para os pilares ensaiados pela TUBr, considerando o modelo apoiado-engastado (coluna TRF3 da Tabela 12).

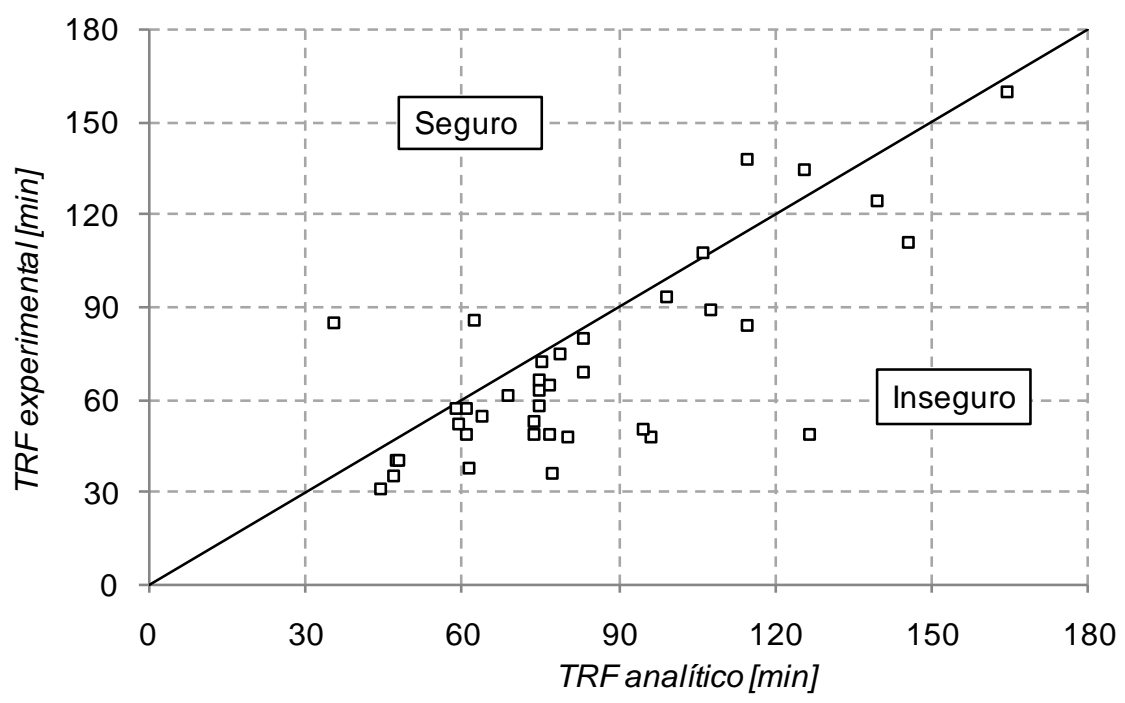

Figura 89 - Comparação entre o TRF obtido experimentalmente e o TRF3 obtido analiticamente pelo método FNC-FOGO com modelo apoiado-engastado, pilares ensaiados pela TUBr

Percebe-se claramente que a maior parte dos valores de TRF calculados resultou contra a segurança. A média da relação entre os resultados analíticos e os resultados experimentais $\left(\mathrm{TRF} 3_{\text {analítico }} / \mathrm{TRF}_{\text {teste }}\right)$ resultou 1,27 , com desvio-padrão de 0,39 e coeficiente de variação igual a 0,31. É possível concluir, portanto, que o modelo apoiado-engastado não é adequado para o cálculo analítico do TRF desses pilares. A adoção do modelo biapoiado para o cálculo do TRF dos pilares ensaiados pela TUBr mostrou ser a opção mais segura (coluna TRF4 da Tabela 12 e Figura 88). O mesmo modelo de cálculo foi adotado também por Holmberg e Anderberg (1993) quando da calibração do software CONFIRE®.

Por último, foram avaliados os efeitos da consideração das deformações térmicas do aço e do concreto no TRF calculado dos pilares. A Figura 90 apresenta a comparação entre os valores de TRF obtidos experimentalmente e os obtidos analiticamente pelo método FNCFOGO (valores da coluna TRF2 da Tabela 11). 


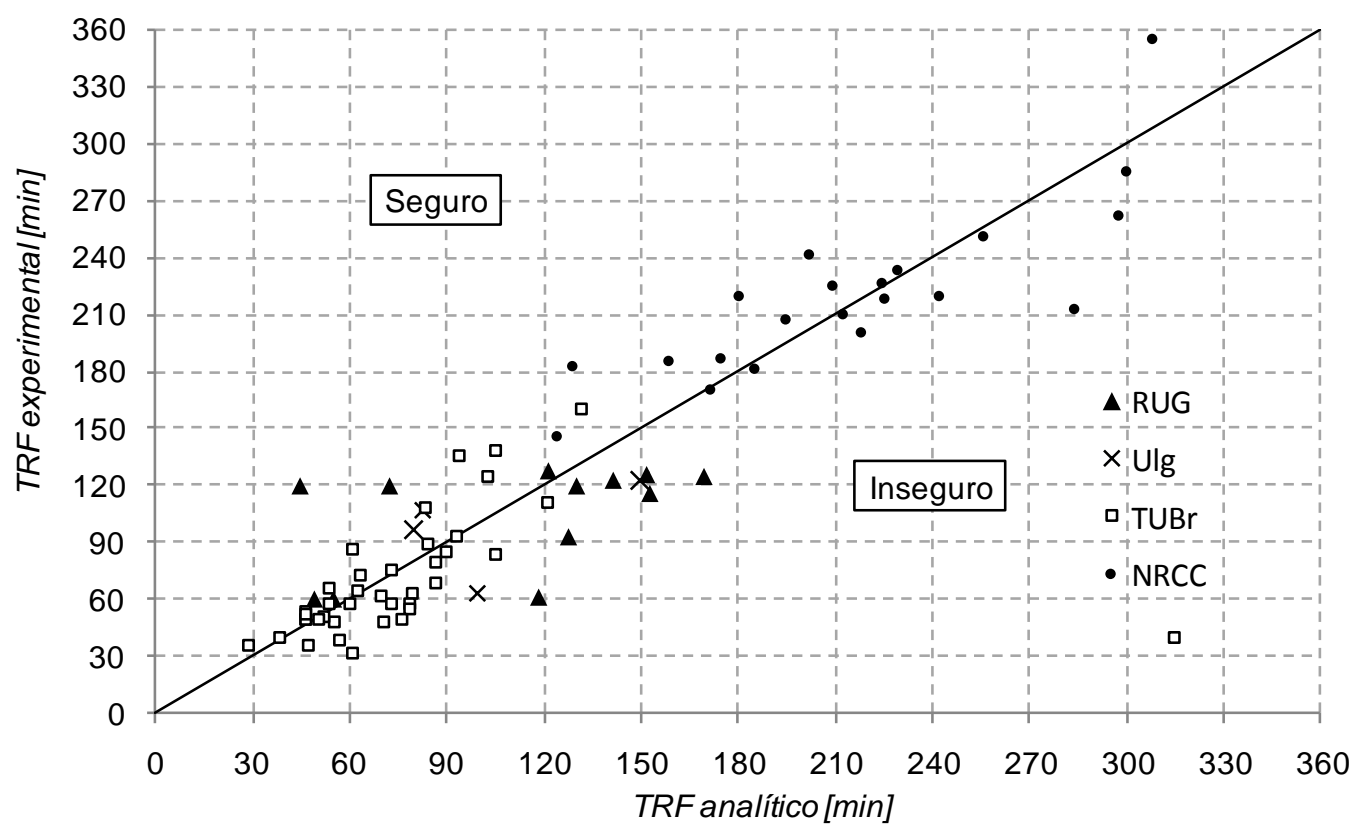

Figura 90 - Comparação entre o TRF obtido experimentalmente e o TRF2 obtido analiticamente pelo método FNC-FOGO desconsiderando as deformações térmicas

Percebe-se que a maioria dos valores de TRF calculados fica contra a segurança quando se desconsideram as deformações térmicas dos materiais. Dos 76 pilares calculados, somente 33 pilares $(43,4 \%)$ apresentaram relação $\mathrm{TRF} 2_{\text {analítico }} / \mathrm{TRF}_{\text {teste }} \leq 1$. A média da relação entre os resultados analíticos e os resultados experimentais $\left(\mathrm{TRF} 2_{\text {analítico }} / \mathrm{TRF}_{\text {teste }}\right)$ resultou 1,14 , com desvio-padrão de 0,83 e coeficiente de variação igual a 0,73 . O efeito foi mais significativo nos pilares calculados pelo modelo biapoiado. Desse grupo de 55 pilares biapoiados, 39 pilares $(70,9 \%)$ apresentaram relação $\mathrm{TRF} 2_{\text {analítico }} / \mathrm{TRF}_{\text {teste }} \leq 1$. Analisando esses resultados, fica evidente a necessidade de considerar as deformações térmicas (itens 4.1.6.1 e 4.2.3 deste trabalho) no cálculo analítico do TRF de pilares em situação de incêndio. Para o modelo de cálculo utilizado neste trabalho, o autor constatou ser bastante simples a programação computacional para a consideração das deformações térmicas.

\subsection{PILARES ENSAIADOS PELO BRS}

Na década de 1930, o laboratório do Building Research Station - BRS, do Reino Unido, realizou o ensaio experimental de 88 pilares em situação de incêndio (COSTA, 2006). Todos os pilares ensaiados possuíam seção transversal quadrada e comprimento nominal igual a 3,048 m ou 3,0988 m. O modo de fixação dos pilares ao equipamento de ensaio permitia 
expansão longitudinal e impedia a rotação das extremidades dos pilares (modelo biengastado). A presença dos chanfros foi desconsiderada nos cálculos feitos pelo método FNC-FOGO, uma vez que a área líquida da seção transversal (descontando a área dos chanfros) corresponde a aproximadamente $99 \%$ da área bruta.

A Tabela 13 apresenta os valores do TRF obtidos experimentalmente, os valores calculados neste trabalho usando o método FNC-FOGO e os calculados por Costa (2006) usando o Método A do Eurocode 2 (EN 1992-1-2:2004). 
Tabela 13 - TRF medidos e calculados dos pilares ensaiados pelo BRS

\begin{tabular}{|c|c|c|c|c|c|c|c|c|c|c|c|c|c|c|c|c|c|c|c|}
\hline \multirow[b]{2}{*}{ no. } & \multirow[b]{2}{*}{ Lab. } & \multirow[b]{2}{*}{ Rótulo } & \multicolumn{2}{|c|}{ Seção transv. } & \multirow[b]{2}{*}{$\begin{array}{c}\text { Chanfro } \\
(\mathrm{mm})\end{array}$} & \multirow[b]{2}{*}{$\mathrm{L}(\mathrm{m})$} & \multicolumn{4}{|c|}{ Armaduras } & \multirow[b]{2}{*}{$\begin{array}{c}\mathrm{a} \\
(\mathrm{mm})\end{array}$} & \multicolumn{3}{|c|}{ Materiais } & \multirow[b]{2}{*}{$\begin{array}{l}\mathrm{N}_{\mathrm{Sd}, \mathrm{fi}} \\
(\mathrm{kN})\end{array}$} & \multicolumn{3}{|c|}{ TRF (min) } & \multirow[b]{2}{*}{ Observações } \\
\hline & & & $\begin{array}{c}\mathrm{b} \\
(\mathrm{cm})\end{array}$ & $\begin{array}{c}\mathrm{h} \\
(\mathrm{cm})\end{array}$ & & & $\mathrm{n}$ & $\begin{array}{c}\phi \\
(\mathrm{mm})\end{array}$ & $\begin{array}{c}\mathrm{As} \\
\left(\mathrm{cm}^{2}\right)\end{array}$ & $\begin{array}{c}\rho= \\
A_{s} / A_{c}\end{array}$ & & $\begin{array}{c}\mathrm{f}_{\mathrm{c}} \\
(\mathrm{MPa})\end{array}$ & $\begin{array}{c}\mathrm{f}_{\mathrm{y}} \\
(\mathrm{MPa})\end{array}$ & agregado & & Teste & $\begin{array}{l}\text { COSTA(2006) } \\
\text { Mét. A EC2 }\end{array}$ & $\begin{array}{c}\text { TRF5 } \\
\text { analítico }\end{array}$ & \\
\hline 81 & $\overline{B R S}$ & $\mathrm{C} 27$ & 15,24 & 15,24 & 12,70 & 3,0988 & 4 & 12,70 & 5,07 & $2,18 \%$ & 31,75 & 23,96 & 275 & silicoso* & 209 & 69 & 28 & 49,3 & cantos chanfrados \\
\hline 82 & BRS & $\mathrm{C} 41$ & 15,24 & 15,24 & 12,70 & 3,0988 & 4 & 22,23 & 15,52 & $6,68 \%$ & 36,51 & 22,79 & 275 & silicoso* & 346 & 62 & 16 & 45,2 & cantos chanfrados \\
\hline 83 & BRS & $\mathrm{C} 11$ & 25,40 & 25,40 & 25,40 & 3,0988 & 4 & 12,70 & 5,07 & $0,79 \%$ & 31,75 & 22,68 & 275 & silicoso* & 463 & 126 & 56 & 114,4 & cantos chanfrados \\
\hline 84 & BRS & $\mathrm{C} 13$ & 25,40 & 25,40 & 25,40 & 3,0988 & 4 & 12,70 & 5,07 & $0,79 \%$ & 31,75 & 11,97 & 275 & silicoso* & 448 & 134 & 19 & 29,9 & cantos chanfrados \\
\hline 85 & BRS & $\mathrm{C} 15$ & 25,40 & 25,40 & 25,40 & 3,0988 & 4 & 12,70 & 5,07 & $0,79 \%$ & 31,75 & 13,85 & 275 & silicoso ${ }^{*}$ & 508 & 136 & 19 & 29,9 & cantos chanfrados \\
\hline 86 & BRS & $\mathrm{C} 21$ & 25,40 & 25,40 & 19,05 & 3,0988 & 4 & 28,58 & 25,65 & $3,98 \%$ & 42,86 & 23,13 & 275 & silicoso* & 725 & 108 & 65 & 96,5 & cantos chanfrados \\
\hline 87 & BRS & $\mathrm{C} 23$ & 25,40 & 25,40 & 25,40 & 3,0988 & 4 & 12,70 & 5,07 & $0,79 \%$ & 31,75 & 30,92 & 275 & silicoso* & 623 & 98 & 56 & 113,6 & cantos chanfrados \\
\hline 88 & BRS & $\mathrm{C} 24$ & 25,40 & 25,40 & 12,70 & 3,0988 & 4 & 12,70 & 5,07 & $0,79 \%$ & 31,75 & 28,93 & 275 & silicoso* & 658 & 103 & 48 & 93,8 & cantos chanfrados \\
\hline 89 & BRS & $\mathrm{C} 30$ & 25,40 & 25,40 & 12,70 & 3,0988 & 4 & 12,70 & 5,07 & $0,79 \%$ & 31,75 & 31,33 & 275 & silicoso* & 465 & 120 & 73 & 178,2 & cantos chanfrados \\
\hline 90 & BRS & $\mathrm{C} 31$ & 25,40 & 25,40 & 12,70 & 3,0988 & 4 & 12,70 & 5,07 & $0,79 \%$ & 31,75 & 29,21 & 275 & silicoso* & 463 & 120 & 70 & 167,3 & cantos chanfrados \\
\hline 91 & BRS & $\mathrm{C} 32$ & 25,40 & 25,40 & 12,70 & 3,0988 & 4 & 12,70 & 5,07 & $0,79 \%$ & 31,75 & 30,02 & 275 & silicoso* & 463 & 120 & 71 & 171,9 & cantos chanfrados \\
\hline 92 & BRS & $\mathrm{C} 35$ & 25,40 & 25,40 & 12,70 & 3,0988 & 4 & 12,70 & 5,07 & $0,79 \%$ & 31,75 & 12,82 & 275 & silicoso* & 465 & 112 & 20 & 39,0 & cantos chanfrados \\
\hline 93 & BRS & $\mathrm{C} 46$ & 25,40 & 25,40 & 19,05 & 3,0988 & 4 & 31,75 & 31,67 & $4,91 \%$ & 47,63 & 24,37 & 275 & silicoso* & 919 & 62 & 63 & 93,9 & cantos chanfrados \\
\hline 94 & BRS & $\mathrm{C} 20$ & 27,94 & 27,94 & 25,40 & 3,0988 & 4 & 15,88 & 7,92 & $1,01 \%$ & 33,34 & 21,43 & 275 & silicoso* & 711 & 53 & 44 & 66,2 & cantos chanfrados \\
\hline 95 & BRS & $\mathrm{C} 33$ & 27,94 & 27,94 & 25,40 & 3,0988 & 4 & 15,88 & 7,92 & $1,01 \%$ & 46,04 & 27,46 & 275 & silicoso* & 586 & 119 & 104 & 159,7 & cantos chanfrados \\
\hline 96 & BRS & $\mathrm{C} 34$ & 27,94 & 27,94 & 19,05 & 3,0988 & 4 & 15,88 & 7,92 & $1,01 \%$ & 46,04 & 27,51 & 275 & silicoso* & 858 & 80 & 74 & 87,5 & cantos chanfrados / sem colapso \\
\hline 97 & BRS & $\mathrm{C} 36$ & 27,94 & 27,94 & 19,05 & 3,0988 & 4 & 15,88 & 7,92 & $1,01 \%$ & 46,04 & 17,60 & 275 & silicoso* & 586 & 120 & 72 & 85,3 & cantos chanfrados / sem colapso \\
\hline 98 & BRS & C37 & 27,94 & 27,94 & 19,05 & 3,0988 & 4 & 15,88 & 7,92 & $1,01 \%$ & 46,04 & 20,58 & 275 & silicoso* & 586 & 120 & 84 & 104,7 & cantos chanfrados / carregam. variável \\
\hline 99 & BRS & $\mathrm{C} 38$ & 27,94 & 27,94 & 19,05 & 3,0988 & 4 & 15,88 & 7,92 & $1,01 \%$ & 46,04 & 25,88 & 275 & silicoso* & 598 & 84 & 99 & 134,9 & cantos chanfrados / pilar revestido \\
\hline 100 & BRS & C39 & 27,94 & 27,94 & 19,05 & 3,0988 & 4 & 15,88 & 7,92 & $1,01 \%$ & 46,04 & 22,03 & 275 & silicoso* & 586 & 120 & 89 & 114,1 & cantos chanfrados / sem colapso \\
\hline 101 & BRS & $\mathrm{C} 42$ & 27,94 & 27,94 & 19,05 & 3,0988 & 4 & 15,88 & 7,92 & $1,01 \%$ & 53,98 & 23,82 & 275 & silicoso* & 711 & 120 & 79 & 104,5 & cantos chanfrados / sem colapso \\
\hline 102 & BRS & $\mathrm{C} 82$ & 27,94 & 27,94 & 19,05 & 3,0988 & 4 & 31,75 & 31,67 & $4,06 \%$ & 53,98 & 29,58 & 275 & silicoso* & 912 & 120 & 110 & 133,8 & cantos chanfrados \\
\hline 103 & BRS & $\mathrm{C} 86$ & 27,94 & 27,94 & 19,05 & 3,0988 & 4 & 31,75 & 31,67 & $4,06 \%$ & 53,98 & 30,71 & 275 & silicoso* & 912 & 227 & 113 & 137,4 & cantos chanfrados \\
\hline 104 & BRS & C87 & 27,94 & 27,94 & 19,05 & 3,0988 & 4 & 31,75 & 31,67 & $4,06 \%$ & 53,98 & 29,33 & 275 & silicoso* & 912 & 221 & 110 & 132,8 & cantos chanfrados \\
\hline 105 & BRS & E25/S3 & 27,94 & 27,94 & 19,05 & 3,0988 & 4 & 31,75 & 31,67 & $4,06 \%$ & 53,98 & 20,44 & 275 & silicoso* & 907 & 120 & 85 & 104,6 & cantos chanfrados \\
\hline 106 & BRS & $\mathrm{C} 89$ & 27,94 & 27,94 & 19,05 & 3,0988 & 4 & 31,75 & 31,67 & $4,06 \%$ & 53,98 & 23,54 & 275 & silicoso* & 608 & 189 & 129 & 160,8 & cantos chanfrados \\
\hline 107 & BRS & $\mathrm{C} 90$ & 27,94 & 27,94 & 19,05 & 3,0988 & 4 & 31,75 & 31,67 & $4,06 \%$ & 53,98 & 25,14 & 275 & silicoso* & 608 & 86 & 133 & 166,2 & cantos chanfrados \\
\hline 108 & BRS & $\mathrm{C} 88$ & 27,94 & 27,94 & 19,05 & 3,0988 & 4 & 31,75 & 31,67 & $4,06 \%$ & 53,98 & 23,89 & 275 & silicoso* & 608 & 83 & 130 & 162,0 & cantos chanfrados \\
\hline 109 & BRS & $\mathrm{C} 12$ & 30,48 & 30,48 & 25,40 & 3,0988 & 4 & 15,88 & 7,92 & $0,85 \%$ & 58,74 & 14,60 & 275 & silicoso* & 779 & 38 & 75 & 47,4 & cantos chanfrados \\
\hline 110 & BRS & E16/S8 & 35,56 & 35,56 & 19,05 & 3,0988 & 4 & 19,05 & 11,40 & $0,90 \%$ & 47,63 & 24,61 & 275 & silicoso* & 857 & 82 & 122 & 227,6 & cantos chanfrados / sem colapso \\
\hline 111 & BRS & $\mathrm{C} 28$ & 40,64 & 40,64 & 12,70 & 3,0988 & 4 & 22,23 & 15,52 & $0,94 \%$ & 36,51 & 22,44 & 275 & silicoso* & 1231 & 120 & 88 & 163,5 & cantos chanfrados / sem colapso \\
\hline 112 & BRS & $\mathrm{C} 44$ & 40,64 & 40,64 & 19,05 & 3,0988 & 8 & 34,93 & 76,64 & $4,64 \%$ & 52,39 & 18,53 & 275 & silicoso* & 2092 & 120 & 113 & 106,1 & cantos chanfrados \\
\hline 113 & BRS & $\mathrm{C} 47$ & 40,64 & 40,64 & 19,05 & 3,0988 & 8 & 34,93 & 76,64 & $4,64 \%$ & 52,39 & 27,95 & 275 & silicoso* & 2361 & 60 & 133 & 133,3 & cantos chanfrados \\
\hline 114 & BRS & $\mathrm{C} 45$ & 50,80 & 50,80 & 19,05 & 3,0988 & 4 & 44,45 & 62,07 & $2,41 \%$ & 66,68 & 24,85 & 275 & silicoso* & 3258 & 120 & 185 & 125,7 & cantos chanfrados \\
\hline 115 & BRS & $\mathrm{C} 48$ & 50,80 & 50,80 & 19,05 & 3,0988 & 4 & 44,45 & 62,07 & $2,41 \%$ & 66,68 & 36,13 & 275 & silicoso* & 3657 & 120 & 203 & 175,9 & cantos chanfrados \\
\hline 116 & BRS & $\mathrm{C} 29$ & 51,44 & 51,44 & 12,70 & 3,0988 & 4 & 28,58 & 25,65 & $0,97 \%$ & 42,86 & 24,17 & 275 & silicoso* & 1983 & 176 & 137 & 259,3 & cantos chanfrados \\
\hline 117 & BRS & 1 & 30,48 & 30,48 & --- & 3,0988 & 4 & 22,23 & 15,52 & $1,67 \%$ & 33,34 & 17,32 & 275 & silicoso* & 747 & 56 & 49 & 55,1 & \\
\hline 118 & BRS & 2 & 27,94 & 27,94 & --- & 3,0988 & 4 & 19,05 & 11,40 & $1,46 \%$ & 34,93 & 22,51 & 275 & silicoso* & 747 & 83 & 51 & 71,9 & \\
\hline
\end{tabular}

continua 
continuação

\begin{tabular}{|c|c|c|c|c|c|c|c|c|c|c|c|c|c|c|c|c|c|c|c|}
\hline \multirow[b]{2}{*}{ no. } & \multirow[b]{2}{*}{ Lab. } & \multirow[b]{2}{*}{ Rótulo } & \multicolumn{2}{|c|}{ Seção transv. } & \multirow[b]{2}{*}{$\begin{array}{l}\text { Chanfro } \\
(\mathrm{mm})\end{array}$} & \multirow[b]{2}{*}{$\mathrm{L}(\mathrm{m})$} & \multicolumn{4}{|c|}{ Armaduras } & \multirow[b]{2}{*}{$\begin{array}{c}\mathrm{a} \\
(\mathrm{mm})\end{array}$} & \multicolumn{3}{|c|}{ Materiais } & \multirow[b]{2}{*}{$\begin{array}{l}\mathrm{N}_{\mathrm{Sd}, \mathrm{fi}} \\
(\mathrm{kN})\end{array}$} & \multicolumn{3}{|c|}{ TRF (min) } & \multirow[b]{2}{*}{ Observações } \\
\hline & & & $\begin{array}{c}\mathrm{b} \\
(\mathrm{cm})\end{array}$ & $\begin{array}{c}\mathrm{h} \\
(\mathrm{cm})\end{array}$ & & & $\mathrm{n}$ & $\begin{array}{c}\phi \\
(\mathrm{mm})\end{array}$ & $\begin{array}{c}\begin{array}{c}\text { As } \\
\left(\mathrm{cm}^{2}\right)\end{array} \\
\end{array}$ & $\begin{array}{c}\rho= \\
A_{s} / A_{c}\end{array}$ & & $\begin{array}{c}\mathrm{f}_{\mathrm{c}} \\
(\mathrm{MPa})\end{array}$ & $\begin{array}{c}f_{\mathrm{y}} \\
(\mathrm{MPa})\end{array}$ & agregado & & Teste & $\begin{array}{l}\text { COSTA(2006) } \\
\text { Mét. A EC2 }\end{array}$ & $\begin{array}{c}\text { TRF5 } \\
\text { analítico }\end{array}$ & \\
\hline 119 & BRS & 3 & 25,40 & 25,40 & --- & 3,0988 & 4 & 15,88 & 4 & 15,88 & 33,34 & 26,37 & 275 & silicoso* & 747 & 44 & 39 & 68,1 & \\
\hline 120 & BRS & 4 & 20,32 & 20,32 & --- & 3,0988 & 4 & 19,05 & 4 & 19,05 & 34,93 & 35,99 & 275 & silicoso* & 747 & 63 & 10 & 41,0 & \\
\hline 121 & BRS & 6 & 38,10 & 38,10 & --- & 3,0988 & 4 & 28,58 & 4 & 28,58 & 42,86 & 20,37 & 275 & silicoso* & 996 & 125 & 106 & 164,8 & \\
\hline 122 & BRS & 7 & 35,56 & 35,56 & --- & 3,0988 & 4 & 25,40 & 4 & 25,40 & 38,10 & 24,30 & 275 & silicoso* & 1495 & 71 & 58 & 72,9 & \\
\hline 123 & BRS & 8 & 30,48 & 30,48 & --- & 3,0988 & 4 & 22,23 & 4 & 22,23 & 36,51 & 34,33 & 275 & silicoso* & 1495 & 52 & 47 & 52,1 & \\
\hline 124 & BRS & 10 & 48,26 & 48,26 & --- & 3,0988 & 4 & 22,23 & 4 & 22,23 & 36,51 & 21,89 & 275 & silicoso* & 747 & 420 & 151 & 330,0 & \\
\hline 125 & BRS & 12 & 35,56 & 35,56 & --- & 3,0988 & 4 & 34,93 & 4 & 34,93 & 52,39 & 33,64 & 275 & silicoso* & 2242 & 75 & 86 & 91,0 & \\
\hline 126 & BRS & 15 & 48,26 & 48,26 & --- & 3,0988 & 4 & 28,58 & 4 & 28,58 & 42,86 & 24,37 & 275 & silicoso* & 2989 & 91 & 120 & 163,4 & \\
\hline 127 & BRS & 16 & 40,64 & 40,64 & --- & 3,0988 & 8 & 28,58 & 8 & 28,58 & 42,86 & 28,84 & 275 & silicoso* & 2989 & 145 & 74 & 29,0 & \\
\hline 128 & BRS & 17 & 22,86 & 22,86 & --- & 3,0988 & 4 & 28,58 & 4 & 28,58 & 42,86 & 20,65 & 275 & silicoso* & 747 & 58 & 39 & 52,0 & \\
\hline 129 & BRS & 18 & 27,94 & 27,94 & --- & 3,0988 & 8 & 31,75 & 8 & 31,75 & 47,63 & 18,81 & 275 & silicoso* & 1495 & 77 & 58 & 85,4 & \\
\hline 130 & BRS & 19 & 35,56 & 35,56 & --- & 3,0988 & 8 & 38,10 & 8 & 38,10 & 57,15 & 22,99 & 275 & silicoso* & 2242 & 85 & 113 & 139,8 & \\
\hline 131 & BRS & 20 & 40,64 & 40,64 & --- & 3,0988 & 8 & 44,45 & 8 & 44,45 & 66,68 & 18,04 & 275 & silicoso* & 2989 & 77 & 131 & 133,2 & \\
\hline 132 & BRS & 21 & 38,10 & 38,10 & --- & 3,0988 & 4 & 28,58 & 4 & 28,58 & 42,86 & 19,91 & 275 & silicoso* & 1495 & 47 & 70 & 70,8 & \\
\hline 133 & BRS & 22 & 38,10 & 38,10 & --- & 3,0988 & 4 & 28,58 & 4 & 28,58 & 42,86 & 27,31 & 275 & silicoso* & 1495 & 78 & 94 & 119,7 & sem colapso, aplicado $897 \mathrm{kN}$ após $7 \mathrm{~h}$ \\
\hline 134 & BRS & 23 & 38,10 & 38,10 & --- & 3,0988 & 4 & 28,58 & 4 & 28,58 & 42,86 & 32,56 & 275 & silicoso* & 1495 & 161 & 107 & 184,7 & \\
\hline 135 & BRS & 26 & 38,10 & 38,10 & --- & 3,0988 & 4 & 28,58 & 4 & 28,58 & 42,86 & 16,00 & 275 & silicoso* & 747 & 198 & 113 & 187,7 & \\
\hline 136 & BRS & 27 & 38,10 & 38,10 & --- & 3,0988 & 4 & 28,58 & 4 & 28,58 & 42,86 & 18,48 & 275 & silicoso* & 498 & 248 & 143 & 330,9 & \\
\hline 137 & BRS & 28 & 38,10 & 38,10 & --- & 3,0988 & 4 & 28,58 & 4 & 28,58 & 42,86 & 15,72 & 275 & silicoso* & 1495 & 70 & 50 & 45,7 & \\
\hline 138 & BRS & A1 & 38,10 & 38,10 & --- & 3,0988 & 4 & 28,58 & 4 & 28,58 & 42,86 & 17,65 & 275 & silicoso* & 947 & 122 & 101 & 130,1 & sem colapso durante o teste \\
\hline 139 & BRS & A2 & 38,10 & 38,10 & --- & 3,0988 & 4 & 28,58 & 4 & 28,58 & 42,86 & 17,10 & 275 & silicoso* & 1495 & 74 & 57 & 51,9 & \\
\hline 140 & BRS & $\mathrm{A} 3$ & 38,10 & 38,10 & --- & 3,0988 & 4 & 28,58 & 4 & 28,58 & 42,86 & 17,93 & 275 & silicoso* & 1495 & 62 & 61 & 56,9 & \\
\hline 141 & BRS & A4 & 38,10 & 38,10 & --- & 3,0988 & 4 & 28,58 & 4 & 28,58 & 42,86 & 17,10 & 275 & silicoso* & 299 & 358 & 161 & 420,0 & \\
\hline 142 & BRS & A5 & 38,10 & 38,10 & --- & 3,0988 & 4 & 28,58 & 4 & 28,58 & 42,86 & 15,72 & 275 & silicoso* & 1495 & 65 & 50 & 26,2 & \\
\hline 143 & BRS & A6 & 38,10 & 38,10 & --- & 3,0988 & 4 & 28,58 & 4 & 28,58 & 42,86 & 15,44 & 275 & silicoso* & 996 & 123 & 88 & 95,9 & \\
\hline 144 & BRS & A7 & 30,48 & 30,48 & --- & 3,0988 & 4 & 22,23 & 4 & 22,23 & 36,51 & 12,41 & 275 & silicoso* & 249 & 214 & 107 & 242,7 & \\
\hline 145 & BRS & A8 & 30,48 & 30,48 & --- & 3,0988 & 4 & 22,23 & 4 & 22,23 & 36,51 & 12,41 & 275 & silicoso* & 349 & 122 & 89 & 145,6 & sem colapso durante o teste \\
\hline 146 & BRS & A9 & 25,40 & 25,40 & --- & 3,0988 & 4 & 15,88 & 4 & 15,88 & 33,34 & 19,86 & 275 & silicoso* & 249 & 175 & 90 & 139,0 & \\
\hline 147 & BRS & A10 & 25,40 & 25,40 & --- & 3,0988 & 4 & 15,88 & 4 & 15,88 & 33,34 & 20,17 & 275 & silicoso* & 249 & 122 & 124 & 140,6 & sem colapso durante o teste \\
\hline 148 & BRS & A11 & 48,26 & 48,26 & --- & 3,0988 & 8 & 22,23 & 8 & 22,23 & 36,51 & 15,17 & 275 & silicoso* & 2242 & 119 & 86 & 39,3 & \\
\hline 149 & BRS & A12 & 48,26 & 48,26 & --- & 3,0988 & 8 & 22,23 & 8 & 22,23 & 36,51 & 15,17 & 275 & silicoso* & 1794 & 122 & 108 & 65,5 & sem colapso durante o teste \\
\hline 150 & BRS & A13 & 48,26 & 48,26 & --- & 3,0988 & 4 & 28,58 & 4 & 28,58 & 42,86 & 16,55 & 275 & silicoso* & 996 & 351 & 185 & 329,2 & \\
\hline 151 & BRS & A14 & 48,26 & 48,26 & --- & 3,0988 & 4 & 28,58 & 4 & 28,58 & 42,86 & 16,55 & 275 & silicoso* & 2192 & 122 & 124 & 182,7 & sem colapso durante o teste \\
\hline 152 & BRS & $18 \mathrm{~A}$ & 40,64 & 40,64 & --- & 3,0988 & 4 & 22,23 & 4 & 22,23 & 36,51 & 12,41 & 275 & silicoso* & 1495 & 46 & 26 & 21,2 & \\
\hline 153 & BRS & $\mathrm{C} 23$ & 25,40 & 25,40 & --- & 3,0988 & 4 & 12,70 & 4 & 12,70 & 31,75 & 30,92 & 275 & silicoso* & 623 & 98 & 57 & 116,4 & \\
\hline 154 & BRS & $\mathrm{C} 24$ & 25,40 & 25,40 & $\mathrm{NF}^{*}$ & 3,0988 & 4 & 12,70 & 4 & 12,70 & 31,75 & 28,93 & 275 & silicoso* & 658 & 103 & 49 & 93,9 & cantos chanfrados \\
\hline 155 & BRS & $\mathrm{C} 28$ & 40,64 & 40,64 & $\mathrm{NF}^{*}$ & 3,0988 & 4 & 22,23 & 4 & 22,23 & 36,51 & 22,44 & 275 & silicoso* & 1231 & 120 & 89 & 162,8 & cantos chanfrados / sem colapso \\
\hline 156 & BRS & $\mathrm{C} 30$ & 25,40 & 25,40 & $\mathrm{NF}^{*}$ & 3,0988 & 4 & 12,70 & 4 & 12,70 & 31,75 & 31,31 & 275 & silicoso* & 465 & 120 & 74 & 179,7 & cantos chanfrados \\
\hline
\end{tabular}

continua 
conclusão

\begin{tabular}{|c|c|c|c|c|c|c|c|c|c|c|c|c|c|c|c|c|c|c|c|}
\hline \multirow[b]{2}{*}{ no. } & \multirow[b]{2}{*}{ Lab. } & \multirow[b]{2}{*}{ Rótulo } & \multicolumn{2}{|c|}{ Seção transv. } & \multirow[b]{2}{*}{$\begin{array}{c}\text { Chanfro } \\
(\mathrm{mm})\end{array}$} & \multirow[b]{2}{*}{$\mathrm{L}(\mathrm{m})$} & \multicolumn{4}{|c|}{ Armaduras } & \multirow[b]{2}{*}{$\begin{array}{c}\mathrm{a} \\
(\mathrm{mm})\end{array}$} & \multicolumn{3}{|c|}{ Materiais } & \multirow[b]{2}{*}{$\begin{array}{l}\mathrm{N}_{\mathrm{Sd}, \mathrm{fi}} \\
(\mathrm{kN})\end{array}$} & \multicolumn{3}{|c|}{$\mathrm{TRF}(\min )$} & \multirow[b]{2}{*}{ Observações } \\
\hline & & & $\begin{array}{c}\mathrm{b} \\
(\mathrm{cm})\end{array}$ & $\begin{array}{c}\mathrm{h} \\
(\mathrm{cm})\end{array}$ & & & $\mathrm{n}$ & $\begin{array}{c}\phi \\
(\mathrm{mm})\end{array}$ & $\begin{array}{c}\text { As } \\
\left(\mathrm{cm}^{2}\right)\end{array}$ & $\begin{array}{c}\rho= \\
A_{s} / A_{c}\end{array}$ & & $\begin{array}{c}\mathrm{f}_{\mathrm{c}} \\
(\mathrm{MPa})\end{array}$ & $\begin{array}{c}\mathrm{f}_{\mathrm{y}} \\
(\mathrm{MPa})\end{array}$ & agregado & & Teste & $\begin{array}{l}\text { COSTA(2006) } \\
\text { Mét. A EC2 }\end{array}$ & $\begin{array}{c}\text { TRF5 } \\
\text { analítico }\end{array}$ & \\
\hline 158 & BRS & $\mathrm{C} 32$ & 25,40 & 25,40 & $\mathrm{NF}^{*}$ & 3,0988 & 4 & 12,70 & 5,07 & $0,79 \%$ & 31,75 & 30,02 & 275 & silicoso* & 463 & 120 & 72 & 173,5 & cantos chanfrados / sem colapso \\
\hline 159 & BRS & $\mathrm{C} 33$ & 27,94 & 27,94 & $\mathrm{NF}^{*}$ & 3,0988 & 4 & 15,88 & 7,92 & $1,01 \%$ & 46,04 & 27,46 & 275 & silicoso* & 586 & 119 & 105 & 159,3 & cantos chanfrados \\
\hline 160 & BRS & C34 & 27,94 & 27,94 & $\mathrm{NF}^{*}$ & 3,0988 & 4 & 15,88 & 7,92 & $1,01 \%$ & 46,04 & 27,51 & 275 & silicoso* & 858 & 80 & 75 & 87,4 & cantos chanfrados \\
\hline 161 & BRS & $\mathrm{C} 35$ & 25,40 & 25,40 & $\mathrm{NF}^{*}$ & 3,0988 & 4 & 12,70 & 5,07 & $0,79 \%$ & 31,75 & 12,82 & 275 & silicoso* & 465 & 112 & 21 & 40,3 & cantos chanfrados \\
\hline 162 & BRS & $\mathrm{C} 46$ & 25,40 & 25,40 & $\mathrm{NF}^{*}$ & 3,0988 & 4 & 31,75 & 31,67 & $4,91 \%$ & 47,63 & 24,37 & 275 & silicoso* & 919 & 62 & 64 & 93,8 & cantos chanfrados \\
\hline 163 & BRS & $\mathrm{C} 82$ & 27,94 & 27,94 & $\mathrm{NF}^{*}$ & 3,0988 & 4 & 31,75 & 31,67 & $4,06 \%$ & 53,98 & 29,58 & 275 & silicoso* & 912 & 120 & 111 & 133,7 & cantos chanfrados / sem colapso \\
\hline 164 & BRS & $\mathrm{C} 86$ & 27,94 & 27,94 & $\mathrm{NF}^{*}$ & 3,0988 & 4 & 31,75 & 31,67 & $4,06 \%$ & 53,98 & 30,71 & 275 & silicoso* & 912 & 227 & 114 & 137,3 & cantos chanfrados \\
\hline 165 & BRS & $\mathrm{C} 87$ & 27,94 & 27,94 & $\mathrm{NF}^{*}$ & 3,0988 & 4 & 31,75 & 31,67 & $4,06 \%$ & 53,98 & 29,33 & 275 & silicoso* & 912 & 221 & 111 & 132,8 & cantos chanfrados \\
\hline 166 & BRS & $\mathrm{C} 88$ & 27,94 & 27,94 & $\mathrm{NF}^{*}$ & 3,0988 & 4 & 31,75 & 31,67 & $4,06 \%$ & 53,98 & 23,89 & 275 & silicoso* & 608 & 83 & 131 & 161,9 & cantos chanfrados \\
\hline 167 & BRS & $\mathrm{C} 89$ & 27,94 & 27,94 & $\mathrm{NF}^{*}$ & 3,0988 & 4 & 31,75 & 31,67 & $4,06 \%$ & 53,98 & 23,54 & 275 & silicoso* & 608 & 189 & 130 & 160,8 & cantos chanfrados \\
\hline 168 & BRS & $\mathrm{C} 90$ & 27,94 & 27,94 & $\mathrm{NF}^{*}$ & 3,0988 & 4 & 31,75 & 31,67 & $4,06 \%$ & 53,98 & 25,14 & 275 & silicoso* & 608 & 86 & 134 & 166,2 & cantos chanfrados \\
\hline 158 & BRS & $\mathrm{C} 32$ & 25,40 & 25,40 & $\mathrm{NF}^{*}$ & 3,0988 & 4 & 12,70 & 5,07 & $0,79 \%$ & 31,75 & 30,02 & 275 & silicoso* & 463 & 120 & 72 & 173,5 & cantos chanfrados / sem colapso \\
\hline
\end{tabular}

* adotou-se a hipótese do concreto ter sido feito com agregado silicoso, que é mais sensível aos efeitos da elevação da temperatura

* NF: valor não fornecido 
A Figura 91 apresenta a comparação entre os valores de TRF obtidos experimentalmente e os obtidos analiticamente pelo método FNC-FOGO (valores da coluna TRF5 da Tabela 13).

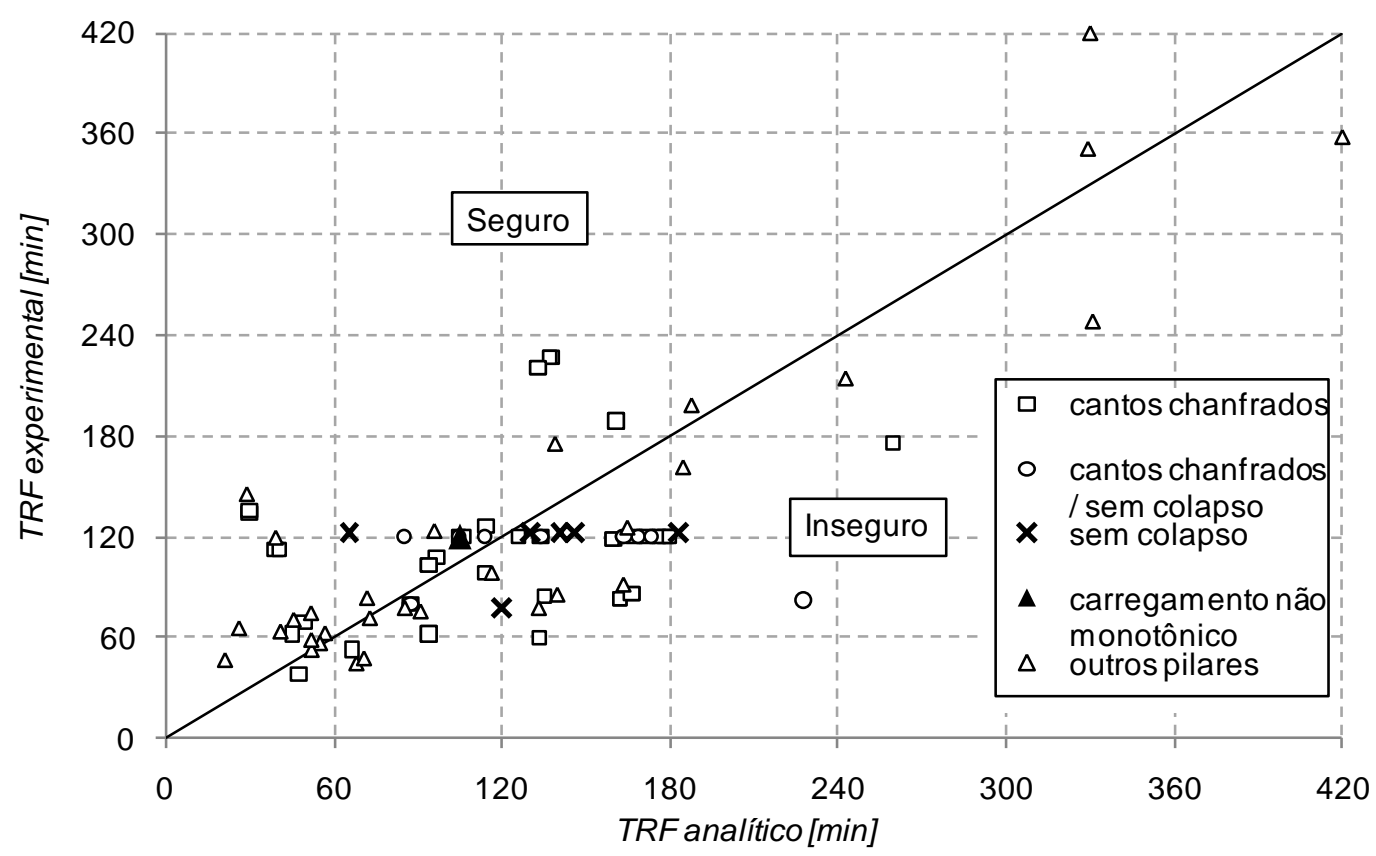

Figura 91 - Comparação entre o TRF obtido experimentalmente e o TRF5 obtido analiticamente pelo método FNC-FOGO, pilares ensaiados pelo Building Research Station - BRS

A média da relação entre os resultados analíticos e os resultados experimentais (TRF5 $\left.5_{\text {analítico }} / \mathrm{TRF}_{\text {teste }}\right)$ resultou 1,10 , com desvio-padrão de 0,47 e coeficiente de variação igual a 0,42. Percebe-se elevada dispersão dos resultados, superior ao observado para o grupo de 76 pilares usados na calibração do Método A do Eurocode 2 (EN 1992-1-2:2004) apresentado anteriormente.

Dos 88 pilares ensaiados, $49(55,7 \%)$ apresentaram resultados contra a segurança quando calculados pelo método FNC-FOGO (TRF5 analítico $\left./ \mathrm{TRF}_{\text {teste }} \geq 1\right)$. No entanto, desse grupo de 49 pilares, 12 (24,5\%) não apresentaram colapso durante o ensaio experimental. É provável que os tempos de resistência ao fogo reais desses pilares fossem superiores aos registrados.

Em relação ao grupo de 49 pilares que apresentaram resultados contra a segurança quando calculados pelo método FNC-FOGO, 29 (59,2\%) possuíam os cantos chanfrados. Como os pilares possuíam apenas 4 barras longitudinais posicionadas nos cantos da seção transversal, a presença dos chanfros pode ter favorecido um aumento da temperatura mais significativo do que se não houvessem chanfros. 
Analisando a influência da resistência do concreto nos resultados, dos 88 pilares ensaiados, 39 pilares possuíam concreto com resistência $\mathrm{f}_{\mathrm{c}} \geq 24 \mathrm{MPa}$. Desse grupo, 31 pilares $(79,5 \%)$ apresentaram resultados contra a segurança quando calculados pelo método FNCFOGO.

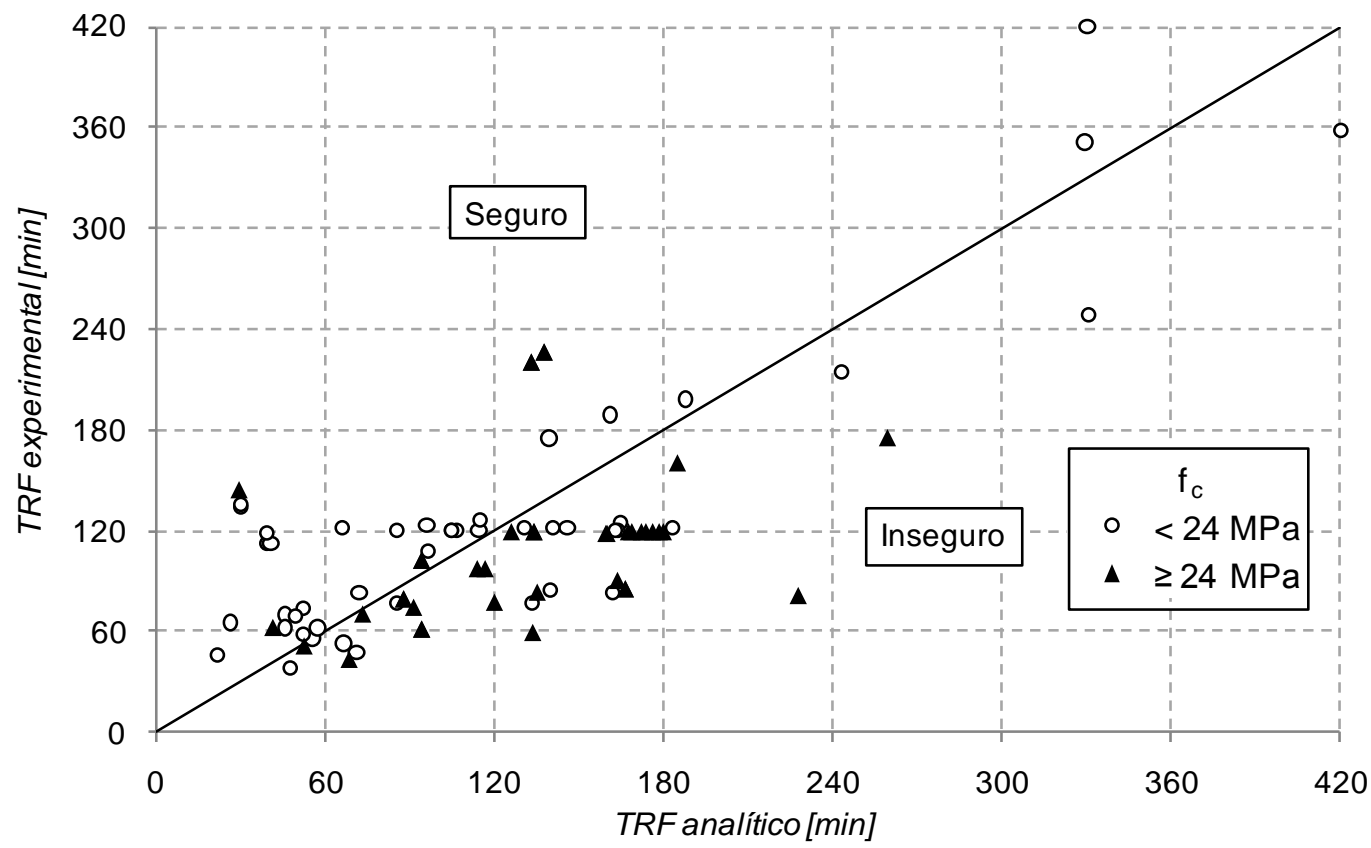

Figura 92 - Análise da influência da resistência do concreto no cálculo analítico do TRF dos pilares ensaiados pelo Building Research Station - BRS

Em relação às armaduras longitudinais, as suas características aparentemente não tiveram efeito significativo na precisão dos resultados calculados pelo método FNC-FOGO. A Tabela 14 e Tabela 15 apresentam a análise da influência da taxa geométrica e diâmetro das armaduras no TRF calculado pelo método FNC-FOGO para os pilares ensaiados pelo BRS.

Tabela 14 - Análise da influência da taxa de armaduras $\rho$ no TRF calculado pelo método FNC-FOGO para os pilares ensaiados pelo Building Research Station - BRS

\begin{tabular}{|c|c|c|c|}
\hline$\rho=\mathbf{A}_{\mathrm{s}} / \mathbf{A}_{\mathrm{c}}$ & $N^{0}$. de pilares & $\mathrm{TRF}_{\text {calc }} / \mathrm{TRF}_{\text {teste }} \geq 1,0\left[\mathrm{n}^{0}\right.$ pilares] & $\mathrm{TRF}_{\text {calc }} / \mathrm{TRF}_{\text {teste }} \geq 1,0[\%]$ \\
\hline$\leq 1,0 \%$ & 22 & 13 & 59,1 \\
\hline $\begin{array}{c}1,0 \% \text { a } \\
2,0 \%\end{array}$ & 37 & 21 & 56,8 \\
\hline$>2,0 \%$ & 29 & 15 & 51,8 \\
\hline
\end{tabular}


Tabela 15 - Análise da influência do diâmetro das barras longitudinais no TRF calculado pelo método FNC-FOGO para os pilares ensaiados pelo Building Research Station - BRS

\begin{tabular}{cccc}
\hline $\boldsymbol{\phi}[\mathbf{m m}]$ & $\mathbf{N}^{\mathbf{0}}$. de pilares & $\mathbf{T R F}_{\text {calc }} / \mathbf{T R F}_{\text {teste }} \geq \mathbf{1 , 0}\left[\mathbf{n}^{\mathbf{0}}\right.$ pilares] & $\mathbf{T R F}_{\text {calc }} / \mathbf{T R F}_{\text {teste }} \geq \mathbf{1 , 0}[\boldsymbol{\%}]$ \\
\hline$<20$ & 33 & 18 & 54,5 \\
\hline 20 a 28 & 12 & 6 & 50,0 \\
\hline$>28$ & 43 & 25 & 58,1 \\
\hline
\end{tabular}

As dimensões da seção transversal aparentemente não afetaram significativamente a precisão dos resultados analíticos, conforme mostra a Tabela 16.

Tabela 16 - Análise da influência das dimensões da seção transversal no TRF calculado pelo método FNCFOGO para os pilares ensaiados pelo Building Research Station - BRS

\begin{tabular}{|c|c|c|c|}
\hline $\mathrm{b}=\mathbf{h}[\mathrm{cm}]$ & $\mathrm{N}^{\mathbf{0}}$. de pilares & $\mathrm{TRF}_{\text {calc }} / \mathrm{TRF}_{\text {teste }} \geq 1,0$ [n $\mathrm{n}^{0}$ pilares] & $\mathrm{TRF}_{\text {calc }} / \mathrm{TRF}_{\text {teste }} \geq 1,0[\%]$ \\
\hline$<26$ & $\overline{25}$ & 12 & 48,0 \\
\hline 26 a 30 & 25 & 13 & 52,0 \\
\hline 30 a 40 & 22 & 15 & 68,2 \\
\hline$>40$ & 16 & 9 & 56,3 \\
\hline
\end{tabular}

Por fim, deve-se lembrar que o grupo de pilares analisados foi ensaiado pelo BRS há aproximadamente 80 anos, portanto essa base de dados pode não ser totalmente confiável. Não se sabe quais as especificações dos equipamentos de ensaio disponíveis naquela época nem as reais condições em que foram realizados os experimentos. 


\section{CONCLUSÕES}

Neste trabalho foi desenvolvido um método, denominado FNC-FOGO, para o cálculo do tempo de resistência ao fogo de pilares de concreto armado em situação de incêndio submetidos à flexão normal composta (FNC). O processo é análogo ao utilizado para o cálculo de pilares de concreto armado à temperatura ambiente, mas leva em conta a influência do aquecimento nas propriedades dos materiais, a atuação das deformações térmicas e a não linearidade geométrica do problema, baseado nas relações momento-curvatura.

Para validar as hipóteses de cálculo adotadas, o método FNC-FOGO foi aplicado ao cálculo do TRF dos 76 pilares utilizados no desenvolvimento do Método A do Eurocode 2 (EN 1992-1-2:2004). O TRF calculado analiticamente pelo método FNC-FOGO resultou a favor da segurança para 62 pilares $(81,6 \%)$, quando comparado ao TRF medido experimentalmente. A média da relação entre os resultados analíticos e os resultados experimentais $\left(\mathrm{TRF}_{\text {analítico }} / \mathrm{TRF}_{\text {experimental }}\right)$ resultou 0,82 , com desvio-padrão de 0,22 e coeficiente de variação igual a 0,27 . Nos cálculos feitos por Costa (2006), aplicando o Método A do Eurocode 2 (EN 1992-1-2:2004) ao mesmo grupo de pilares, a média da relação entre os resultados analíticos e os resultados experimentais $\left(\mathrm{TRF}_{\text {calculado }} / \mathrm{TRF}_{\text {experimental }}\right)$ resultou 1,18 , com desvio-padrão de 0,43 e coeficiente de variação igual a 0,36 . Sendo assim, os resultados do método FNC-FOGO ficaram mais a favor da segurança e apresentaram menor variação que os resultados do Método A do Eurocode 2 (EN 1992-1-2:2004) aplicado ao grupo de 76 pilares que lhe deu origem.

Um estudo adicional foi feito neste trabalho, aplicando o método FNC-FOGO a um grupo de 88 pilares ensaiados na década de 1930 pelo Building Research Station - BRS, do Reino Unido. A comparação entre o TRF calculado analiticamente pelo método FNC-FOGO e o TRF medido experimentalmente mostrou elevada dispersão entre os resultados, além de muitos resultados analíticos terem ficado contra a segurança. Deve-se lembrar que o grupo de pilares analisados foi ensaiado pelo BRS há aproximadamente 80 anos, portanto essa base de dados não é totalmente confiável. Não se sabe quais as especificações dos equipamentos de ensaio disponíveis naquela época nem as reais condições em que foram realizados os experimentos.

Com base nas constatações anteriores, pode-se afirmar que os resultados do método FNC-FOGO apresentam boa correlação com resultados experimentais de fontes confiáveis, ficando a favor da segurança na maioria dos casos. 
Como o método FNC-FOGO foi desenvolvido à luz de procedimentos de engenharia e matemática consistentes, o mesmo possui vantagem em relação aos métodos simplificados no que diz respeito ao campo de validade. Os métodos simplificados, por estarem intimamente relacionados aos dados usados na sua calibração, não podem ser extrapolados com segurança para casos além dos seus limites de validade, pois os resultados podem ser bastante imprevisíveis e discrepantes. É importante evidenciar o caráter genérico e a capacidade de abrangência do método FNC-FOGO, que permite a avaliação dos mais variados casos, baseado em procedimentos com fundamentação teórica rigorosa e logicamente organizados.

Apesar de ter sido desenvolvido para pilares submetidos à flexão normal composta com aquecimento simétrico na seção transversal, o método FNC-FOGO tem potencial para ser estendido a casos de flexão composta oblíqua (FCO) e aquecimento assimétrico da seção transversal. A falta de ensaios experimentais impede a calibração do método, mas mesmo assim pode ser considerado mais apto para o cálculo de pilares sob FCO do que métodos simplificados. Isso porque a fundamentação do método FNC-FOGO já foi testada e validada para o cálculo de pilares de concreto armado à temperatura ambiente, sendo usada normalmente na prática atual de projetos. O cálculo de pilares de concreto armado em situação de incêndio sob FCO é de suma importância, pois a maioria dos pilares reais está submetida à FCO. Mesmo que um pilar seja considerado como submetido unicamente à FNC, qualquer imperfeição geométrica, aquecimento não uniforme ou mesmo spalling não uniforme podem resultar em um caso de FCO.

Uma questão fundamental quando se trata do desenvolvimento de métodos avançados de cálculo de estruturas de concreto em situação de incêndio é a consideração correta das parcelas de deformações dos materiais. As explicações disponíveis na literatura são por vezes fragmentadas e pouco claras. Por isso, dedicou-se neste trabalho um item específico para tratar do tema (4.1.6), com o objetivo de esclarecer o assunto e orientar sobre o uso correto dos diagramas tensão-deformação dos materiais dados nas normas técnicas. As deformações transientes do concreto sob temperaturas elevadas devem ser sempre consideradas, de forma explícita ou implícita, nas formulações. Essa consideração é fundamental para a coerência e precisão dos resultados analíticos, quando comparados aos resultados de ensaios experimentais. A avaliação de diversos estudos anteriores permitiu concluir que o diagrama tensão-deformação do concreto dado pelo Eurocode 2 (EN 1992-1-2:2004), que considera de forma implícita as diversas parcelas de deformação do concreto sob temperaturas elevadas (exceto a deformação térmica específica linear, tratada em separado), possui desempenho satisfatório para o cálculo do TRF de elementos de concreto armado em situação de incêndio. 
A pesquisa sobre o spalling, fenômeno bastante danoso às estruturas de concreto em situação de incêndio, indicou que sua previsão ainda é um assunto bastante controverso, cujos estudos estão atualmente em andamento. Contudo, deve ser evitado ao máximo, pois o fenômeno pode diminuir significativamente os níveis de segurança da estrutura em situação de incêndio. Além da redução da área da seção transversal dos elementos estruturais, a expulsão das camadas superficiais de concreto expõe as armaduras diretamente ao fogo, resultando em rápida perda de resistência das mesmas. O conhecimento dos mecanismos do spalling e seus fatores de influência servem como guias para adoção de medidas contra a sua ocorrência, como por exemplo: uso de proteção térmica nas estruturas, adição de fibras de polipropileno na mistura de concreto $(0,05 \%$ a $0,1 \%$ em massa), uso de agregados de baixa expansão térmica e estáveis sob temperaturas elevadas, entre outros.

Outras recomendações para o projeto de pilares de concreto armado em situação de incêndio referem-se ao posicionamento das armaduras longitudinais. É recomendável adotar barras de bitolas menores e em maior número, evitando a concentração das barras nos cantos da seção transversal. Isso porque nos cantos se observa as maiores temperaturas da seção transversal, além da elevada probabilidade de ocorrência de spalling nessa região. $\mathrm{O}$ uso de barras em camadas também é uma alternativa. Apesar das barras mais internas perderem eficiência mecânica, as mesmas estarão protegidas termicamente por uma camada significativa de concreto.

\subsection{SUGESTÕES PARA TRABALHOS FUTUROS}

O comportamento de estruturas de concreto em situação de incêndio ainda possui diversos assuntos a serem esclarecidos, traduzindo-se num campo totalmente aberto a pesquisas, tanto do ponto de vista dos materiais quanto do ponto de vista da modelagem da estrutura como um todo e seus elementos componentes. No Brasil, há diversos estudos importantes em andamento (CALIL et al., 2010). Sugere-se a seguir alguns tópicos que necessitam estudos mais detalhados:

- Ensaios experimentais de pilares em escala real são fundamentais para a calibração de modelos numéricos. A falta de ensaios é atualmente uma das maiores barreiras ao avanço do conhecimento sobre estruturas de concreto em situação de incêndio, pois, apesar de existirem modelos numéricos altamente 
avançados, faltam dados para a correta calibração e validação desses modelos. Quanto ao tipo de ensaio, devem ser investigados casos de pilares submetidos à flexão composta oblíqua, carregamentos com grande excentricidade e aquecimento não uniforme da seção transversal, tanto para pilares feitos com concreto de resistência normal quanto para concretos de alto desempenho;

- Caracterização rigorosa dos materiais, fornecendo informações para que os modelos numéricos possam capturar e prever os fenômenos observados experimentalmente;

- Como há dúvidas quanto à determinação das curvas de condutividade térmica do concreto propostas pelo Eurocode 2 (EN 1992-1-2:2004), as mesmas deveriam ser reavaliadas, com base em resultados de ensaios aferidos com maior precisão;

- Estudos aprofundados utilizando o Método do Pivô Móvel ou outros métodos de cálculo com limitação das deformações, abrangendo o maior número possível de casos possíveis de existir na prática, de forma a investigar a confiabilidade do método;

- Estudos quanto à consideração do spalling nos modelos numéricos;

- Estudos numéricos e experimentais sobre a interação entre os diversos elementos estruturais em cenários de incêndios reais. 


\section{REFERÊNCIAS}

ACI. American Concrete Institute - Commiteee 318. Building code requirements for structural concrete and commentary, American Concrete Institute: Detroit, MI, Estados Unidos, 2006.

AL TECHNOLOGIES LTD. Building Technology. AL Technologies Ltd., 2011. Acesso em: 28 fev. 2011.

ALI, F. A.; O'CONNOR, D.; ABU-TAIR, A. Explosive spalling of high-strength concrete columns in fire. Magazine of Concrete Research, 53 (3), 2001. pp. 197-204.

ALI, F. et al. Outcomes of a major research on fire resistance of concrete columns. Fire Safety Journal, 39, p. 433-445, 2004.

ANDERBERG, Y.; FORSÉN, N. E. Fire resistance of concrete structures. Report LUTVDG/(TVBB-3009), Lund Institute of Technology, Division of Building Fire Safety and Technology. Lund, Suécia. 1982.

ANDERBERG, Y.; HAKSEVER, A. Comparison between measured and computed structural response of some reinforced concrete columns in fire. Fire Safety Journal, n. 4, 1981. p. 293-297.

ASSOCIAÇÃO BRASILEIRA DE NORMAS DE NORMAS TÉCNICAS (ABNT). NBR 6120 - Cargas para o cálculo de estruturas de edificações. ABNT. Rio de Janeiro. 1980.

ASSOCIAÇÃO BRASILEIRA DE NORMAS DE NORMAS TÉCNICAS (ABNT). NBR 14432 - Exigências de resistência ao fogo de elementos construtivos de edificações Procedimento. ABNT. Rio de Janeiro. 2001.

ASSOCIAÇÃO BRASILEIRA DE NORMAS DE NORMAS TÉCNICAS (ABNT). NBR 6118 - Projeto de Estruturas de Concreto - Procedimento. ABNT. Rio de Janeiro. 2003.

ASSOCIAÇÃO BRASILEIRA DE NORMAS DE NORMAS TÉCNICAS (ABNT). NBR 8681 - Ações e segurança nas estruturas - Procedimento. ABNT. Rio de Janeiro. 2003. 
ASSOCIAÇÃO BRASILEIRA DE NORMAS DE NORMAS TÉCNICAS (ABNT). NBR15200 - Projeto de estruturas de concreto em situação de incêndio. ABNT. Rio de Janeiro. 2004.

ASTM. AMERICAN SOCIETY FOR TESTING AND MATERIALS. E119-2000: standard test methods for fire tests of building construction and materials, Philadelphia, Estados Unidos, 2000.

BAILEY, C. Holistic behaviour of concrete buildings in fire. Proceedings of the Institution of Civil Engineers, Structures and Buildings 152, p. 199-212, ago. 2002.

BAILEY, C. G.; BURGESS, I. W.; PLANK, R. J. Computer simulation of a full-scale structural fire test. The Structural Engineer, 74 (6), p. 93-100, 1996.

BAMONTE, P.; LO MONTE, F. Modelling R/C columns in fire according to different constitutive models for heated concrete. Structures in Fire (Proceedings of the sixth international conference), p. 320-327, DEStech Publications, Inc., USA, 2010.

BEITEL, J.; IWANKIW, N. Analysis of needs and existing capabilities for full-scale fire resistance testing. NIST Report GCR 02-843. Gaithersburg, Estados Unidos. 2002.

BENMARCE, A.; GUENFOUD, M. Behaviour of axially restrained high strenght concrete columns under fire. Construction \& Builading Materials, 57 (5), p. 283-287, 2005.

BISBY, L. A.; GREEN, M. F.; KODUR, V. K. R. Modelling the behaviour of fiber reinforced polymer-confined concrete columns exposed to fire. Journal of Composite for Construction, 9, p. 15-24, 2005.

BRATINA, S. et al. Numerical modelling of behaviour of reinforced concrete columns in fire and comparison with Eurocode 2. International Journal of Solids and Structures, 42, p. 5715-5733, 2005.

CAI, J.; BURGESS, I.; PLANK, R. A generalised steel/reiforced concrete beam-column element model for fire conditions. Engineering Structures 25, p. 817-833, 2003.

CALIL, C. J. et al. Structures fire safety: the brazilian research project. Structures in Fire (Proceedings of the sixth international conference), p. 1001-1007, DEStech Publications, Inc., USA, 2010. 
CAPUA, D.; MARI, A. Nonlinear analysis of reinforced concrete cross-sections exposed to fire. Fire Safety Journal, 42, p. 139-149, 2007.

CB-PMESP. Corpo de Bombeiros - Polícia Militar do Estado de São Paulo. Resistência ao fogo dos elementos de construção. Instrução Técnica do Corpo de Bombeiros (IT 08/2011), [Decreto Lei n 46.076 do Estado de São Paulo, 31 de agosto de 2001], Secretaria de Estado dos Negócios da Segurança Pública, São Paulo, 2011.

CHOW, W. K.; LIU, D. Equivalent load of reiforced concrete columns under fire. Structural Survey, Vol. 27, No. 3, p. 230-240, 2009.

COSTA, C. N. Relatório de estágio de doutoramento no exterior - PDEE. University of Manchester - Institute of Science and Technology. Manchester, Reino Unido. 2006.

COSTA, C. N. Dimensionamento de elementos de concreto armado em situação de incêndio. Tese (Doutorado) - Escola Politécnica da Universidade de São Paulo, Departamento de Engenharia de Estruturas e Geotécnica, São Paulo. 2008.

COSTA, C. N.; SILVA, V. P. Dimensionamento de pilares em situação de incêndio, conforme a nova NBR 15200.2004 - uma análise crítica. Anais do $47^{\circ}$ Congresso Brasileiro do Concreto. Olinda, Pernambuco: IBRACON. 2005.

CUOGHI, R. S.; FIGUEIREDO, A. S. Aspectos de análise de risco das estruturas de concreto em situação de incêndio. São Paulo: EPUSP, 2007. 31 p.

DOTREPPE, J. -C. BDA 5.2 Background for tabulated data - Method A for columns. [S.1.]: Revision Draft. CEN/TC250/SC2, 2003.

DOTREPPE, J. -C. Comparison of fire resistance of columns in tabulated data to test results. [S.1.]: Background Document. CEN/TC 250/SC2/PT 1-2 Doc N 182, 2004.

DYWIDAG-SYSTEMS INTL. TICO Ultrasonic Tester. DYWIDAG-Systems International, 2011. Disponivel em: <http://www.dsiequipment.com/en/productinformation/equipment/beton-baustoffe-bauteile/ultrasonic-testingtico.html>. Acesso em: 28 fev. 2011.

ELLINGWOOD, B.; LIN, T. D. Flexure and shear behaviour of concrete beams during fires. ASCE Journal of Structural Engineering 1176, p. 440-458, 1991. 
ENEA; PADOVA UNIVERSITY. HIgh TEmperature COncrete and SPalling. HITECOSP, 1999. Disponivel em: <http://info.casaccia.enea.it/Hitecosp/>. Acesso em: 28 fev. 2011.

EUROPEAN COMMITTEE FOR STANDARDIZATION (CEN). Eurocode 1: actions on structures - part 1.2: general actions - actions on structures exposed to fire. EN 1991-12. CEN. Bruxelas, Bélgica. 2004.

EUROPEAN COMMITTEE FOR STANDARDIZATION (CEN). Eurocode 2: design of concrete structures - part 1.2: general rules - structural fire design. EN 1992-1-2. CEN. Bruxelas, Bélgica. 2004.

FELICETTI, R. The drilling resistance test for the assessment of fire damaged concrete. Cement \& Concrete Composites 28, p. 321-329, 2006.

FELICETTI, R.; GAMBAROVA, P. G.; MEDA, A. Residual behavior of steel rebars and R/C sections after a fire. Construction and Building Materials 23, p. 3546-3555, 2009.

FERNANDES, M. A. S. Dimensionamento de esforços resistentes em barras de aço sob incêndio natural compartimentado "one zone". 165 f. Dissertação (Mestrado) - Escola Politécnica da Universidade de São Paulo, Departamento de Engenharia de Estruturas e Geotécnica, São Paulo. 2006.

FIB, F. I. D. B. Bulletin 38 - Fire design of concrete structures. Lausanne, Suíça: EPFL, 2007.

FIB, F. I. D. B. Bulletin 46 - Fire design of concrete structures - structural behaviour and assessment. Lausanne, Suíça: EPFL, 2008.

FLETCHER, I. A. et al. The behaviour of concrete structures in fire. Thermal Science 11 (2), 2007. pp. 33-57.

FRANÇA, R. L. S. Relações momento-curvatura em peças de concreto armado submetidas à flexão oblíqua composta. 291 f. Dissertação (Mestrado) - Escola Politécnica da Universidade de São Paulo, Departamento de Engenharia de Estruturas e Geotécnica, São Paulo. 1984.

FRANSSEN, J. -M. Design of concrete columns based on EC2 tabulated data - a critial review. In:. Proceedings of the first international workshop "Structures in Fire" - SiF 
2000. 2. ed. Copenhagen: Universidade de Liège / Danish Institute of Fire Technology / CIBW14 Fire, 2000.

FRANSSEN, J. -M. Fire resistance of reinforced concrete columns - Belgian method $\mathbf{N}^{\circ} \mathbf{1}$ (tabulated data). Background Document. Liège: CEN, 2001.

FRANSSEN, J. -M. Functionalities of the software SAFIR. Université de Liège, Faculté des Sciences Appliquées, Génie Civil et Géologie, Mécanique des Matériaux \& Structures. Liège, Bélgica. 2005.

FRANSSEN, J. -M.; DOTREPPE, J. -C. Fire tests and calculation method for circular concrete columns. Fire Technology, New York, v. 39, Issue 1., 2003.

GEORGALI, B.; TSAKIRIDIS, P. E. Microstructure of fire-damaged concrete. A case study. Cement \& Concrete Composites, 27, p. 255-259, 2005.

GERMANN INSTRUMENTS A/S. GERMANN INSTRUMENTS A/S. Germann $\begin{array}{lllll}\text { Instruments } & \mathbf{A} / \mathbf{S}, & 2009 . & \text { Disponivel }\end{array}$ <http://www.germann.org/?strArticle=test_systems>. Acesso em: 28 fev. 2011.

GERNAY, T.; FRANSSEN, J. -M. Consideration of transient creep in the Eurocode constitutive model for concrete in the fire situation. Structures in Fire (Proceedings of the sixth international conference), p. 784-791, DEStech Publications, Inc., USA, 2010.

HAN, C. G. et al. Performance of spalling resistance of high performance concrete with polyproylene fiber contents and lateral confinement. Cement \& Concrete Research, 35, p. 1747-1753, 2005.

HARMATHY, T. Z. Fire safety design \& concrete. Essex, Reino Unido: Longman Scientific \& Technical, 1993.

HARMATHY, T. Z.; SULTAN, M. A.; MACLAURIN, J. W. Comparison of severity of exposure in ASTM E119 and ISO 834 fire resistance tests. Journal of testing and evaluation, v. 15, Nov. 1987. p. 371-375.

HOLMBERG, S.; ANDERBERG, Y. Concrete structures and fire. Computer simulations and a design method for fire exposed concrete columns. FSD Project No. 92-52. Stockholm: FSD, 1993. 
HUANG, Z.; BURGESS, I. W.; PLANK, R. J. Non-linear analysis of reinforced concrete slabs subjected to fire. ACI Structural Journal, 96 (1), p. 127-135, 1999.

HUANG, Z.; BURGESS, I. W.; PLANK, R. J. Non-linear beam-column element for 3D modelling of general cross-sections in fire. Research Report DCSE/03/F/1, Department of Civil \& Structural Engineering, University of Sheffield: Reino Unido, 2003.

HUANG, Z.; BURGESS, I. W.; PLANK, R. J. Behaviour of reinforced concrete structures in fire. Fourth International Workshop on Structures in Fire, Aveiro, Portugal, Maio 2006. pp. 561-572.

HUANG, Z.; BURGESS, I. W.; PLANK, R. J. Three-dimensional analysis of reinforced concrete beam-column structures in fire. Journal of Structural Engineering, ASCE, 135 (10), outubro 2009. pp. 1201-1212.

HUANG, Z.; PLATTEN, A. Nonlinear finite element analysis of planar reinforced concrete members subjected to fires. ACI Structural Journal 94, p. 272-282, 1997.

IMPACT TEST EQUIPMENT LTD. Internal Fracture Tester. Impact Test Equipment Ltd., 2010. Disponivel em: <http://www.impact-test.co.uk/products/407-Internal-FractureTest/3723-Internal-Fracture-Tester/>. Acesso em: 28 fev. 2011.

ISO. INTERNATIONAL ORGANIZATION FOR STANDARDIZATION. Fire-resistance tests - Elements of building construction - Part 1.1: General requirements for fire resistance testing, Geneva, Suíça [Revision of first edition (ISO 834:1975)], 1990.

JANSSON, R. Material properties related to fire spalling of concrete. Report TVBM3143. Lund, Suécia: Division of building materials, Lund Institute of technology, Lund University, 2008.

KHOURY, G. A. Effect of fire on concrete and concrete structures. Progress in Structural Engineering and Materials, v. 2, No. 4, Abril $2000 \mathrm{~b}$.

KHOURY, G. A. Strain of concrete during two thermal cycles. Part 1: strain over two cycles, during first heating and at subsequent constant temperatures. Magazine of Concrete Research, 58 (6), p. 367-385, Agosto 2006a. 
KHOURY, G. A. Strain of concrete during two thermal cycles. Part 2: strain during first cooling and subsequent thermal cycle. Magazine of Concrete Research, 58 (6), p. 387-400, Agosto 2006b.

KHOURY, G. A. Strain of concrete during two thermal cycles. Part 3: isolation of strain components and strain model development. Magazine of Concrete Research, 58 (6), Setembro 2006c.

KHOURY, G. A. Fire and concrete: from materials behaviour to application. International workshop "Fire design of concrete structures - from materials modelling to structural performance", p. 3-24, University of Coimbra, Portugal, Novembro 2007.

KHOURY, G. A. Polypropylene fibres in heated concrete. Part 2: pressure relief mechanisms and modelling criteria. Magazine of Concrete Research 60 (3), 2008. 189-204.

KHOURY, G. A. et al. Modelling of heated concrete. Magazine of concrete research, 54, No. 2, Abril 2002. pp. 77-101.

KHOURY, G. A.; ANDERBERG, Y. Concrete spalling review. FSD. [S.1.]. 2000a.

KODUR, V. K. R. et al. Fire endurance experiments on high-strength concrete columns. National Research Council of Canada, NRC RD Bulletin 138. Canadá. 2004.

KODUR, V. K. R.; RAUT, N. K. Design equation for predicting fire resistance of reinforced concrete columns. Structural Concrete 10, No. 2, p. 73-86, jun. 2009.

LENNON, T. et al. Designer`s guide to EN 1991-1-2, 1992-1-2, 1993-1-2 and 1994-1-2 Handbook for the fire design of steel, composite and concrete structures to the Eurocodes. Londres, Reino Unido: Thomas Telford Publishing, 2006.

LI, L. -Y.; PURKISS, J. A. Stress-strain constitutive equations of concrete at elevated temperatures. Fire Safety Journal, 40, p. 669-686, 2005.

LIE, T. T. Fire resistance of reinforced concrete columns: a parametric study. Journal of Fire Protection Engineering, 1 (4), p. 121-130, 1989.

LIE, T. T. Structural fire protection. New York: American Society of Civil Engineers (ASCE), 1992. 
LIE, T. T.; LIN, T. D. Influence of restraint on fire performance of reiforced concrete columns. Fire Safety Science - Proceedings of the first international symposium, Gaithersburg, p. 291-300, 1985.

LIN, T. D. et al. Fire resistance of reinforced concrete columns. Research and Development Bulletin RD101B, Portland Cement Association. Skokie, Illinois, Estados Unidos. 1992.

MARTINS, A. M. B.; RODRIGUES, J. P. C. Behavior of concrete columns subjected to fire. Structures in Fire (Proceedings of the sixth international conference), p. 181-188, DEStech Publications, Inc., USA, 2010.

MEDA, A.; GAMBAROVA, P.; BONOMI, P. Hight-performance concrete in fire-exposed R/C sections. ACI Structural Journal 99 (3), p. 277-287, 2002.

MENDES NETO, F. Concreto estrutural avançado - análise de seções transversais sob flexão normal composta. São aulo: Pini, 2009.

NAJJAR, S. R.; BURGESS, I. W. A nonlinear analysis for three-dimensional steel frames in fire conditions. Engineering Structures, 18, p. 77-89, 1996.

NĚMECĚK, J.; PADEVĚT, P.; BITTNAR, Z. Effect of stirrups on behavior of normal and high strenght concrete columns. Acta Polytechnica, Vol. 44, No. 5-6, Czech Technical University Publishing House, 2004.

NRCC. Thermal expansion of reinforced concrete structures in fire. National Research Council Canada, 2009. Disponivel em: <http://www.nrccnrc.gc.ca/eng/ibp/irc/ci/v14no3/6.html>. Acesso em: 28 fev. 2011.

ORTON. Thermoanalytical Instruments. Edward Orton Jr. Ceramic Foundation, 2010. Disponivel em: <http://www.ortonceramic.com/instruments/GlassDilatometer.shtml>. Acesso em: 28 fev. 2011.

PLIYA, P.; BEAUCOUR, A. -L.; NOUMOWÉ, A. How the steel fibres improve the residual properties of concrete subjected to high temperature. Structures in Fire (Proceedings of the sixth international conference), p. 767-774, DEStech Publications, Inc., USA, 2010. 
POYESHYAR CO. LTD. Non-Destructive Concrete Testing. POYESHYAR Co. Ltd. Inspection Equipment Supplier, 2011. Disponivel em: <http://www.poyeshyar.com/CNDT.HTM>. Acesso em: 28 fev. 2011.

PURKISS, J. A. Fire safety engineering. 2. ed. Oxford, Reino Unido: Elsevier, 2007.

RAUT, N. K.; KODUR, V. K. R. Modeling the fire response of reinforced concrete columns under biaxial bending. Structures in Fire (Proceedings of the sixth international conference), p. 206-215, DEStech Publications, Inc., USA, 2010.

REIN, G. et al. Multi-storey fire analysis for high-rise buildings. 11th Interflam, Londres, Reino Unido, set. 2007. 605-616.

RIVA, P. Nonlinear and plastic analysis of RC concrete beams. Proc. Intl. Workshop Fire Design of Concrete Structures: What now? What next? Milão, Itália: Starry Link Editore. 2005.

SANTOS, R. T. D. Modelos numéricos de pilares mistos curtos de seções circulares de aço preenchidos com concreto em situação de incêndio. Dissertação (Mestrado - Programa de Pós-Graduação e Área de Concentração em Engenharia de Estruturas). Escola de Engenharia de São Carlos da Universidade de São Paulo. São Carlos. 2009.

SCHLEICH, J. -B. Properties of the materials. Implementation of Eurocodes: Design of buildings for the fire situation: Hadbook 5, Luxemburgo: KI CTU/CKAIT/RWTH/IET/UOP/TNO/IMK/BRE, Chapt. 5. p. V-1-V-28. Leonardo Da Vinci Pilot Project CZ/02/B/F/PP-134007, 2005.

SCHREFLER, B. A. et al. Thermo-hydro-mechanical modelling of high performance concrete at high temperatures. Engineering computations, Vol. 19, No. 7, 2002. pp. 787819.

SHORT, N. R.; PURKISS, J. A.; GUISE, S. E. Assessment of fire damaged concrete using colour image analysis. Construction and Building Materials 15, p. 9-15, 2001.

SILVA, V. P. Estruturas de aço em situação de incêndio. Reimpressão. São Paulo: Zigurate, 2004. 249 p. 
SILVA, V. P. Dimensionamento de pilares de concreto armado em situação de incêndio. Uma alteranativa ao método tabular da NBR 15200:2004. Revista Ibracon de estruturas e materiais n. 4, São Paulo, v. 1, p. 331-392, Dezembro 2008.

TAN, K. H.; YAO, Y. Fire resistance of four-faced heated reinforced concrete columns. Journal of Structural Engineering, Vol. 129, No. 9, p. 1220-1229, 2003.

TAN, K. H.; YAO, Y. Fire resistance of reinforced concrete columns subjected to 1-, 2- and 3-face heating. Journal of Structural Engineering, Vol. 130, No. 11, p. 1820-1828, 2004.

TENCHEV, R.; PURNELL, P. An application of a damage constitutive model to concrete at high temperature and prediction of spalling. International Journal of Solids \& Structures, 42, p. 6550-6565, 2005.

TERRO, M. J. Numerical modelling of the behaviour of concrete structures in fire. ACI Structural Journal, v. 95, n. 2, p. 183-193, 1998.

TEST MARK INDUSTRIES. Windsor Probe Kit for Concrete Testing. Test Mark Industries, 2011. Disponivel em: <http://www.testmark.net/showitem-533.html>. Acesso em: 28 fev. 2011.

TLD. Harshaw 5500 Automatic Dosimetry Reader. Thermoluminescent Dosimeter (TLD), 2010. Acesso em: 28 fev. 2011.

ULM, F.; COUSSY, O.; BAZANT, Z. The "Chunnel" Fire. I: Chemoplastic softening in rapidly heated concrete. Journal of Engineering Mechanics, 125, p. 272-282, 1999.

WADE, C. A. et al. Concrete blade columns in fire. Proceedings - Concrete 97 Conference. Adelaide, Austrália: [s.n.]. 1997.

WU, B. et al. Fire resistance of reinforced concrete columns with square cross section. Advances in Structural Engineering Vol. 10, No. 4, p. 353-369, 2007.

XU, Y.-Y.; WU, B. Fire resistance of reinforced concrete columns with L-, T- and +-shaped cross-sections. Fire Safety Journal 44, p. 869-880, 2009.

ZHA, X. X. Three-dimensional non-linear analysis of reinforced concrete members in fire. Building and Environment 38, p. 297-307, 2003. 